\title{
Treatment of newly diagnosed glioblastoma in the elderly: a network meta-analysis (Review)
}

Hanna C, Lawrie TA, Rogozińska E, Kernohan A, Jefferies S, Bulbeck H, Ali UM, Robinson T, Grant $\mathrm{R}$

Hanna C, Lawrie TA, Rogozińska E, Kernohan A, Jefferies S, Bulbeck H, Ali UM, Robinson T, Grant R.

Treatment of newly diagnosed glioblastoma in the elderly: a network meta-analysis.

Cochrane Database of Systematic Reviews 2020, Issue 3. Art. No.: CD013261.

DOI: 10.1002/14651858.CD013261.pub2.

www.cochranelibrary.com 
TABLE OF CONTENTS

HEADER

ABSTRACT

PLAIN LANGUAGE SUMMARY

SUMMARY OF FINDINGS

BACKGROUND

OBJECTIVES

METHODS

RESULTS

Figure 1.

Figure 2.

Figure 3.

Figure 4.

Figure 5.

DISCUSSION

Figure 6.

AUTHORS' CONCLUSIONS

ACKNOWLEDGEMENTS

REFERENCES

CHARACTERISTICS OF STUDIES

DATA AND ANALYSES

Analysis 1.1. Comparison 1 Radiotherapy (50 Gy) versus supportive care, Outcome $1 \mathrm{HRQOL}$.

Analysis 1.2. Comparison 1 Radiotherapy (50 Gy) versus supportive care, Outcome 2 Cognition.

Analysis 1.3. Comparison 1 Radiotherapy (50 Gy) versus supportive care, Outcome 3 Fatigue.

Analysis 1.4. Comparison 1 Radiotherapy (50 Gy) versus supportive care, Outcome 4 Progression-free survival. .....................

Analysis 2.1. Comparison 2 Short-course radiotherapy versus standard radiotherapy, Outcome $1 \mathrm{HRQOL}$ at 4 weeks. .............

Analysis 2.2. Comparison 2 Short-course radiotherapy versus standard radiotherapy, Outcome $2 \mathrm{HRQOL}$ at 8 weeks. .............

Analysis 2.3. Comparison 2 Short-course radiotherapy versus standard radiotherapy, Outcome 3 Treatment toxicity G3+. ......

Analysis 3.1. Comparison 3 Chemotherapy versus radiotherapy, Outcome 1 Progression-free survival.

Analysis 3.2. Comparison 3 Chemotherapy versus radiotherapy, Outcome 2 Thromboembolic event G3+.

Analysis 3.3. Comparison 3 Chemotherapy versus radiotherapy, Outcome 3 Neutropenia G3+.

Analysis 3.4. Comparison 3 Chemotherapy versus radiotherapy, Outcome 4 Lymphopenia G3+.

Analysis 3.5. Comparison 3 Chemotherapy versus radiotherapy, Outcome 5 Thrombocytopenia G3+.

Analysis 3.6. Comparison 3 Chemotherapy versus radiotherapy, Outcome 6 Infection G3+.

Analysis 3.7. Comparison 3 Chemotherapy versus radiotherapy, Outcome 7 Fatigue/asthenia G3+.

Analysis 3.8. Comparison 3 Chemotherapy versus radiotherapy, Outcome 8 Nausea/vomiting G3+.

Analysis 3.9. Comparison 3 Chemotherapy versus radiotherapy, Outcome 9 Weight loss G3+.

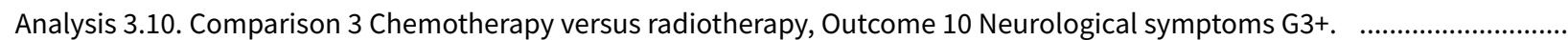

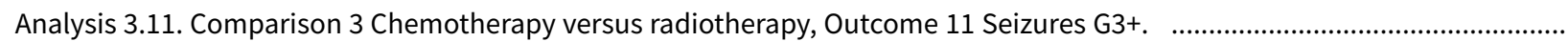

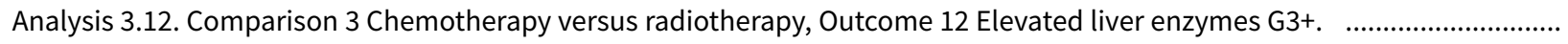

Analysis 3.13. Comparison 3 Chemotherapy versus radiotherapy, Outcome 13 Cutaneous adverse event G3+. .......................

Analysis 4.1. Comparison 4 Chemoradiotherapy versus radiotherapy, Outcome 1 Progression-free survival. ...........................

Analysis 4.2. Comparison 4 Chemoradiotherapy versus radiotherapy, Outcome 2 Neutropenia G3+.

Analysis 4.3. Comparison 4 Chemoradiotherapy versus radiotherapy, Outcome 3 Thrombocytopenia G3+. ............................

Analysis 4.4. Comparison 4 Chemoradiotherapy versus radiotherapy, Outcome 4 Lymphopenia G3+.

Analysis 4.5. Comparison 4 Chemoradiotherapy versus radiotherapy, Outcome 5 Leucopenia G3+.

Analysis 4.6. Comparison 4 Chemoradiotherapy versus radiotherapy, Outcome 6 Anaemia G3+.

Analysis 4.7. Comparison 4 Chemoradiotherapy versus radiotherapy, Outcome 7 Treatment toxicity G3+.

Analysis 5.1. Comparison 5 Other + chemoradiotherapy versus chemoradiotherapy, Outcome 1 Progression-free survival. ......

Analysis 5.2. Comparison 5 Other + chemoradiotherapy versus chemoradiotherapy, Outcome 2 Thromboembolic events G3+. .

Analysis 6.1. Comparison 6 Other + radiotherapy (40 Gy) versus radiotherapy (40 Gy), Outcome 1 Progression-free survival. ....

Analysis 6.2. Comparison 6 Other + radiotherapy ( $40 \mathrm{~Gy}$ ) versus radiotherapy (40 Gy), Outcome 2 Thromboembolic events G3+. 
Analysis 6.3. Comparison 6 Other + radiotherapy ( $40 \mathrm{~Gy}$ ) versus radiotherapy (40 Gy), Outcome 3 Haematological events G3+. . 102 Analysis 6.4. Comparison 6 Other + radiotherapy ( $40 \mathrm{~Gy}$ ) versus radiotherapy (40 Gy), Outcome 4 Infections G3+. ................... Analysis 6.5. Comparison 6 Other + radiotherapy ( $40 \mathrm{~Gy}$ ) versus radiotherapy (40 Gy), Outcome 5 Fatigue G3+. ...................... 102 Analysis 6.6. Comparison 6 Other + radiotherapy ( $40 \mathrm{~Gy}$ ) versus radiotherapy (40 Gy), Outcome 6 Seizures G3+. ...................... 102 Analysis 6.7. Comparison 6 Other + radiotherapy ( $40 \mathrm{~Gy})$ versus radiotherapy (40 Gy), Outcome 7 Headaches G3+. ................. 103 Analysis 6.8. Comparison 6 Other + radiotherapy ( $40 \mathrm{~Gy}$ ) versus radiotherapy (40 Gy), Outcome 8 Neuropsychiatric events G3+. 103 Analysis 6.9. Comparison 6 Other + radiotherapy (40 Gy) versus radiotherapy (40 Gy), Outcome 9 Neurological events G3+. .... 103 Analysis 6.10. Comparison 6 Other + radiotherapy ( $40 \mathrm{~Gy}$ ) versus radiotherapy (40 Gy), Outcome 10 Hypertension G3+. .......... 103 Analysis 6.11. Comparison 6 Other + radiotherapy ( $40 \mathrm{~Gy}$ ) versus radiotherapy (40 Gy), Outcome 11 Cutaneous adverse events 104 G3+.

Analysis 6.12. Comparison 6 Other + radiotherapy (40 Gy) versus radiotherapy (40 Gy), Outcome 12 Gastrointestinal events G3+.

ADDITIONAL TABLES 
[Intervention Review]

\section{Treatment of newly diagnosed glioblastoma in the elderly: a network meta-analysis}

Catherine Hanna1a, Theresa A Lawrie2b, Ewelina Rogozińska², Ashleigh Kernohan³, Sarah Jefferies ${ }^{4}$, Helen Bulbeck ${ }^{5}$, Usama M Ali6, Tomos Robinson ${ }^{3}$, Robin Grant ${ }^{7}$

1Department of Oncology, University of Glasgow, Glasgow, UK. ${ }^{2}$ The Evidence-Based Medicine Consultancy Ltd, Bath, UK. ${ }^{3}$ Institute of Health \& Society, Newcastle University, Newcastle upon Tyne, UK. ${ }^{4}$ Department of Oncology, Addenbrooke's Hospital, Cambridge, UK. ${ }^{5}$ Director of Services, brainstrust, Cowes, UK. ${ }^{6}$ Nuffield Department of Population Health, University of Oxford, Oxford, UK. ${ }^{7}$ Edinburgh Centre for Neuro-Oncology (ECNO), Western General Hospital, Edinburgh, UK

${ }^{a}$ Authors $1 \& 2$ contributed equally to this work. ${ }^{b}$ Authors $1 \& 2$ contributed equally to this work

Contact address: Theresa A Lawrie, The Evidence-Based Medicine Consultancy Ltd, 3rd Floor Northgate House, Upper Borough Walls, Bath, BA1 1RG, UK. tesslawrie@gmail.com.

Editorial group: Cochrane Gynaecological, Neuro-oncology and Orphan Cancer Group.

Publication status and date: Edited (no change to conclusions), published in Issue 3, 2020.

Citation: Hanna C, Lawrie TA, Rogozińska E, Kernohan A, Jefferies S, Bulbeck H, Ali UM, Robinson T, Grant R. Treatment of newly diagnosed glioblastoma in the elderly: a network meta-analysis. Cochrane Database of Systematic Reviews 2020, Issue 3. Art. No.: CD013261. DOI: 10.1002/14651858.CD013261.pub2.

Copyright ( 2020 The Cochrane Collaboration. Published by John Wiley \& Sons, Ltd.

\section{A B S T R A C T}

\section{Background}

A glioblastoma is a fatal type of brain tumour for which the standard of care is maximum surgical resection followed by chemoradiotherapy, when possible. Age is an important consideration in this disease, as older age is associated with shorter survival and a higher risk of treatment-related toxicity.

\section{Objectives}

To determine the most effective and best-tolerated approaches for the treatment of elderly people with newly diagnosed glioblastoma. To summarise current evidence for the incremental resource use, utilities, costs and cost-effectiveness associated with these approaches.

\section{Search methods}

We searched electronic databases including the Cochrane Central Register of Controlled Trials (CENTRAL), MEDLINE and Embase to 3 April 2019, and the NHS Economic Evaluation Database (EED) up to database closure. We handsearched clinical trial registries and selected neuro-oncology society conference proceedings from the past five years.

\section{Selection criteria}

Randomised trials (RCTs) of treatments for glioblastoma in elderly people. We defined 'elderly' as 70+ years but included studies defining 'elderly' as over $65+$ years if so reported.

\section{Data collection and analysis}

We used standard Cochrane methods for study selection and data extraction. Where sufficient data were available, treatment options were compared in a network meta-analysis (NMA) using Stata software (version 15.1). For outcomes with insufficient data for NMA, pairwise meta-analysis were conducted in RevMan. The GRADE approach was used to grade the evidence. 


\section{Main results}

We included 12 RCTs involving approximately 1818 participants. Six were conducted exclusively among elderly people (either defined as 65 years or older or 70 years or older) with newly diagnosed glioblastoma, the other six reported data for an elderly subgroup among a broader age range of participants. Most participants were capable of self-care. Study quality was commonly undermined by lack of outcome assessor blinding and attrition. NMA was only possible for overall survival; other analyses were pair-wise meta-analyses or narrative syntheses.

Seven trials contributed to the NMA for overall survival, with interventions including supportive care only (one trial arm); hypofractionated radiotherapy (RT40; four trial arms); standard radiotherapy (RT60; five trial arms); temozolomide (TMZ; three trial arms); chemoradiotherapy (CRT; three trial arms); bevacizumab with chemoradiotherapy (BEV_CRT; one trial arm); and bevacizumab with radiotherapy (BEV_RT). Compared with supportive care only, NMA evidence suggested that all treatments apart from BEV_RT prolonged survival to some extent.

\section{Overall survival}

High-certainty evidence shows that CRT prolongs overall survival (OS) compared with RT40 (hazard ratio (HR) $0.67,95 \%$ confidence interval (CI) 0.56 to 0.80 ) and low-certainty evidence suggests that CRT may prolong overall survival compared with TMZ (TMZ versus CRT: HR 1.42, $95 \% \mathrm{Cl} 1.01$ to 1.98). Low-certainty evidence also suggests that adding BEV to CRT may make little or no difference (BEV_CRT versus CRT: HR $0.83,95 \% \mathrm{Crl} 0.48$ to 1.44 ). We could not compare the survival effects of CRT with different radiotherapy fractionation schedules (60 $\mathrm{Gy} / 30$ fractions and $40 \mathrm{~Gy} / 15$ fractions) due to a lack of data. When treatments were ranked according to their effects on OS, CRT ranked higher than TMZ, RT and supportive care only, with the latter ranked last. BEV plus RT was the only treatment for which there was no clear benefit in OS over supportive care only.

One trial comparing tumour treating fields (TTF) plus adjuvant chemotherapy (TTF_AC) with adjuvant chemotherapy alone could not be included in the NMA as participants were randomised after receiving concomitant chemoradiotherapy, not before. Findings from the trial suggest that the intervention probably improves overall survival in this selected patient population.

We were unable to perform NMA for other outcomes due to insufficient data. Pairwise analyses were conducted for the following.

\section{Quality of life}

Moderate-certainty narrative evidence suggests that overall, there may be little difference in QoL between TMZ and RT, except for discomfort from communication deficits, which are probably more common with RT ( 1 study, 306 participants, $P=0.002$ ). Data on QoL for other comparisons were sparse, partly due to high dropout rates, and the certainty of the evidence tended to be low or very low.

\section{Progression-free survival}

High-certainty evidence shows that CRT increases time to disease progression compared with RT40 (HR $0.50,95 \% \mathrm{Cl} 0.41$ to 0.61 ); moderate-certainty evidence suggests that RT60 probably increases time to disease progression compared with supportive care only (HR $0.28,95 \% \mathrm{Cl} 0.17$ to 0.46$)$, and that BEV_RT probably increases time to disease progression compared with $\mathrm{RT} 40$ alone (HR $0.46,95 \% \mathrm{Cl}$ 0.27 to 0.78 ). Evidence for other treatment comparisons was of low- or very low-certainty.

\section{Severe adverse events}

Moderate-certainty evidence suggests that TMZ probably increases the risk of grade $3+$ thromboembolic events compared with RT60 (risk ratio (RR) $2.74,95 \% \mathrm{Cl} 1.26$ to 5.94 ; participants $=373$; studies $=1$ ) and also the risk of grade $3+$ neutropenia, lymphopenia, and thrombocytopenia. Moderate-certainty evidence also suggests that CRT probably increases the risk of grade 3+ neutropenia, leucopenia and thrombocytopenia compared with hypofractionated RT alone. Adding BEV to CRT probably increases the risk of thromboembolism (RR $16.63,95 \% \mathrm{Cl} 1.00$ to 275.42 ; moderate-certainty evidence).

\section{Economic evidence}

There is a paucity of economic evidence regarding the management of newly diagnosed glioblastoma in the elderly. Only one economic evaluation on two short course radiotherapy regimen ( $25 \mathrm{~Gy}$ versus $40 \mathrm{~Gy}$ ) was identified and its findings were considered unreliable.

\section{Authors' conclusions}

For elderly people with glioblastoma who are self-caring, evidence suggests that CRT prolongs survival compared with RT and may prolong overall survival compared with TMZ alone. For those undergoing RT or TMZ therapy, there is probably little difference in QoL overall. Systemic anti-cancer treatments TMZ and BEV carry a higher risk of severe haematological and thromboembolic events and CRT is probably associated with a higher risk of these events. Current evidence provides little justification for using BEV in elderly patients outside a clinical trial setting. Whilst the novel TTF device appears promising, evidence on QoL and tolerability is needed in an elderly population. QoL and economic assessments of CRT versus TMZ and RT are needed. More high-quality economic evaluations are needed, in which a broader scope of costs (both direct and indirect) and outcomes should be included. 


\section{PLAIN LANGUAGE SUMMARY}

\section{Treatment options for newly diagnosed glioblastoma in older people}

\section{What is the issue?}

Glioblastoma is a fatal type of brain tumour. The standard treatment of newly diagnosed glioblastoma is to remove as much of the tumour as possible by operation, and then to give chemotherapy (an anti-cancer medicine called temozolomide (TMZ)) and radiotherapy. TMZ is usually given at the same time as radiotherapy (concomitant chemotherapy), and also for about six months after radiotherapy (adjuvant chemotherapy). Together, these treatments can be called chemoradiotherapy (CRT). However, not all people, particularly the elderly, are fit enough to receive CRT, which can have serious side-effects. In this review we evaluated evidence on different treatments that have been looked at in older people with newly diagnosed glioblastoma, to find out which treatments may help.

\section{How we conducted the review}

We searched for trials that compared different treatments in elderly people with newly diagnosed glioblastoma and also for studies on cost-effectiveness. We defined 'the elderly' as $70+$ years, but also included data from patients $65+$ years old if studies did not give results for the 70+ age group. We used standard Cochrane methods to assess studies and collect data. We compared treatments in a network metaanalysis (NMA), which allowed us to rank different treatments options.

\section{What we found}

We found 12 studies evaluating different options including radiotherapy, chemotherapy, supportive (palliative) care, combinations of treatments, and a medical device that is worn on the head and emits an electric field (known as tumour treating fields). Most people enrolled in these studies did not have serious disabilities. In the NMA, we compared the effects of seven treatments on patients overall survival. All treatments tested in the NMA apart from one, in which an agent called bevacizumab (BEV) was combined with radiotherapy, clearly prolonged survival compared with supportive care only. The strongest evidence we found showed that CRT leads to a longer survival time than short-course radiotherapy only; but weaker evidence suggested that CRT also prolongs survival compared with TMZ only. When we ranked all treatments according to their effectiveness in prolonging survival time, CRT ranked higher than TMZ, RT and supportive care only, with the latter ranked last.

A study of tumour treating fields could not be included in the NMA because it was conducted among fitter elderly patients who had already received part of their CRT. Evidence from this study suggested that adding tumour treating fields after radiotherapy probably improves survival in this fitter group of patients.

With regard to quality of life, evidence suggested that the impact of TMZ and radiotherapy-only treatments is probably not very different, except for greater discomfort from communication deficits with radiotherapy. Quality of life evidence was hard to interpret for other treatment options because it tended to be limited by high dropout rates, as people with glioblastoma do not live very long and may not feel like filling out questionnaires when they feel unwell.

With regard to other outcomes, high-certainty evidence showed that CRT delays disease progression compared with radiotherapy only. Evidence also suggested that adding BEV to short-course radiotherapy probably delays disease progression, but may not improve overall survival. TMZ and BEV are more toxic to blood cells than radiotherapy and are associated with an increased risk of blood clots and blood vessel blockages (thromboembolism).

\section{Our conclusions}

For reasonably fit elderly people with glioblastoma, evidence suggests that CRT prolongs survival compared with radiotherapy or TMZ alone, and that any of these three treatment options may prolong survival compared with supportive care only. Serious adverse events affecting blood components are more common with anti-cancer medicines TMZ and BEV. There is not enough evidence on BEV to support its use in elderly people with glioblastoma outside of a research setting. More evidence is needed on how different treatments impact quality of life and health costs. Age alone is unlikely to be the best determinant of optimal treatment of older people with glioblastoma. 


\section{SUMMARY OF FINDINGS}

Summary of findings for the main comparison. Summary of findings on overall survival comparing treatments to supportive care only

Estimates of effects, certainty assessment and rankings of different treatment options compared with supportive care only on overall survival in elderly people with glioblastoma

\section{Patient or population: elderly people with newly diagnosed glioblastoma}

Interventions: radiotherapy with $40 \mathrm{~Gy}$ in 15 fractions (RT40); radiotherapy with $60 \mathrm{~Gy}$ in 30 fractions (RT60); chemoradiotherapy (CRT); chemoradiotherapy plus bevacizumab (BEV_CRT); radiotherapy plus bevacizumab (BEV_RT); temozolomide (TMZ)

\section{Comparison: supportive care only}

Outcome: overall survival

\begin{tabular}{|c|c|c|c|c|}
\hline $\begin{array}{l}\text { All intervention options } \\
\text { (7 RCTs; } 1540 \text { participants in total)* }\end{array}$ & $\begin{array}{l}\text { Relative effect (network } \\
\text { estimate) } \star \star \\
(95 \% \mathrm{CI})\end{array}$ & $\begin{array}{l}\text { Illustrative absolute } \\
\text { effects for death at } 6 \\
\text { months ( } 95 \% \mathrm{Cls})\end{array}$ & $\begin{array}{l}\text { Certainty of } \\
\text { the evidence } \\
\text { (GRADE) }\end{array}$ & Ranking $¥$ \\
\hline $\begin{array}{l}\text { Supportive care only }{ }^{\star \star \star} \\
\text { (1 RCT, } 81 \text { participants) }\end{array}$ & Reference comparator & $76 \operatorname{per} 100^{\star \star \star}$ & $\begin{array}{l}\text { Reference com- } \\
\text { parator }\end{array}$ & 7.0 (worst) \\
\hline $\begin{array}{l}\text { RT60 } \\
\text { (5 RCTs; } 713 \text { participants) }\end{array}$ & HR $\mathbf{0 . 4 7}$ (0.29 to 0.76 ) & $\begin{array}{l}49 \text { per } 100 \\
(34 \text { to } 66)\end{array}$ & $\begin{array}{l}\oplus \oplus \oplus \ominus \\
\text { Moderate }^{1}\end{array}$ & 5.0 \\
\hline $\begin{array}{l}\text { BEV_RT } \\
\text { (1 RCT; } 75 \text { participants) }\end{array}$ & HR 0.48 (0.23 to 1.00$)$ & $\begin{array}{l}50 \text { per } 100 \\
(28 \text { to } 76)\end{array}$ & Not graded 2 & 4.7 \\
\hline $\begin{array}{l}\text { RT40 } \\
\text { (4 RCTs; } 930 \text { participants) }\end{array}$ & HR 0.44 (0.25 to 0.77$)$ & $\begin{array}{l}47 \text { per } 100 \\
(30 \text { to } 67)\end{array}$ & $\begin{array}{l}\oplus \oplus \odot \ominus \\
\text { Low3 }\end{array}$ & 4.3 \\
\hline $\begin{array}{l}\text { TMZ } \\
\text { (3 RCTs, } 538 \text { participants) }\end{array}$ & HR 0.42 (0.25 to 0.71$)$ & $\begin{array}{l}45 \text { per } 100 \\
(30 \text { to } 64)\end{array}$ & $\begin{array}{l}\oplus \oplus \ominus \ominus \\
\text { Low }^{3}\end{array}$ & 3.8 \\
\hline $\begin{array}{l}\text { CRT } \\
\text { (2 RCTs; } 635 \text { participants) }\end{array}$ & HR 0.30 (0.17 to 0.53 ) & $\begin{array}{l}35 \text { per } 100 \\
\text { (22 to } 53)\end{array}$ & Not graded 2 & 1.8 \\
\hline $\begin{array}{l}\text { BEV_CRT } \\
\text { (1 RCT; } 73 \text { participants) }\end{array}$ & HR 0.25 (0.11 to 0.54 ) & $\begin{array}{l}30 \text { per } 100 \\
\text { (15 to } 54 \text { ) }\end{array}$ & Not graded 2 & 1.4 \\
\hline
\end{tabular}

\section{NMA-'Summary of findings' table definitions}

Estimates are reported as HR: hazard ratio, $\mathbf{C l}$ : confidence interval,NMA: network meta-analysis.

* This refers to the number of studies in the network evaluating the given intervention and the number of participants involved in these studies.

** All NMA effect estimates in this 'Summary of findings' table are derived 100\% from indirect evidence, except for the comparison of RT60 versus supportive care, which was directly compared in one study. Where there was no common comparator for the comparison we did not grade the certainty of the evidence.

\section{*** The assumed effect of supportive care is based on Keime-Guibert 2007 data, which may be slightly overestimated because a high proportion of patients underwent biopsy only.}


$¥$ These rankings do not take into account the certainty of the evidence and should be interpreted with caution. The estimates of ungraded evidence are very uncertain.

\section{GRADE Working Group grades of evidence}

High certainty: we are very confident that the true effect lies close to that of the estimate of the effect.

Moderate certainty: we are moderately confident in the effect estimate; the true effect is likely to be close to the estimate of the effect, but there is a possibility that it is substantially different.

Low certainty: our confidence in the effect estimate is limited; the true effect may be substantially different from the estimate of the effect.

Very low certainty: we have very little confidence in the effect estimate; the true effect is likely to be substantially different from the estimate of effect.

1 Downgraded - 1 as the evidence was derived from a single small study.

2 There was no common comparator for the comparison (i.e. the intervention was not connected in a loop in the evidence network), therefore we did not grade the certainty of the evidence.

3 Contributing direct evidence was of moderate or low certainty.

Abbreviations

BEV_CRT; chemoradiotherapy plus bevacizumab; CI: confidence interval; CRT; chemoradiotherapy; HR: hazard ratio: RT40; radiotherapy (40 Gy in 15 fractions); RT60; radiotherapy (60 Gy in 30 fractions); SC; supportive care; TMZ; temozolomide; TTF_AC; tumour treating fields plus adjuvant chemotherapy) after concomitant CRT)

\section{Summary of findings 2. Summary of findings on overall survival comparing treatments to hypofractionated radiotherapy}

Estimates of effects and certainty assessments compared with hypofractionated radiotherapy (40 Gy/15 fractions) on overall survival in elderly people with newly diagnosed glioblastoma

Patient or population: elderly people with newly diagnosed glioblastoma

Interventions: chemoradiotherapy (CRT); chemoradiotherapy plus bevacizumab (BEV_CRT); radiotherapy plus bevacizumab (BEV_RT); temozolomide (TMZ)

Comparison: hypofractionated radiotherapy (RT 40)

Outcome: overall survival

\begin{tabular}{|c|c|c|c|}
\hline $\begin{array}{l}\text { All intervention options } \\
\text { (7 RCTs; } 1540 \text { participants in total)* }\end{array}$ & $\begin{array}{l}\text { Relative effect (network esti- } \\
\text { mate) }{ }^{\star *} \\
(95 \% \mathrm{CI})\end{array}$ & $\begin{array}{l}\text { Illustrative absolute effects } \\
\text { for death at } 12 \text { months }(95 \% \\
\text { CIs) }\end{array}$ & $\begin{array}{l}\text { Certainty of the } \\
\text { evidence } \\
\text { (GRADE) }\end{array}$ \\
\hline $\begin{array}{l}\text { RT } 40 \\
\text { (4 RCTs; } 930 \text { participants) }\end{array}$ & Reference comparator & $78 \operatorname{per} 100^{\star \star \star}$ & $\begin{array}{l}\text { Reference com- } \\
\text { parator }\end{array}$ \\
\hline $\begin{array}{l}\text { BEV_RT } \\
\text { (1 RCT; } 75 \text { participants) }\end{array}$ & HR 1.08 (0.66 to 1.78 ) & $\begin{array}{l}81 \text { per } 100 \\
\text { (63 to } 93)\end{array}$ & $\begin{array}{l}\oplus \oplus \ominus \ominus \\
\text { Low1 }\end{array}$ \\
\hline $\begin{array}{l}\text { TMZ } \\
\text { (3 RCTs, } 538 \text { participants) }\end{array}$ & HR 0.95 (0.71 to 1.26$)$ & $\begin{array}{l}76 \text { per } 100 \\
(66 \text { to } 85)\end{array}$ & $\begin{array}{l}\oplus \oplus \odot \ominus \\
\text { Low1 }\end{array}$ \\
\hline $\begin{array}{l}\text { CRT } \\
\text { (2 RCTs; } 635 \text { participants) }\end{array}$ & HR 0.67 (0.56 to 0.80 ) & $\begin{array}{l}64 \text { per } 100 \\
\text { (57 to } 70)\end{array}$ & $\begin{array}{l}\oplus \oplus \oplus \oplus \\
\text { High }\end{array}$ \\
\hline BEV_CRT & HR 0.56 (0.31 to 0.99$)$ & 57 per 100 & $\begin{array}{l}\oplus \oplus \oplus \ominus \\
\text { Moderate }^{2}\end{array}$ \\
\hline
\end{tabular}


For the comparison with standard radiotherapy (60 Gy/30 fractions) see Summary of findings 3.

\section{NMA-'Summary of findings' table definitions}

Estimates are reported as HR: hazard ratio. $\mathbf{C l}$ : confidence interval.

${ }^{\star \star \star}$ The assumed absolute effect of RT40 is based on Perry 2017 data.

NMA: network meta-analysis

\section{GRADE Working Group grades of evidence}

High certainty: we are very confident that the true effect lies close to that of the estimate of the effect.

Moderate certainty: we are moderately confident in the effect estimate; the true effect is likely to be close to the estimate of the effect, but there is a possibility that it is substantially different.

Low certainty: our confidence in the effect estimate is limited; the true effect may be substantially different from the estimate of the effect.

Very low certainty: we have very little confidence in the effect estimate; the true effect is likely to be substantially different from the estimate of effect.

${ }^{1}$ Contributing direct evidence was of low certainty (study design limitations and imprecision).

${ }^{2}$ Contributing direct evidence was of high or moderate certainty.

\section{Summary of findings 3. Summary of findings on overall survival comparing treatments to standard radiotherapy}

Estimates of effects and certainty assessment compared with standard radiotherapy (60 Gy/30 fractions) on overall survival in elderly people with newly diagnosed glioblastoma

\section{Patient or population: elderly people with newly diagnosed glioblastoma}

Interventions: radiotherapy with 40 Gy in 15 fractions (RT 40); chemoradiotherapy (CRT); chemoradiotherapy plus bevacizumab (BEV_CRT); radiotherapy plus bevacizumab (BEV_RT); temozolomide (TMZ);

Comparison: standard radiotherapy (RT 60)

Outcome: overall survival

\begin{tabular}{|c|c|c|}
\hline $\begin{array}{l}\text { All intervention options } \\
\text { (7 RCTs; } 1540 \text { participants in total)* }\end{array}$ & $\begin{array}{l}\text { Relative effect (network estimate) } \star \star \\
(95 \% \mathrm{Cl})\end{array}$ & $\begin{array}{l}\text { Certainty of the evi- } \\
\text { dence } \\
\text { (GRADE) }\end{array}$ \\
\hline $\begin{array}{l}\text { RT } 60 \\
\text { (5 RCTs; } 713 \text { participants) }\end{array}$ & Reference comparator & Reference comparator \\
\hline $\begin{array}{l}\text { RT } 40 \\
\text { (4 RCTs; } 930 \text { participants) }\end{array}$ & HR 0.94 (0.72 to 1.23$)$ & $\begin{array}{l}\oplus \oplus \odot \odot \\
\text { Low } \mathbf{1}\end{array}$ \\
\hline $\begin{array}{l}\text { BEV_RT } \\
\text { (1 RCT; } 75 \text { participants) }\end{array}$ & HR 1.01 (0.58 to 1.79 ) & $\begin{array}{l}\oplus \odot \odot \odot \\
\text { Very low } \mathbf{1 , 2}\end{array}$ \\
\hline $\begin{array}{l}\text { TMZ } \\
\text { (3 RCTs, } 538 \text { participants) }\end{array}$ & HR 0.89 (0.71 to 1.11$)$ & $\begin{array}{l}\oplus \odot \odot \odot \\
\text { Very low3 }\end{array}$ \\
\hline CRT & HR 0.63 (0.46 to 0.87 ) & $\begin{array}{l}\oplus \oplus \ominus \ominus \\
\text { Low }\end{array}$ \\
\hline
\end{tabular}


(2 RCTs; 635 participants)

\begin{tabular}{lll}
\hline BEV_CRT & HR $0.52(0.28$ to 0.98$)$ & Not graded \\
(1 RCT; 73 participants) &
\end{tabular}

\section{NMA-'Summary of findings' table definitions}

Estimates are reported as HR: hazard ratio. Cl: confidence interval. For assumed median survival times and absolute effect estimates, please refer to Summary of findings for the main comparison.

NMA: network meta-analysis

\section{GRADE Working Group grades of evidence}

High certainty: we are very confident that the true effect lies close to that of the estimate of the effect.

Moderate certainty: we are moderately confident in the effect estimate; the true effect is likely to be close to the estimate of the effect, but there is a possibility that it is substantially different.

Low certainty: our confidence in the effect estimate is limited; the true effect may be substantially different from the estimate of the effect.

Very low certainty: we have very little confidence in the effect estimate; the true effect is likely to be substantially different from the estimate of effect.

1 Contributing direct evidence was of low certainty (study design limitations and imprecision).

2 Downgraded for imprecision.

3 Contributing direct evidence of very low certainty (imprecision, study design limitations and inconsistency).

\section{Summary of findings 4 . Summary of findings on quality of life}

\section{The effect of different treatment comparisons for newly diagnosed glioblastoma in the elderly on quality of life}

\section{Patient or population: elderly people with newly diagnosed glioblastoma}

\section{Interventions: one treatment option}

\section{Comparison: an alternative treatment option}

\begin{tabular}{|c|c|c|c|c|}
\hline $\begin{array}{l}\text { Compari- } \\
\text { son }\end{array}$ & Narrative summary of evidence & $\begin{array}{l}\text { No of stud- } \\
\text { ies } \\
\text { (elderly } \\
\text { partici- } \\
\text { pants) }\end{array}$ & $\begin{array}{l}\text { Certainty } \\
\text { of the ev- } \\
\text { idence } \\
\text { (GRADE) }\end{array}$ & Comments \\
\hline $\begin{array}{l}\text { RT vs } \\
\text { support- } \\
\text { ive care } \\
\text { only }\end{array}$ & $\begin{array}{l}\text { Evidence on relative } \mathrm{HRQ} \text { RL is very } \\
\text { uncertain. }\end{array}$ & $\begin{array}{l}1 \text { study } \\
\text { ( } 59 \text { partici- } \\
\text { pants at } \\
30 \text { day and } \\
26 \text { at } 135 \\
\text { day time } \\
\text { points, } \\
\text { respective- } \\
\text { ly) }\end{array}$ & $\begin{array}{l}\oplus \odot \Theta \odot \\
\text { Low }^{\mathbf{1}, \mathbf{2}}\end{array}$ & $\begin{array}{l}\text { The study reported that global assessments of de- } \\
\text { terioration over time also did not differ significant- } \\
\text { ly between the two groups. } \\
\text { The dropout rate was high and unbalanced so find- } \\
\text { ings were difficult to interpret. }\end{array}$ \\
\hline $\begin{array}{l}\text { Hypofrac- } \\
\text { tionat- } \\
\text { ed RT } \\
\text { vs stan- } \\
\text { dard RT } \\
\text { (60Gy/30 } \\
\text { fractions) }\end{array}$ & $\begin{array}{l}\text { There may be little difference in } \\
\text { HRQoL scores between hypofrac- } \\
\text { tionated } \\
\text { and standard fractionation sched- } \\
\text { ules in the } 6 \text { to } 8 \text { weeks following } \\
\text { treatment. }\end{array}$ & $\begin{array}{l}2 \text { studies } \\
\text { (partici- } \\
\text { pants num- } \\
\text { bered }\end{array}$ & $\begin{array}{l}\oplus \odot \odot \ominus \\
\text { Low }^{\mathbf{1}, \mathbf{2}}\end{array}$ & $\begin{array}{l}\text { One study compared a } 25 \text { Gy schedule with a } 40 \\
\text { Gy schedule; the other compared a } 40 \text { Gy schedule } \\
\text { with a standard } 60 \text { Gy schedule. }\end{array}$ \\
\hline
\end{tabular}




\begin{tabular}{|c|c|c|c|c|}
\hline & & $\begin{array}{l}85 \text { and } 24 \text {, } \\
\text { respective- } \\
\text { ly, at the } \\
\text { furthest } \\
\text { time point) }\end{array}$ & & \\
\hline TMZ vs RT & $\begin{array}{l}\text { No significant differences in global } \\
\text { QoL scores at } 3,6 \text {, or } 12 \text { month mea- } \\
\text { surements. However, there was a } \\
\text { significant difference in discomfort } \\
\text { from communication deficits, which } \\
\text { were greatest for those receiving } \\
\text { RT who died at between } 6 \text { and } 12 \\
\text { months ( } P=0.002) \text {. }\end{array}$ & $\begin{array}{l}1 \text { study } \\
\text { (306 partic- } \\
\text { ipants) }\end{array}$ & $\begin{array}{l}\oplus \oplus \oplus \odot \\
\text { Moder- } \\
\text { ate }^{3}\end{array}$ & $\begin{array}{l}\text { Evidence was not downgraded for attrition be- } \\
\text { cause data were reported for } 82 \% \text { of participants in } \\
\text { each group for this outcome. }\end{array}$ \\
\hline CRT vs RT & $\begin{array}{l}\text { Authors reported that quality of life } \\
\text { was similar in the two treatment } \\
\text { groups. See Comments. }\end{array}$ & $\begin{array}{l}1 \text { study } \\
\text { (562 par- } \\
\text { ticipants; } \\
\text { number } \\
\text { with QOL } \\
\text { data was } \\
\text { unclear) }\end{array}$ & $\begin{array}{l}\text { Not grad- } \\
\text { ed }\end{array}$ & $\begin{array}{l}\text { Investigators noted that attrition impacted the } \\
\text { quantity of data. They conducted analyses using } \\
\text { time to deterioration (with deterioration defined } \\
\text { as a 10-point decrease in the score on the function } \\
\text { domain or a 10-point increase in the score on the } \\
\text { symptom domain) and plotted QoL scores over } \\
\text { time. They reported that "There were no other clin- } \\
\text { ically important differences between trial groups, } \\
\text { which supports our observation that quality of life } \\
\text { was similar in the two treatment groups." }\end{array}$ \\
\hline $\begin{array}{l}\text { BEV_CRT } \\
\text { vs CRT }\end{array}$ & $\begin{array}{l}\text { This was reported for the overall } \\
\text { trial but not for elderly subgroup } \\
\text { specifically. }\end{array}$ & $\begin{array}{l}1 \text { study } \\
\text { (73 partici- } \\
\text { pants) }\end{array}$ & $\begin{array}{l}\text { Not grad- } \\
\text { ed }\end{array}$ & $\begin{array}{l}\text { The authors reported significantly delayed deterio- } \\
\text { ration in HRQoL scores in favour of BEV_CRT across } \\
\text { five main HRQoL domains (global health, commu- } \\
\text { nication, social functioning, motor function, physi- } \\
\text { cal functioning). When progression of disease was } \\
\text { removed as a deterioration event, the time to clin- } \\
\text { ically significant deterioration or death remained } \\
\text { statistically significant for communication, social } \\
\text { functioning and global health. }\end{array}$ \\
\hline $\begin{array}{l}\text { BEV_RT } \\
\text { VS RT }\end{array}$ & $\begin{array}{l}\text { Investigators reported that "before } \\
\text { progression, no differences were de- } \\
\text { tected for individual scales in a gen- } \\
\text { eralized linear mixed model, except } \\
\text { for less favourable values in arm } A \\
\text { (BEV) for global health }(P=0.048) \\
\text { and pain }(P=0.027) " .\end{array}$ & $\begin{array}{l}1 \text { study } \\
\text { ( } 75 \text { partici- } \\
\text { pants) }\end{array}$ & $\begin{array}{l}\text { Not grad- } \\
\text { ed }\end{array}$ & $\begin{array}{l}\text { In the publication, global health was reported in } \\
\text { a forest plot along with individual HRQoL items, } \\
\text { such as cognitive functioning, emotional function- } \\
\text { ing and pain, measured with EORTC QLQ-C30/BN20 } \\
\text { scales. No other data were provided or obtained. }\end{array}$ \\
\hline $\begin{array}{l}\text { RIN_CRT } \\
\text { vs con- } \\
\text { trol/CRT }\end{array}$ & $\begin{array}{l}\text { This was reported for overall trial } \\
\text { but not for elderly subgroup specifi- } \\
\text { cally. }\end{array}$ & $\begin{array}{l}1 \text { study } \\
\text { (174 partic- } \\
\text { ipants) }\end{array}$ & $\begin{array}{l}\text { Not grad- } \\
\text { ed }\end{array}$ & $\begin{array}{l}\text { Investigators reported no significant differences } \\
\text { between patients in their trial arms in any of the } \\
\text { HRQoL measures. }\end{array}$ \\
\hline $\begin{array}{l}\text { TTF_AC } \\
\text { vs CRT }\end{array}$ & $\begin{array}{l}\text { This was reported for overall trial } \\
\text { but not for elderly subgroup specifi- } \\
\text { cally. } 4\end{array}$ & $\begin{array}{l}1 \text { study } \\
\text { (134 partic- } \\
\text { ipants) }\end{array}$ & $\begin{array}{l}\text { Not grad- } \\
\text { ed }\end{array}$ & $\begin{array}{l}\text { There was no significant difference in HRQoL re- } \\
\text { ported between the trial arms, except for itchy skin } \\
\text { which was more prominent in the TTFields arm } \\
\text { at } 3,6 \text { and } 9 \text { months }(P=0.005, P=0008, P=0.04) \text {. } \\
\text { There was no significant difference at } 12 \text { months. }\end{array}$ \\
\hline $\begin{array}{l}\text { IRI_BEV_RT } \\
\text { vs CRT }\end{array}$ & $\begin{array}{l}\text { This was reported for overall trial } \\
\text { but not for elderly subgroup specifi- } \\
\text { cally. }\end{array}$ & $\begin{array}{l}1 \text { study } \\
\text { (34 partici- } \\
\text { pants) }\end{array}$ & $\begin{array}{l}\text { Not grad- } \\
\text { ed }\end{array}$ & $\begin{array}{l}\text { There was no significant difference between the } \\
\text { treatment arms. }\end{array}$ \\
\hline
\end{tabular}

GRADE Working Group grades of evidence 
High certainty: we are very confident that the true effect lies close to that of the estimate of the effect.

Moderate certainty: we are moderately confident in the effect estimate; the true effect is likely to be close to the estimate of the ef-

fect, but there is a possibility that it is substantially different.

Low certainty: our confidence in the effect estimate is limited; the true effect may be substantially different from the estimate of the effect.

Very low certainty: we have very little confidence in the effect estimate; the true effect is likely to be substantially different from the estimate of effect.

1Sparse data from single studies [-1]

2 Serious risk of bias from attrition $[-1]$

3 Downgraded because data were presented graphically and effects could not be estimated.

4 In this trial (Stupp 2017a) TTF_AC was compared with adjuvant chemotherapy (TMZ) only, after both arms had received concomitant CRT. Abbreviations: BEV_CRT: chemoradiotherapy plus bevacizumab; BEV_RT: radiotherapy plus bevacizumab; CI: confidence interval; CRT: chemoradiotherapy; HR: hazard ratio; IRI: irinotecan; RT: radiotherapy; TMZ: temozolomide; TTF_AC: tumour treating fields with adjuvant chemotherapy (after concomitant CRT) (TTF_AC); RIN_CRT: rindopepimut after CRT.

\section{Summary of findings 5. Summary of findings on progression-free survival}

The effect of different treatment comparisons for newly diagnosed glioblastoma in the elderly on progression-free survival

\section{Patient or population: elderly people with newly diagnosed glioblastoma}

\section{Interventions: one treatment option}

Comparison: an alternative treatment option

\begin{tabular}{|c|c|c|c|c|}
\hline $\begin{array}{l}\text { Progres- } \\
\text { sion-free sur- } \\
\text { vival }\end{array}$ & $\begin{array}{l}\text { Relative ef- } \\
\text { fect } \\
(95 \% \mathrm{CI})\end{array}$ & $\begin{array}{l}\text { No of studies } \\
\text { (elderly partici- } \\
\text { pants) }\end{array}$ & $\begin{array}{l}\text { Certainty } \\
\text { of the ev- } \\
\text { idence } \\
\text { (GRADE) }\end{array}$ & Comments \\
\hline $\begin{array}{l}\text { RT vs support- } \\
\text { ive care only }\end{array}$ & $\begin{array}{l}\text { HR } 0.28(0.17 \\
\text { to } 0.46)\end{array}$ & $\begin{array}{l}1 \text { study ( } 81 \text { partici- } \\
\text { pants) }\end{array}$ & $\begin{array}{l}\oplus \oplus \oplus \odot \\
\text { Moder- } \\
\text { ate }^{1}\end{array}$ & $\begin{array}{l}\text { Median time to progression was } 3.5 \text { months in the RT arm vs } \\
1.3 \text { months in the supportive care arm of this study (Keime- } \\
\text { Guibert 2007). }\end{array}$ \\
\hline $\begin{array}{l}\text { Hypofraction- } \\
\text { ated RT vs } \\
\text { standard RT } \\
\text { (60Gy/30 frac- } \\
\text { tions) }\end{array}$ & $\begin{array}{l}\text { HR not report- } \\
\text { ed }\end{array}$ & $\begin{array}{l}1 \text { study (64 partici- } \\
\text { pants) }\end{array}$ & $\begin{array}{l}\text { Not grad- } \\
\text { ed }\end{array}$ & $\begin{array}{l}\text { This study (Roa } 2015 \text { ) reported that median progression-free } \\
\text { survival showed no statistically significant difference be- } \\
\text { tween arms ( } 4.2 \text { v } 4.2 \text { months in arms } 1 \text { and } 2 \text {, respectively; } P \\
=0.716 \text { ). }\end{array}$ \\
\hline TMZ vs RT & $\begin{array}{l}\text { HR } 1.15(0.92 \\
\text { to } 1.44)\end{array}$ & $\begin{array}{l}1 \text { study ( } 373 \text { par- } \\
\text { ticipants) }\end{array}$ & $\begin{array}{l}\oplus \oplus \odot \ominus \\
\text { Low }^{2,3}\end{array}$ & No additional comments. \\
\hline CRT vs RT & $\begin{array}{l}\text { HR } 0.50(0.41 \\
\text { to } 0.61)\end{array}$ & $\begin{array}{l}1 \text { study } \\
\text { (562 participants) }\end{array}$ & $\begin{array}{l}\oplus \oplus \oplus \oplus \\
\text { High }\end{array}$ & No additional comments. \\
\hline $\begin{array}{l}\text { BEV_CRT vS } \\
\text { CRT }\end{array}$ & $\begin{array}{l}\text { HR } 0.78(0.46 \\
\text { to } 1.32)\end{array}$ & $\begin{array}{l}1 \text { study ( } 73 \text { partici- } \\
\text { pants) }\end{array}$ & $\begin{array}{l}\oplus \oplus \Theta \Theta \\
\operatorname{Low} \mathbf{1 , 2}\end{array}$ & $\begin{array}{l}\text { In this study (AVAglio 2014), BEV_CRT did not increase overall } \\
\text { survival either relative to CRT alone for elderly patients. }\end{array}$ \\
\hline BEV_RT vs RT & $\begin{array}{l}\text { HR } 0.46(0.27 \\
\text { to } 0.78)\end{array}$ & $\begin{array}{l}1 \text { study ( } 75 \text { partici- } \\
\text { pants) }\end{array}$ & $\begin{array}{l}\oplus \oplus \oplus \ominus \\
\text { Moder- } \\
\text { ate1 }\end{array}$ & $\begin{array}{l}\text { Despite delaying disease progression in this study (ARTE } \\
\text { 2018), BEV_RT did not increase overall survival. }\end{array}$ \\
\hline $\begin{array}{l}\text { RIN_CRT vs } \\
\text { CRT }\end{array}$ & \multicolumn{4}{|c|}{ Not reported separately for elderly subgroup. } \\
\hline
\end{tabular}




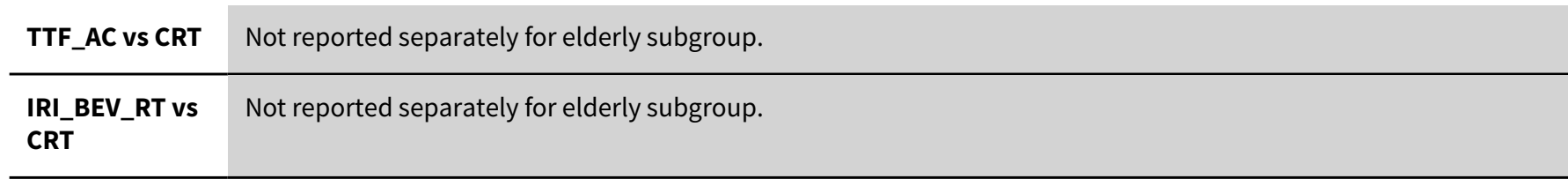

\section{GRADE Working Group grades of evidence}

High certainty: we are very confident that the true effect lies close to that of the estimate of the effect.

Moderate certainty: we are moderately confident in the effect estimate; the true effect is likely to be close to the estimate of the effect, but there is a possibility that it is substantially different.

Low certainty: our confidence in the effect estimate is limited; the true effect may be substantially different from the estimate of the effect.

Very low certainty: we have very little confidence in the effect estimate; the true effect is likely to be substantially different from the estimate of effect.

1Sparse data from single studies [-1]

2 Serious risk of bias from attrition [-1]

3 Serious imprecision

Abbreviations:BEV_CRT: chemoradiotherapy plus bevacizumab; BEV_RT: radiotherapy plus bevacizumab; CI: Confidence interval; HR: hazard ratio;IRI: irinotecan; RT: radiotherapy; CRT: chemoradiotherapy; TMZ: temozolomide; TTF_AC: tumour treating fields with adjuvant chemotherapy (after concomitant CRT) (TTF_AC); RIN_CRT: rindopepimut after CRT.

\section{Summary of findings 6 . Summary of findings on severe adverse events}

\section{The effect of different treatments for newly diagnosed glioblastoma on severe adverse events}

\section{Patient or population: elderly people with newly diagnosed glioblastoma}

\section{Settings: any}

\section{Intervention: one treatment option}

Comparison: an alternative treatment option

\begin{tabular}{|c|c|c|c|c|}
\hline $\begin{array}{l}\text { Compari- } \\
\text { son }\end{array}$ & $\begin{array}{l}\text { Narrative summary of } \\
\text { evidence }\end{array}$ & $\begin{array}{l}\text { No of } \\
\text { studies } \\
\text { (elderly } \\
\text { partici- } \\
\text { pants) }\end{array}$ & $\begin{array}{l}\text { Certainty } \\
\text { of the ev- } \\
\text { idence } \\
\text { (GRADE) }\end{array}$ & Comments \\
\hline $\begin{array}{l}\text { RT vs } \\
\text { support- } \\
\text { ive care } \\
\text { only }\end{array}$ & Not reported. & NA & NA & None \\
\hline $\begin{array}{l}\text { Hypofrac- } \\
\text { tionat- } \\
\text { ed RT } \\
\text { vs stan- } \\
\text { dard RT } \\
\text { (60Gy/30 } \\
\text { fractions) }\end{array}$ & $\begin{array}{l}\text { This outcome was on- } \\
\text { ly reported in one small } \\
\text { study and there were no } \\
\text { instances of grade } 3 \text { or } \\
\text { higher treatment-related } \\
\text { toxicity. }\end{array}$ & $\begin{array}{l}1 \text { study } \\
(61)\end{array}$ & $\begin{array}{l}\text { Not grad- } \\
\text { ed }\end{array}$ & None \\
\hline TMZ vs RT & $\begin{array}{l}\text { TMZ probably increases } \\
\text { the risk of thromboembol- } \\
\text { ic and haematological ad- } \\
\text { verse events }\end{array}$ & $\begin{array}{l}1 \text { study } \\
(373)\end{array}$ & $\begin{array}{l}\oplus \oplus \oplus \odot \\
\text { Moder- } \\
\text { ate1 }\end{array}$ & $\begin{array}{l}\text { Thrombocytopenia occurred in } 24 \mathrm{TMZ} \text { vs } 8 \text { RT participants } \\
\text { (RR } 2.74,95 \% \mathrm{Cl} 1.26 \text { to } 5.94 \text { ) and lymphocytopenia occurred } \\
\text { in } 16 \mathrm{TMZ} \text { vs } 2 \text { RT participants (RR } 7.30,95 \% \mathrm{Cl} 1.70 \text { to } 31.31 \text { ). }\end{array}$ \\
\hline
\end{tabular}




\begin{tabular}{|c|c|c|c|c|}
\hline CRT vs RT & $\begin{array}{l}\text { CRT probably increases } \\
\text { the risk of haematological } \\
\text { adverse events }\end{array}$ & $\begin{array}{l}1 \text { study } \\
(562)\end{array}$ & $\begin{array}{l}\oplus \oplus \oplus \ominus \\
\text { Moder- } \\
\text { ate }^{1}\end{array}$ & $\begin{array}{l}\text { Neutropenia occurred in } 22 \text { CRT vs } 2 \text { RT participants (RR } 10.30 \text {; } \\
95 \% \text { Cl } 2.45 \text { to } 43.34 \text { ); throbocytopenia occurred in } 30 \text { CRT vs } \\
1 \text { RT participants (RR } 28.56,95 \% 3.92 \text { to } 207.86 \text { ); lymphocy- } \\
\text { topenia occurred in } 73 \text { CRT vs } 26 \text { RT participants (RR } 2.65,95 \% \\
\text { Cl } 1.75 \text { to } 4.01 \text { ); leucopenia occurred in } 19 \text { CRT vs } 1 \text { RT partici- } \\
\text { pant (RR } 18.16,96 \% \text { Cl } 2.45 \text { to } 124.64 \text { ); and anaemia occurred } \\
\text { in } 3 \text { CRT vs } 0 \text { RT participants (RR } 6.69,95 \% \text { Cl } 0.35 \text { to } 128.88 \text { ). }\end{array}$ \\
\hline $\begin{array}{l}\text { BEV_CRT } \\
\text { vs CRT }\end{array}$ & $\begin{array}{l}\text { BEV_CRT probably in- } \\
\text { creases the risk of grade } \\
3+\text { thromboembolic } \\
\text { events. }\end{array}$ & $\begin{array}{l}1 \text { study } \\
\text { (73) }\end{array}$ & $\begin{array}{l}\oplus \oplus \oplus \odot \\
\text { Moder- } \\
\text { ate }^{1}\end{array}$ & $\begin{array}{l}\text { Other adverse events data were not available for elderly sub- } \\
\text { group specifically. For the larger study sample, Grade } 3+\text { cere- } \\
\text { bral bleeding events ( } 2.0 \% \text { versus } 0.9 \%) \text { and wound healing } \\
\text { events ( } 3.3 \% \text { vs } 1.6 \%) \text { were higher in the BEV plus CRT arm } \\
\text { versus CRT alone. There were also higher rates of Grade } 3+ \\
\text { thrombocytopenia ( } 15 \% \text { vs } 9.8 \%) \text { and infection rates }(12.8 \% \\
\text { versus } 7.8 \%) \text { in the BEV_CRT arm. }\end{array}$ \\
\hline $\begin{array}{l}\text { BEV_RT } \\
\text { VS RT }\end{array}$ & $\begin{array}{l}\text { There was little or no dif- } \\
\text { ference in thromboem- } \\
\text { bolic, haematological, } \\
\text { and other severe adverse } \\
\text { events reported in this one } \\
\text { small study. }\end{array}$ & $\begin{array}{l}1 \text { study } \\
(75)\end{array}$ & $\begin{array}{l}\oplus \oplus \Theta \ominus \\
\text { Low } \mathbf{1}\end{array}$ & $\begin{array}{l}\text { An example of these non-statistically significant findings for } \\
\text { thrombocytopenia are that this SAE occurred in } 8 \text { BEV_RT vs } \\
2 \text { RT participants (RR } 2.00,95 \% \mathrm{Cl} 0.46 \text { vs } 8.73 \text { ). Haematologi- } \\
\text { cal SAEs occurred in } 2 \text { vs } 0 \text { participants, respectively (RR } 2.55 \text {, } \\
95 \% \mathrm{Cl} 0.13 \text { vs 51.17). }\end{array}$ \\
\hline $\begin{array}{l}\text { RIN_CRT } \\
\text { vs CRT }\end{array}$ & $\begin{array}{l}\text { This was reported for over- } \\
\text { all trial but not for elderly } \\
\text { subgroup specifically. }\end{array}$ & $\begin{array}{l}1 \text { study } \\
\text { (174 par- } \\
\text { ticipants) }\end{array}$ & $\begin{array}{l}\text { Not grad- } \\
\text { ed }\end{array}$ & $\begin{array}{l}\text { The most common severe adverse events for the experimental } \\
\text { (rindopepimut) versus control arm of the trial were: thrombo- } \\
\text { cytopenia ( } 9 \% \text { vs } 6 \%) \text {, fatigue ( } 2 \% \text { vs } 5 \%) \text {, brain oedema ( } 2 \% \\
\text { vs } 3 \%) \text {, seizure ( } 2 \% \text { vs } 2 \% \text { ) and headache ( } 2 \% \text { vs } 3 \%) \text {. There } \\
\text { was one death, secondary to pulmonary embolism, that was } \\
\text { assessed as potentially related to the treatment in the experi- } \\
\text { mental arm. }\end{array}$ \\
\hline $\begin{array}{l}\text { TTF_AC } \\
\text { vs AC }\end{array}$ & $\begin{array}{l}\text { This was reported for over- } \\
\text { all trial but not for elderly } \\
\text { subgroup specifically. }\end{array}$ & $\begin{array}{l}1 \text { study } \\
\text { (134 par- } \\
\text { ticipants) }\end{array}$ & $\begin{array}{l}\text { Not grad- } \\
\text { ed }\end{array}$ & $\begin{array}{l}\text { Overall, it was reported that there was no significant increase } \\
\text { in rates of severe adverse events when TTF were added to ad- } \\
\text { juvant chemotherapy ( } 48 \% \text { vs } 44 \%, P=0.58 \text { ). }\end{array}$ \\
\hline $\begin{array}{l}\text { IRI_BEV_RT } \\
\text { vs CRT }\end{array}$ & $\begin{array}{l}\text { This was reported for over- } \\
\text { all trial but not for elderly } \\
\text { subgroup specifically. }\end{array}$ & $\begin{array}{l}1 \text { study } \\
\text { ( } 34 \text { partic- } \\
\text { ipants) }\end{array}$ & $\begin{array}{l}\text { Not grad- } \\
\text { ed }\end{array}$ & $\begin{array}{l}\text { Overall, rates of severe adverse events were } 72 \% \text { in the experi- } \\
\text { mental arm and } 84 \% \text { in the CRT arm. In the experimental arm, } \\
\text { severe vascular events were most common ( } 11.8 \%) \text { and two } \\
\text { cerebral haemorrhages occurred (one fatal). For patients in } \\
\text { the CRT arm, severe haematological toxicity was most com- } \\
\text { mon }(18.2 \%) \text {. }\end{array}$ \\
\hline
\end{tabular}

GRADE Working Group grades of evidence

High certainty: we are very confident that the true effect lies close to that of the estimate of the effect.

Moderate certainty: we are moderately confident in the effect estimate; the true effect is likely to be close to the estimate of the effect, but there is a possibility that it is substantially different.

Low certainty: our confidence in the effect estimate is limited; the true effect may be substantially different from the estimate of the effect.

Very low certainty: we have very little confidence in the effect estimate; the true effect is likely to be substantially different from the estimate of effect.

1 Downgraded -2 for sparse data from small single study and imprecision

Abbreviations: BEV_CRT: chemoradiotherapy plus bevacizumab; BEV_RT: radiotherapy plus bevacizumab; CI: confidence interval; $\mathbf{H R}$ : hazard ratio; RT: radiotherapy; CRT: chemoradiotherapy; IRI: irinotecan; NA: not applicable; TMZ: temozolomide; TTF_AC: tumour treating fields with adjuvant chemotherapy (after concomitant CRT) (TTF_AC); RIN_CRT: rindopepimut after CRT. 


\section{B A C K G R O U N D}

\section{Description of the condition}

Glioblastoma multiforme is a high-grade, aggressive primary tumour of the central nervous system with a poor prognosis. The incidence of glioblastoma is increasing and this rise is most rapid in the elderly (Ferguson 2014). Use of the term 'the elderly' in relation to glioblastoma commonly refers to people 70 years and older (NCCN 2018). Age is an important consideration in the treatment of glioblastoma as it is a negative prognostic indicator (Lorimer 2017). A Surveillance Epidemiology and End Results (SEER) population analysis reported that for every year increase in patient age, there was a statistically significant decrease in survival (Thumma 2012). Median survival drops from about 12 to 18 months for younger people with glioblastoma, to three to six months for older age cohorts (Brodbelt 2015).

The molecular status of glioblastoma is also an important prognostic factor and several molecular subtypes of glioblastoma have been recognised (Lara-Velazquez 2017). One of the most important molecular signatures is $0^{6}$-methylguanine-DNAmethyltransferase (MGMT) promoter methylation, which has been shown to confer predictive and prognostic benefit (Malmstrom 2012; Yin 2014). Treatment for glioblastoma is not curative and the natural history of the disease is that patients will relapse after treatment and it will ultimately be a fatal condition (Louis 2016). Retrospective studies have shown that older people are less likely to get aggressive, multi-modality treatment (Iwamoto 2008; Lorimer 2017; Paszat 2001), but people with glioblastoma across all age groups who do get active treatment live longer (Brodbelt 2015). Direct healthcare costs for the management of malignant gliomas (malignant glioma encompasses anaplastic glioma, i.e. World Health Organization (WHO) grade 3 and 4) have been estimated at USD 32,764 per patient (2011 data; Raizer 2015).

\section{Description of the intervention}

The 'standard of care' of treatment for patients aged under 70 years of age with glioblastoma consists of surgery followed by radiotherapy ( $60 \mathrm{~Gy}$ in 30 fractions) with concomitant and adjuvant temozolomide (TMZ) chemotherapy (NCCN 2018; Stupp 2005). This management plan is less often used in the elderly for the following reasons.

- People over 70 years old were not included in the landmark trial (Stupp 2005), and a subsequent communication of the results of an exploratory subgroup analysis revealed that the survival benefit in this trial was not statistically significant for a subgroup of people aged 66 to 70 years (Laperriere 2013).

- Shorter radiotherapy courses or chemotherapy alone can lead to better outcomes for the elderly than the standard course of radiotherapy. Patients rarely live long enough to develop late complications from radiation therapy, therefore larger fraction size may be justified to allow for a shortened course of treatment.

- Both chemotherapy and radiotherapy treatment toxicities are often greater in the elderly (Lawrence 2011; Sijben 2008).

- The shorter predicted survival time for older people with glioblastoma means that they might spend much of this time recovering from the six-week course of radiotherapy.
Small prospective (Vuorinen 2003), and retrospective studies (Chaichana 2011a; Chaichana 2011b), have shown that, for people aged 65 and over with glioblastoma, maximal debulking (resection) is associated with better survival and a trend to longer time remaining independent versus biopsy alone. Therefore maximal resection, if feasible, is the recommended primary approach to glioblastoma in the elderly (NCCN 2018). Depending on a person's performance status, radiotherapy or chemotherapy, or both, can then be added. As it remains unclear which treatment is best for glioblastoma in the elderly, participation in clinical trials is strongly encouraged (NCCN 2018). There is little evidence to guide treatment of recurrent glioblastoma in the elderly and approaches are based on retrospective studies (Socha 2016).

\section{Treatment with either radiotherapy or chemotherapy}

A randomised trial of radiotherapy ( $50 \mathrm{~Gy}$ delivered over a period of five to six weeks) versus best supportive care showed that radiotherapy conferred a 12-week survival benefit in older people with malignant glioma (Keime-Guibert 2007). Another randomised trial found that radiotherapy (60 Gy over a period of six to seven weeks) was as effective as intensive ("dose-dense") TMZ chemotherapy alone (Wick 2012). There is increasing interest in using hypofractionated radiotherapy (radiotherapy delivered over shorter period of time, e.g. 40 Gy in 15 fractions over three weeks and $34 \mathrm{~Gy}$ in 10 fractions over two weeks) for older people with glioblastoma, as these have been found to have similar survival benefits compared to the standard regimen of $60 \mathrm{~Gy}$ in 30 fractions over a period of six weeks (Malmstrom 2012; Roa 2004).

\section{Combination treatment}

A randomised trial has shown that adding TMZ to hypofractionated radiotherapy for older people with glioblastoma confers a survival advantage compared to hypofractionated radiotherapy alone (Minniti 2012; Perry 2017), but not necessarily for those people with MGMT unmethylated tumours.

\section{How the intervention might work}

Surgery is an important step in the treatment of glioblastoma. Also, there is evidence that surgery improves one- and two-year survival rates compared to biopsy alone (Brown 2016). The extent of surgery can be divided into three main categories which have different definitions in the literature: 'maximal' debulking or gross total resection (GTR), subtotal resection (STR), and biopsy. The role of maximal debulking surgery is to minimise the tumour volume that remains to optimise the impact of subsequent treatment modalities, which are likely to be more effective against small volume tumours (Lara-Velazquez 2017).

Radiotherapy is delivered to the primary tumour or the surgical cavity with a margin to account for microscopic spread, patient movement, and set-up error (Niyazi 2016). One of the most important mechanisms of action of radiation therapy is the promotion of double strand breaks in DNA which, if left unrepaired, will result in cell death (Baskar 2014). DNA damage is more likely to occur in rapidly dividing cells, such as glioblastoma tumour cells, rather than normal brain which has a slower rate of cellular turn over. This provides the therapeutic index between the tumour and normal surrounding tissue.

Systemic chemotherapy can enhance the therapeutic effect of radiotherapy but is also an effective treatment on its own. 
The most widely used chemotherapy agent for newly diagnosed glioblastoma is TMZ, which acts as a DNA alkylating agent (Zhang 2012). Those tumours with MGMT-promoter methylation lack the MGMT enzyme which repairs the cytotoxic damage caused by TMZ, thereby making tumour cells more chemosensitive.

\section{Why it is important to do this review}

Previous research has demonstrated that increasing age has an important effect on overall survival and tolerability of treatment for patients with a diagnosis of glioblastoma (Thumma 2012). Increasing age, regardless of performance status, has an important influence on treatment decisions made by clinicians (Palmer 2018), however there is still a lack of consensus on the optimal treatment options for the elderly subgroup of patients with glioblastoma.

It is recognised that treating older people with glioblastoma presents unique challenges and that the standard approach is not always appropriate. There have been several randomised trials in recent years that have tested therapeutic strategies specifically for older people with glioblastoma (e.g. Malmstrom 2012; Perry 2017 Roa 2004; Wick 2012). Other trials including younger people have also performed subgroup analysis to test if therapeutic benefit is maintained in older people. Due to the variation in age thresholds to define the 'elderly', performance status, treatment regimens, and molecular subtypes, it has been difficult to translate these individual studies into clinical practice. This is also because the focus of many intervention trials is on survival, which might not be the most important outcome to elderly people with glioblastoma; rather, the quality of the remainder of their life might be their most important consideration. As the median age of diagnosis is around 64 years of age (Ostrom 2015), a significant proportion of newly diagnosed patients fall into the 'elderly' category.

There is been some evidence to suggest that total direct costs of care associated with glioblastoma have been increasing over recent years with the increased use of costly systemic anti-cancer treatments (Henaine 2016; Ray 2014). Selecting the appropriate management strategy for an elderly patient group is important from a quality of life perspective and also has significant resource implications (Raizer 2015). It has been estimated the average cost for a regimen of TMZ to treat a person with newly diagnosed glioblastoma is USD 46,693 (USD in 2018 converted from NZD 2005) (Hamilton 2005). It is therefore important to understand the costs and benefits to avoid implementing costly and potentially toxic treatment for little clinical benefit.

Currently there is no clear consensus on how to apply the available evidence to guide treatment of the individual person seen in clinic. A systematic review and network meta-analysis (NMA) of randomised trials would help to inform the best approach to the treatment of older individuals with newly diagnosed glioblastoma and help to identify research gaps.

\section{O B J E C T IVES}

To determine the most effective and best-tolerated approaches for the treatment of elderly people with newly diagnosed glioblastoma. To summarise current evidence for the incremental resource use, utilities, costs and cost-effectiveness associated with these approaches.

\section{METHODS}

\section{Criteria for considering studies for this review}

\section{Types of studies}

- Randomised controlled trials (RCTs) for evidence on effectiveness and safety.

- Full economic evaluations (cost-effectiveness analyses, costutility analyses, and cost-benefit analyses) conducted alongside any study design and any model-based economic evaluations for economic evidence.

\section{Types of participants}

Elderly people undergoing treatment for histologically confirmed newly diagnosed glioblastoma. For the purpose of this Cochrane Review, we defined 'elderly' as 70 years and older; however, where investigators defined the 'elderly' as over 65 years of age, we included these studies. We included studies of people of all ages that reported subgroup findings for elderly people (over 65 or 70 years of age) provided the participants in the subgroup numbered more than 20. We also included the mixed data if it was clear that $80 \%$ or more of participants in the study were over the age of 65 years. Similarly, where the study population included both grade 3 or 4 gliomas (anaplastic astrocytomas or glioblastoma), we tried to obtain separate data for participants with glioblastoma; if this was not possible, we considered including the study if more than half the study population had glioblastoma.

\section{Types of interventions}

Interventions evaluated alone or in combination with each other versus any of the other interventions included the following.

- Radiotherapy (standard, hypofractionated, and other techniques).

- Chemotherapy (temozolomide (TMZ) and other types).

We included all available regimens of radiotherapy and chemotherapy that were evaluated in randomised trials. If we identified interventions in the included studies of which we were not aware, we considered including them after we assessed their comparability with those interventions named above. We excluded phase 1 and 2 studies of novel interventions that have been shown to be detrimental and have not been developed further.

It was not possible to create separate networks according to the type of surgical procedure (gross total resection (GTR), subtotal resection (STR), and biopsy only). Within each network we assumed that any participants within the network could be randomised to any of the interventions e.g. an elderly person with histologically confirmed glioblastoma could be equally likely to be randomised to standard radiotherapy, chemotherapy, any combination of these or supportive care.

\section{Types of outcome measures}

\section{Primary outcomes}

- Overall survival (time from randomisation to death from any cause).

- Quality of life (QoL), as measured using a standardised questionnaire, e.g. the European Organisation for Research and Treatment of Cancer (EORTC) QLQ-C30 or QLQ-BN20 (specific for 
brain cancer), or the Functional Assessment of Cancer Therapy scale (FACT-G (general) or FACT-Br (specific for brain cancer)).

\section{Secondary outcomes}

- Progression-free survival (time from randomisation to disease progression or death from any cause).

- Severe adverse events, according to standardised scales, e.g. Common Terminology Criteria for Adverse Events (CTCAE).

- Cognitive impairment (objective or subjective), as measured by an overall cognitive function score, as a change-over-time score, or reported as individual cognitive function domains, e.g. verbal fluency, processing speed, memory, attention, and executive functioning, using a standardised measurement tool, e.g. Mini Mental State Exam (MMSE), EORTC, FACT.

- Functional impairment or disability, as measured by an overall ability score and/or as a change of ability over time score using a standardised measurement tool, e.g. Karnofsky Performance Status Scale, Neurological Functions Score, EORTC, FACT; or as a categorical outcome as defined by investigators.

- Fatigue, according to CTCAE, EORTC, or as defined by investigators.

- Economic outcomes:

* resource use for health care;

* health state utilities;

* costs of health care;

* incremental cost-effectiveness.

\section{Search methods for identification of studies}

\section{Electronic searches}

For studies on the effects of the interventions, we searched the following databases to 3 April 2019:

- The Cochrane Central Register of Controlled Trials (CENTRAL; 2019, Issue 4), in the Cochrane Library;

- MEDLINE via Ovid (1946 to March week 4 2019);

- Embase via Ovid (1980 to 2019 week 13).

For economic evidence we searched the following databases:

- MEDLINE via Ovid (January 2015 to March week 4 2019);

- Embase via Ovid (January 2015 to 2019 week 13);

- NHS Economic Evaluation Database (EED) to December 2014.

The NHS EED database was searched up to the end of December 2014 (when the last records were added to that database) and MEDLINE and Embase from 1 January 2015, as the NHS EED already included comprehensive searches of these databases prior to 2015. We also considered relevant grey literature (such as health technology assessments, reports, and working papers) for inclusion.

Please refer to Appendix 1 for the CENTRAL, MEDLINE, and Embase search strategies.

We did not apply language restrictions to any literature searches.

\section{Searching other resources}

We searched the following for ongoing trials.
- ClinicalTrials.gov (clinicaltrials.gov/)

- WHO International Clinical Trials Registry Platform (ICTRP) (apps.who.int/trialsearch/)

If ongoing trials that have not been published were identified through these searches, we approached the principal investigators to ask for an update on the trial status and any relevant unpublished data, if available.

We used the related articles feature of PubMed and handsearched the reference lists of included studies to identify newly published articles and additional studies of relevance. We also handsearched conference proceedings from 2014 to 2018 (five years) of the British Neuro-Oncology Society, the Society of Neuro-Oncology, the European Association of Neuro-Oncology and the World Federation of Neuro-Oncology Societies conferences for relevant ongoing or unpublished studies.

\section{Data collection and analysis}

\section{Selection of studies}

For the results of search 1 (trials of effects of interventions), the Information Specialist at the Cochrane Gynaecological, Neurooncology and Orphan Cancer Group (CGNOC) downloaded all titles and abstracts retrieved by electronic searching to EndNote $\mathrm{X} 8$ and removed duplicates. Two review authors (TAL, $\mathrm{CH}$, or $E R$ ) independently screened the remaining records and excluded studies that clearly did not meet the eligibility criteria. For potentially eligible records, copies of the full texts were obtained and three review authors (TAL, CH and ER) independently assessed them for eligibility. The respective review authors resolved any disagreements through discussion and, if necessary, consulted at least one other review author. We used Covidence to facilitate this study selection process and documented the reasons for exclusion of studies accordingly.

To inform the economic outcomes, full economic evaluations (cost-effectiveness analyses, cost-utility analyses, and cost-benefit analyses), we considered cost analyses and comparative resourceutilisation studies. Studies carried out alongside relevant RCTs and model-based studies were considered for inclusion. Two review authors (TR and AK) independently screened for eligible studies.

\section{Data extraction and management}

Two review authors (TAL, $\mathrm{CH}$, or ER) independently extracted data from included studies using a pre-designed data extraction form (Higgins 2011). We extracted the following data.

- Author contact details.

- Country.

- Setting.

- Dates of participant accrual.

- Funding source.

- Inclusion and exclusion criteria.

- Study design.

- Study population and baseline characteristics:

* number of participants enrolled;

* number of participants analysed;

* age;

* gender. 
- Potential effect modifiers:

* molecular type of glioblastoma;

* performance status.

- Intervention details:

* type of intervention, dose, timing, and other regimen details;

* Type of comparator.

- Risk of bias assessment (see below).

- Duration of follow-up.

- Primary outcome(s) of the study.

- Review outcomes:

* For time-to-event outcomes (overall and progression-free survival) we extracted the hazard ratio (HR) with its $95 \%$ confidence interval $(\mathrm{Cl})$ for time points as reported by the study authors. We noted the definition of and procedure used to identify progression. Where reported, we also extracted dichotomous data for these outcomes at author-specified time points.

* For dichotomous outcomes (e.g. serious adverse events), we extracted the number of participants in each treatment arm that experienced the outcome of interest and the number of participants assessed.

* For continuous outcomes (e.g. QoL scores), we extracted the value and standard deviation of the outcome of interest and the number of participants assessed at the relevant time point in each group. We also extracted change-from-baseline score data where reported and noted the type of scale used.

* We extracted adjusted statistics where reported.

* Where possible, all data extracted were those relevant to an intention-to-treat analysis, in which participants were analysed in the groups to which they were assigned.

* We resolved differences between review authors by discussion or by appeal to a third review author when necessary.

\section{Assessment of risk of bias in included studies}

We assessed the risk of bias using Cochrane's 'Risk of bias' tool and the criteria specified in the Cochrane Handbook for Systematic Reviews of Interventions (Higgins 2011). This included assessment of the following.

- Random sequence generation.

- Allocation concealment.

- Blinding of participants and healthcare providers.

- Blinding of outcome assessors.

- Incomplete outcome data (more than 20\% missing data considered high risk).

- Selective reporting of outcomes.

- Other possible sources of bias, e.g. lack of a power calculation, baseline differences in group characteristics.

Two review authors (ER and $\mathrm{CH}$ ) independently assessed risk of bias and resolved any differences in opinion by discussion or by consulting a third review author (TAL). We summarised judgements in 'Risk of bias' tables along with the characteristics of the included studies and interpreted the results of meta-analyses in light of the overall 'Risk of bias' assessment. For more details about the 'Risk of bias' assessment see Appendix 2.
We assessed economic evaluation studies for bias in two stages. The first stage involved assessing risk of bias from the sources of the effectiveness data. In economic evaluations carried out alongside clinical trials, we assessed these using the Cochrane 'Risk of bias' tool, as described above. If the economic evaluation was model-based, we used the ROBIS tool to assess bias in the effectiveness studies (Whiting 2016). The second stage involved assessing the risk of bias of the economic evidence (i.e. assessing the overall methodological quality). This was done using the Consolidated health Economic Evaluation Reporting Standards (CHEERS) checklist (Husereau 2013).

\section{Measures of treatment effect}

\section{Effectiveness data}

- For time-to-event outcomes (e.g. overall survival), we extracted the hazard ratio (HR) with its $95 \%$ confidence interval $(\mathrm{Cl})$.

- For continuous outcomes (e.g. QoL scores) we assumed that study authors would use different measurement scales, therefore, we planned to estimate the standardised mean difference (SMD) and its 95\% Cl using the pooled data. However, if the same measurement scale was used, we estimated the mean difference (MD) and its $95 \% \mathrm{Cl}$. If studies did not report total values but, instead, reported change-frombaseline outcomes, we combined these change values with total measurement outcomes by using the (unstandardised) MD method in Review Manager 5 (RevMan 5) (RevMan 2014). We used subgroups to distinguish between MDs of change scores and MDs of final values, and pooled the subgroups in an overall analysis (Higgins 2011).

- For dichotomous outcomes, we calculated the effect size as a risk ratio (RR) with its $95 \% \mathrm{Cl}$.

\section{Economic data}

Two review authors (AK and TR) independently extracted data from relevant economic studies and summarised this information in tables. We extracted data on the following.

- Type of evaluations.

- Sources of effectiveness data.

- Cost data.

- Sources of cost data.

- Sources of outcome valuations.

- Analytical approach.

\section{Unit of analysis issues}

Two review authors (TAL and ER) assessed unit of analysis issues according to Higgins 2011, and resolved any differences in opinion by discussion. These included reports where there are multiple observations for the same outcome (e.g. repeated measurements with different scales or at different time points, recurring events). If meta-analysis was not feasible or meaningful, we extracted data from all scales or time points and attempted to describe them narratively.

\section{Multi-arm trials}

We included multi-arm trials in this review. We treated multi-arm studies as multiple independent comparisons in pairwise metaanalyses and did not combine data from different arms. In the 
network meta-analysis (NMA) we accounted for the correlation between the effect sizes derived from the same study (White 2015).

\section{Dealing with missing data}

We did not impute missing data. In the event of missing data, we wrote to study authors to request the data on primary outcomes and describe in the 'Characteristics of included studies' tables how any missing data were obtained.

\section{Assessment of heterogeneity}

\section{Assessment of clinical and methodological heterogeneity}

We assessed clinical heterogeneity between studies by comparing characteristics of included participants, and interventions in each meta-analysis of each comparison, by visual inspection of forest plots, by estimation of the percentage heterogeneity between trials which cannot be ascribed to sampling variation (Higgins 2003), by a formal statistical test of the significance of the heterogeneity (Deeks 2001), and, where possible, by subgroup analyses. If there was evidence of substantial heterogeneity, we investigated and reported the possible reasons for this.

\section{Assessment of consistency across treatment comparisons}

We examined the assumption of consistency by assessing the distribution of potential effect modifiers across the pairwise comparisons (Cipriani 2013; Jansen 2013; Salanti 2012). The assumption would hold if the following were true.

- The common treatment used to compare different interventions indirectly was similar when it appeared in different trials.

- All pairwise comparisons did not differ with respect to the distribution of effect modifiers.

\section{Assessment of statistical heterogeneity and inconsistency}

\section{Assumptions when estimating the heterogeneity}

In standard pairwise meta-analyses, we estimated different heterogeneity variances for each pairwise comparison. In the NMA, we assumed a common estimate for the heterogeneity variance across the different comparisons (White 2015).

\section{Measures and tests for heterogeneity}

We assessed the presence of statistical heterogeneity within the pairwise comparisons using the 12 statistic, which is the percentage of variability that cannot be attributed to random error (Higgins 2003).

\section{Assessment of statistical inconsistency}

We were not able to assess statistically the global agreement between the various sources of evidence in a network of interventions (consistency). However, we were able to apply a local approach using a node-splitting method (Dias 2010).

\section{Assessment of reporting biases}

In pairwise comparisons, if there were 10 or more studies included in meta-analyses, we had planned to investigate reporting biases (such as publication bias) using funnel plots. However, in none of the analyses were 10 or more studies included.

\section{Data synthesis}

\section{Methods for direct treatment comparisons}

Initially we performed standard pairwise meta-analyses for each comparison using the random-effects model in Stata statistical software version 15.1 (STATA) and Review Manager software (RevMan 2014).

\section{Methods for indirect and mixed comparisons}

We conducted network meta-analyses within a frequentist framework using multivariate meta-analysis (White 2015), if we considered participants, comparisons, and outcomes to be sufficiently similar to ensure an answer that was clinically meaningful. We also used STATA commands for visualising and reporting NMA results (Chaimani 2015). If meta-analysis was not possible but limited data were available, we attempted to synthesise narrative summaries according to guidance in the Cochrane Handbook.

We summarised characteristics and results of included economic evaluations using additional tables, supplemented by a narrative summary that compared and evaluated methods used and principal results between studies. Unit cost data were also tabulated, when available. We reported the currency and price year applicable to measures of costs in each original study alongside measures of costs, incremental costs, and incremental cost-effectiveness by study. Where details of currency and price year were available in original studies, we converted measures of costs, incremental costs, and cost-effectiveness to (latest year) international dollars value using implicit price deflators for gross domestic product (GDP) and GDP Purchasing Power Parities (EPPI Centre Cost Converter 2016). Details of the methodological characteristics of individual included health economics studies was summarised in Characteristics of included studies tables. All elements of the economics component of this review were conducted according to current guidance on the use of economics methods in the preparation and maintenance of Cochrane Reviews (Higgins 2011; Shemilt 2018; Wijnen 2016).

\section{'Summary of findings' tables and results reporting}

\section{Effectiveness summary of findings}

We presented the primary outcomes in the 'Summary of findings' tables. Evidence for pairwise comparisons was assessed based on GRADEpro Guideline Development Tool (GDT) methods (GRADEpro 2015) (i.e. we assessed risk of bias, inconsistency, imprecision, indirectness and publication bias), whereas network evidence was assessed using the approach suggested by Puhan 2014 and advanced by Brignardello-Petersen 2018. Narrative evidence summaries were prepared if data could not be synthesised and assessed according to the GRADE approach suggested by Murad 2017. The certainty of pairwise and network evidence for each outcome was rated as 'high', 'moderate', 'low' or 'very low' as defined according to the GRADE approach.

- High certainty: we are very confident that the true effect lies close to that of the estimate of the effect.

- Moderate certainty: we are moderately confident in the effect estimate; the true effect is likely to be close to the estimate of the effect, but there is a possibility that it is substantially different. 
- Low certainty: our confidence in the effect estimate is limited; The true effect may be substantially different from the estimate of the effect.

- Very low certainty: We have very little confidence in the effect estimate; the true effect is likely to be substantially different from the estimate of effect.

To assess the network evidence, we assessed the certainty of the direct evidence (if any), the indirect evidence (if estimable) and the network evidence in this order. Direct evidence was assessed using the standard (pairwise) GRADE approach, but without assessing imprecision (i.e. we assessed risk of bias, inconsistency, indirectness and publication bias). Indirect evidence ratings, based on the certainty rating of the lower of the two arms forming the loop in the network diagram, were assessed when they contributed more than the direct evidence to the network estimates. The final step was to assess the certainty of the network effect estimate based on whether intransitivity was present (i.e. whether there were differences in study characteristics that may modify the effect in the direct comparisons that form the basis for the indirect estimate; Puhan 2014). The network estimate was assessed in the first instance as being equivalent to the higher of the direct and indirect estimates, and incoherence and imprecision were then considered, with downgrading by one level accordingly if serious. Where no direct evidence was available and when the treatments did not have a common comparator, we presented the network estimate but did not rate the certainty of the evidence. Where possible, we estimated the absolute effects of treatments relative to the effect of a given reference comparator based on an assumed risk, the source of which was stated. For median survival times, we based illustrative absolute effects on hazard ratios (HRs).

'Summary of findings' tables were designed following the approach suggested by Schunemann 2009 and by Yepes-Nuñez 2019. In the 'Summary of findings' tables we provided justification for each assessment about the confidence in the estimates of effect (e.g. reasons for downgrading the certainty of the evidence), with confidence assessed as $95 \%$ credible intervals ( $\mathrm{Crl})$. Two review authors (TAL and ER) independently assessed the certainty of the evidence. We resolved any differences of opinion by discussion. We interpreted the graded evidence based on the Cochrane Effective Practice and Organisation of Care (EPOC) Group's guidance (Cochrane EPOC 2015) and, for time-to-event evidence, on suggestions in Barraclough 2011.

\section{Relative treatment ranking}

We computed ranking of probabilities for all included treatments and obtained a treatment hierarchy using the surface under the cumulative ranking curve (SUCRA). For primary outcomes, we assessed the robustness of these findings in sensitivity analysis.

\section{Economic evaluation summary of findings}

For the economic evaluation studies, we presented the following findings in a table.

- Method of economic evaluation

- Costs

- Outcomes

- Incremental cost-effectiveness ratio

\section{Subgroup analysis and investigation of heterogeneity}

For pairwise comparisons we assessed heterogeneity using the $1^{2}$ statistic that measures the percentage of variability that cannot be attributed to random error (Higgins 2003). We considered clinical heterogeneity and risk of bias in the interpretation of any heterogeneity. The certainty of the evidence was downgraded for heterogeneity where $\mathrm{I}^{2} \geq 60 \%$.

Due to sparse structure of the network, we assumed no substantial statistical heterogeneity and fitted a fixed-effect model. However, we performed sensitivity analyses to examine the impact of our original assumptions by applying an alternative classification of radiotherapy with $50 \mathrm{~Gy}$ in one study (KeimeGuibert 2007); removing one of the arms from three-arm trial (hypofractionated radiotherapy Malmstrom 2012), and splitting the chemoradiotherapy node according to the radiation dose (hypofractionated radiotherapy and $60 \mathrm{~Gy}$ ).

For primary outcomes, we had planned to assess findings by the different age thresholds used by investigators to define the elderly and by MGMT methylation status; however, data were insufficient for these subgroup analyses.

\section{Sensitivity analysis}

We performed sensitivity analyses to investigate assumptions that we made to facilitate a connected network, including:

- pooling data from a study utilising a radiotherapy dose of 50Gy with studies utilising 60 Gy or 40 Gy dose schedules;

- pooling data from study arms utilising combined chemoradiation, where studies utilised 60 Gy or 40 Gy radiotherapy dose schedules.

We based these assumptions on calculations of the equivalent doses (EQD2) and biologically effective doses (BED) of the different radiotherapy schedules utilised in included studies (Table 1). Note that data from trials using $34 \mathrm{~Gy} / 10$ fractions were pooled with those of $40 \mathrm{~Gy} / 15$ schedules in our NMA, as we considered the BEDs of these schedules to be sufficiently similar.

We also conducted sensitivity analysis to investigate the impact of a single three-arm study forming the only loop in the network and to justify the lack of assessment of inconsistency (see above).

\section{RES U LTS}

\section{Description of studies}

\section{Results of the search}

\section{Intervention studies}

Searches conducted on the 13 June 2018 and the 3 April 2019 led to the identification of 12 included studies (with 31 associated records) and two potentially eligible ongoing studies (with three associated records). We identified the following numbers of records through the first electronic database search.

- MEDLINE: 1946 to May week 52018 - 930 records

- Embase: 1980 to 2018 week 24 - 848 records

- CENTRAL: Issue 52018 - 1571 records 
The results of this initial search are summarised in Figure 1. Following de-duplication across the databases, the combined total yield was 2493 records. The Information Specialist at the Cochrane Gynaecological, Neuro-oncology and Orphan Cancer (CGNOC) Group ran these records through the Cochrane RCT 'Classifier', which uses machine learning to identify records that are likely to be randomised controlled trials (RCTs). Following classification, 1462 records were identified as having more than a $10 \%$ likelihood of being RCTs, whilst 1031 references had less than a 10\% likelihood of being RCTs. The Information Specialist then de-duplicated the remaining 1462 records and sifted out the clearly irrelevant records (e.g. those that related to other types of cancers). Two study authors $(\mathrm{CH}, \mathrm{TAL})$ independently screened the remaining yield of 990 records. Out of these, 12 studies (ARTE 2018; AVAglio 2014; GLARIUS 2016; Green 1983; Keime-Guibert 2007; Malmstrom 2012; Perry 2017; Roa 2004; Roa 2015; Stupp 2017a; Weller 2017; Wick 2012) with 31 associated records were finally included (Figure 1). Additionally, one ongoing study was identified (NCT01602588). 
Figure 1. Study flow diagram (search date 13 June 2018)

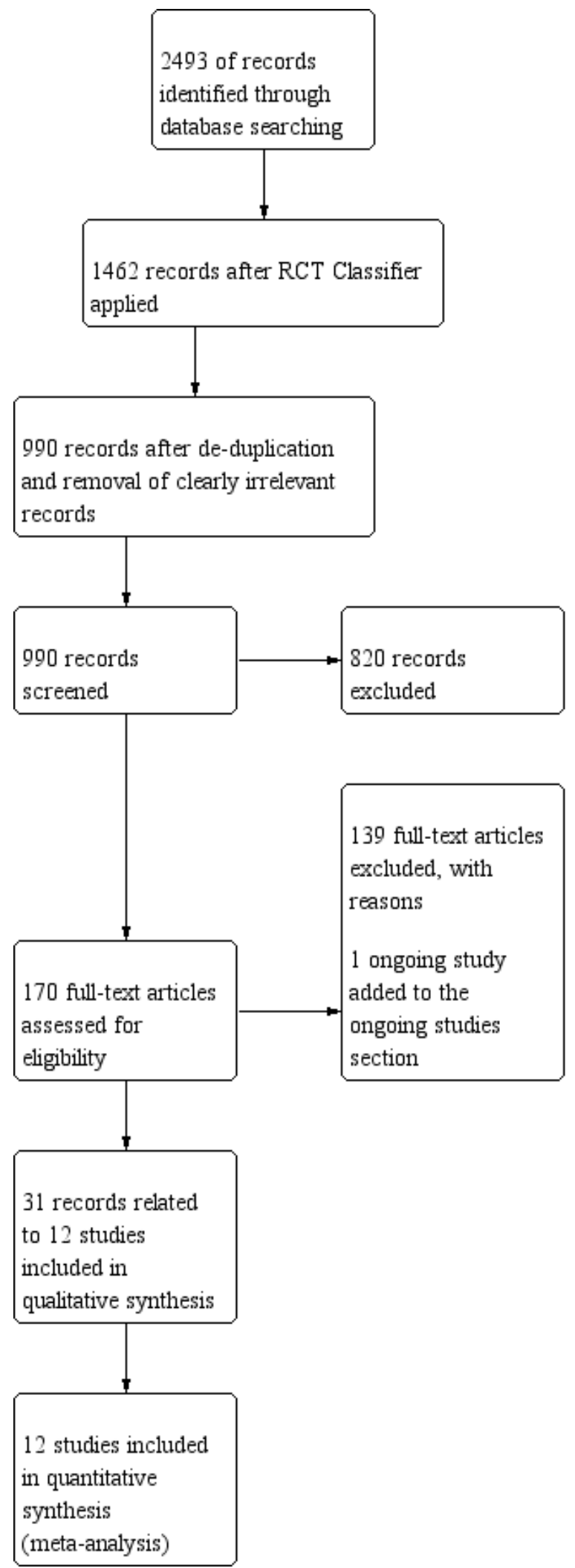

The top-up search on 3 April 2019 yielded 125 additional records to be screened on title and abstract. After de-duplication and screening on title and abstract, six full-text papers were retrieved.
Three of these papers were additional publications related to two already included studies (AVAglio 2014; GLARIUS 2016), the other three were excluded with reasons. Additionally, searches of clinical 
trial registries and of relevant society conference proceedings from 2014 to 2018 identified one ongoing trial (NUTMEG 2018) and four potentially eligible records, respectively. The ongoing trial was added to the Ongoing studies section, including one conference abstract (NUTMEG 2018). The other three conference abstracts were classified as excluded studies. The results of the top-up search are summarised in Figure 2. 
Figure 2. Study flow diagram (search date 3 April 2019).

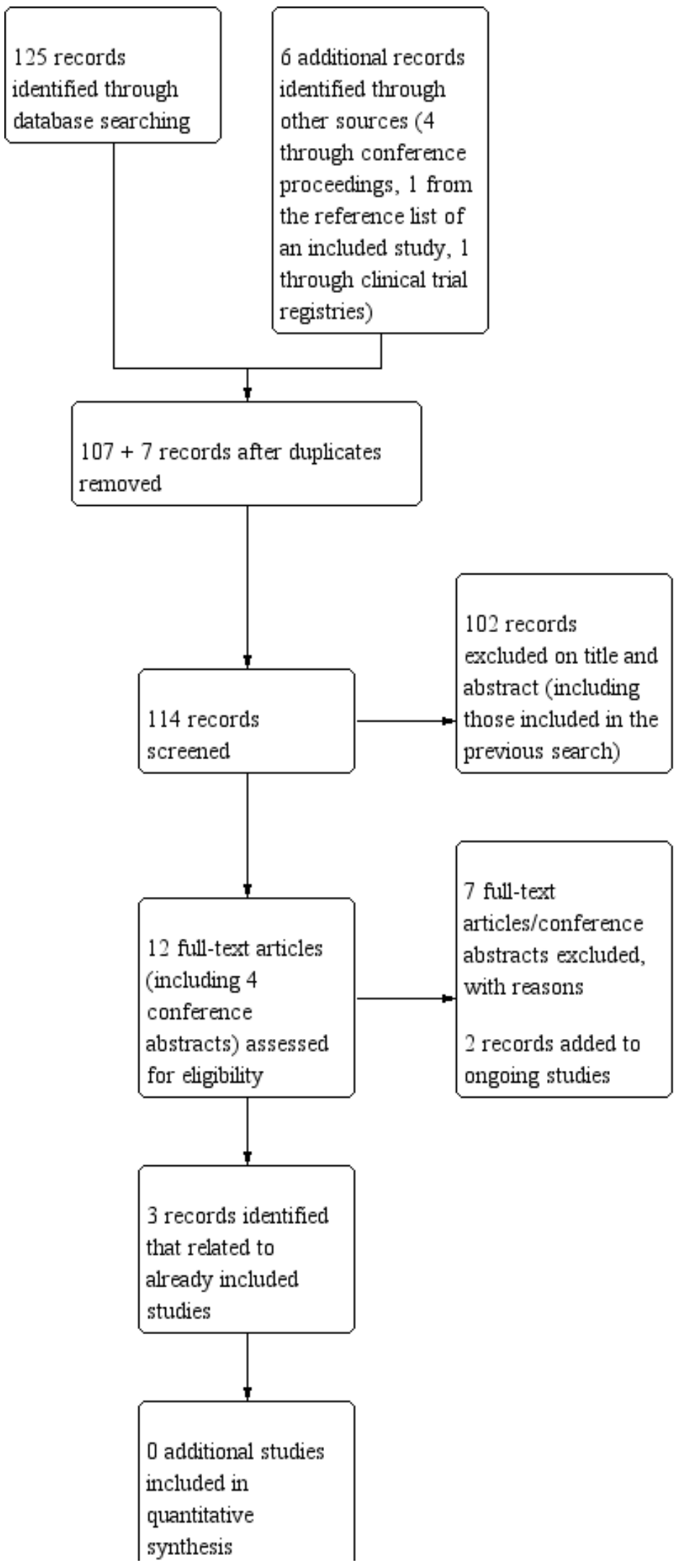


Figure 2. (Continued)

\begin{tabular}{|l|}
$\begin{array}{l}\text { quantıtative } \\
\text { synthesis } \\
\text { (meta-analysis) }\end{array}$ \\
\hline
\end{tabular}

\section{Economic studies}

For economic studies, we identified the following numbers of records through electronic database searches conducted on 13 June 2018.

- MEDLINE: 1946 to May week 52018 - 113 records

- Embase: 1980 to 2018 week 24 - 151 records

Following de-duplication across these databases, the total yield to be sifted was 101 records. The top-up search conducted on the 3 April 2019 yielded an additional 22 records. Five titles and abstracts were identified for full-text screening (Ghosh 2018, Jiang 2017; Moroney 2017; Roussakou 2017; Waschke 2018), one of which (Ghosh 2018) was included.

\section{Included studies}

We included 12 RCTs, six were conducted exclusively among elderly people (either defined as 65 years or older or 70 years or older) with newly diagnosed glioblastoma (ARTE 2018; Keime-Guibert 2007; Perry 2017; Roa 2004; Roa 2015; Wick 2012). The other six RCTs included patients from a broader age range and reported some data separately for their elderly subgroup (AVAglio 2014; GLARIUS 2016; Green 1983; Malmstrom 2012; Stupp 2017a; Weller 2017), which we extracted for this review.

\section{Numbers recruited and analysed}

Altogether, approximately 1818 elderly participants involved in the included studies contributed data to the review. In seven studies, the elderly participants analysed numbered less than 100. In five studies (Green 1983; Malmstrom 2012; Perry 2017; Stupp 2017a; Wick 2012); the number analysed was more than 100 , equalling to $107,123,562,134$, and 373 participants, respectively.

\section{Location of studies}

Six studies were conducted in the following individual countries: Canada (Roa 2004), France (Keime-Guibert 2007), Germany (Wick 2012; GLARIUS 2016), the USA (Green 1983); Switzerland (ARTE 2018); the rest were multi-country studies (AVAglio 2014; Malmstrom 2012; Perry 2017; Roa 2015; Stupp 2017a; Weller 2017).

\section{Dates of recruitment}

Accrual occurred before 1980 in one study (Green 1983) and between 1996 and 2001 in another (Roa 2004). In all other studies, accrual occurred from 2000 onwards.

\section{Funding}

Seven studies were funded by pharmaceutical companies (ARTE 2018: Roche Pharmaceuticals; AVAglio 2014: Hoffmann-La Roche; GLARIUS 2016: Roche Pharmaceuticals; Malmstrom 2012: Merck; Perry 2017: Schering-Plough/Merck; Weller 2017: Celldex Therapeutics; Wick 2012: Merck, Sharp \& Dohme; two of these (Malmstrom 2012; Perry 2017) also received grants from national cancer research funds. One study (Stupp 2017a) received funding from a medical device company, Novocure Ltd). The rest were funded by research grants from national cancer research funds or charities.

\section{Characteristics of study participants}

Also see Table 2.

\section{Age}

Eight studies defined older patients using an age threshold of 65 years, two studies (AVAglio 2014; Keime-Guibert 2007) used an age threshold of 70 years, and two studies recruited participants from 60 years of age (Malmstrom 2012; Roa 2004). One of the latter studies defined an older subgroup using a threshold of 70 (Malmstrom 2012), whereas the other did not define an older subgroup and presented all data together (Roa 2004). As the mean age of participants in the latter study was about 72 years with a standard deviation of about five years, the majority of participants in this study would have been over 65 years of age, but the exact proportion of the sample that this represents was unclear (see Risk of bias in included studies).

\section{Gender}

Most studies had participant gender ratios of about 3 to 2 in favour of male participants; however, in two studies, the proportion of men and women was roughly equal (Roa 2015; Wick 2012).

\section{Performance status}

Most studies required that participants had a certain performance status prior to enrolment and did not recruit participants who were not self-caring. Thus, participants of six studies specified Karnofsky performance scores (KPS) of 60 or more (ARTE 2018; Wick 2012), or 70 or more (GLARIUS 2016; Green 1983; Keime-Guibert 2007; Stupp 2017a). Two studies specified an Eastern Cooperative Oncology Group (ECOG) performance status of 0 to 2 (Perry 2017; Weller 2017), and two specified a World Health Organization (WHO) performance status of 0 to 2 (AVAglio 2014; Malmstrom 2012). Two studies, however, recruited participants with poorer performance status (minimum KPS of 50) (Roa 2004; Roa 2015), patients with a KPS of 50 require considerable assistance and frequent medical care (Table 3).

06-methylguanine DNA methyltransferase (MGMT)-methylation status

Eight studies reported the MGMT-methylation status of their participants (ARTE 2018; AVAglio 2014; GLARIUS 2016; Malmstrom 2012; Perry 2017; Stupp 2017a; Weller 2017; Wick 2012). In the overall samples, the MGMT-methlyated status was represented by at least $21 \%$ of participants with these test results: in ARTE 2018 26\%, in AVAglio 2014 47\%, in Malmstrom 2012 46.6\%, in Perry 2017 37\%, in Stupp 2017a 34\%, in Weller 2017, and 20\% in Wick 2012. In GLARIUS 2016, all participants had MGMT-unmethylated glioblastomas. For two studies in which the elderly were a subgroup (Malmstrom 2012; Weller 2017), MGMT-methylation status was reported for the broader sample and might not necessarily have reflected the MGMT-methylation status of the elderly subgroup relevant to this review. 


\section{Interventions and comparisons}

Most studies (10) randomised participants to two treatment arms but one trial (Malmstrom 2012) had three treatment arms and one had four treatment arms (Green 1983). The majority of treatments offered to patients were either radiotherapy alone, systemic anti-cancer treatment (SACT) alone, or a combination of both. One trial (Keime-Guibert 2007) had a standard management arm of supportive care, and one RCT used a medical device, known as tumour treating fields (TTF), in combination with radiotherapy and TMZ (Stupp 2017a) in its experimental arm. All studies randomised participants after diagnosis and before radiotherapy and/or chemotherapy with the exception of Stupp 2017a and Weller 2017, both of which randomised participants after chemoradiotherapy and before commencement on adjuvant TMZ.

In the trials that included elderly patients only (ARTE 2018; KeimeGuibert 2007; Perry 2017; Roa 2004; Roa 2015; Wick 2012), the reference treatment arms were radiotherapy alone (60 Gy in 30 fractions (Roa 2004; Wick 2012), or 40 Gy in 15 fractions (ARTE 2018; Perry 2017; Roa 2015)), or supportive care (Keime-Guibert 2007). The experimental arms in these trials were hypofractionated radiotherapy treatment alone (40 Gy in 15 fractions (Roa 2004), or $25 \mathrm{~Gy}$ in five fractions (Roa 2015), radiotherapy (40 Gy in 15 fractions combined with a systematic anti-cancer treatment TMZ (Perry 2017) or bevacizumab (ARTE 2018), radiotherapy (50 Gy in 28 fractions with supportive care (Keime-Guibert 2007), or TMZ alone (Wick 2012).

In the six trials (AVAglio 2014; GLARIUS 2016; Green 1983; Malmstrom 2012; Stupp 2017a; Weller 2017) that included patients of all ages, with the elderly as a subgroup, the radiotherapy fractionation in the reference treatment was exclusively $60 \mathrm{~Gy}$ in 30 fractions. In the reference arms of the trials, this was used alone (Malmstrom 2012), in combination with concomitant and adjuvant TMZ +/- placebo (AVAglio 2014; GLARIUS 2016; Stupp 2017a; Weller 2017), or in combination with intravenous carmustine (BCNU) (Green 1983). The experimental arms in these trials were mostly 60 Gy of radiotherapy in 30 fractions in combination with additional or alternative SACTs (AVAglio 2014; GLARIUS 2016; Green 1983; Weller 2017). Malmstrom 2012 was the only trial that included an experimental treatment arm with TMZ alone and hypofractionated radiotherapy alone (34 Gy in six fractions over two weeks). Stupp 2017 a was the only trial to include a medical device (TTF) and they used this device in their experimental arm in combination with adjuvant TMZ following chemoradiotherapy (60 Gy of radiotherapy plus TMZ).

\section{Radiotherapy fractionation and delivery}

All of the included RCTs, except one (Green 1983) used megavoltage (MV) photon radiotherapy to the tumour or tumour bed with a 2 $\mathrm{cm}$ to $3 \mathrm{~cm}$ margin. Green 1983 used whole brain radiotherapy (WBRT), which is likely a reflection of the more limited technological capabilities to deliver conformal radiotherapy in the 1970s when this trial was open to recruitment. A comparison of the biologically effective dose (BED) and E2D2 of radiotherapy fractionation schedules used across all trials is outlined in Table 1.

\section{Systemic anti-cancer treatment}

TMZ was the most frequently used SACT. When combined with $60 \mathrm{~Gy}$ in 30 fractions, it was used as per the "Stupp" regimen (Stupp 2005). This comprises $75 \mathrm{mg} / \mathrm{m} 2$ of TMZ given concomitantly with six weeks of radiotherapy, followed by adjuvant treatment delivered over five days each month at a dose of $150 \mathrm{mg} / \mathrm{m} 2$ to $200 \mathrm{mg} /$ $\mathrm{m} 2$. In the original Stupp regimen (Stupp 2005), adjuvant treatment was continued for a total of six cycles. AVAglio 2014; GLARIUS 2016; Stupp 2017a all followed this regimen. Weller 2017 specified that adjuvant TMZ could be continued for six to 12 cycles or longer, and Perry 2017 specified that up to 12 adjuvant cycles of TMZ could be delivered. When TMZ was used alone (Wick 2012, Malmstrom 2012), this was given orally using a week-on/week-off schedule of $100 \mathrm{mg} /$ $\mathrm{m} 2 /$ day for up to six months of treatment (Wick 2012) or $200 \mathrm{mg} / \mathrm{m} 2$ on days one to five of every 28 days for up to six cycles (Malmstrom 2012).

Bevacizumab was used in the experimental arm of three trials (ARTE 2018, AVAglio 2014, GLARIUS 2016) and was delivered intravenously at a dose of $10 \mathrm{mg} / \mathrm{kg}$ every two weeks in all of these trials. Irinotecan was used in combination with bevacizumab and radiotherapy in the GLARIUS 2016 trial and delivered intravenously at a dose of $125 \mathrm{mg} / \mathrm{m} 2$ every two weeks.

Green 1983 combined WBRT with intravenous BCNU (80 mg/ $\mathrm{m} 2$ /day on three successive days every eight weeks) in their reference arm. In the first experimental arm of this trial, BCNU was replaced by high-dose oral methylprednisolone $(400 \mathrm{mg} / \mathrm{m} 2 /$ day in three divided doses for seven days) in four weekly cycles, and their second experimental arm combined BCNU and high-dose methylprednisolone. The last experimental arm in the trial by Green 1983 , combined WBRT with procarbazine which was given orally at a total dose of $150 \mathrm{mg} / \mathrm{m} 2 /$ day in three or four divided doses for 28 consecutive days every eight weeks.

Finally, Weller 2017 used rindopepimut (500 ug) admixed with 150 ug granulocyte-macrophage colony-stimulating factor (GM-CSF), given via monthly intradermal injection in their experimental arm and 100 ug keyhole limpet haemocyanin in their control arm, both in combination with standard oral TMZ $(150 \mathrm{mg} / \mathrm{m} 2$ to $200 \mathrm{mg} /$ $\mathrm{m} 2$ for 5 of 28 days) for six to 12 months or longer. In this trial, all patients had completed standard chemoradiation with $60 \mathrm{~Gy}$ of radiotherapy and concomitant TMZ prior to commencing treatment in either the experimental or control treatment arm.

\section{Other treatments}

\section{Carmustine wafers}

Although not randomised between arms, Stupp 2017a was the only trial that specified that treatment with implanted carmustine wafers was permitted for patients on either arm of their trial. The proportion of patients receiving carmustine wafers in each arm was not reported.

\section{Medical devices}

Stupp 2017a was the only trial to use a medical device. Tumour treating fields (TTF) comprise an external medical device that is worn by the patient. It consists of four transducer arrays which are connected to a portable device. These arrays are applied to the patients' shaved scalp via nine electrodes and emit lowintensity, intermediate frequency $(200 \mathrm{kHz})$ alternating electric fields to the brain. The patient carries the device in a backpack and is encouraged to wear the device for at least 18 hours per day. Determining the layouts of the transducer is performed using a TTF mapping software system. Patients and their families are trained on how to use the device and how to trouble shoot problems with the device by nursing staff and a device technician. The patients 
must replace the transducer arrays twice weekly and the treatment is delivered on an outpatient basis. Participants in the Stupp 2017a trial were randomised after the completion of chemoradiation and, therefore, the TTF treatment was given in the adjuvant setting only in combination with TMZ, and not given concomitantly with radiotherapy. TTF treatment was to be initiated at least four weeks but not more than seven weeks from the last day of radiotherapy.

\section{Supportive care}

Keime-Guibert 2007 was the only trial to include supportive care as a management option. This was used alone in the reference arm and in combination with radiotherapy (50 Gy in 28 fractions) in the experimental arm. Supportive care was defined as any mixture of treatment with corticosteroids and anti-epileptics, as well as physical and psychological support and management by a palliative care team. There was no information on the timing of when referral to the palliative care team was made.

\section{Outcomes and follow-up}

Table 4 outlines both the primary and secondary outcomes from each of the included trials that were of interest for the purposes of this review, along with the evaluation tools used to assess each outcome. All of the included trials, except Green 1983, reported overall survival outcomes using time-to-event analysis and provided median overall survival for either all participants (ARTE 2018; Keime-Guibert 2007; Malmstrom 2012; Perry 2017; Roa 2004; Wick 2012), or for a subgroup of patients if the trial was not restricted to recruiting elderly patients (AVAglio 2014; GLARIUS 2016; Roa 2015; Stupp 2017a; Weller 2017). Although reporting median survival, several trials did not provide a hazard ratio to show the difference between survival for elderly patients in different treatment arms (ARTE 2018; GLARIUS 2016; Roa 2015). Median survival data, where reported, are tabulated in Table 5.

The proportion of patients alive at six months (Roa 2004, Wick 2012), 12 months (ARTE 2018; Malmstrom 2012; Perry 2017; Wick 2012), 18 months (Perry 2017) and 24 months (Perry 2017) was also used to report survival outcomes. Stupp 2017a and Green 1983 reported the proportion of patients who had died by the end of the study period.

The second main outcome of interest was health-related quality of life (HRQoL). The most common tools used to collect HRQoL data were patient-completed questionnaires, specifically the European Organisation for the Research and Treatment of Cancer (EORTC) QLQ-C30 and QLQ-BN20 questionnaires. The results of HRQoL outcomes for elderly patients using these questionnaires were reported for five trials (ARTE 2018; Keime-Guibert 2007; Malmstrom 2012; Perry 2017; Wick 2012). Roa 2004 was the only trial to use the Functional Assessment of Cancer Therapy-Brain (FACT-Br) questionnaire but the results of using this tool were not reported due to a low completion rate. Several of the studies that included both younger and elderly patients did record HRQoL, but did not report results of these assessments for elderly subgroups separately (AVAglio 2014, GLARIUS 2016, Green 1983, Stupp 2017a, Weller 2017).

Follow-up times were varied and were often not documented in the trial publications. For those trials that did specify their follow- up time, AVAglio 2014 had follow-up for at least 17 months (with the end of study at 64 months after opening) and Stupp 2017a specified a median follow-up of 40 months (interquartile range, 34 to 66 months) with a minimum follow-up of 24 months. Only two patients in the over- 65 age group were alive at 60 months of followup. Wick 2012 had a minimum follow-up of 12 months (median 25.2 months (range 20.0 to not reached)). Roa 2015 specified that all patients were followed up until death.

\section{Excluded studies}

In selecting studies for evaluation of treatment effectiveness, excluded studies numbered 145 records. Studies were excluded mainly for the following reasons.

Ineligible study design, e.g. non-randomised trial; editorial: Bent 2009; Blumenthal 2018; Boisen 2018; Boxerman 2013; Catterall 1980; Chamberlain 2005; Chong 2018; Cohen 2005; Corn 1994; Das 2017; Dherijha 2018; Espana 1978; Halperin 1993; Jeremic 1999; Koc 2008; Lamers 2008; Lorimer 2016; McCarthy 2017; Napolitano 1999; Pinzi 2017; Reyes-Botero 2018; Soffietti 2017; Solth 2018; Stupp 2002; Vellayappan 2017 (25 studies)

Ineligible study population, e.g. not elderly participants; not newly diagnosed glioblastoma: Ali 2018; Armstrong 2013; Athanassiou 2005; Balana 2016; Bampoe 2000; Batchelor 2013; Beije 2015; Bhandari 2013; Bhandari 2017; Bleehen 1981; Bleehen 1991; Blumenthal 2015; Bogdahn 2011; Boiardi 1992; Bower 1997; Brandes 2016; Brisman 1976; Brown 2016; Buckner 2001; Buckner 2006; Carpentier 2017; Castro 1997; Chang 1983; Chauffer 2014; Cianfriglia 1980; Clarke 2009; Combs 2008; Curran 1992; Deutsch 1989; Dinapoli 1993; Du 2018; Duncan 1986; Elinzano 2018; Eljamel 2008; Elliott 1997; Eyre 1983; Farkkila 1994; Field 2015; Field 2017; Fischer 1985; Fulton 1984; Gaber 2013; Gilbert 2013; Glinski 1993; Grossman 2003; Halperin 1996; Harada 1996; Hatlevoll 1985; Henriksson 2006; Hiesiger 1995; Hildebrand 1994; Hitchon 1999; Hofland 2014; Imbesi 2006; Iwadate 1993; Karacetin 2011; Kim 2011; Knerich 1990; Kocher 2008; Kochii 2000; Kong 2017; Lanzetta 2003; Lee 2015; Lenartz 2000; Levin 1979; Levin 2000; Levin 2006; Lissoni 1993; Ludgate 1988; Mallick 2018; Mao 2015; Marshall 2006; Montemor 2008; MRC 1983; Nabors 2015; Nelson 1988; Payne 1982; Peszynski 1988; Phillips 2003; Prados 2001; Reagan 1976; Shapiro 1976; Shapiro 1989; Shapiro 1992; Sharma 2003; Simpson 1976; Sneed 1998; Socha 2016; Solero 1979; Solomon 2013; Souhami 2004; Stadler 1984; Stupp 2005; Stupp 2009; Stupp 2014; Stupp 2015; Szczepanek 2013; Takakura 1986; Taphoorn 2005; Urtasun 1982; Ushio 1985; Wakabayashi 2018; Wang 2008; Weller 2003; Werner-Wasik 1996; Westphal 2003; Westphal 2006; Westphal 2015; Wick 2009; Wick 2016; Yang 2018; Zhu 2017 (112 studies).

Other reasons were insufficient information (three studies: Felzmann 2013; Felzmann 2014; Muragaki 2017) and a different study objective (five studies:Stragliotto 2013; Stummer 2006; Stummer 2011; Stummer 2017; Westphal 2013).

\section{Risk of bias in included studies}

All included studies were RCTs and the trial quality was generally high, with most studies assessed as having a low risk of bias overall Figure 3. For the individual study risk of bias explanations, please refer to the Characteristics of included studies tables. 
Figure 3. 'Risk of bias' summary: review authors' judgements about each risk of bias item for each included study.

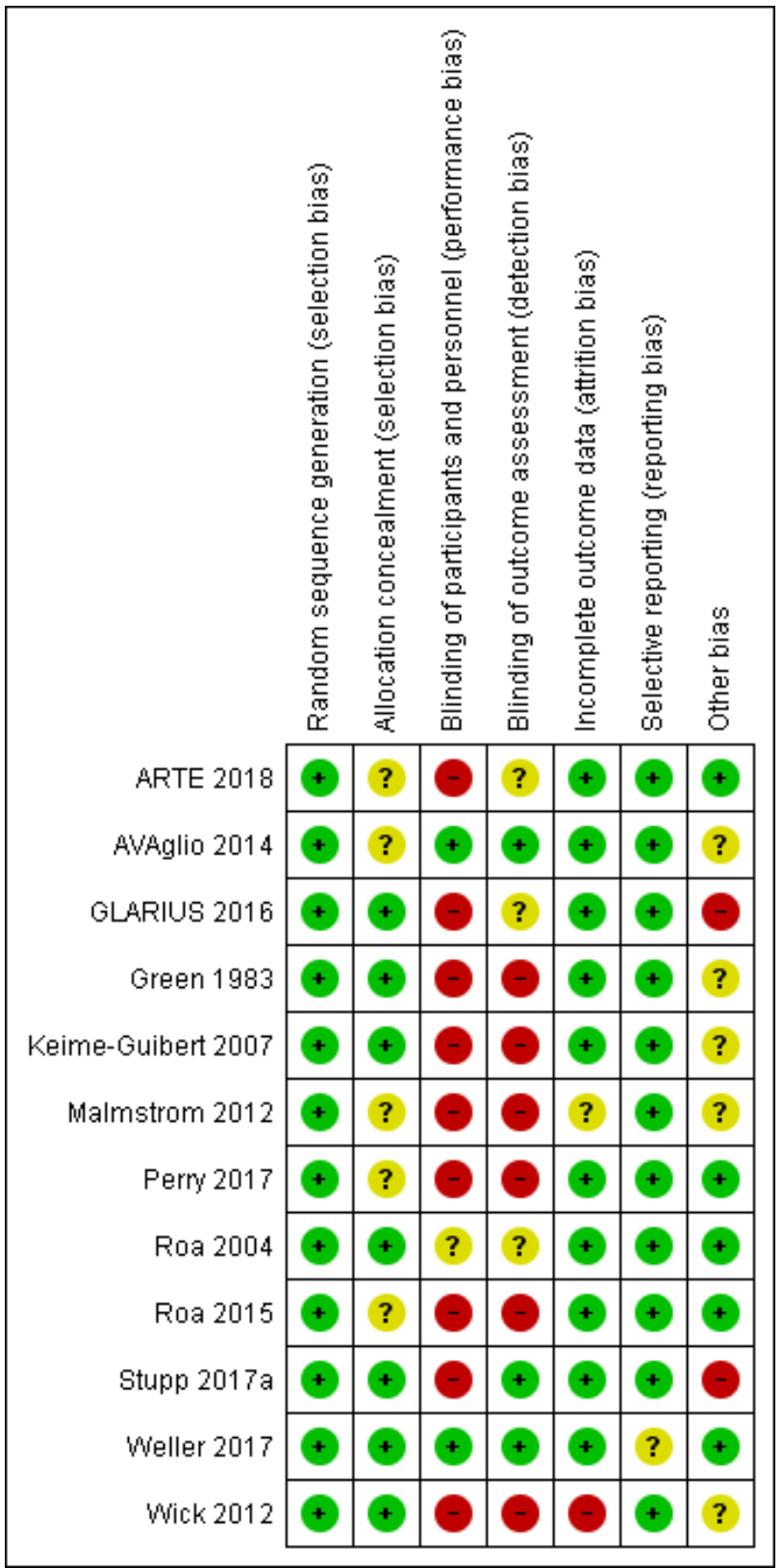

\section{Allocation}

The method of randomisation was described for all of the studies; therefore, all studies were at low risk of bias for the sequence generation criterion. Regarding concealment allocation at the participant selection stage, sixr studies were assessed as being at low risk of bias for this criterion (Green 1983; Keime-Guibert 2007; Roa 2004; Stupp 2017a; Weller 2017; Wick 2012). However, allocation concealment was not clearly described in the other studies, which were assessed as having unclear risk of bias for this criterion.

\section{Blinding}

Most studies were open-label studies, therefore, were potentially at a high risk of bias for blinding, and most did not describe assessor blinding. However, two studies was double-blinded (AVAglio 2014;
Weller 2017) and, therefore, were assessed as having a low risk of bias for this criterion.

\section{Incomplete outcome data}

For the primary outcome, most included studies had good followup with low dropout rates. One study (Wick 2012) that compared radiotherapy with temozolomide had relatively higher dropout rates in the radiotherapy arm (14\% versus $5 \%)$, which might have influenced the findings. This study was assessed as having an unclear risk of bias for this domain." Weller 2017 had unclear risk for this domain.

For studies that measured quality of life in an elderly population (Perry 2017; Roa 2004; Roa 2015), attrition was a problem that had a major impact on the quality of these findings. We therefore 
considered these studies to be at high risk of attrition bias for quality of life findings.

\section{Selective reporting}

All studies reported pre-specified outcomes and were considered to be at a low risk of bias for this criterion.

\section{Other potential sources of bias}

In the context of the review evidence, Stupp 2017a represented a high risk of bias due to the timing of randomisation in this trial. Randomisation was performed for a select group of patients who had completed concomitant chemoradiotherapy without progressive disease as those who died during chemoradiotherapy or who had severe early toxicities would have dropped out by the time of randomisation. Consequently, we decided not to include this trial in the quantitative synthesis due to concern over networks transitivity. .

Similarly, Weller 2017 randomised participants after concomitant chemoradiotherapy and its findings would have downgraded for indirectness; however, this trial contributed no data to metaanalyses. All patients in the GLARIUS 2016 trial had MGMT unmethylated glioblastoma, which is associated with a shorter survival time than MGMT-methylated tumours. Whilst this could bias the findings of review meta-analyses, this trial contributed no data to pooled analyses. REview authors had no other serious risk of bias concerns, although in some studies the risk of bias due to protocol deviations was assessed as unclear.

\section{Quality of economic studies}

The quality of the trial on which Ghosh 2018 is based has been discussed in the previous section (Roa 2015). The study was found to have a low risk of bias (with the exception of the blinding, which is open-label). The Consolidated health Economic Evaluation Reporting Standards (CHEERs) checklist (Husereau 2013) and the Consensus on Health Economic Criteria (CHEC (checklist (Evers 2005) were applied to the study to assess the quality of economic evaluation as recommended but the current guidelines (Shemilt 2018). The results can be found in Table 6 and Table 7. The results of the CHEERS reporting checklist show that a number of parameters are not reported (e.g. sources of costs, time horizon, perspective). The results of the CHEC checklist show that there a number of issues with the methodological quality of the study, including inappropriate costing and analysis methods.

\section{Effects of interventions}

See: Summary of findings for the main comparison Summary of findings on overall survival comparing treatments to supportive care only; Summary of findings 2 Summary of findings on overall survival comparing treatments to hypofractionated radiotherapy; Summary of findings 3 Summary of findings on overall survival comparing treatments to standard radiotherapy; Summary of findings 4 Summary of findings on quality of life; Summary of findings 5 Summary of findings on progression-free survival; Summary of findings 6 Summary of findings on severe adverse events

\section{Results of network meta-analysis (NMA)}

Network meta-analysis could only be performed for the primary outcome of overall survival.

\section{Overall Survival}

Seven trials contributed data to this time-to-event outcome and, across all studies included in the NMA, the following treatments were used either as the experimental or the comparison treatment (Figure 4).

\section{Figure 4.}

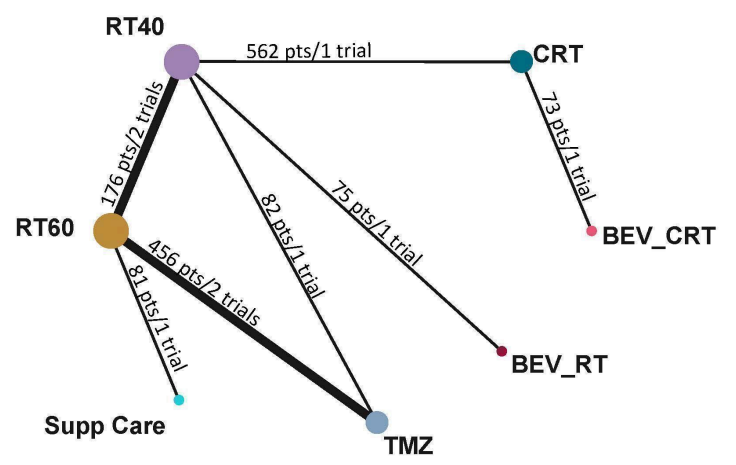

Main network of treatment interventions for glioblastoma in the elderly

Outcome: Overall Survival (time-to-event data) 
- Four trial arms of hypofractionated radiotherapy (40 Gy/15 fractions) (RT 40)

- Five trial arms of standard radiotherapy (60 Gy/30 fractions), including one trial utilising a $50 \mathrm{~Gy} / 28$ fractions (RT 60)

- One trial arm of supportive care only (SuppCare)

- Three trial arms of temozolomide (TMZ)

- Two trial arms of chemoradiotherapy, including one trial utilising $40 \mathrm{~Gy}$ in 15 fractions and one utilising 60 Gy in 30 fractions (CRT)

- One trial arm of bevacizumab plus chemoradiotherapy (BEV CRT)

- One trial arm of bevacizumab plus radiotherapy (BEV RT)
The forest plot is presented in Figure 5 and effect estimates and certainty ratings for the overall survival network can be found in Table 8. Evidence derived from the network only (i.e. where there were no common comparators) was not graded. Pooled network estimates suggested that, compared with supportive care only, any of the treatments except for bevacizumab plus radiotherapy lead to better overall survival. However, only three treatments (RT40, RT60 and TMZ) could be compared either directly or indirectly with supportive care through a common comparator. The graded evidence related to the three comparisons with direct and/or indirect evidence can be interpreted as follows. 


\section{Figure 5. Forest plot of all treatment comparisons for overall survival}

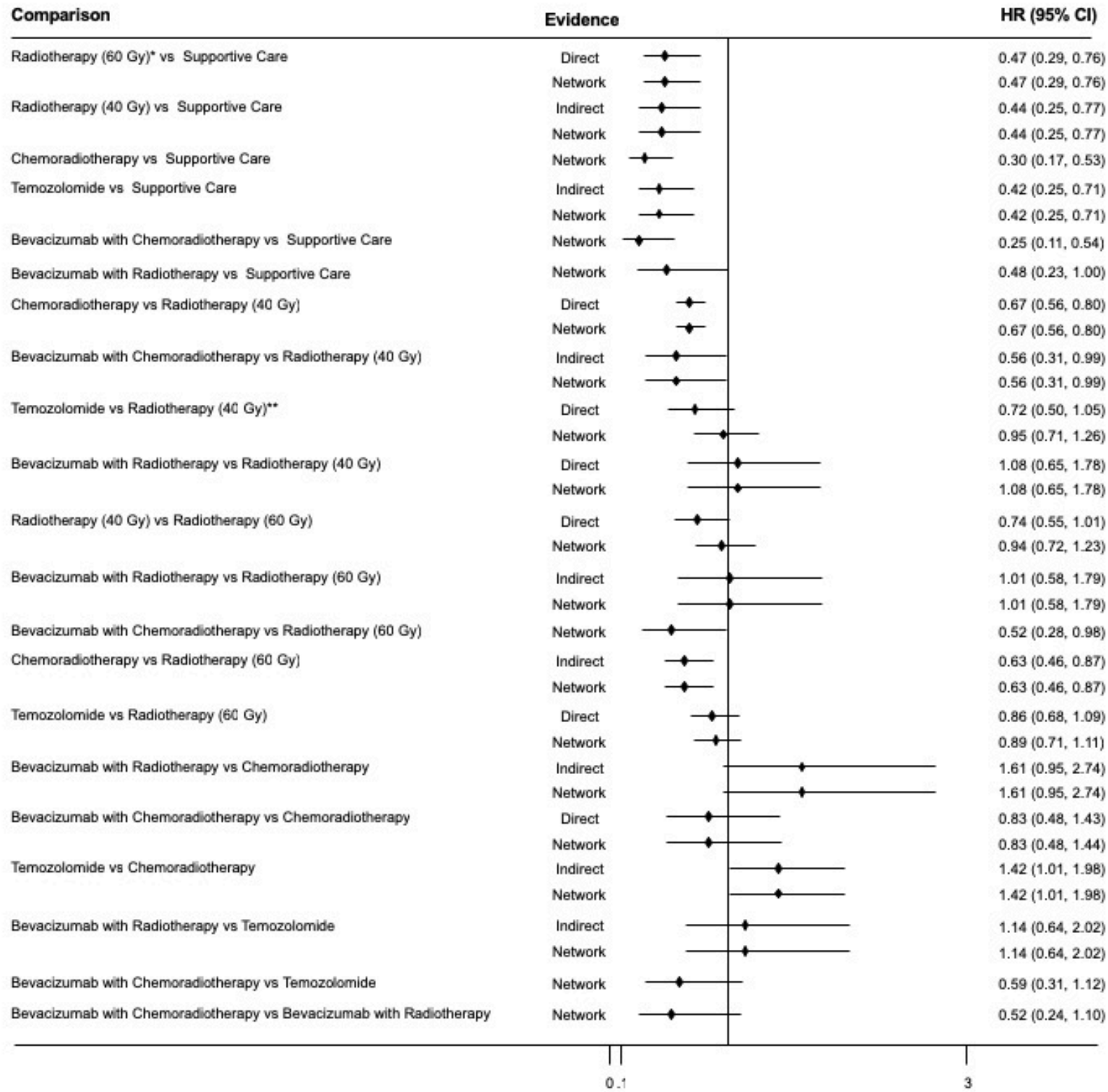


Figure 5. (Continued)

- RT60 probably improves overall survival time compared with supportive care only (HR $0.47,95 \% \mathrm{Cl} 0.29$ to 0.76 ; moderatecertainty evidence)

- RT40 may improve overall survival time compared with supportive care only (HR $0.44,95 \% \mathrm{Cl} 0.25$ to 0.77 ; low-certainty evidence)

- TMZ may improve overall survival time compared with supportive care only (HR $0.42,95 \% \mathrm{Cl} 0.25$ to 0.71 ; low-certainty evidence)

- Effect estimates of other treatment options compared with supportive care were not graded for the reasons given in the Summary of findings for the main comparison.

Similarly, pooled network estimates for four treatments (CRT, BEV_CRT, TMZ, and BEV-RT ) could be compared with hypofractionated radiotherapy (RT40) through a common comparator, and graded evidence can be interpreted as follows.

- CRT improves overall survival time compared with RT40 (HR $0.67,95 \% \mathrm{Cl} 0.56$ to 0.80 ; high-certainty evidence). On average, this equates to a $33 \%$ lower risk of death over the course of the disease and a $49 \%$ increase in survival time.

- BEV_CRT probably improves overall survival time compared with RT40 (HR $0.56,95 \% \mathrm{Cl} 0.31$ to 0.99 ; moderate-certainty evidence)

- There may be little or no difference in overall survival time between TMZ and RT40 (HR 0.95, 95\% Cl 0.71 to 1.26; lowcertainty evidence)

- There may be little or no difference in overall survival time between BEV_RT and RT40 (HR 1.08, 95\% Cl 0.66 to 1.78; lowcertainty evidence)

Based on these findings, the average absolute effects on risk of death and median survival time of treatments relative to supportive care have been illustrated in Summary of findings 2 .

Pooled network estimates for four treatments (RT40, BEV_RT, TMZ and CRT) could be compared with 'standard' radiotherapy (60 Gy in 30 fractions) through a common comparator. The graded evidence related to these comparisons can be interpreted as follows.

- There may be little or no difference in overall survival time between RT40 and RT60 (HR 0.94, 95\% Cl 0.72 to 1.23; lowcertainty evidence)

- CRT may improve survival time compared with RT60 (HR 0.63, $95 \% \mathrm{Cl} 0.46$ to 0.87 ; low-certainty evidence)

- The evidence on effects of TMZ and BEV_RT compared with RT60 was graded very low-certainty.

Based on these findings, the average absolute effects on risk of death and median survival time of treatments relative to RT40 have been illustrated in Summary of findings 3.

Interpretation of other graded network estimates are as follows.
- BEV_RT may be associated with shorter overall survival time compared with CRT, however, the effect estimate includes the possibility of little or no difference (HR 1.61, 95\% Cl 0.95 to 2.74; low-certainty evidence)

- There may be little or no difference in overall survival time between BEV_CRT and CRT (HR 0.83, 95\% Cl 0.48 to 1.44; lowcertainty evidence)

- TMZ may be associated with shorter overall survival time compared with CRT (HR 1.42, 95\% Cl 1.01 to 1.98; low-certainty evidence)

- The evidence on effects of BEV_RT compared with TMZ was graded very low-certainty.

\section{Ranking the treatments according to effectiveness}

Table 9 gives an overview of mean SUCRA ranking of treatments according to relative effects on overall survival. BEV with CRT was ranked as the best treatment and supportive care only as the worst treatment. The second best treatment was CRT and the third best treatment was TMZ. These rankings should be interpreted with caution as they do not take into account the certainty of the evidence.

\section{Sensitivity Analysis}

Four sensitivity analyses were conducted and ranking of treatments relative to each other remained consistent with the main network findings (Table 9).

\section{Overall survival data from included studies not contributing data to the NMA}

There were five trials (GLARIUS 2016, Green 1983, Roa 2015, Weller 2017 and Stupp 2017a) that did not contribute overall survival data to the NMA.

For the elderly subgroup of patients aged 65 and over, Green 1983 reported the number of deaths (103/107) and the death rate (number of deaths per 10 patient months). The death rate in the elderly subgroup was significantly higher $(P<0.00001)$ than in other age groups, however there was no evaluation of how death rates compared between the treatment groups.

For the Roa 2015 trial, a separate publication reported survival data per protocol and by intention-to-treat (ITT) for the 61 elderly patients (65 and over) who participated (Guedes de Castro 2017). The median overall survival difference was not statistically different in patients receiving $25 \mathrm{~Gy}$ in 5 fractions of radiotherapy compared to those receiving $40 \mathrm{~Gy}$ in 15 fractions of radiotherapy (6.8 months; $95 \% \mathrm{Cl}$, 4.5-9.1 months compared to 6.2 months; $95 \% \mathrm{Cl}$, 4.7-7.7 months, respectively, $\mathrm{P}=0.936$, no hazard ratio provided). The ITT analysis was conducted separately for 'elderly and not frail' patients and 'elderly and frail' patients and there was no significant difference in overall survival detected between treatment arms for either comparison.

For the GLARIUS 2016 trial, a separate abstract reported overall survival data for the modified intention-to-treat (ITT population for 
patients aged 65 and over $(n=34)$ compared with younger patients. In the RT + BEV/IRI arm, younger patients survived significantly longer compared with those aged 65+ (median overall survival of 17.5 months for patients aged under 65 versus 13.4 months for patients aged $65+, P<0.001$ ). For patients treated with CRT, no significant difference was found between age groups (median overall survival for younger patients was 20.0 months compared to 17.3 months for patients aged $65+, \mathrm{P}=0.567$ ). Whilst the median overall survival for patients aged $65+$ years was reported as 13.4 months and 17.3 months in the BEV/IRI and TMZ arms, respectively, there was no direct comparison stating the level of significance for overall survival between treatment arms performed for this age group.

Weller 2017 reported the number of deaths for patients with maximally resected disease (MRD) receiving rindopepimut and TMZ (31/46) versus TMZ only (36/50), with a corresponding HR of 1.21 $(95 \% \mathrm{Cl}, 0.71$ to $2.06, \mathrm{P}=0.48)$. This was also reported for the group of patients with significant residual disease (SRD) (HR $0.68,95 \% \mathrm{Cl}$, $0.39-1.19, P=0.18$ ). Thus, there were no clear differences in overall survival between treatment arms for either participant population.

Lastly, in Stupp 2017a, tumour treating fields plus adjuvant temozolomide (TTF_AC) was compared with adjuvant temozolomide only among patients receiving CRT. In the subgroup of patients 65 years and older, the estimated HR was 0.51 ( $95 \%$ $\mathrm{Cl}, 0.33$ to 0.77 ) in favour of TTF_AC, with $11 \%$ of participants in the TTF_AC (10/89) and 4\% (2/45) in the CRT only group alive by the end of the study. This trial was not incorporated into NMA because participants were randomised after they had received radiotherapy and concomitant chemotherapy (i.e. participants received treatment prior to the study interventions), while other studies in the NMA randomised participants before they had received radiotherapy or chemotherapy (i.e. were participants were treatment-naive).

\section{Other Outcomes}

Evidence from pairwise comparisons of trial data pertaining to elderly participants is reported by treatment comparison below.

\section{Radiotherapy versus supportive care}

One study (Keime-Guibert 2007) with 81 participants contributed data to this comparison.

\section{Health-related quality of life (HRQOL)}

Evidence related to $\mathrm{HRQOL}$ at $30,60,90$ and 135 day time points after diagnosis. The data suggested slightly better HRQoL scores among people receiving supportive care at the first three time points, and slightly better HRQoL scores for the radiotherapy arm at the 135 day time point (Analysis 1.1). This study also reported cognition (Analysis 1.2) and fatigue scores (Analysis 1.3) for these time points. At the furthest time point (135 days), cognition scores favoured the supportive care arm, whereas there was no clear difference in fatigue scores between the study arms at any time point. As evidence was derived from a single small study with high, unequal attrition (low response rate to questionnaires and more deaths occurring in the supportive care group), we assessed the $\mathrm{HRQ}$ L findings as low-certainty evidence.

\section{Progression-free survival}

Evidence suggested that radiotherapy probably improves progression-free survival compared with supportive care only (HR $0.28,95 \% \mathrm{Cl} 0.17$ to 0.46 ; moderate-certainty evidence, with downgrading as evidence was derived from a small single study).

\section{Severe adverse events}

Not reported.

\section{Hypofractionated radiotherapy versus standard radiotherapy (60 Gy)}

One included study compared $40 \mathrm{~Gy} / 15$ fraction schedule with a $60 \mathrm{~Gy} / 30$ fraction schedule (Roa 2004) and another compared a 25 $\mathrm{Gy} / 5$ fraction schedule with a $40 \mathrm{~Gy} / 15$ fraction schedule (Roa 2015), therefore data were not pooled.

\section{Health-related quality of life (HRQOL)}

Data were reported at four weeks and eight weeks after treatment in Roa 2015 and these suggested that there may be little or no difference in $\mathrm{HRQ}$ L between $25 \mathrm{~Gy} / 5$ fraction and $40 \mathrm{~Gy} / 15$ fraction schedules at either time point after the one-week and three-week treatment schedules, respectively (Analysis 2.1; Analysis 2.2). In Roa 2004, HRQoL data were measured using the KPS at three and six weeks after treatment as medians with interquartile ranges (IQRs) and, similarly suggested little or no difference in effect on HRQoL. Subsequent follow-up of participants in Roa 2004 also suggested little difference in average HRQoL scores, however, attrition increased with time. We downgraded the certainty of this narrative evidence of little or no difference in HRQoL to low (sparse data [-1] and attrition bias [-1]).

\section{Severe adverse events}

There were no instances of grade 3 or higher treatment-related toxicity in Roa 2004 (Analysis 2.3), and this outcome was not reported in Roa 2015.

\section{Progression-free survival}

This was not reported in Roa 2004. Roa 2015 provided a KM curve but not a hazard ratio for (HR) progression-free survival. Alongside the KPM curve, it was reported that median progressionfree survival showed no statistically significant difference between arms (4.2 versus 4.2 months in arms 1 and 2, respectively; $P=0.716$ ). We did not grade this evidence.

\section{Chemotherapy (TMZ) versus radiotherapy}

Two studies contributed overall survival data for this comparison (Malmstrom 2012; Wick 2012) but only one of them (Wick 2012) reported additional outcomes separately for the elderly population of interest.

\section{Health-related quality of life}

Wick 2012 reported no clinically meaningful or significant differences in overall QoL scores at 3, 6, or 12 month measurements or other individual QoL items (emotional function, social function, nausea and vomiting, fatigue, loss of appetite, future uncertainty), except for discomfort from communication deficits, which were greatest for patients in the radiotherapy group who died at between six and 12 months $(P=0.002)$. They were presented graphically over time in a supplementary appendix without raw data. 


\section{Progression-free survival}

Evidence from Wick 2012 suggested that there may be little or no difference in event-free survival (where events were progression or death) between TMZ and standard radiotherapy (373 participants; HR $1.15,95 \% \mathrm{Cl} 0.92$ to 1.44 ; Analysis 3.1; low-certainty evidence, downgraded for study design limitations and imprecision).

\section{Severe adverse events}

Evidence derived from Wick 2012 (373 participants) suggested that, compared with standard radiotherapy.

- TMZ increases the risk of thromboembolic events (Analysis 3.2) and increases the risk of severe (grade $3+$ ) neutropenia, lymphopenia, and thrombocytopenia (Analysis 3.3; Analysis 3.4; Analysis 3.5; moderate-certainty evidence, downgraded -1 for imprecision); however the confidence intervals are imprecise and the actual effect may differ from the point estimate in these analyses.

- There may be little or no difference in the risk of serious infection, fatigue, nausea and vomiting, weight loss, neurological symptoms, seizures, elevated liver enzymes, and cutaneous adverse events (Analysis 3.6; Analysis 3.7; Analysis 3.8; Analysis 3.9; Analysis 3.10; Analysis 3.11; Analysis 3.12; Analysis 3.13; all low-certainty evidence, downgraded -2 for serious imprecision).

\section{Chemoradiotherapy (TMZ plus radiotherapy) versus radiotherapy}

Evidence from one study (Perry 2017) contributed data to outcomes other than overall survival for an elderly population. The radiotherapy schedule used in this study was $40 \mathrm{~Gy}$ in 15 fractions.

\section{Health-related quality of life}

This was briefly reported in Perry 2017 and investigators noted that attrition impacted the quantity of data. They conducted analyses using time to deterioration (with deterioration defined as a 10-point decrease in the score on the function domain or a 10-point increase in the score on the symptom domain) and plotted QoL scores over time. They reported that quote: "only nausea and vomiting and constipation were associated with significant differences in time to deterioration, which was shorter in the CRT group than in the radiotherapy alone group. They reported that ".There were no other clinically important differences between trial groups, which supports our observation that quality of life was similar in the two treatment groups." We did not grade this evidence.

\section{Progression-free survival}

The evidence suggested that chemoradiotherapy delays disease progression compared with radiotherapy only (562 participants; HR $0.50,95 \% \mathrm{Cl} 0.41$ to 0.61 ; Analysis 4.1 ; high-certainty evidence).

\section{Severe adverse events}

Evidence suggested that chemoradiotherapy probably increases the risk of grade $3+$ neutropenia, thrombocytopenia, and leucopenia, however the confidence intervals are imprecise and the actual effect may differ from the point estimate in these analyses. (Analysis 4.2; Analysis 4.3; Analysis 4.4; Analysis 4.5; moderatecertainty evidence, downgraded for imprecision).

Other evidence suggested that there is probably little or no difference in grade $3+$ anaemia (Analysis 4.6) and other grade 3+ treatment-related toxicity (Analysis 4.7) (both moderate-certainty evidence, downgraded due to imprecision).

\section{Bevacizumab plus CRT (TMZ plus radiotherapy) versus CRT}

One study with 73 participants (AVAglio 2014) contributed data to this pairwise comparison.

\section{Health-related quality of life}

This was reported for overall trial but not for elderly subgroup specifically (for overall findings, see below).

\section{Progression-free survival}

Evidence suggested that adding bevacizumab to chemoradiotherapy may make little or no difference to disease progression ( $\mathrm{HR} 0.78,95 \% \mathrm{Cl} 0.46$ to 1.32 ; low-certainty evidence, downgraded due to imprecision and study design limitations; Analysis 5.1).

\section{Severe adverse events}

Evidence suggested that adding bevacizumab to chemoradiotherapy probably increases the risk of grade 3+ thromboembolic events compared with CRT alone (RR 16.63, 95\% $\mathrm{Cl} 1.00$ to 275.42; moderate-certainty evidence, downgraded due to imprecision; Analysis 5.2). No other adverse events were reported for the elderly only. Serious adverse events reported for the overall sample including younger participants can be found below.

\section{Bevacizumab plus radiotherapy versus radiotherapy}

One study with 75 participants (ARTE 2018) contributed data to this pairwise comparison.

\section{Health-related quality of life}

In the publication, global health was reported in a forest plot along with individual $\mathrm{HRQ}$ L items, such as cognitive functioning, emotional functioning and pain, measured with EORTC QLQC30/BN20 scales. Investigators reported that quote: "before progression, no differences were detected for individual scales in a generalized linear mixed model, except for less favourable values in arm A for global health $(\mathrm{P}=0.048)$ and pain $(\mathrm{P}=0.027)$ ". No other data were provided or obtained and we did not grade this evidence.

\section{Progression-free survival}

Evidence suggested that adding bevacizumab to radiotherapy probably delays disease progression ( $\mathrm{HR} 0.46,95 \% \mathrm{Cl} 0.27$ to 0.78 ; moderate-certainty evidence, downgraded due to study design limitations; Analysis 6.1).

\section{Severe adverse events}

Low-certainty evidence suggested that there may be little or no difference in various grade $3+$ adverse events reported in this study, including thromboembolic events (Analysis 6.3); haematological events (Analysis 6.2); infections (Analysis 6.4); fatigue (Analysis 6.5); seizures (Analysis 6.6); headache (Analysis 6.7); neuropsychiatric events (Analysis 6.8); neurological events (Analysis 6.9); hypertension (Analysis 6.10); cutaneous adverse events (Analysis 6.11); and gastrointestinal events (Analysis 6.12). 
Other comparisons did not report progression-free survival for the elderly subgroups of participants.

\section{Health-related quality of life (HRQOL) and adverse event data not specific to elderly patients}

Several of the included studies (AVAglio 2014; GLARIUS 2016; Green 1983; Malmstrom 2012; Roa 2004; Stupp 2017a; Weller 2017) reported $H R Q \circ L$ or adverse event data for the overall trial population but not separately for the elderly subgroup of patients. Although they are not specific to the elderly population, these overall findings may give some indication of the degree of toxicity of the treatments and any detriment to patients' quality of life for the elderly subgroup too. We have therefore presented the main results below with corresponding $P$ values when available. This evidence is not rated for certainty.

\section{Health-related quality of life (HRQOL)}

- Malmstrom 2012 measured HRQoL at baseline, six weeks and three months using EORTC QLQ-C30 and BN-20 questionnaires. Patients in the TMZ arm generally reported better quality of life than in either of the radiotherapy arms (60 Gy and $34 \mathrm{~Gy}$ ), but ratings for global health status were similar.

- AVAglio 2014 reported HRQoL outcomes in a separate publication (Taphoorn 2015). The addition of BEV to CRT delayed deterioration (reported as deterioration-free survival (DFS)) across five pre-selected HRQoL scale measures (global health, physical functioning, social functioning, motor dysfunction and communication deficit). Deterioration was defined as a clinically significant deterioration in HRQoL (worsening of 10 or more points on the respective HRQoL scale), progressive disease, or death. It was suggested that the delayed disease progression in the BEV_CRT arm (reported in the main publication) may have influenced the DFS result. When progressive disease was excluded as an event, participants treated with BEV_CRT had a statistically significantly delayed deterioration in HRQoL domains of communication, social functioning and global health but not for motor dysfunction or physical functioning.

- GLARIUS 2016, which compared treatment with CRT versus treatment with RT60 in combination with concomitant and adjuvant bevacizumab and adjuvant irinotecan, reported HRQoL using QLQ C30 and BN20 questionnaires measured at baseline and every three months until death or end of study. There was no significant difference between the treatment arms.

- Weller 2017 compared adding rindopepimut or control to adjuvant TMZ after CRT and reported no significant differences between patients in their trial arms in any of the HRQoL measures.

- Stupp 2017a reported HRQoL in a separate publication (Taphoorn 2018). There was no significant difference in HRQoL reported between the trial arms, except for itchy skin which was more prominent in the TTF arm at 3, 6 and 9 months $(P=0.005$, $P=0008, P=0.04)$. There was no significant difference at 12 months.

\section{Severe adverse events (Common Terminology Criteria for Adverse Events (CTCAE) grade 3+)}

- Green 1983 reported the percentage of patients in each of the four trial groups that experienced specific toxicities. The proportion of patients in the procarbazine arm who suffered a grade $3+$ dermatologic or allergic reaction $(25 \%)$ and nausea and/or vomiting (12.5\%) were both significantly higher than for the other three arms of the trial. Infection rates were highest for the BCNU and methylprednisolone arm (34.3\%) and rates of uncontrolled diabetes and skeletomuscular complications were highest for the methylprednisolone arm $(3.5 \%$ and $7.8 \%$, respectively).

- Malmstrom 2012 reported toxicity using WHO grading for adverse events, except for nausea and vomiting for which they used the CTCAE version 2.0. In the overall population, episodes of grade $3+$ haematological toxicities (neutropenia, pancytopenia and thrombocytopenia) were only seen in the TMZ arm. The incidence of grade $3+$ seizures and fatigue was more common in the radiotherapy arms compared to the TMZ arm. Infection rates were similar across all arms. There were two patients who had fatal infections, one in the TMZ group and one in the 60 Gy RT group. There was one death in the TMZ group attributed to bleeding due to grade 2 thrombocytopenia.

- AVAglio 2014 used CTCAE v3.0 to measure severe adverse events. Grade $3+$ cerebral bleeding events $(2.0 \%$ versus $0.9 \%)$ and wound healing events (3.3\% versus $1.6 \%$ ) were higher in the BEV plus CRT arm versus CRT alone. There were also higher rates of G3+ thrombocytopenia (15\% versus $9.8 \%$ ) and infection rates $(12.8 \%$ versus $7.8 \%)$ in the BEV arm.

- GLARIUS 2016 used CTCAE v3.0 to measure severe adverse events. Rates of severe adverse events were $72 \%$ for the bevacizumab (BEV)-irinotecan (IRI) plus RT 60 arm, and $84 \%$ in the CRT arm. For the BEV/IRI/RT60 arm, severe vascular events were most common (11.8\%) and two cerebral haemorrhages occurred (one fatal). For patients in the CRT arm, severe haematological toxicity was most common (18.2\%).

- In Weller 2017, the most common severe adverse events for the experimental (rindopepimut) versus placebo arm of the trial were: thrombocytopenia ( $9 \%$ versus $6 \%$ ), fatigue ( $2 \%$ versus $5 \%$ ), brain oedema ( $2 \%$ versus $3 \%$ ), seizure ( $2 \%$ versus $2 \%$ ) and headache $(2 \%$ versus $3 \%)$. There was one death, secondary to pulmonary embolism, that was assessed as potentially related to the treatment in the experimental arm.

- Stupp 2017a reported that there was no significant increase in rates of severe adverse events when TTF were added to adjuvant chemotherapy ( $48 \%$ versus $44 \%, P=0.58$ ). There was a numerically higher incidence of some adverse events in the TTF group but the authors report that this was a reflection of the longer duration of TMZ treatment in this group due to delayed occurrence of progression and that the difference disappeared when adverse event incidence was normalised to duration of treatment. There was a higher incidence of skin toxicity (grade 3 in $2 \%$ ) for the TTF arm compared to the control arm.

\section{Economic evidence}

The economic evaluation that was identified (Ghosh 2018) was a cost-effectiveness analysis (CEA) and cost-utility analysis (CUA). The associated study compared the use of a short course of radiotherapy in elderly patients based on the trial by Roa 2015 . The trial reports clinical outcomes were expressed as overall survival and progression-free survival for the CEA and as quality adjusted life years (QALYs) for the CUA (Table 10).

Direct unit medical costs (i.e. costs which result from the utilisation of the medical intervention) were collected from the associated trial (Roa 2015). The costs were broken down for each country participating in the trial. These costs were shown in an additional table. No indirect costs (i.e. costs associated with losses as a 
consequence of illness, such as production or leisure time lost to patients and their families) were included. The direct costs included the costs of the dexamethasone, magnetic resonance imaging (MRI) scans, computed tomography (CT) scans and radiotherapy (Table 11). The authors presented costs as USD 2015, but did not describe the methods for converting the costs from the various participating countries. The mean total cost of the $25 \mathrm{~Gy}$ arm was $\$ 2,475$ and the mean total cost for the 40 Gy arm was $\$ 2,868$. The authors report that confidence intervals were undefined for the difference in cost due to the negative -cost difference, although the scientific rationale for this statement is unclear, as there is no reason why a $\mathrm{Cl}$ could not be estimated when the point estimate for the difference in cost between the short course and commonly used RTs is negative.

The results of the cost-effectiveness were expressed as Incremental Cost Effectiveness Ratios (ICERs). The reported ICERs in USD were $\$ 3,062$ for the restricted mean overall survival per life-year gained and $-\$ 17,693$ USD for the restricted mean progression-free survival. The presentation of negative ICERs is not advised, as negative data points have no meaningful ordering (O'Brien 2002). For overall survival, the study reports a net benefit with $25 \mathrm{~Gy}$ of $-\$ 46,907$ at a societal willingness to pay level $\$ 50,000$, a net benefit of $\$ 93,438$ at the $\$ 100,000$ threshold, and a net benefit of $-\$ 159,970$ at the $\$ 200,000$ threshold. For progression-free survival, net benefit is reported as $-\$ 1,933$ at the $\$ 50,000$ threshold, $-\$ 4,241$ at the $\$ 100,000$, and $-\$ 8,680$ at the $\$ 200,000$ threshold. Given the clinical outcome data presented in the paper, it is unclear how these numbers are calculated as they do not make intuitive sense.

The utility values for the CUA were derived from three different mapping algorithms from the EORTC QLQ-C30 questionnaire (Kontodimopoulos 2009;Kim 2012; McKenzie 2009). Two reviews have identified limitations in using the EORTC QLQ-C30 mapping algorithms and the three algorithms used in this study performed poorly in validation tests, so their outputs should be used cautiously (Doble 2016; Woodcock 2018). The authors held the assumption that the participants would survive for four months with either treatment. The QALY valued for the $40 \mathrm{~Gy}$ treatment was therefore: $\mathrm{QALY}$ overall $=0: 333$ times the utility obtained at baseline. However, the QALY calculated using the mapping algorithm was calculated as: QALY = Utility at month 1 times 0:083 + Utility at month 4 times 0:333. This would result in a $25 \mathrm{~Gy}$ treated QALY being calculated for five months, whereas the 40 Gy treated individual was being calculated for four months, which was against the authors stated assumption. This means that the gains calculated for the QALY ICERs may be due to this potential calculation error rather than the effect of the intervention itself.

Stochastic sensitivity analysis was carried out in the form of bootstrapping to assess sampling uncertainty. The authors did not carry out a deterministic sensitivity analysis, as variation in cost and survival effect size were analysed using the bootstrap procedure and cost-effectiveness acceptability curves. This is not in line with current UK guidelines (NICE 2012) who recommend the use of deterministic and probabilistic sensitivity analysis to assess parameter uncertainty. The International Society of Pharmacoeconomics and Outcomes Research (ISPOR) guidelines also recommend the examination of parameter uncertainty (Husereau 2013).

The authors conclude that since their ICER values are less than the threshold, they can conclude that the 25 Gy radiotherapy is costeffective. The review authors cannot replicate the results of this economic evaluation from the data presented and the study results should be considered with extreme caution. As this was the only study identified and has potential quality issues, this demonstrates a paucity of economic evidence regarding the management of newly diagnosed glioblastoma in the elderly.

\section{Quality of Economic studies}

The quality of the trial on which Ghosh 2018 is based (Roa 2015) has been discussed in Risk of bias in included studies. The study was found to have a low risk of bias (with the exception of the blinding, which was open-label). The CHEERs checklist (Husereau 2013) and the CHEC checklist (Evers 2005) were applied to the study to assess the quality of economic evaluation as recommended by the current guidelines (Shemilt 2018). The results from these can be found in Table 6 and Table 7. The results of the CHEERS reporting checklist show that there a number of parameters are not reported (e.g. sources of costs, time horizon, perspective). The results of the CHEC checklist show that there a number of issues with the methodological quality of the study, including inappropriate costing and analysis methods.

\section{DISCUSSION}

\section{Summary of main results}

The review included 12 studies involving approximately 1818 elderly participants and several different treatment comparisons. Seven treatment options could be connected in a network metaanalysis (NMA) for the outcome of overall survival. Other treatments and outcomes were evaluated in pairwise comparisons where data were available.

\section{Overall survival}

We found high-certainty evidence that chemoradiotherapy results in a $33 \%$ lower risk of death on average over the course of the disease after diagnosis (20\% to $44 \%$ lower), or about a $50 \%$ increase in survival time compared to treatment with hypofractionated radiotherapy (RT) (40 Gy) alone. Other evidence was assessed as moderate to very low certainty, with most evidence graded as low or very low certainty, meaning that the effect estimates may be substantially different from those estimated in our network metaanalysis (NMA). However, all treatments evaluated led to a clear increase in survival time relative to supportive care only, except for the bevacizumab plus radiotherapy option.

In terms of treatment rankings, bevacizumab (BEV) added to chemoradiotherapy (CRT) ranked as the best treatment, CRT ranked second best, temozolomide (TMZ) ranked third best, hypofractionated radiotherapy fourth, and supportive care only ranked last. These ranking should be interpreted with caution as they do not take into account the certainty of the evidence, notably that there may be little or no difference in overall survival when BEV is added to CRT. Therefore, the higher position of BEV_CRT in the ranking is not supported by evidence of a clear survival benefit over CRT. On sensitivity analysis, when CRT40 (with 40 Gy RT) and CRT60 (with 60 Gy RT) interventions were considered separately, CRT (with RT40 Gy) ranked first in the larger of the two networks thus created.

Summary of findings with illustrative effects can be found in the Summary of findings for the main comparison, Summary of findings 2 and Summary of findings 3 . We were unable to conduct subgroup analyses by age threshold $65+$ or $70+$ 
year threshold), or methylguanine-DNA-methyltransferase (MGMT) methylation status; few included studies reported the latter and where these data were present, they were usually reported for the sample overall and not for the elderly subgroup.

\section{Quality of life}

Moderate-certainty narrative evidence suggests that overall, there may be little difference in quality of life between TMZ and radiotherapy, except for discomfort from communication deficits, which were more common with radiotherapy. Data on quality of life for other treatment comparisons were sparse and negatively impacted by attrition, with the limited available evidence derived from elderly participants suggesting little or no difference in quality of life with radiotherapy versus supportive care only, and short course versus longer/standard radiotherapy courses (Summary of findings 4). Narrative evidence from a single study of chemoradiotherapy versus radiotherapy only suggesting little difference in quality of life was not graded.

\section{Progression-free survival}

High-certainty evidence shows that chemoradiotherapy delays disease progression compared with hypofractionated radiotherapy only. Moderate-certainty evidence suggests that radiotherapy with 60 Gy probably delays disease progression compared with supportive care only and that bevacizumab with radiotherapy probably delays disease progression compared with hypofractionated radiotherapy alone. Evidence for other treatment comparisons is of low or very low certainty.

\section{Severe adverse events}

Moderate-certainty evidence suggests that severe haematological toxicities and thromboembolism are more common with TMZ than with radiotherapy and the risk probably increases with the addition of BEV to CRT.

\section{Economic evaluations}

The review identified a single economic evaluation in the target population. This study had a number of issues relating to methodological quality so the results should be interpreted very cautiously. This demonstrates a current lack of economic evidence evaluating different strategies of managing of newly diagnosed glioblastoma in the elderly. Other economic evaluations that were identified did not consider the over 65's with newly diagnosed glioblastoma as a relevant population or subgroup.

\section{Overall completeness and applicability of evidence}

The only outcome that could be assessed in a network was that of overall survival. Thus, it is not known how the treatment options compare with regard to the other important review outcomes, such as quality of life or severe adverse events. This is a serious limitation of the evidence gathered in this review as a treatment ranked as best for overall survival, for example, could be worst for quality of life. More research on quality of life among patients receiving treatment for glioblastoma is necessary to elucidate these other relative effects. However, attrition is a notable problem for investigators gathering these sorts of data.

In general, the review evidence is applicable to elderly patients with a Karnofsky Performance Score of more than 70 per cent, i.e. those patients capable of self-care (see Table 3). We found little evidence to inform guidance on the most appropriate treatments for people with KPS less than 70 percent. Two studies that evaluated different hypofractionated radiotherapy regimen included patients at the frailer end of the spectrum, using a KPS of 50 percent (Roa 2004; Roa 2015). Evidence from Roa 2015 suggested little or no difference in the median survival between a $25 \mathrm{~Gy} / 5$ fraction regimen and the $40 \mathrm{~Gy} / 15$ fraction regimen among elderly and frail patients; however, the effectiveness of the $25 \mathrm{~Gy} / 5$ fraction regimen could not be evaluated against other possible treatment options in the network due to insufficient data. Malmstrom 2012 also permitted entry to their trial of patients (7/291 patients) with a WHO performance status of 3 if this was specifically due to neurological status. However, this was a minority of patients and the outcomes for these patients were not reported separately.

Data were also relatively scarce for certain treatments, particularly newer treatment options (e.g. those employing bevacizumab) and some treatment options lacked overall survival data in a comparable form (e.g. radiotherapy given as 25Gy in five fractions); therefore, such treatments could not be ranked at all against other treatments. Crucially, we were unable to compare chemoradiotherapy utilising $60 \mathrm{~Gy}$ in 30 fractions (standard) with hypofractionated regimens, either directly or indirectly, due to limitations of the network connections. Therefore, we could not ascertain a network effect estimate for standard versus a hypofractionated chemoradiotherapy regimen, nor rank these different regimen.

One study (Roa 2015) compared two hypofractionated chemoradiotherapy regimen ( $25 \mathrm{~Gy}$ in five fractions versus $40 \mathrm{~Gy}$ in 15 fractions). Unfortunately, we were unable to compare and rank the $25 \mathrm{~Gy}$ radiotherapy regimen because the overall survival data in this study were reported as median survival times with P-values, rather than as time-to-event data (HRs and $95 \% \mathrm{Cls}$ ). The difference in median survival was not statistically significant $(P=0.936)$. We rated the resulting evidence as low-certainty. We were unable to obtain the relevant time-to-event data from the investigators for this review.

In addition to the limitations of the evidence with respect to performance status mentioned above, there were very few data on health-related quality of life (HRQOL) and severe adverse effects reported specifically for elderly patients. In studies where the elderly were a subgroup of a sample with a broader age range, these outcomes were frequently reported by investigators for the overall sample. When we found no specific data on these outcomes for the elderly, we reported the main findings for the broader age group at the end of the results section. However the applicability of these findings to an elderly population is not known and the actual relative effects may be quite different.

\section{Quality of the evidence}

The network evidence that was rated as high quality/certainty was:

- chemoradiotherapy increases time to death and delays disease progression compared with hypofractionated radiotherapy.

Evidence of moderate quality/certainty, meaning that our actual effect may differ somewhat from our point estimate (or may change with further research), included the following: 
- chemoradiotherapy increases the risk of grade $3+$ neutropenia, thrombocytopenia, and leucopenia compared with hypofractionated radiotherapy alone;

- bevacizumab plus chemoradiotherapy increases time to death compared with hypofractionated radiotherapy alone;

- standard radiotherapy increases time to death and delays disease progression compared with supportive care only;

- bevacizumab plus radiotherapy delays disease progression compared with hypofractionated radiotherapy alone;

- temozolomide increases the risk of grade 3+ thromboembolic events, neutropenia, lymphopenia, and thrombocytopenia compared with standard radiotherapy; and

- bevacizumab plus chemoradiotherapy increases the risk of thromboembolic events compared with chemoradiotherapy alone.

Other evidence was low or very low quality/certainty and the effect estimates (if any) are likely to change with further research. Data on quality of life were sparse and the certainty of the evidence tended to be of very low quality/certainty or unrateable.

SUCRA sSurface under the cumulative ranking curve) ranking does not take into account the certainty of the evidence and a high-ranked treatment may be based on low-certainty evidence (Mbuagbaw 2017). In our main NMA, the evidence on bevacizumab added to chemoradiotherapy compared with chemotherapy alone was less robust than the evidence on chemoradiotherapy alone; however, it ranked higher than the latter. When compared with chemoradiotherapy, low-certainty evidence suggested that the addition of bevacizumab to chemoradiotherapy did not improve overall survival, highlighting that rankings should be interpreted with caution and that more research evidence may be needed to improve the certainty of the rankings.

\section{Potential biases in the review process}

There were some important differences between trial inclusion criteria, treatments and outcome reporting that could not be accounted for in this review process and could have contributed to potential bias.

\section{Definitions of 'the elderly'}

Eight trials defined the elderly subgroup as $65+$ years old (ARTE 2018; GLARIUS 2016; Green 1983; Perry 2017; Roa 2015; Stupp 2017a; Weller 2017; Wick 2012), and only three studies contributed data for the elderly according to the review focus of $70+$ years old (AVAglio 2014; Keime-Guibert 2007; Malmstrom 2012) (Table 2). People aged between 65 and 70 years were shown to have a longer median survival compared with those of $70+$ years $(6$ months versus 3.2 months, respectively) in a large UK audit (Brodbelt 2015). Our decision to pool data for these studies was pragmatic and taken at the protocol stage, because we knew that data specifically for the $70+$ age group would be sparse.

We also included one study (Roa 2004) that defined elderly patients as aged $60+$ years because the review protocol dictated that the overall results from trials including younger patients could be included if the proportion of patients in the trial aged over 65 years exceeded $80 \%$. In Roa 2004, the mean participant age was 72.4 years for patients treated with $60 \mathrm{~Gy}$ and 71.0 years for patients treated with $40 \mathrm{~Gy}$. The standard deviation for these groups was 5.4 and 5.5 years, respectively. Therefore the majority of participants in this trial were likely to be aged over 65 years; whether the proportion exceeded $80 \%$ as per our inclusion criteria is unclear. After attempting to contact the authors of Roa 2004, with no further information on the proportion of patients included aged over 65 years obtained, we decided to include this study based on this rationale. The median survival of 5.1 months in the RT60 arm of this trial was similar to the median survival reported by Malmstrom 2012 for patients aged 70+ who received 60 Gy (5.2 months), and less than the median survival reported for patients aged $70+$ in Keime-Guibert 2007 (29.1 weeks), who received $50 \mathrm{~Gy}$, and for patients aged 65+ in Wick 2012 (9.6 months) who received 60 Gy.

As younger participants survive longer than older participants, the effect of including studies with $65+$ year old participants might have over-estimated the beneficial effects of treatments for the $70+$ year old age group.

\section{Radiotherapy treatment}

Green 1983 was the oldest study included in the review and was published 21 years before the next included study (Roa 2004). As whole brain radiotherapy was used (WBRT) was used in Green 1983 , the radiotherapy volume treated was much larger than the treatment volumes specified for the other trials that included radiotherapy. The larger treatment volume and likely sub-optimal planning and treatment delivery techniques would be considered unacceptable by modern standard and is likely to have affected the tolerability of the treatment and the rate of adverse events, especially for elderly patients. Whilst we included this trial, it did not contribute survival data to the NMA or data for pairwise comparisons of other review outcomes, therefore any potential bias introduced by including this study would be minimal.

\section{Timing of randomisation}

Most trials randomised patients in the period following surgical resection when they were radiotherapy- and chemotherapy-naive. Two trials (Stupp 2017a; Weller 2017) performed randomisation after patients had completed concomitant CRT and both specified that patients must have received at least $90 \%$ of the planned radiotherapy dose (60 Gy). This will have selected for a group of patients with a better prognosis than those in trials using the earlier time point of randomisation, by excluding those patients who were unable to tolerate treatment due to adverse events or who died or progressed prior to finishing radiotherapy. Whilst Stupp 2017a reported relevant time-to-event data for the elderly subgroup, we did not include these data in the NMA due to the risk of intransitivity.

\section{Survival times}

Most of the included studies (including Stupp 2017a and Weller 2017, which randomised participants after concomitant CRT) calculated overall survival from the time of randomisation, but for several studies the starting point for overall survival analysis was not described (ARTE 2018; AVAglio 2014; GLARIUS 2016) and for one trial (Wick 2012), overall survival was measured from the date of surgery.

\section{Tumour response assessment}

For those trials that reported a response rate or progressionfree survival, several (ARTE 2018; AVAglio 2014; Keime-Guibert 2007; Perry 2017; Stupp 2017a; Weller 2017; Wick 2012) used repeated magnetic resonance imaging (MRI) for the basis of their assessments. Roa 2015 did not specify the modality of 
imaging and in Keime-Guibert 2007, imaging was permitted with MRI or computed tomography (CT). ARTE 2018 and Weller 2017 used the response assessment in neuro-oncology (RANO) criteria (Wen 2010), GLARIUS 2016; Stupp 2017a; Wick 2012 specified the MacDonald criteria (MacDonald 1990), and AVAglio 2014; Keime-Guibert 2007; Perry 2017 described their response criteria, which were based on specific MRI appearances and/or steroid use and symptoms. Roa 2015 did not specify the criteria used. Although there are similarities between these response criteria, the differences may mean that the response rate or progression-free survival. results across these trials are not comparable.

\section{Extent of surgical resection}

Extent of surgical resection influences prognosis (Pessina 2018). Most trials permitted inclusion of patients who had undergone biopsy or partial or complete surgical resection. In the KeimeGuibert 2007 trial, which was one of the older included studies, at least half the participants had biopsy only. Including this trial in the NMA might, therefore, have led to the effect on overall survival estimated for other treatments to be slightly over-estimated.

In the trial by Weller 2017, the primary analysis was conducted on patients who had maximal surgical resection (MRD) only. Whilst in the context of NMA, this could have favourably biased the effect of the study intervention, Weller 2017 did not contribute data to the NMA, therefore did not bias the NMA findings. The extent of resection was not described in ARTE 2018, and we did not evaluate the extent of possible bias from including this trial; however, the direct evidence derived from this trial in the NMA was rated low certainty.

\section{Molecular subtypes}

Two trials included patients with disease of particular molecular subtypes only, which may not have been comparable with patients included in other trials. Weller 2017 specified that only patients with glioblastoma with confirmed epidermal growth factor receptor (EGFR) vlll expression were eligible for trial inclusion. The rationale was that rindopepimut was most likely to be active in disease expressing this mutation. This explains the relatively small number of patients enrolled $(n=745)$ compared to the number assessed for eligibility ( $n=4652$ ). In the GLARIUS 2016 trial, only patients with unmethylated MGMT were eligible for trial inclusion. As MGMT methylation has a known prognostic effect on survival of patients with glioblastoma, it is important to consider the results of this trial and how they compare to results from other trials in this context.

\section{Analysis and grading}

For the main NMA for overall survival, comparing all treatments with supportive care only, we made the following assumptions:

- that it was reasonable to pool data on chemoradiotherapy (combined TMZ and radiotherapy), irrespective of the radiotherapy dose schedule used (40 Gy/15 fractions and 60 Gy/30 fractions in Perry 2017 and AVAglio 2014, respectively);

- that data on a $50 \mathrm{~Gy} / 28$ fraction radiotherapy schedule from the one study (Keime-Guibert 2007) employing this unconventional dose schedule could be pooled with those of $60 \mathrm{~Gy} / 30$ fraction.

The rationale for the first assumption was that 'standard' chemoradiotherapy might include either radiotherapy schedule combined with TMZ. In addition, pairwise analysis suggested that there was no clear difference in overall survival between $40 \mathrm{~Gy} / 15$ and the $60 \mathrm{~Gy} / 30$ schedules when employed without chemotherapy. However, the decision to pool these data was also influenced by the fact that pooling these data would facilitate a connected network. To evaluate the extent to which the first assumption impacted the findings of the review, we conducted a sensitivity analysis by not pooling these data, which resulted in a network with a disconnected (separate) comparison (Figure 6C). Findings of the relative effects of the interventions were similar to the main findings and made no difference to the treatment ranking of chemoradiotherapy. In grading this evidence, we therefore did not downgrade the evidence on chemoradiotherapy for intransitivity (differences in study characteristics that may modify treatment effect) because intransitivity did not appear to have a serious impact on the estimates of effect. 
Figure 6. Network diagrams for four sensitivity analyses

A

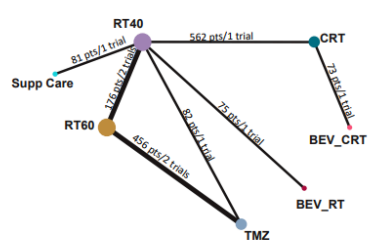

Senstitity A Analysis A: Keime-Guibert 2007 R riso armis coded as RTIO

C

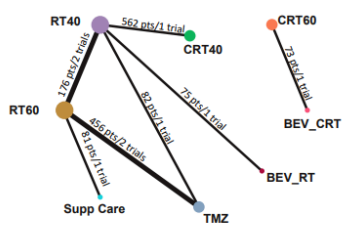

B

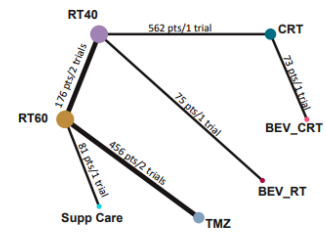

D
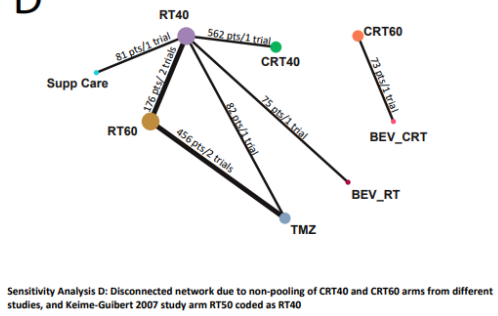

With respect to the second assumption, we performed a sensitivity analysis by pooling the Keime-Guibert 2007 data (RT50 Gy) with the $40 \mathrm{~Gy} / 15$ fraction node (Figure $6 \mathrm{~A}$ ) and found that this also made no difference to the treatment rankings. Similarly, we did not downgrade the evidence for intransitivity.

The only loop in the network was derived from a single study with three arms (Malmstrom 2012), which led to duplication of data at the hypofractionated RT node in the main analysis. To evaluate the impact of this on the findings, we performed a sensitivity analysis by removing one of the study arms (TMZ versus hypofractionated RT) (Figure 6B). This made little difference to effect estimates and treatment rankings, therefore we did not downgrade for intransitivity (differences in study characteristics that may modify treatment effect).

Where studies evaluated the radiotherapy schedules only (i.e. without chemotherapy), we did not pool data for $40 \mathrm{~Gy} / 15$ and 60 $\mathrm{Gy} / 30$ schedules. However, we conducted an exploratory analysis by collapsing these nodes to evaluate the extent to which so doing would have impacted on the review findings.

Because most treatments were not part of a loop in the main network analysis, and the only loop came from a single study such that the results for the nodes in the loop correlated with one another, it was not possible to calculate indirect estimates of effect. This meant that we had to adopt a modified grading approach as it was not possible to assess incoherence (differences between the direct and indirect estimates of effect).

\section{Calculation of absolute risk of death}

As an assumed baseline risk for supportive care, we used survival data from Keime-Guibert 2007. Whilst this is an older study and had a lower proportion of patients having had maximal surgical resection, it was the only one to evaluate supportive care only. Noting that in the an epidemiological glioblastoma study (Brodbelt 2015), the death rate for the 70+ age group was approximately $50 \%$ at three months from diagnosis (with a median survival of 3.2 months reported), we felt that the Keime-Guibert 2007 data were a reasonable baseline against which to illustrate the potential effects of the different treatments. Relative to the Keime-Guibert 2007 data, it could be argued then, for the relevant comparisons, that the estimates of more recent interventions relate to maximal surgical resection plus the experimental option (e.g. CRT) and not just the experimental option alone.

\section{Agreements and disagreements with other studies or reviews}

Our review evidence on hypofractionated (40 Gy) versus standard radiotherapy, suggesting little or no difference in overall survival between these radiotherapy doses, contrasts with evidence from Bleehen 1991, a trial conducted among mostly younger patients, which implied that higher radiotherapy doses were more effective. Bleehen 1991 compared postoperative treatment with 60 Gy RT in 30 fractions with 45 Gy RT in 20 fractions for patients with grade 3 or grade 4 glioma aged $18+$ years, reporting that the higher dose significantly improved overall survival in this study. Although $61 \%(n=272)$ of patients in Bleehen 1991 had a diagnosis of glioblastoma and $32 \%(n=140)$ were aged over 60 , no subgroup analyses for an elderly cohort were reported and therefore it is impossible to know if the same survival advantage would have been seen for the group of older (65+) patients in this trial.

Reyes-Botero 2018 was a single-arm, non-randomised phase II trial $(\mathrm{n}=66)$ which treated patients aged $70+$, and with a : Karnofsky performance score (KPS) of under 70 with TMZ 130-150 mg/m2 per day for five days every four weeks concomitantly with BEV 
$10 \mathrm{mg} / \mathrm{kg}$ every two weeks. Median overall survival of 23.9 weeks (95\% confidence interval $(\mathrm{Cl}), 19$ to 27.6 weeks) was less than observed for patients of the same age treated with TMZ alone using the same schedule (9.0 months, $95 \% \mathrm{Cl}, 6.2$ to 11.8 months) in a trial included in this NMA (Malmstrom 2012), however the patients in Malmstrom 2012 had better performance status. The adverse events which occurred from using TMZ and BEV were reported by the Reyes-Botero 2018 authors to be tolerable; however, there were three deaths from pulmonary embolism, intestinal perforation and cerebral haemorrhage, which were recorded as probably being attributed to treatment. These are in keeping with the characteristic adverse events accompanying treatment with BEV described in trials included in this review (ARTE 2018; AVAglio 2014; GLARIUS 2016).

We know from service audits, surveys and guidelines (Brodbelt 2015; NCCN 2018; NICE 2018; Palmer 2018), that best supportive care is often the most popular treatment option for patients with poorer performance status. Although most studies in our review included relatively fit patients (KPS over 60 to 70), two trials (Roa 2004; Roa 2015) included unfit (KPS as low as 50) elderly patients. Findings from these two trials suggest that less intensive and less toxic treatment options, such as $40 \mathrm{~Gy}$ in 15 fractions or $25 \mathrm{~Gy}$ in five fractions, may be appropriate in selected cases. Interestingly, the median survival for unfit, elderly patients in Roa 2015 (reported in Guedes de Castro 2017) was superior in both treatment arms (40 Gy in 15 fractions ( 6.2 months; $95 \% \mathrm{Cl}, 4.7$ to 7.7 months), $25 \mathrm{~Gy}$ in five fractions ( 6.8 months; $95 \%, 4.5$ to 9.1 months)), compared with survival outcomes previously reported for fitter elderly patients receiving best supportive care alone (median overall survival 3.9 months, Keime-Guibert 2007).

Gállego 2011 was a single-arm phase II trial of TMZ (150 to $\mathrm{mg} / \mathrm{m} 2 /$ day $200 \mathrm{mg} / \mathrm{m} 2 /$ day for five days every four weeks until progression) in elderly (age $>70$ years) and frail (KPS less than 70) patients. Median overall survival was six months and, in the small subgroup of patients known to have MGMT methylated disease, median survival was 31 weeks. Overall, quality of life and cognition improved on treatment and approximately one third of patients showed an improvement in KPS of at least 10 points. Although not a direct comparison, this survival time is also longer than reported for fitter elderly patients receiving supportive care alone (Keime-Guibert 2007). In line with conclusions from Roa 2004 and Roa 2015, this suggests that active treatment in carefully selected patients of poorer performance status can be well-tolerated without significant deterioration in quality of life.

Cost-effectiveness evaluations of glioblastoma treatments specific to elderly populations are needed. A Canadian observational study that reported a median overall survival of six months among its elderly glioblastoma cohort, found that at least one in five of these over 65 -year-olds spent more than $20 \%$ of their remaining time as inpatients (Moroney 2017); therefore, understanding the potential resource implications of this group is important. There are existing economic evaluation studies in non-elderly populations, but we are unsure of their quality and applicability. Specifically, we are uncertain about the applicability of some recent economic evaluations on BEV and tumour treating fields (TTF) that have been conducted in non-elderly populations with newly diagnosed glioblastoma (Bernard Arnoux 2016; Gazauskas 2019; Kovic 2015).

\section{AUTHORS' CONCLUSIONS}

\section{Implications for practice}

Evidence from recent service audits and surveys show a wide variation in treatment practice, with an often large proportion of elderly glioblastoma patients not treated with any active treatment after surgical intervention (Chong 2018; Palmer 2018; Solth 2018). The evidence in this review may, therefore, be useful to clinicians and patients considering active treatment by facilitating discussions around the likely magnitude of benefit from various active treatment options compared with supportive care alone. It is important to note that age alone is unlikely to be the best determinant of optimal treatment of older people with glioblastoma, which requires an holistic patient-centred approach.

Comparing seven interventions in a network with best supportive care, mainly among elderly people capable of self-care, the estimates for the relative effects of active treatment suggest a survival benefit in most scenarios. The exception was the treatment of bevacizumab (BEV) with radiotherapy, where the $95 \%$ confidence interval $(\mathrm{Cl})$ included the possibility of no difference. Where illustrative median survival times were estimated, they suggest that all may offer some months of survival benefit (illustrative median overall survivals of 6.8 to 7.7 months for standard radiotherapy and chemotherapy options, respectively) compared with bestsupportive care only (median of 3.2 months for the 70+ age group in Brodbelt 2015).

Chemoradiotherapy (CRT) performs well in this analysis for elderly patients with good performance status. Although no direct comparison of CRT with 60 Gy versus $40 \mathrm{~Gy}$ was possible, CRT with $40 \mathrm{~Gy}$ was more effective and ranked higher than : temozolomide (TMZ) or radiotherapy alone. Also, the available evidence suggests that hypofractionated ( $40 \mathrm{~Gy}$ ) regimen may be as effective and welltolerated as standard $60 \mathrm{~Gy}$ regimen. Even shorter radiotherapy schedules (25 Gy in five fractions and 34 Gy over two weeks) have been tested in the elderly, but unfortunately it was not possible to comment on their effectiveness relative to $40 \mathrm{~Gy}$ or other treatment options because the $34 \mathrm{~Gy}$ regimen was included in the $40 \mathrm{~Gy}$ node for this network meta-analysis (NMA) and the 25 Gy regimen did not contribute survival data to the NMA. It is therefore not possible to deduce if there are any important differences between the hypofractionated regimens, or whether shorter regimens should or could be used in practice.

We know from previous surveys and guidelines (NCCN 2018; NICE 2018), that best supportive care is often the most popular treatment option for patients with poorer performance status. We found little evidence to guide clinical practice in this regard, although findings from individual studies suggest that less intensive and less toxic treatment options may be appropriate.

BEV has a high-treatment ranking, but it is not clear what added benefit, if any, is derived from the addition of BEV to CRT or radiotherapy alone. BEV_CRT improves survival compared with radiotherapy alone with moderate certainty; however, CRT alone is also superior to radiotherapy alone. When BEV_RT was compared with radiotherapy alone, the evidence was more uncertain. In light of the evidence found, there is currently no justification for adding $\mathrm{BEV}$ to radiotherapy or CRT, outside of a clinical trial setting. 


\section{Implications for research}

\section{Hypofractionated radiotherapy}

An important gap in knowledge highlighted by this review is the relative effectiveness and tolerability of CRT with hypofractionated regimen (40 Gy or other regimen) compared with standard CRT for elderly patients. In terms of giving short-course radiotherapy alone, the most commonly used regimen tested being $40 \mathrm{~Gy}$ in 15 fractions. Alternative regimens such as $25 \mathrm{~Gy}$ in five fractions used in patients with poor performance status (Roa 2015) and 34 Gy in 3.4 Gy fractions over two weeks in fit patients (Malmstrom 2012) have shown encouraging outcomes for elderly patients when compared to $40 \mathrm{~Gy}$ in 15 fractions (Roa 2015) or 60 Gy in 30 fractions (Malmstrom 2012), respectively. Future research to compare shorter regimens, such as $25 \mathrm{~Gy}$ in five fractions, against 40 Gy in 15 fractions in fitter patients would be useful. Shorter, but equally effective treatments save days on treatment for patients and could potentially be a more efficient use of resources. It would be important to measure toxicity in fitter patients receiving higher radiotherapy doses per fraction, as adverse side effects not seen in frailer patients may emerge in fitter patients if they live for longer. Studies which assess the cost-effectiveness of both the provision of the radiotherapy and the resulting complications could potentially inform future decision making about the most efficient strategy radiotherapy for elderly patients.

\section{Bevacizumab (BEV)}

The limitations of the evidence for using BEV to treat elderly patients with glioblastoma have been outlined. More certain evidence of beneficial effects and cost-effectiveness of BEV use would be needed before using it in this population outside of clinical trials.

\section{Other systemic anti-cancer treatment (SACT)}

Apart from TMZ, no systemic anti-cancer agents have made an important contribution to improving survival for elderly patients with glioblastoma. We await the results of a trial using hydroxychloroquine (NCT01602588) and a trial using a type of immunotherapy, which has offered such impressive benefits in other malignancies (NUTMEG 2018), although has yet to show promise for patients with glioblastoma .It would also be informative to assess the cost-effectiveness of these drugs in elderly populations.

\section{Tumour treating fields (TTF)}

The trial of TTF combined with adjuvant chemotherapy reported the longest overall survival compared with the other interventions (Table 5), however, participants comprised a selected group with a more favourable prognosis. More research is required to understand if the survival benefit reported in this trial would still be demonstrated if elderly patients had been randomised prior to CRT. Also, health-related quality of life (HRQoL) and adverse events were only reported for the overall trial cohort. Any impact on HRQoL and tolerability of wearing a portable device for at least
18 hours per day and managing technical issues relating to the device may differ for elderly patients compared to those in younger categories and it would be important to report these outcomes for elderly patients separately. Cost-effectiveness studies should be conducted alongside these trials.

\section{Definition of elderly and reporting of $\mathrm{HRQOL}$ for elderly patients}

Any future trials for elderly patients with glioblastoma would benefit from using a clear definition of the elderly. We have chosen aged $70+$ for our definition and trials including younger patients often use 70 as an age cut-off (e.g. Bleehen 1991; Stupp 2017a). Despite the importance of understanding toxicity and tolerability of treatments for older patients, HRQoL and adverse event data for elderly patients with glioblastoma are sparse and any future research which clearly articulates these outcomes for elderly patients would be welcomed.

\section{Prediction of patients most likely to benefit from treatment}

Two of the trials included in this analysis used molecular subtyping to choose the patients to include in their studies (GLARIUS 2016; Weller 2017). Future research that allows tailoring of treatments, with improved therapeutic index, based on molecular subtyping (Pinzi 2017) and other predictive biomarkers may mean that more specific, less toxic treatments could be offered to patients. This would be particularly useful for older patients who are less likely to tolerate combined, intensive treatment regimens.

Additional approaches to guide treatment decisions that require further investigation to guide treatment decisions for elderly patients with glioblastoma include the use of novel imaging techniques (Pinzi 2017) and geriatric and frailty assessment prior to treatment. It has been shown that specific cognitive and frailty evaluation is seldom performed prior to treatment but, when used, has been reported to alter treatment decisions by neuro-oncologists in up to $50 \%$ of cases. (Lorimer 2016). Further investigation into which assessments are both useful and pragmatic to perform in the clinic will help clinicians make better informed treatment decisions for their patients.

\section{ACKNOWLEDGEMENTS}

We thank the Gynaecological, Neuro-oncology and Orphan Cancers (GNOC) Information Specialist, Jo Platt, for preparing the search strategy; the Managing Editors, Gail Quinn and Clare Jess, for their advice and editorial support; and Assistant Managing Editor, Tracey Harrison, for administrative support.

This project was supported by the National Institute for Health Research (NIHR), via Cochrane Programme Grant funding (NIHR $16 / 144$ ) to the GNOC. The views and opinions expressed therein are those of the review authors and do not necessarily reflect those of the Systematic Reviews Programme, the NIHR, the NHS, or the Department of Health.

We thank the referees for helpful suggestions and comments, including Juliet Brock, Paul Brown and Riccardo Soffietti. 


\section{RE F E R E N CES}

\section{References to studies included in this review}

\section{ARTE 2018 \{published data only\}}

Weller M, Tabatabai G, Roelcke U, Hottinger A, Joeger F, Schmid A, et al. The randomized phase II ARTE trial:

Bevacizumab plus hypofractionated radiotherapy versus radiotherapy alone in elderly patients with newly diagnosed globlastoma. Journal of Neuro-oncology. Official Journal of the Society of Neuro-Oncology 22nd Annual Scientific Meeting 16-19 November 2017. 2017; Vol. 19.

Wirsching HG, Tabatabai G, Hottinger A, Plasswilm L, Roelcke $\mathrm{U}$, Conen $\mathrm{K}$, et al. Bevacizumab plus hypofractionated radiotherapy versus radiotherapy alone in elderly patients with glioblastoma: the arte trial. Journal of Neurooncology. Conference: 5th quadrennial meeting of the world federation of neuro-oncology societies, WFNOS. Switzerland 2017;19(Supplement 3):iii13.

* Wirsching HG, Tabatabai G, Roelcke U, Hottinger A, Jorger F, Schmid A, et al. Bevacizumab plus hypofractionated radiotherapy versus radiotherapy alone in elderly patients with glioblastoma: the randomized, open-label, Phase II ARTE trial. Annals of Oncology 2018;29:1423-30.

\section{AVAglio 2014 \{published data only\}}

Chinot OL, Nishikawa R, Mason W, Henriksson R, Saran F, Cloughesy T, et al. Upfront bevacizumab may extend survival for glioblastoma patients WHO do not receive second-line therapy: an exploratory analysis of AVAglio. Journal of Neuro-oncology 2016;18(9):1313-8.

Chinot OL, Wick W, Mason W, Henriksson R, Saran F, Nishikawa R, et al. Bevacizumab plus radiotherapytemozolomide for newly diagnosed glioblastoma. New England Journal of Medicine 2014;370(8):709-22.

Mason W, Cloughesy T, Wick W, Henriksson R, Saran F, Nishikawa R, et al. Overview of arterial thromboembolic events (ATES) in avaglio, a randomized, placebo-controlled phase iii trial of bevacizumab, radiotherapy and temozolomide (BEV+RT/ TMZ) for newly diagnosed glioblastoma. Neurology 2014; Vol. 82 , issue 10 SUPPL. 1.

Nowosielski M, Ellingson BM, Chinot OL, Garcia J, Revil C, Radbruch A, et al. Radiologic progression of glioblastoma under therapy-an exploratory analysis of AVAglio. Neuro-oncology 2018;20(4):557-66.

* Saran F, Chinot OL, Henriksson R, Mason W, Wick W, Cloughesy T, et al. Bevacizumab, temozolomide, and radiotherapy for newly diagnosed glioblastoma: comprehensive safety results during and after first-line therapy CNO CN-01414428. Journal of Neuro-Oncology 2016;18(7):991-1001.

Taphoorn MJ, Henriksson R, Bottomley A, Cloughesy T, Wick W, Mason WP, et al. Health-related quality of life in a randomized phase III study of bevacizumab, temozolomide, and radiotherapy in newly diagnosed glioblastoma. Journal of Clinical Oncology 2015;33:2166-75.
GLARIUS 2016 \{published data only\}

* Herrlinger U, Schafer N, Steinbach JP, Weyerbrock A, Hau P, Goldbrunner R, et al. Bevacizumab plus irinotecan versus temozolomide in newly diagnosed 06-methylguanineDNA methyltransferase nonmethylated glioblastoma: the randomized GLARIUS Trial CNO - CN-01382982. Journal of Clinical Oncology 2016;34(14):1611-9.

Kebir S, Hattingen E, Schaub C, Schafer N, Steinbach J, Weyerbrock A, et al. Effect of age on outcome in the glarius trial. Journal of Neuro-Oncology 2016;18:vi5.

Schafer N, Proescholdt M, Steinbach JP, Weyerbrock A, Hau P, Grauer $\mathrm{O}$, et al. Quality of life in the GLARIUS trial randomizing bevacizumab/irinotecan versus temozolomide in newly diagnosed, MGMT-nonmethylated glioblastoma. Neurooncology 2018;20(7):975-85.

Schaub C, Kebir S, Junold N, Hattingen E, Schafer N, Steinbach JP, et al. Tumor growth patterns of MGMT-nonmethylated glioblastoma in the randomized GLARIUS trial. Journal of Cancer Research and Clinical Oncology 2018;144(8):1581-9.

\section{Green 1983 \{published data only\}}

Green SB, Byar DP, Walker MD, Pistenmaa DA, Alexander E Jr, Batzdorf $U$, et al. Comparisons of carmustine, procarbazine, and high-dose methylprednisolone as additions to surgery and radiotherapy for the treatment of malignant glioma. Cancer Treatment Reports 1983;67(2):121-32.

Keime-Guibert 2007 \{published data only\}

* Keime-Guibert F, Chinot O, Taillandier L, Cartalat-Carel S, Frenay M, Kantor G, et al. Radiotherapy for glioblastoma in the elderly. New England Journal of Medicine 2007;356(15):1527-35.

Lopez S, Taillibert S, Idbaih A, Simon JM, Mazeron JJ. Should elderly patients with glioblastoma be proposed to radiotherapy?. Cancer Radiotherapie 2008;12(8):827-30.

\section{Malmstrom 2012 \{published data only\}}

Malmstrom A, Grønberg BH, Marosi C, Stupp R, Frappaz D, Schultz $\mathrm{H}$, et al. Temozolomide versus standard 6-week radiotherapy versus hypofractionated radiotherapy in patients older than 60 years with glioblastoma: the Nordic randomised, phase 3 trial. Lancet. Oncology 2012;13(9):916-26.

\section{Perry 2017 \{published data only\}}

* Perry JR, Laperriere N, O'Callaghan CJ, Brandes AA, Menten J, Phillips $C$, et al. Short-course radiation plus temozolomide in elderly patients with glioblastoma. New England Journal of Medicine 2017;376(11):1027-37.

Perry JR, O'Callaghan CJ, Ding K, Roa W, Mason WP, Cairncross JG, et al. A phase III randomized controlled trial of short-course radiotherapy with or without concomitant and adjuvant temozolomide in elderly patients with glioblastoma (NCIC CTG CE.6, EORTC 26062-22061, TROG 08.02, NCT00482677). Journal of Clinical Oncology 2012;30(15 SUPPL. 1):(no pagination). 


\section{Roa 2004 \{published data only\}}

Roa W, Brasher PM, Bauman G, Anthes M, Bruera E, Chan A, et al. Abbreviated course of radiation therapy in older patients with glioblastoma multiforme: a prospective randomized clinical trial. Journal of Clinical Oncology 2004;22(9):1583-8.

\section{Roa 2015 \{published data only\}}

Fidarova E, Ghosh S, Kepka L, Sinaika V, Kumar N, Matiello J, et al. Quality of life in elderly/frail patients with glioblastoma multiforme: results of a randomized phase III study comparing short and standard course of radiotherapy. Supportive Care in Cancer 2015;23:S4.

Ghosh S, Baker S, de Castro DG, Kepka L, Kumar N, Sinaika V, et al. Improved cost-effectiveness of short-course radiotherapy in elderly and/or frail patients with glioblastoma. Radiotherapy and Oncology 2018;127(1):114-20.

Guedes de Castro D, Matiello J, Roa W, Ghosh S, Kepka L, Kumar N, et al. Survival outcomes with short-course radiation therapy in elderly patients with glioblastoma: data from a randomized Phase 3 Trial. International Journal of Radiation Oncology, Biology, Physics 2017;98(4):931-8.

Kepka L, Roa W, Kumar N, Sinaika V, Matiello J, Lomidze D, et al. Short course vs. standard course radiotherapy, in elderly and/ or fragile patients with glioblastoma multiforme. Radiotherapy and Oncology 2014;111:S204-S205.

* Roa W, Kepka L, Kumar N, Sinaika V, Matiello J, Lomidze D, et al. International Atomic Energy Agency randomized phase III study of radiation therapy in elderly and/or frail patients with newly diagnosed glioblastoma multiforme. Journal of Clinical Oncology 2015;33(35):4145-50.

\section{Stupp 2017a \{published data only\}}

Stupp R, Hegi ME, Idbaih A, Steinberg DM, Lhermitte B, Read W, et al. Tumor treating fields added to standard chemotherapy in newly diagnosed glioblastoma (GBM): final results of a randomized, multi-center, phase III trial. Cancer research. Conference: American association for cancer research annual meeting 2017. United states. 2017; Vol. 77, issue 13 Supplement 1 (no pagination).

Stupp R, Ram Z. Standard of care temozolomide chemotherapy +/- tumor treating fields (TTFIELDS) in newly diagnosed glioblastoma. final results of the phase III EF-14 clinical trial. Neuro-oncology. Conference: 5 th quadrennial meeting of the world federation of neuro-oncology societies, WFNOS. Switzerland. 2017; Vol. 19, issue Supplement 3:iii15.

* Stupp R, Taillibert S, Kanner A, Read W, Steinberg DM, Lhermitte $B$, et al. Effect of tumor-treating fields plus maintenance temozolomide vs maintenance temozolomide alone on survival in patients with glioblastoma: A randomized clinical trial CNO - CN-01442958. JAMA 2017;318(23):2306-16.

Taphoorn MJ, Dirven L, Kanner AA, Lavy-Shahaf G, Weinberg U, Taillibert S, et al. Influence of treatment with tumor-treating fields on health-related quality of life of patients with newly diagnosed glioblastoma a secondary analysis of a randomized clinical trial. JAMA 2018;4(4):495-504.

\section{Weller 2017 \{published data only\}}

Weller M, Butowski N, Tran DD, Recht LD, Lim M, Hirte H, et al. Rindopepimut with temozolomide for patients with newly diagnosed, EGFRvIII-expressing glioblastoma (ACT IV): a randomised, double-blind, international phase 3 trial. Lancet Oncology 2017;10:1373-85.

\section{Wick 2012 \{published data only\}}

Wick W, Hartmann C, Engel C, Stoffels M, Felsberg J, Stockhammer F, et al. NOA-04 randomized phase III trial of sequential radiochemotherapy of anaplastic glioma with procarbazine, lomustine, and vincristine or temozolomide. Journal of Clinical Oncology 2009;27(35):5874-80.

Wick W, Meisner C, Platten M, Simon M, Nikkhah G, Papsdorf K, et al. MGMT promoter methylation as a predictive biomarker for response to radiotherapy versus chemotherapy in malignant astrocytomas in the elderly: the NOA-08 trial. Journal of Clinical Oncology 2012;30:14.

* Wick W, Platten M, Meisner C, Felsberg J, Tabatabai G, Simon M, et al. Temozolomide chemotherapy alone versus radiotherapy alone for malignant astrocytoma in the elderly: the NOA-08 randomised, phase 3 trial. Lancet Oncology 2012;13(7):707-15.

\section{References to studies excluded from this review}

Ali 2018 \{published data only\}

Ali AN, Zhang P, Yung WK, Chen Y, Movsas B, Urtasun RC, et al. NRG oncology RTOG 9006: a phase III randomized trial of hyperfractionated radiotherapy (RT) and BCNU versus standard RT and BCNU for malignant glioma patients. Journal of NeuroOncology 2018;137(1):39-47.

\section{Armstrong 2013 \{published data only\}}

Armstrong TS, Wefel JS, Wang M, Gilbert MR, Won M, Bottomley A, et al. Net clinical benefit analysis of radiation therapy oncology group 0525: a phase III trial comparing conventional adjuvant temozolomide with dose-intensive temozolomide in patients with newly diagnosed glioblastoma. Journal of Clinical Oncology 2013;31(32):4076-84.

\section{Athanassiou 2005 \{published data only\}}

Athanassiou H, Synodinou M, Maragoudakis E, Paraskevaidis M, Verigos C, Misailidou D, et al. Randomized phase II study of temozolomide and radiotherapy compared with radiotherapy alone in newly diagnosed glioblastoma multiforme. Journal of Clinical Oncology 2005;23(10):2372-7.

\section{Balana 2016 \{published data only\}}

Balana C, De Las Penas R, Sepulveda JM, Gil-Gil MJ, Luque R, Gallego O, et al. Bevacizumab and temozolomide versus temozolomide alone as neoadjuvant treatment in unresected glioblastoma: the GENOM 009 randomized phase II trial. Journal of Neuro-Oncology 2016;127(3):569-79.

\section{Bampoe 2000 \{published data only\}}

Bampoe J, Laperriere N, Pintilie M, Glen J, Micallef J, Bernstein MD. Quality of life in patients with glioblastoma multiforme participating in a randomized study of 
brachytherapy as a boost treatment. Journal of Neurosurgery 2000;93(6):917-26.

\section{Batchelor 2013 \{published data only\}}

Batchelor TT, Mulholland P, Neyns B, Nabors LB, Campone M, Wick $A$, et al. Phase III randomized trial comparing the efficacy of cediranib as monotherapy, and in combination with lomustine, versus lomustine alone in patients with recurrent glioblastoma. Journal of Clinical Oncology 2013;26:3212-8.

Beije 2015 \{published data only\}

Beije N, Kraan J, Taal W, van der Holt B, Oosterkamp HM, Walenkamp M, et al. Prognostic value and kinetics of circulating endothelial cells in patients with recurrent glioblastoma randomised to bevacizumab plus lomustine, bevacizumab single agent or lomustine single agent. A report from the Dutch Neuro-Oncology Group BELOB trial. British Journal of Cancer 2015;113(2):226-31.

\section{Bent 2009 \{published data only\}}

Bent MJ, Dubbink HJ, Sanson M, Lee-Haarloo CR, Hegi M, Jeuken JW, et al. MGMT promoter methylation is prognostic but not predictive for outcome to adjuvant PCV chemotherapy in anaplastic oligodendroglial tumors: a report from EORTC Brain Tumor Group Study 26951. Journal of Clinical Oncology 2009;27(35):5881-6.

\section{Bhandari 2013 \{published data only\}}

Bhandari M, Gandhi AK, Julka PK, Sarkar C, Sharma D, Rath GK. Comparative study of six cycles versus twelve cycles of adjuvant temozolomide post concurrent chemoradiation in newly diagnosed glioblastoma. Journal of Clinical Oncology 2013;10:suppl.e13034. [DOI: 10.1200/jco.2013.31.15]

\section{Bhandari 2017 \{published data only\}}

Bhandari M, Gandhi AK, Devnani B, Kumar P, Sharma DN, Julka, PK. Comparative study of adjuvant temozolomide six cycles versus extended 12 cycles in newly diagnosed glioblastoma multiforme. Journal of Clinical and Diagnostic Research 2017;11(5):XC04-8.

\section{Bleehen 1981 \{published data only\}}

Bleehen NM, Wiltshire CR, Plowman PN, Watson JV, Gleave JR, Holmes AE, et al. A randomized study of misonidazole and radiotherapy for grade 3 and 4 cerebral astrocytoma. British Journal of Cancer 1981;43(4):436-42.

\section{Bleehen 1991 \{published data only\}}

Bleehen NM, Stenning SP. A medical research council trial of two radiotherapy doses in the treatment of grades 3 and 4 astrocytoma. The medical research council brain tumour working party. British Journal of Cancer 1991;64(4):769-74.

\section{Blumenthal 2015 \{published data only\}}

Blumenthal DT, Rankin C, Stelzer KJ, Spence AM, Sloan AE, Moore DF Jr, et al. A Phase III study of radiation therapy (RT) and 06-benzylguanine + BCNU versus RT and BCNU alone and methylation status in newly diagnosed glioblastoma and gliosarcoma: southwest Oncology Group (SWOG) study S0001. International Journal of Clinical Oncology 2015;20(4):650-8.

\section{Blumenthal 2018 \{published data only\}}

Blumenthal DT, Won M, Mehta MP, Gilbert MR, Brown PD, Bokstein $\mathrm{F}$, et al. Short delay in initiation of radiotherapy for patients with glioblastoma-effect of concurrent chemotherapy: a secondary analysis from the NRG Oncology/Radiation Therapy Oncology Group database. Neuro-oncology 2018;20(7):966-74.

Bogdahn 2011 \{published data only\}

Bogdahn U, Hau P, Stockhammer G, Venkataramana NK, Mahapatra AK, Suri A, et al. Targeted therapy for high-grade glioma with the TGF- $\beta 2$ inhibitor trabedersen: results of a randomized and controlled phase llb study. Journal of NeuroOncology 2011;13(1):132-42.

Boiardi 1992 \{published data only\}

Boiardi A, Silvani A, Milanesi I, Broggi G, Fariselli L. Efficacy of '8drugs-in-one-day' combination in treatment of recurrent GBM patients. Journal of Neuro-Oncology 1992;12(2):153-8.

\section{Boisen 2018 \{published data only\}}

Boisen MK, Holst CB, Consalvo N, Chinot OL, Johansen JS. Plasma YKL-40 as a biomarker for bevacizumab efficacy in patients with newly diagnosed glioblastoma in the phase 3 randomized AVAglio trial. Oncotarget 2018;9(6):6752-62.

Bower 1997 \{published data only\}

Bower M, Newlands E, Bleehen NM, Brada M, Begent RJ, Calvert $\mathrm{H}$, et al. Multicentre CRC Phase II trial of temozolomide in recurrent or progressive high-grade glioma. Cancer, Chemotherapy and Pharmacology 1997;40(6):484-8.

Boxerman 2013 \{published data only\}

Boxerman JL, Zhang Z, Safriel Y, Larvie M, Snyder BS, Jain R, et al. Early post-bevacizumab progression on contrast-enhanced $\mathrm{MRI}$ as a prognostic marker for overall survival in recurrent glioblastoma: results from the ACRIN 6677/RTOG 0625 Central Reader Study. Journal of Neuro-Oncology 2013;15(7):945-54.

\section{Brandes 2016 \{published data only\}}

Brandes AA, Finocchiaro G, Zagonel V, Reni M, Caserta C, Fabi A et al. AVAREG: a phase II, randomized, noncomparative study of fotemustine or bevacizumab for patients with recurrent glioblastoma. Journal of Neuro-Oncology 2016;18(9):1304-12.

\section{Brisman 1976 \{published data only\}}

Brisman R, Housepian EM, Chang C, Duffy P, Balis E. Adjuvant nitrosourea therapy for glioblastoma. Archives of Neurology 1976;33:745-50.

\section{Brown 2016 \{published data only\}}

Brown N, McBain C, Nash S, Hopkins K, Sanghera P, Saran F, et al. Multi-center randomized phase II study comparing cediranib plus gefitinib with cediranib plus placebo in subjects with recurrent/progressive glioblastoma. PLOS One 2016;11(5):1-15.

\section{Buckner 2001 \{published data only\}}

Buckner JC, Schomberg PJ, McGinnis WL, Cascino TL, Scheithauer BW, O'Fallon JR, et al. A phase III study of radiation therapy plus carmustine with or without recombinant interferon-alpha in the treatment of patients with newly diagnosed high-grade glioma. Cancer 2001;92(2):420-33. 


\section{Buckner 2006 \{published data only\}}

Buckner JC, Ballman KV, Michalak JC, Burton GV, Cascino TL, Schomberg PJ, et al. Phase III trial of carmustine and cisplatin compared with carmustine alone and standard radiation therapy or accelerated radiation therapy in patients with glioblastoma multiforme: North Central Cancer Treatment Group 93-72-52 and Southwest Oncology Group 9503 trials. Journal of Clinical Oncology 2006;24(24):3871-9.

\section{Carpentier 2017 \{published data only\}}

Carpentier AF, Lambert J. Intracerebral injection of CpG oligonucleotide for patients with de novo glioblastoma-A phase II multicentric, randomised study. European Journal of Cancer 2017;17:30-7.

\section{Castro 1997 \{published data only\}}

Castro JR, Phillips TL, Prados M, Gutin P, Larson DA, Petti PL, et al. Neon heavy charged particle radiotherapy of glioblastoma of the brain. International Journal of Radiation Oncology, Biology, Physics 1997;38(2):257-61.

\section{Catterall 1980 \{published data only\}}

Catterall M, Bloom HJ, Ash DV, Walsh L, Richardson A, Uttley D, et al. Fast neutrons compared with megavoltage $x$-rays in the treatment of patients with supratentorial glioblastoma: a controlled pilot study. International Journal of Radiation Oncology, Biology, Physics 1980;6(3):261-6.

\section{Chamberlain 2005 \{published data only\}}

Chamberlain MC, Recht LD, Glantz M. Regarding "abbreviated course of radiation therapy in older patients with glioblastoma multiforme: a prospective randomized clinical trial". Journal of Clinical Oncology 2005;23(7):1587-8.

\section{Chang 1983 \{published data only\}}

Chang CH, Horton J, Schoenfeld D, Salazer O, Perez-Tamayo R, Kramer S, et al. Comparison of postoperative radiotherapy and combined postoperative radiotherapy and chemotherapy in the multidisciplinary management of malignant gliomas. A joint Radiation Therapy Oncology Group and Eastern Cooperative Oncology Group study. Cancer 1983;6:997-1007.

\section{Chauffer 2014 \{published data only\}}

Chauffer B, Feuvret L, Bonnetain F, Taillandier L, Frappaz D, Taillia $\mathrm{H}$, et al. Randomized phase II trial of irinotecan and bevacizumab as neo-adjuvant and adjuvant to temozolomidebased chemoradiation compared with temozolomidechemoradiation for unresectable glioblastoma: Final results of the TEMAVIR study from ANOCEF. Annals of Oncology 2014;25(7):1442-7.

\section{Chinnaiyan 2018 \{published data only\}}

Chinnaiyan P, Won M, Wen PY, Rojiani AM, Werner-Wasik M, Shih HA, et al. A randomized phase II study of everolimus in combination with chemoradiation in newly diagnosed glioblastoma: results of NRG Oncology RTOG 0913. Journal of Neuro-Oncology 2018;20(5):666-73.

\section{Chong 2018 \{published data only\}}

Chong M, Lorimer C, Hanna C. An audit of the management of elderly patients with glioblastoma in the UK: have recent trial results changed treatment?. Neuro-Oncology. Proceedings of the 2018 British Neuro-Oncology Society meeting. 2018; Vol. 20:v355-v361.

\section{Cianfriglia 1980 \{published data only\}}

Cianfriglia F, Pompili A, Riccio A, Grassi A. CCNU-chemotherapy of hemispheric supratentorial glioblastoma multiforme. Cancer 1980;45(6):1289-99.

\section{Clarke 2009 \{published data only\}}

Clarke JL, Iwamoto FM, Sul J, Panageas K, Lassman AB, DeAngelis LM, et al. Randomized phase II trial of chemoradiotherapy followed by either dose-dense or metronomic temozolomide for newly diagnosed glioblastoma. Journal of Clinical Oncology 2009;27(23):3861-7.

Cohen 2005 \{published data only\}

Cohen MH, Johnson JR, Pazdur R. Food and drug administration drug approval summary: temozolomide plus radiation therapy for the treatment of newly diagnosed glioblastoma multiforme. Clinical Cancer Research 2005;11(19):6767-71.

\section{Combs 2008 \{published data only\}}

Combs SE, Wagner J, Bischof M, Welzel T, Edler L, Rausch R, et al. Radiochemotherapy in patients with primary glioblastoma comparing two temozolomide dose regimens. International Journal of Radiation Oncology, Biology, Physics 2008;71(4):999-1005.

\section{Corn 1994 \{published data only\}}

Corn BW, Yousem DM, Scott CB, Rotman M, Asbell SO, Nelson DF, et al. White matter changes are correlated significantly with radiation dose. Observations from a randomized dose-escalation trial for malignant glioma (Radiation Therapy Oncology Group 83-02). Cancer 1994;74(10):2828-35.

\section{Curran 1992 \{published data only\}}

Curran WJ Jr, Scott CB, Nelson JS, Weinstein AS, Phillips TL, Murray $\mathrm{K}$, et al. A randomized trial of accelerated hyperfractionated radiation therapy and bis-chloroethyl nitrosourea for malignant glioma. A preliminary report of Radiation Therapy Oncology Group 83-02. Cancer 1992;70(12):2909-17.

Das 2017 \{published data only\}

Das S, Kim AH, Chang S, Berger MS. Management of elderly patients with glioblastoma after CE.6. Frontiers in Oncology 2017;7:1-3.

\section{Deutsch 1989 \{published data only\}}

Deutsch M, Green SB, Strike TA, Burger PC, Robertson JT, Selker RG, et al. Results of a randomized trial comparing BCNU plus radiotherapy, streptozotocin plus radiotherapy, $\mathrm{BCNU}$ plus hyperfractionated radiotherapy, and $\mathrm{BCNU}$ following misonidazole plus radiotherapy in the postoperative treatment of malignant glioma. International Journal of Radiation Oncology, Biology, Physics 1989;16(6):1389-96. 
Dherijha 2018 \{published data only\}

Dherijha M, Alakandy L, Barrett C. Treatment outcomes in newly diagnosed malignant glioma in the elderly. NeuroOncology. Conference proceedings of the 23rd Annual Scientific meeting of the Society of Neuro-Oncology. 2018; Vol. 20, Issue suppl_6:i20.

\section{Dinapoli 1993 \{published data only\}}

Dinapoli RP, Brown LD, Arusell RM, Earle JD, O'Fallon JR, Buckner JC, et al. Phase III comparative evaluation of PCNU and carmustine combined with radiation therapy for high-grade glioma. Journal of Clinical Oncology 1993;11(7):1316-21.

\section{Du 2018 \{published data only\}}

Du C, Li Z, Huang Z, Wang, R. Efficacy of timorazolamide combined with three-dimensional conformal radiotherapy on residual disease after surgery of glioblastoma. International Journal of Clinical and Experimental Medicine 2018;11(3):2861-6.

\section{Duncan 1986 \{published data only\}}

Duncan W, McLelland J, Jack WJ, Arnott SJ, Davey P, Gordon A, et al. The results of a randomised trial of mixed-schedule (neutron/photon) irradiation in the treatment of supratentorial Grade III and Grade IV astrocytoma. British Journal of Radiology 1986;59(700):379-783.

\section{Elinzano 2018 \{published data only\}}

Elinzano H, Glantz M, Mrugala M, Kesari S, Piccioni DE, Kim L, et al. PPX and concurrent radiation for newly diagnosed glioblastoma without MGMT methylation: A randomized Phase II Study: brUOG 244. American Journal of Clinical Oncology: Cancer Clinical Trials 2018;41(2):159-62.

\section{Eljamel 2008 \{published data only\}}

Eljamel MS, Goodman C, Moseley H. ALA and photofrin $\left({ }^{\circledR}\right)$ fluorescence-guided resection and repetitive PDT in glioblastoma multiforme: a single centre Phase III randomised controlled trial. Lasers in Medical Science 2008;23(4):361-7.

\section{Elliott 1997 \{published data only\}}

Elliott TE, Dinapoli RP, O'Fallon JR, Krook JE, Earle JD, Morton RF, et al. Randomized trial of radiation therapy (RT) plus dibromodulcitol (DBD) versus RT plus BCNU in high grade astrocytoma. Journal of Neuro-Oncology 1997;33(3):239-50.

\section{Espana 1978 \{published data only\}}

Espana P, Wiernik PH, Walker MD. Phase II study of dianhydrogalactitol in malignant glioma. Cancer Treatment Reports 1978;62(8):1199-200.

\section{Eyre 1983 \{published data only\}}

Eyre HJ, Quagliana JM, Eltringham JR, Frank J, et al. Randomized comparisons of radiotherapy and CCNU versus radiotherapy, CCNU plus procarbazine for the treatment of malignant gliomas following surgery. A Southwest Oncology Group Report. Journal of Neuro-Oncology 1983;1(3):171-7.

\section{Farkkila 1994 \{published data only\}}

Farkkila M, Jaaskelainen J, Kallio M, Blomstedt G, Raininko R, Virkkunen P, et al. Randomised, controlled study of intratumoral recombinant gamma-interferon treatment in newly diagnosed glioblastoma. British Journal of Cancer 1994;70(1):138-41.

Felzmann 2013 \{published data only\}

Felzmann T, Buchroithner J, Marosi C, Nowosielski M, Von Campe G, Oberndorfer S, et al. Dendritic cell-based cancer immune therapy for glioblastoma multiforme: First trends from a randomised efficacy study. Onkologie 2013;36:95-6.

\section{Felzmann 2014 \{published data only\}}

Felzmann T, Buchroithner J, Marosi C, Nowosielski M, Campe G, Oberndorfer S, et al. A randomized clinical trial for the treatment of glioblastoma multiforme with the individualized dendritic cell-based cancer immunotherapy AV0113. Journal of Clinical Oncology 2014;32:15 SUPPL. 1.

Field 2015 \{published data only\}

Field KM, Simes J, Nowak AK, Cher L, Wheeler H, Hovey EJ, et al. Randomized phase 2 study of carboplatin and bevacizumab in recurrent glioblastoma. Journal of Neuro-Oncology 2015;17(11):1504-13.

\section{Field 2017 \{published data only\}}

Field KM, King MT, Simes J, Espinoza D, Barnes EH, Sawkins K, et al. Health-related quality of life outcomes from CABARET: a randomized phase 2 trial of carboplatin and bevacizumab in recurrent glioblastoma. Journal of Neuro-Oncology 2017;133(3):623-31.

\section{Fischer 1985 \{published data only\}}

Fischer SP, Lindermuth J, Hash C, Shenkin HA. Levamisole in the treatment of glioblastoma multiforme. Journal of Surgical Oncology 1985;28(3):214-6.

\section{Fulton 1984 \{published data only\}}

Fulton DS, Urtasun RC, Shin KH, Geggie PH, Thomas H, Muller PJ, et al. Misonidazole combined with hyperfractionation in the management of malignant glioma. International Journal of Radiation Oncology, Biology, Physics 1984;10(9):1709-12.

\section{Gaber 2013 \{published data only\}}

Gaber M, Selim H, El-Nahas T. Prospective study evaluating the radiosensitizing effect of reduced doses of temozolomide in the treatment of Egyptian patients with glioblastoma multiforme CNO - CN-00915672. Cancer Management and Research 2013;5(1):349-56.

\section{Gilbert 2013 \{published data only\}}

Gilbert R, Wang M, Aldape KD, Stupp R, Hegi ME, Jaeckle KA, et al. Dose-dense temozolomide for newly diagnosed glioblastoma: a randomized phase III clinical trial CNO CN-00960255. Journal of Clinical Oncology 2013;31(32):4085-91.

Glinski 1993 \{published data only\}

Glinski B. Postoperative hypofractionated radiotherapy versus conventionally fractionated radiotherapy in malignant gliomas. A preliminary report on a randomized trial. Journal of NeuroOncology 1993;16:167-72. 


\section{Grossman 2003 \{published data only\}}

Grossman SA, O'Neill A, Grunnet M, Mehta M, Pearlman JL, Wagner $\mathrm{H}$, et al. Phase III study comparing three cycles of infusional carmustine and cisplatin followed by radiation therapy with radiation therapy and concurrent carmustine in patients with newly diagnosed supratentorial glioblastoma multiforme: Eastern Cooperative Oncology Group Trial 2394. Journal of Clinical Oncology 2003;21(8):1485-91.

Halperin 1993 \{published data only\}

Halperin EC, Gaspar L, Imperato J, Salter M, Herndon J, Dowling S. An analysis of radiotherapy data from the CNS cancer consortium's randomized prospective trial comparing AZQ to BCNU in the treatment of patients with primary malignant brain tumors. The CNS cancer consortium. American Journal of Clinical Oncology 1993;16(4):277-83.

\section{Halperin 1996 \{published data only\}}

Halperin EC, Herndon J, Schold SC, Brown M, Vick N, Cairncross JG, et al. A phase III randomized prospective trial of external beam radiotherapy, mitomycin C, carmustine, and 6-mercaptopurine for the treatment of adults with anaplastic glioma of the brain. CNS Cancer Consortium. International Journal of Radiation Oncology, Biology, Physics 1996;34(4):793-802.

\section{Harada 1996 \{published data only\}}

Harada K, Kurisu K, Arita K, Sugiyama K, Isobe N, Sadatomo T, et al. A clinical evaluation of two therapies for a malignant glioma: Radiation combined with MCNU and radiation combined with MCNU plus interferon-beta. Japanese Journal of Neurosurgery 1996;5(5):351-6.

\section{Hatlevoll 1985 \{published data only\}}

Hatlevoll R, Lindegaard KF, Hagen S, Kristiansen K, Nesbakken R, Torvik A, et al. Combined modality treatment of operated astrocytomas grade 3 and 4 . A prospective and randomized study of misonidazole and radiotherapy with two different radiation schedules and subsequent CCNU chemotherapy. Stage II of a prospective multicenter trial of the Scandinavian Glioblastoma Study Group. Cancer 1985;56(1):41-7.

\section{Henriksson 2006 \{published data only\}}

Henriksson R, Malmstrom A, Bergstrom P, Bergh G, Trojanowski T, Andreasson L, et al. High-grade astrocytoma treated concomitantly with estramustine and radiotherapy. Journal of Neuro-Oncology 2006;78(8):321-6.

\section{Hiesiger 1995 \{published data only\}}

Hiesiger EM, Green SB, Shapiro WR, Burger PC, Selker RG, Mahaley MS, et al. Results of a randomized trial comparing intra-arterial cisplatin and intravenous PCNU for the treatment of primary brain tumors in adults: Brain Tumor Cooperative Group trial 8420A. Journal of Neuro-Oncology 1985;25(2):143-54.

\section{Hildebrand 1994 \{published data only\}}

Hildebrand J, Sahmoud T, Mignolet F, Brucher JM, Afraa D. Adjuvant therapy with dibromodulcitol and BCNU increases survival of adults with malignant gliomas. EORTC Brain Tumor Group. Neurology 1994;44(9):1479-83.

\section{Hitchon 1999 \{published data only\}}

Hitchon PW, Schneider P, Vangilder JC, Torner JC, Wen BC, Jani SK. Long-term follow-up of brachytherapy in untreated malignant glioma. Journal of Radiosurgery 1999;2(3):129-33.

\section{Hofland 2014 \{published data only\}}

Hofland KF, Hansen S, Sorensen M, Engelholm S, Schultz HP, Muhic A, et al. Neoadjuvant bevacizumab and irinotecan versus bevacizumab and temozolomide followed by concomitant chemoradiotherapy in newly diagnosed glioblastoma multiforme: A randomized phase II study CNO - CN-00995427. Acta Oncologica 2014;53(7):939-44.

Imbesi 2006 \{published data only\}

Imbesi F, Marchioni E, Benericetti E, Zappoli F, Galli A, Corato M, et al. A randomized phase III study: comparison between intravenous and intraarterial ACNU administration in newly diagnosed primary glioblastomas. Anticancer Research 2006;26(1B):553-8.

Iwadate 1993 \{published data only\}

Iwadate Y, Namba H, Saegusa T, Sueyoshi K. Intra-arterial mannitol infusion in the chemotherapy for malignant brain tumors. Journal of Neuro-Oncology 1993;15(2):185-93.

\section{Jeremic 1999 \{published data only\}}

Jeremic B, Shibamoto Y, Grujicic D, Milicic B, Stojanovic M, Nickolic N, et al. Short-course radiotherapy in elderly and frail patients with glioblastoma multiforme. A phase II study. Journal of Neuro-Oncology 1999;44:85-90.

\section{Karacetin 2011 \{published data only\}}

Karacetin D, Okten B, Yalcin B, Incekara O. Concomitant temozolomide and radiotherapy versus radiotherapy alone for treatment of newly diagnosed glioblastoma multiforme CNO CN-00887888. Journal of BUON 2011;16(1):133-7.

\section{Kim 2011 \{published data only\}}

Kim IH, Park CK, Heo DS, Kim CY, Rhee CH, Nam DH, et al. Radiotherapy followed by adjuvant temozolomide with or without neoadjuvant ACNU-CDDP chemotherapy in newly diagnosed glioblastomas: a prospective randomized controlled multicenter phase III trial. Journal of Neuro-Oncology 2011;103(3):595-602.

\section{Knerich 1990 \{published data only\}}

Knerich R, Adinolfi D, Giunta F, Buoncristiani P, Gaetani P, Assietti $R$, et al. Single versus multiple drug therapy in the combined treatment of malignant gliomas. A multicenter study. Journal of Neurosurgical Sciences 1990;34(3-4):251-5.

\section{Koc 2008 \{published data only\}}

Koc K, Anik I, Cabuk B, Ceylan S. Fluorescein sodium-guided surgery in glioblastoma multiforme: a prospective evaluation. British Journal of Neurosurgery 2008;22(1):99-103.

\section{Kocher 2008 \{published data only\}}

Kocher M, Frommolt P, Borberg SK, Ruhl U, Steingraber M, Niewald M, et al. Randomized study of postoperative radiotherapy and simultaneous temozolomide without 
adjuvant chemotherapy for glioblastoma. Strahlentherapie und Onkologie 2008;184(11):572-9.

\section{Kochii 2000 \{published data only\}}

Kochii M, Kitamura I, Goto T, Nishi T, Takeshima H, Saito Y, et al. Randomized comparison of intra-arterial versus intravenous infusion of ACNU for newly diagnosed patients with glioblastoma. Journal of Neuro-Oncology 2000;49(1):63-70.

\section{Kong 2017 \{published data only\}}

Kong DS, Nam DH, Kang SH, Lee JW, Chang JH, Kim JH, et al. Phase III randomized trial of autologous cytokine-induced killer cell immunotherapy for newly diagnosed glioblastoma in Korea. Oncotarget 2017;8(4):7003-13.

\section{Lamers 2008 \{published data only\}}

Lamers LM, Stupp R, van den Bent MJ, Al MJ, Gorlia T, Wasserfallen JB, et al. Cost-effectiveness of temozolomide for the treatment of newly diagnosed glioblastoma multiforme: a report from the EORTC 26981/22981 NCl-C CE3 Intergroup Study. Cancer 2008;112(6):1337-44.

\section{Lanzetta 2003 \{published data only\}}

Lanzetta G, Campanella C, Rozzi A, Nappa M, Costa A, Fedele F, et al. Temozolamide in radio-chemotherapy combined treatment for newly-diagnosed glioblastoma multiforme: phase II clinical trial. Anticancer Research 2003;23(6D):5159-64.

\section{Lee 2015 \{published data only\}}

Lee EQ, Kaley TJ, Duda DG, Schiff D, Lassman AB, Wong ET, et al. A multicenter, phase II, randomized, noncomparative clinical trial of radiation and temozolomide with or without vandetanib in newly diagnosed glioblastoma patients CNO - CN-01161028. Clinical Cancer Research 2015;21(16):3610-8.

\section{Lenartz 2000 \{published data only\}}

Lenartz D, Dott U, Menzel J, Schierholz JM, Beuth J. Survival of glioma patients after complementary treatment with galactoside-specific lectin from mistletoe. Anticancer Research 2000;20(3B):2073-6.

\section{Levin 1979 \{published data only\}}

Levin VA, Wilson CB, Davis R, Wara WM, Pischer TL, Irwin L. A phase III comparison of BCNU, hydroxyurea, and radiation therapy to $\mathrm{BCNU}$ and radiation therapy for treatment of primary malignant gliomas. Journal of Neurosurgery 1979;51(4):526-32.

\section{Levin 2000 \{published data only\}}

Levin VA, Uhm JH, Jaeckle KA, Choucair A, Flynn PJ, Yung WK, et al. Phase III randomized study of postradiotherapy chemotherapy with alpha-difluoromethylornithineprocarbazine, N-(2-chloroethyl)-N'-cyclohexyl-N-nitrosurea, vincristine (DFMO-PCV) versus PCV for glioblastoma multiforme. Clinical Cancer Research 2000;6(10):3878-84.

\section{Levin 2006 \{published data only\}}

Levin VA, Phuphanich S, Yung WK, Forsyth PA, Maestro RD, Perry JR, et al. Randomized, double-blind, placebo-controlled trial of marimastat in glioblastoma multiforme patients following surgery and irradiation. Journal of Neuro-Oncology 2006;78(3):295-302

\section{Lissoni 1993 \{published data only\}}

Lissoni P, Meregalli S, Fossati V, Barni S, Tancini G, Barigozzi P, et al. Radioendocrine therapy of brain tumors with the long acting opioid antagonist naltrexone in association with radiotherapy. Tumori 1993;79(3):198-201.

\section{Lorimer 2016 \{published data only\}}

Lorimer C, Chalmers A, Saran F, Brock J. Glioblastoma in the older person - how do we predict those who will benefit from treatment?. Neuro-Oncology. 2016 Conference proceedings of the British Society of Neuro-Oncology. 2017; Vol. 19, Suppl_1:i27.

\section{Ludgate 1988 \{published data only\}}

Ludgate CM, Douglas BG, Dixon PF, Steinbok P, Jackson SM, Goodman GB. Superfractionated radiotherapy in grade III, IV intracranial gliomas. International Journal of Radiation Oncology, Biology, Physics 1988;15(5):1091-5.

\section{Mallick 2018 \{published data only\}}

Mallick S, Kunhiparambath H, Gupta S, Benson R, Sharma S, Laviraj MA, et al. Hypofractionated accelerated radiotherapy (HART) with concurrent and adjuvant temozolomide in newly diagnosed glioblastoma: a phase II randomized trial (HART-GBM trial). Journal of Neuro-Oncology 2018;140(1):75-82.

\section{Mao 2015 \{published data only\}}

Mao Y, Yao Y, Zhang LW, Lu YC, Chen ZP, Zhang JM, et al. Does early postsurgical temozolomide plus concomitant radiochemotherapy regimen have any benefit in newlydiagnosed glioblastoma patients? A multi-center, randomized, parallel, open-label, Phase II Clinical Trial. Chinese medical journal EMT 2015;128(20):2751-8.

\section{Marshall 2006 \{published data only\}}

Marshall NE, Ballman KV, Michalak JC, Schomberg PJ, Burton GV, Sandler HM, et al. Ototoxicity of cisplatin plus standard radiation therapy vs. accelerated radiation therapy in glioblastoma patients. Journal of Neuro-Oncology EMT 2006;77(3):315-20

\section{McCarthy 2017 \{published data only\}}

McCarthy DJ, Komotar RJ, Starke RM, Sander Connolly E. Randomized trial for short-term radiation therapy with temozolomide in elderly patients with glioblastoma CNO CN-01457599. Clinical Neurosurgery 2017;81(3):N21-3.

\section{Montemor 2008 \{published data only\}}

Montemor JP, Peria FM, Monti CR, Petrilli LS, Colli BO, Carlotti CG Jr. Concurrent chemoradiotherapy with weekly paclitaxel in malignant cerebral glioma treatment. Onkologie 2008;31(8-9):435-9.

\section{MRC 1983 \{published data only\}}

No authors listed. A study of the effect of misonidazole in conjunction with radiotherapy for the treatment of grades 3 and 4 astrocytomas. A report from the MRC Working Party on misonidazole in gliomas. British Journal of Radiology 1983;56(669):673-82 


\section{Muragaki 2017 \{published data only\}}

Muragaki Y, Maruyama T, Ishikawa E, Nitta M, Ikuta S, Yamamoto T, et al. Randomized placebo-controlled trial of autologous formalin-fixed tumor vaccine for newly diagnosed glioblastoma. Neuro-Oncology. Conference: 5th quadrennial meeting of the world federation of neuro-oncology societies, WFNOS. Switzerland. 2017; Vol. 19:iii20.

\section{Nabors 2015 \{published data only\}}

Nabors LB, Fink KL, Mikkelsen T, Grujicic D, Tarnawski R, $\mathrm{Nam} \mathrm{DH}$, et al. Two cilengitide regimens in combination with standard treatment for patients with newly diagnosed glioblastoma and unmethylated MGMT gene promoter: results of the open-label, controlled, randomized phase II CORE study. Journal of Neuro-Oncology 2015;17(5):708-17.

\section{Napolitano 1999 \{published data only\}}

Napolitano M, Keime-Guibert F, Monjour A, Lafitte C, Ameri A, Cornu $P$, et al. Treatment of supratentorial glioblastoma multiforme with radiotherapy and a combination of BCNU and tamoxifen: a phase II study. Journal of Neuro-Oncology 1999;45(3):229-35.

\section{Nelson 1988 \{published data only\}}

Nelson DF, Diener-West M, Horton J, Chang CH, Schoenfeld D, Nelson JS. Combined modality approach to treatment of malignant gliomas - re-evaluation of RTOG 7401/ECOG 1374 with long-term follow-up: a joint study of the Radiation Therapy Oncology Group and the Eastern Cooperative Oncology Group. $\mathrm{NCl}$ monographs: a publication of the National Cancer Institute 1988 , issue 6:279-84.

\section{Payne 1982 \{published data only\}}

Payne DG, Simpson WJ, Keen C, Platts ME. Malignant astrocytoma: hyperfractionated and standard radiotherapy with chemotherapy in a randomized prospective clinical trial. Cancer EMT 1982;50(11):2301-6.

\section{Peszynski 1988 \{published data only\}}

Peszynski J, Trojanowski T, Bielawski A, Leszczyk C, Goscinski I, Skołyszewski J, et al. Analysis of the results of combined treatment of poorly differentiated brain gliomas. Neurologia $i$ Neurochirurgia Polska 1988;22(3):221-7.

\section{Phillips 2003 \{published data only\}}

Phillips C, Guiney M, Smith J, Hughes P, Narayan K, Quong G. A randomized trial comparing $35 \mathrm{~Gy}$ in ten fractions with 60Gy in 30 fractions of cerebral irradiation for glioblastoma multiforme and older patients with anaplastic astrocytoma. Radiotherapy and oncology EMT 2003;68(1):23-6.

\section{Pinzi 2017 \{published data only\}}

Pinzi V. Postoperative chemoradiotherapy for elderly patients with glioblastoma: worsening frailty or increasing survival? Translational Cancer Research 2017;6(Supplement 6):S973S975.

\section{Prados 2001 \{published data only\}}

Prados MD, Wara WM, Sneed PK, McDermott M, Chang SM, Rabbitt J, et al. Phase III trial of accelerated hyperfractionation with or without difluromethylornithine (DFMO) versus standard fractionated radiotherapy with or without DFMO for newly diagnosed patients with glioblastoma multiforme. International Journal of Radiation Oncology, Biology, Physics 2001;49(1):71-7.

Reagan 1976 \{published data only\}

Reagan TJ, Bisel HF, Childs DS, Layton DD, Rhoton AL, Taylor WF. Controlled study of CCNU and radiation therapy in malignant astrocytoma. Journal of Neurosurgery 1976;44(2):186-90.

Reyes-Botero 2018 \{published data only\}

Reyes-Botero G, Cartalat-Carel S, Chinot OL, Barrie M, Taillandier L, Beauchesne P, et al. Temozolomide plus bevacizumab in elderly patients with newly diagnosed glioblastoma and poor performance status: an ANOCEF Phase II trial (ATAG). Oncologist 2018;23(5):524-e44.

Shapiro 1976 \{published data only\}

Shapiro WR, Young DF. Treatment of malignant glioma. A controlled study of chemotherapy and irradiation. Archives of Neurology 1976;33(7):494-50.

\section{Shapiro 1989 \{published data only\}}

Shapiro WR, Green SB, Burger PC, Mahaley MS Jr, Selker RG, VanGilder JC, et al. Randomized trial of three chemotherapy regimens and two radiotherapy regimens in postoperative treatment of malignant glioma. Journal of Neurosurgery 1989;71(1):1-9.

\section{Shapiro 1992 \{published data only\}}

Shapiro WR, Green SB, Burger PC, Selker RG, VanGilder JC, Robertson JT, et al. A randomized comparison of intra-arterial versus intravenous BCNU, with or without intravenous 5fluorouracil, for newly diagnosed patients with malignant glioma. Journal of Neurosurgery 1992;76(5):772-81.

\section{Sharma 2003 \{published data only\}}

Sharma RR, Singh DP, Pathak A, Khandelwal N, Sehgal CM, Kapoor R, et al. Local control of high-grade gliomas with limited volume irradiation versus whole brain irradiation. Neurology India 2003;51(4):512-7.

\section{Simpson 1976 \{published data only\}}

Simpson WJ, Platts ME. Fractionation study in the treatment of glioblastoma multiforme. International Journal of Radiation Oncology, Biology, Physics 1976;1(7-8):639-44.

\section{Sneed 1998 \{published data only\}}

Sneed PK, Stauffer PR, McDermott MW, Diederich CJ, Lamborn KR, Prados MD, et al. Survival benefit of hyperthermia in a prospective randomized trial of brachytherapy boost +/- hyperthermia for glioblastoma multiforme. International Journal of Radiation Oncology, Biology, Physics 1998;40(2):287-95

\section{Socha 2016 \{published data only\}}

Socha J, Kepka L, Ghosh S, Roa W, Kumar N, Sinaika V, et al. Outcome of treatment of recurrent glioblastoma multiforme in elderly and/or frail patients. Journal of Neuro-Oncology 2016;126(3):493-8. 
Soffietti 2017 \{published data only\}

Soffietti R, Pellerino A, Pace A, Carapella C, Dealis C, Caroli M, et al. Dose-dense temozolomide (TMZ) as initial treatment for high-risk oligodendroglial tumors: long-term results of a phase II AINO (Italian Association of Neuro-Oncology) study. NeuroOncology. Conference Proceedings of the Society of NeuroOncology. 2017; Vol. 19, Issue suppl_6:vi2.

\section{Solero 1979 \{published data only\}}

Solero CL, Monfardini S, Brambilla C, Vaghi A, Valagussa P, Morello G, et al. Controlled study with BCNU vs. CCNU as adjuvant chemotherapy following surgery plus radiotherapy for glioblastoma multiforme. Cancer Clinical Trials 1979;2(1):43-8.

\section{Solomon 2013 \{published data only\}}

Solomon MT, Selva JC, Figueredo J, Vaquer J, Toledo C, Quintanal N, et al. Radiotherapy plus nimotuzumab or placebo in the treatment of high grade glioma patients: results from a randomized, double blind trial. BMC Cancer 2013;13(1):299.

\section{Solth 2018 \{published data only\}}

Solth A, Lee JX, Dobson G, Mukerji N, Varma A, Kane P. [Treating high-grade glioma (HGG) in the elderly: has anything changed]. Neuro-Oncology. Proceedings of the 2018 British NeuroOncology Society meeting. 2018; Vol. 20.

\section{Souhami 2004 \{published data only\}}

Souhami L, Seiferheld W, Brachman D, Podgorsak EB, WernerWasik M, Lustig R, et al. Randomized comparison of stereotactic radiosurgery followed by conventional radiotherapy with carmustine to conventional radiotherapy with carmustine for patients with glioblastoma multiforme: report of Radiation Therapy Oncology Group 93-05 protocol. International Journal of Radiation Oncology, Biology, Physics 2004;60(3):853-60.

\section{Stadler 1984 \{published data only\}}

Stadler B, Karcher KH, Kogelnik HD, Szepesi T. Misonidazole and irradiation in the treatment of high-grade astrocytomas: further report of the Vienna Study Group. International Journal of Radiation Oncology, Biology, Physics 1984;10(9):1713-7.

\section{Stragliotto 2013 \{published data only\}}

Stragliotto G, Rahbar A, Solberg NW, Lilja A, Taher C, Orrego A, et al. Effects of valganciclovir as an add-on therapy in patients with cytomegalovirus-positive glioblastoma: a randomized, double-blind, hypothesis-generating study. International Journal of Cancer 2013;133(5):1204-13.

\section{Stummer 2006 \{published data only\}}

Stummer W, Pichlmeier U, Meinel T, Wiestler OD, Zanella F, Roulen HJ, ALA-Glioma Study Group. Fluorescence-guided surgery with 5-aminolevulinic acid for resection of malignant glioma: a randomised controlled multicentre phase III trial. Lancet. Oncology 2006;7(5):392-401.

\section{Stummer 2011 \{published data only\}}

Stummer W, Tonn JC, Mehdorn HM, Nestler U, Franz K, Goetz $C$, et al. Counterbalancing risks and gains from extended resections in malignant glioma surgery: a supplemental analysis from the randomized 5-aminolevulinic acid glioma resection study. Clinical article. Journal of Neurosurgery 2011;114(3):613-23.

Stummer 2017 \{published data only\}

Stummer W, Stepp H, Wiestler OD, Pichlmeier U. Randomized, prospective double-blinded study comparing 3 different doses of 5-aminolevulinic acid for fluorescence-guided resections of malignant gliomas. Clinical Neurosurgery 2017;81(2):230-9.

Stupp 2002 \{published data only\}

Stupp R, Dietrich PY, Ostermann Kraljevic S, Pica A, Maillard I, Maeder $P$, et al. Promising survival for patients with newly diagnosed glioblastoma multiforme treated with concomitant radiation plus temozolamide followed by adjuvant temozolamdide. Journal of Clinical Oncology 2002;20(5):1375-82.

\section{Stupp 2005 \{published data only\}}

Stupp R, Mason WP, Van Den Bent MJ, Weller M, Fisher B, Taphoorn MJ, et al. Radiotherapy plus concomitant and adjuvant temozolomide for glioblastoma. New England Journal of Medicine 2005;352(10):987-96.

\section{Stupp 2009 \{published data only\}}

Stupp R, Hegi ME, Mason WP, van den Bent MJ, Taphoorn MJ, Janzer RC, et al. Effects of radiotherapy with concomitant and adjuvant temozolomide versus radiotherapy alone on survival in glioblastoma in a randomised phase III study: 5-year analysis of the EORTC-NCIC trial. Lancet. Oncology 2009;10(5):459-66.

\section{Stupp 2014 \{published data only\}}

Stupp R, Hegi ME, Gorlia T, Erridge SC, Perry J, Hong YK, et al. Cilengitide combined with standard treatment for patients with newly diagnosed glioblastoma with methylated MGMT promoter (CENTRIC EORTC 26071-22072 study): a multicentre, randomised, open-label, phase 3 trial. Lancet. Oncology 2014;15(10):1100-8.

\section{Stupp 2015 \{published data only\}}

Stupp R, Taillibert S, Kanner AA, Kesari S, Steinber DM, Toms SA, et al. Maintenance therapy with tumor-treating fields plus temozolomide vs temozolomide alone for glioblastoma: a randomized clinical trial. JAMA 2015;314(23):2535-43.

\section{Szczepanek 2013 \{published data only\}}

Szczepanek D, Marchel A, Moskała M, Krupa M, Kunert P, Trojanowski T. Efficacy of concomitant and adjuvant temozolomide in glioblastoma treatment. A multicentre randomized study CNO - CN-00876609. Neurologia $i$ Neurochirurgia Polska 2013;47(2):101-8.

Takakura 1986 \{published data only\}

Takakura K, Abe H, Tanaka R, Kitamura K, Miwa T, Takeuchi K, et al. Effects of ACNU and radiotherapy on malignant glioma. Journal of Neurosurgery 1986;64(1):53-7.

\section{Taphoorn 2005 \{published data only\}}

Taphoorn MJ, Stupp R, Coens C, Osoba D, Kortmann R, van den Bent MJ, et al. Health-related quality of life in patients with glioblastoma: a randomised controlled trial. Lancet 2005;6(12):937-44 
Urtasun 1982 \{published data only\}

Urtasun R, Feldstein ML, Partington J, Tanasichuk H, Miller JD, Russell DB, et al. Radiation and nitroimidazoles in supratentorial high grade gliomas: a second clinical trial. British Journal of Cancer 1982;46(1):101-8.

Ushio 1985 \{published data only\}

Ushio Y, Abe H, Suzuki J, Tanaka R, Kitamura K, Miwa T, et al. Evaluation of ACNU alone and combined with tegafur as additions to radiotherapy of the treatment of malignant gliomas - a co-operative clinical trial. No To Shinkei [Brain and nerve] 1985;37(10):999-1006.

\section{Vellayappan 2017 \{published data only\}}

Vellayappan BA, Halasz LM, Knisely JP, Chang EL, Lo SS. Combined-modality hypofractionated radiotherapy for elderly patients with glioblastoma: setting a new standard. Future science OA 2017;3(3):FSO210.

\section{Wakabayashi 2018 \{published data only\}}

Wakabayashi T, Natsume A, Mizusawa J, Katayama H, Fukuda H, Sumi M, et al. JCOG0911 INTEGRA study: a randomized screening phase II trial of interferonß plus temozolomide in comparison with temozolomide alone for newly diagnosed glioblastoma. Journal of Neuro-oncology 2018;138(3):627-36.

\section{Wang 2008 \{published data only\}}

Wang Q, Wang NY, Sheng HM, Fei YH, Wu D, Shen D. Clinical observation in temozolomide combined with radiotherapy in treatment of postoperative malignant glioma. Chinese Journal of Cancer Prevention and Treatment 2008;15(11):843-5.

\section{Weller 2003 \{published data only\}}

Weller M, Muller B, Koch R, Bamberg M, Krauseneck P, NeuroOncology Working Group of the German Cancer, Society. Neuro-Oncology Working Group 01 trial of nimustine plus teniposide versus nimustine plus cytarabine chemotherapy in addition to involved-field radiotherapy in the first-line treatment of malignant glioma. Journal of Clinical Oncology 2003;21(17):3276-84.

\section{Werner-Wasik 1996 \{published data only\}}

Werner-Wasik M, Scott CB, Nelson DF, Gaspar LE, Murray KJ, Fischbach JA, et al. Final report of a phase I/II trial of hyperfractionated and accelerated hyperfractionated radiation therapy with carmustine for adults with supratentorial malignant gliomas. Radiation Therapy Oncology Group Study 83-02. Cancer 1996;77(8):1535-43.

\section{Westphal 2003 \{published data only\}}

Westphal M, Hilt DC, Bortey E, Delavault R, Olivares R, Warnke PC, et al. A phase 3 trial of local chemotherapy with biodegradeable carmustine (BCNU) wafers (Gliadel ${ }^{\circledR}$ wafers) in patients with primary malignant glioma. Journal of Neurooncology 2003;5(2):79-88.

\section{Westphal 2006 \{published data only\}}

Westphal M, Ram Z, Riddle V, Hilt D, Bortey E, Executive Committee of the Gliadel Study Group. Gliadel ${ }^{\circledR}$ wafer in initial surgery for malignant glioma: long-term follow-up of a multicenter controlled trial CNO - CN-01434084. Acta Neurochirurgica 2006;148(3):269-75.

Westphal 2013 \{published data only\}

Westphal M, Yla-Herttuala S, Martin J, Warnke P, Menei P, Eckland D, et al. Adenovirus-mediated gene therapy with sitimagene ceradenovec followed by intravenous ganciclovir for patients with operable high-grade glioma (ASPECT): a randomised, open-label, phase 3 trial. Lancet. Oncology 2013;14(9):823-33.

\section{Westphal 2015 \{published data only\}}

Westphal M, Heese O, Steinbach JP, Schnell O, Schackert G, Mehdorn $\mathrm{M}$, et al. A randomised, open label phase III trial with nimotuzumab, an anti-epidermal growth factor receptor monoclonal antibody in the treatment of newly diagnosed adult glioblastoma. European Journal of Cancer 2015;51(4):522-32.

\section{Wick 2009 \{published data only\}}

Wick W, Engel C, Combs SE, Nikkhah G, Steinbach J, Kortmann R, et al. NOA-08 randomized phase III trial of 1-weekon/1-week-off temozolomide versus involved-field radiotherapy in elderly (older than age 65) patients with newly diagnosed anaplastic astrocytoma or glioblastoma (Methusalem) [abstract no. LBA2101]. Journal of Clinical Oncology 2010;28(18):949.

\section{Wick 2016 \{published data only\}}

Wick W, Gorlia T, Bady P, Platten M, Van Den Bent MJ, Taphoorn MJ, et al. Phase II study of radiotherapy and temsirolimus versus radiochemotherapy with temozolomide in patients with newly diagnosed glioblastoma without MGMT promoter hypermethylation (EORTC 26082) CNO - CN-01444886. Clinical Cancer Rresearch 2016;22(19):4797-806.

\section{Yang 2018 \{published data only\}}

Yang DY, Bu XY, Zhou ZL, Yan Z, Ma CX, Qu MQ, et al. Enhanced antitumor effects of radiotherapy combined local nimustine delivery rendezvousing with oral temozolomide chemotherapy in glioblastoma patients. Journal of Cancer Research and Therapeutics 2018;14(1):78-83.

\section{Zhu 2017 \{published data only\}}

Zhu JJ, Demireva P, Kanner AA, Pannullo S, Mehdorn M, Avgeropoulos N, et al. Health-related quality of life, cognitive screening, and functional status in a randomized phase III trial (EF-14) of tumor treating fields with temozolomide compared to temozolomide alone in newly diagnosed glioblastoma CNO CN-01418915. Journal of Neuro-oncology 2017;3:545-52.

\section{References to ongoing studies}

NCT01602588 \{published data only\}

${ }^{*}$ NCT. A randomised trial investigating the additional benefit of hydroxychloroquine (HCQ) to short course radiotherapy (SCRT) in patients aged 70 years and older with high grade gliomas (HGG). Https://clinicaltrials.gov/show/nct01602588 2012.

NUTMEG 2018 \{published data only\}

Khasraw M and NUTMEG collaborators. A randomised phase II study of nivolUmab and temozolomide vs temozolomide 
alone in newly diagnosed elderly patients with glioblastoma (NUTMEG). Available at: https://anzctr.org.au/Trial/Registration/ TrialReview.aspx?ACTRN=12617000267358 Accessed 5 July 2019.

Khasraw M, McDonald K, Yip S, Verhaak R, Hemberger A, Hall M, et al. NUTMEG: a randomised phase II study of nivolumab and temozolomide (TMZ) versus TMZ alone in elderly patients with newly diagnosed glioblastoma (GBM): trial in progress. Asiapacific journal of clinical oncology Conference: 45th annual scientific meeting of the clinical oncology society of australia, COSA 2018 Australia 2018;Conference:45th Annual Scientific Meeting of the Clinical Oncology Society of Australia, COSA 2018.

\section{Additional references}

\section{Barraclough 2011}

Barraclough H, Simms L, Govindan R. Biostatistics primer: what a clinician ought to know: hazard ratios. Journal of Thoracic Oncology 2011;6(6):978-82.

\section{Baskar 2014}

Baskar R, Dai J, Wenlong N, Yeo R, Yeoh KW. Biological response of cancer cells to radiation treatment. Frontiers in Molecular Biosciences 2014;1:24.

\section{Bernard Arnoux 2016}

Bernard-Arnoux F, Lamure M, Ducray F, Aulagner G, Honnorat J, Armoiry $X$. The cost-effectiveness of tumor-treating fields therapy in patients with newly diagnosed glioblastoma. NeuroOncology 2016;18(8):1129-36.

\section{Brignardello-Petersen 2018}

Brignardello-Petersen R, Bonner A, Alexander PE, Siemieniuk RA, Furukawa TA, Rochwerg B, et al. Advances in the GRADE approach to rate the certainty in estimates from a network meta-analysis. Epidemiology 2018;98:162.

\section{Brodbelt 2015}

Brodbelt A, Greenberg D, Winters T, Williams M, Vernon S, Collins VP, et al. Glioblastoma in England: 2007-2011. European Journal of Cancer 2015;51(4):533-42.

\section{Chaichana 2011a}

Chaichana KL, Garzon-Muvdi T, Parker S, Weingart JD, Olivi A, Bennett R, et al. Supratentorial glioblastoma multiforme: the role of surgical resection versus biopsy among older patients. Annals of Surgical Oncology 2011;18(1):239-45.

\section{Chaichana 2011b}

Chaichana KL, Chaichana KK, Olivi A, Weingart JD, Bennett R, Brem $\mathrm{H}$, et al. Surgical outcomes for older patients with glioblastoma multiforme: preoperative factors associated with decreased survival. Journal of Neurosurgery 2011;114(3):587-94.

\section{Chaimani 2015}

Chaimani A, Salanti G. Visualizing assumptions and results in network meta-analysis: the network graphs package. Stata Journal 2015;15:4.

\section{Chinot 2014}

Chinot OL, Wick W, Mason W, Henriksson R, Saran F, Nishikawa R, et al. Bevacizumab plus radiotherapytemozolomide for newly diagnosed glioblastoma. New England Journal of Medicine 2014;370(8):709-22.

\section{Cipriani 2013}

Cipriani A, Higgins JP, Geddes JR, Salanti G. Conceptual and technical challenges in network meta-analysis. Annals of Internal Medicine 2013;159(2):130-7.

\section{Cochrane EPOC 2015}

Cochrane Effective Practice, Organisation of Care (EPOC). EPOC resources for review authors. 2015. http://epoc.cochrane.org/ epoc-specific-resources-review-authors. Oslo: Norwegian Knowledge Centre for the Health Services;, (accessed 6 July 2016).

\section{Covidence [Computer program]}

https://www.covidence.org/. Covidence. Version Accessed 21/01/19. https://www.covidence.org/, 2019.

\section{Deeks 2001}

Deeks JJ, Altman DG, Bradburn MJ. Chapter 15: Statistical methods for examining heterogeneity and combining results from several studies in meta-analysis. Systematic Reviews in Health Care: Meta-Analysis in Context. 2nd Edition. London: BMJ Publication Group, 2001.

\section{Dias 2010}

Dias S, Welton NJ, Caldwell DM, Ades AE. Checking consistency in mixed treatment comparison meta-analysis. Statistics in Medicine 2010;29:932-44.

\section{Doble 2016}

Doble B, Lorgelly P. Mapping the EORTC QLQ-C30 onto the EQ-5D-3L: assessing the external validity of existing mapping algorithms. Quality of Life Research 2016;25(4):891-911.

\section{EndNote X8 [Computer program]}

EndNote.com. EndNote X8.2. EndNote.com, 2017.

\section{EPPI Centre Cost Converter 2016}

EPPI-Centre Cost Converter' (v.1.5 last update: 29 April 2016) is a free web-based tool for adjusting estimates of cost expressed in one currency and price year to a specific target currency and price year. https://eppi.ioe.ac.uk/costconversion/ 2016.

\section{Evers 2005}

Evers S, Goossens M, De Vet H, Van Tulder M, Ament A. Criteria list for assessment of methodological quality of economic evaluations: Consensus on Health Economic Criteria. International Journal of Technology Assessment in Health Care 2005;21(2):240-245.

\section{Ferguson 2014}

Ferguson M, Rodrigues G, Cao J, Bauman G. Management of high-grade gliomas in the elderly. Seminars in Radiation Oncology 2014;24(4):279-88. 


\section{Fidarova 2015}

Fidarova E, Ghosh S, Kepka L, Sinaika V, Kumar N, Matiello J, et al. Quality of life in elderly/frail patients with glioblastoma multiforme: results of a randomized phase III study comparing short and standard course of radiotherapy. Supportive Care in Cancer 2015;23:S4.

\section{Gazauskas 2019}

Guzauskas GF, Pollom EL, Stieber VW, Wang BC, Garrison LP. Tumor treating fields and maintenance temozolomide for newly-diagnosed glioblastoma: a cost-effectiveness study. Journal of Medical Economics 2019;22(10):1006-13.

\section{Ghosh 2018}

Ghosh S, Baker S, de Castro DG, Kepka L, Kumar N, Sinaika V, et al. Improved cost-effectiveness of short-course radiotherapy in elderly and/or frail patients with glioblastoma. Radiotherapy and Oncology 2018;127(1):114-20.

\section{GRADEpro 2015 [Computer program]}

McMaster University (developed by Evidence Prime). GRADEpro GDT. Version accessed 21/01/2018. Hamilton (ON): McMaster University (developed by Evidence Prime), 2015.

\section{Guedes de Castro 2017}

Guedes de Castro D, Matiello J, Roa W, Ghosh S, Kepka L, Kumar N, et al. Survival outcomes with short-course radiation therapy in elderly patients with glioblastoma: data from a randomized Phase 3 Trial. International Journal of Radiation Oncology, Biology, Physics 2017;98(4):931-8.

\section{Gállego 2011}

Gallego Pérez-Larraya J, Ducray F, Chinot O, Catry-Thomas I, Taillandier L, Guillamo JS, et al. Temozolomide in elderly patients with newly diagnosed glioblastoma and poor performance status: an ANOCEF phase II trial. Clinical Oncology 2011;29(22):3050-5.

\section{Hamilton 2005}

Hamilton D. Evidence, economics, and emotions: the case for temozolomide. New Zealand Medical Journal 2005;118(1227):U1774.

\section{Henaine 2016}

Henaine AM, Paubel N, Ducray F, Diebold G, Frappaz D, Guyotat J, et al. Current trends in the management of glioblastoma in a French University Hospital and associated direct costs. Journal of Clinical Pharmacy and Therapeutics 2016;41:47-53.

\section{Herrlinger 2016}

Herrlinger U, Schafer N, Steinbach JP, Weyerbrock A, Hau P, Goldbrunner R, et al. Bevacizumab plus irinotecan versus temozolomide in newly diagnosed 06-methylguanineDNA methyltransferase nonmethylated glioblastoma: the randomized GLARIUS Trial CNO - CN-01382982. Journal of Clinical Oncology 2016;34(14):1611-9.

\section{Higgins 2003}

Higgins JP, Thompson SG, Deeks JJ, Altman DG. Measuring inconsistency in meta-analyses. BMJ 2003;327(7414):557-60.

\section{Higgins 2011}

Higgins JP, Green S, editor(s). Cochrane Handbook for Systematic Reviews of Interventions Version 5.1.0 (updated March 2011). The Cochrane Collaboration, 2011. Available from handbook.cochrane.org.

\section{Husereau 2013}

Husereau D, Drummond M, Petrou S, Carswell C, Moher D, Greenberg D, et al. Consolidated Health Economic Evaluation Reporting Standards (CHEERS) - explanation and elaboration: a report of the ISPOR Health Economic Evaluation Publication Guidelines Good Reporting Practices Task Force. Value in Health 2013;16(2):231-50.

\section{Iwamoto 2008}

Iwamoto FM, Reiner AS, Panageas KS, Elkin EB, Abrey LE. Patterns of care in elderly glioblastoma patients. Annals of Neurology 2008;64(6):628-34.

\section{Jansen 2013}

Jansen JP, Naci H. Is network meta-analysis as valid as standard pairwise meta-analysis? It all depends on the distribution of effect modifiers. BMC Medicine 2013;11:epub.

\section{Jiang 2017}

Jiang S, Hill K, Patel D, Waldeck AR, Botteman M, Aly A, et al. Direct medical costs of treatment in newly-diagnosed highgrade glioma among commercially insured US patients. Journal of Medical Economics 2017;20(12):1237-43.

\section{Kebir 2016}

Kebir S, Hattingen E, Schaub C, Schafer N, Steinbach J, Weyerbrock A, et al. Effect of age on outcome in the glarius trial. Journal of Neuro-oncology 2016;18:vi5.

\section{Kim 2012}

Kim SH, Jo MW, Kim HJ, Ahn JH. Mapping EORTC QLQ-C30 onto EQ-5D for the assessment of cancer patients. Health Quality Life Outcomes 2012;10:151.

\section{Kontodimopoulos 2009}

Kontodimopoulos N, Aletras VH, Paliouras D, Niakas D. Mapping the cancer specific EORTC QLQ-C30 to the preferencebased EQ-5D, SF-6D, and 15D instruments. Value Health 2009;12:1151-7.

\section{Kovic 2015}

Kovic B, Xie F. Economic evaluation of bevacizumab for the firstline treatment of newly diagnosed glioblastoma multiforme. Journal of Clinical Oncology 2015;33(20):2296-302.

\section{Laperriere 2013}

Laperriere N, Weller M, Stupp R, Perry JR, Brandes AA, Wick W, et al. Optimal management of elderly patients with glioblastoma. Cancer Treatment Reviews 2013;39(4):350-7.

\section{Lara-Velazquez 2017}

Lara-Velazquez M, Al-Kharboosh R, Jeanneret S, VazquezRamos C, Mahato D, Tavanaiepour D, et al. Advances in brain tumor surgery for glioblastoma in adults. Brain Sciences 2017;7(12):E166. 


\section{Lawrence 2011}

Lawrence YR, Wang M, Dicker AP, Andrews D, Curran WJ Jr, Michalski JM, et al. Early toxicity predicts long-term survival in high-grade glioma. British Journal of Cancer 2011;104(9):1365-71.

\section{Lorimer 2017}

Lorimer CF, Hanna C, Saran F, Chalmers A, Brock J. Challenges to treating older glioblastoma patients: the influence of clinical and tumour characteristics on survival outcomes. Clinical Oncology 2017;29(11):739-47.

\section{Louis 2016}

Louis DN, Perry A, Reifenberger G, von Deimling A, FigarellaBranger D, Cavenee WK, et al. The 2016 World Health Organization Classification of tumors of the central nervous system: a summary. Acta Neuropathologica 2016;131(6):803-20.

\section{MacDonald 1990}

Macdonald DR, Cascino TL, Schold SC, Jr, Cairncross JG. Response criteria for phase II studies of supratentorial malignant glioma. Journal of Clinical Oncology 1990;8:1277-80.

\section{Mason 2014}

Mason W, Cloughesy T, Wick W, Henriksson R, Saran F, Nishikawa R, et al. Overview of arterial thromboembolic events (ATES) in avaglio, a randomized, placebo-controlled phase iii trial of bevacizumab, radiotherapy and temozolomide (BEV+RT/ TMZ) for newly diagnosed glioblastoma. Neurology 2014; Vol. 82 , issue 10 SUPPL. 1.

\section{Mbuagbaw 2017}

Mbuagbaw L, Rochwerg B, Jaeschke R, Heels-Andsell D, Alhazzani W, Thabane L, et al. Approaches to interpreting and choosing the best treatments in network meta-analysis. Systematic Reviews 2017;6:79.

\section{McKenzie 2009}

McKenzie L, van der Pol M. Mapping the EORTC QLQ C-30 onto the EQ-5D instrument: the potential to estimate QALYs without generic preference data. Value Health 2009;12:161-71.

\section{Minniti 2012}

Minniti G, Lanzetta G, Scaringi C, Caporello P, Salvati M, Arcella A, et al. Phase II study of short-course radiotherapy plus concomitant and adjuvant temozolomide in elderly patients with glioblastoma. International Journal of Radiation Oncology, Biology, Physics 2012;83(1):93-9.

\section{Moroney 2017}

Moroney C, Perry JR, Tsang DS, Bilodeau D, Mueller C, Soliman $\mathrm{H}$, et al. Hospitalizations in elderly glioblastoma patients. Annals of Palliative Medicine 2017;6(Suppl 2):S161-9.

\section{Murad 2017}

Murad MH, Mustafa RA, Schünemann HJ, Sultan S, Santesso N. Rating the certainty of the evidence in the absence of a single estimate of effect. Evidence-based Medicine 2017;22(3):85-7.

\section{NCCN 2018}

National Comprehensive Cancer Network. NCCN Guidelines version 1. 2018. Central Nervous System Cancers. www.nccn.org/store/login/login.aspx?ReturnURL=https:// www.nccn.org/professionals/physician_gls/pdf/cns.pdf (accessed 12 April 2018).

\section{NICE 2012}

National Institute for Health and Clinical Excellence. Methods for the development of NICE public health guidance (third edition).. Methods for the development of NICE public health guidance. 3rd Edition. The National Institute for Health and Clinical Excellence, 2012.

\section{NICE 2018}

National Institute for Health and Clinical Excellence. Brain tumours (primary) and brain metastases in adults. www.nice.org.uk/guidance/ng99. NICE, (accessed 08 August 2018).

\section{Niyazi 2016}

Niyazi M, Brada M, Chalmers AJ, Combs SE, Erridge SC, Fiorentino A, et al. ESTRO-ACROP guideline "target delineation of glioblastomas". Radiotherapy and Oncology 2016;118(1):35-42

\section{O'Brien 2002}

O'Brien BJ, Briggs AH. Analysis of uncertainty in health care cost-effectiveness studies: an introduction to statistical issues and methods. Statistical Methods in Medical Research 2002;11(6):455-68.

\section{Oken 1982}

Oken MM, Creech RH, Tormey DC, Horton J, Davis TE, McFadden ET, et al. Toxicity and response criteria of the Eastern Cooperative Oncology Group. American Journal of Clinical Oncology 1982;5:649-55.

\section{Ostrom 2015}

Ostrom QT, Gittleman H, Fulop J, Lui M, Blanda R, Kromer C, et al. CBTRUS statistical report: primary and central nervous system tumors diagnosed in the United States in 2008-2012. Neuro-Oncology 2015;17:iv1-iv62.

\section{Palmer 2018}

Palmer JD, Bhamidipati D, Mehta M, Williams NL, Dicker AP, Werner-Wasik M, et al. Treatment recommendations for elderly patients with newly diagnosed glioblastoma lack worldwide consensus. Journal of Neuro-oncology 2018;140:421-6.

\section{Paszat 2001}

Paszat L, Laperriere N, Groome P, Schulze K, Mackillop W, Holowaty E. A population-based study of glioblastoma multiforme. International Journal of Radiation Oncology, Biology, Physics 2001;51(1):100-7.

\section{Pessina 2018}

Pessina F, Navarria P, Cozzi L, Rudà R, Conti Nibali M, Simonelli M, et al. Is surgical resection useful in elderly newly diagnosed glioblastoma patients? Outcome evaluation 
and prognostic factors assessment. Acta Neurochirurgica 2018;160:1779-87.

\section{Puhan 2014}

Puhan MA, Schünemann HJ, Murad MH, Li T, BrignardelloPetersen R, Singh JA, et al. A GRADE Working Group approach for rating the quality of treatment effect estimates from network meta-analysis. BMJ 2014, 349:g5630. A GRADE Working Group approach for rating the quality of treatment effect estimates from network meta-analysis. BMJ 2014;349:g5630.

\section{Raizer 2015}

Raizer JJ, Fitzner KA, Jacobs DI, Bennett CL, Liebling DB, Luu TH, et al. Economics of malignant gliomas: a critical review. Journal of Oncology Practice 2015;11(1):e59-65.

\section{Ray 2014}

Ray S, Bonafede MM, Mohile NA. Treatment patterns, survival, and healthcare costs of patients with malignant gliomas in a large US commercially insured population. American Health \& Drug Benefits 2014;7(3):140-9.

\section{RevMan 2014 [Computer program]}

Nordic Cochrane Centre, The Cochrane Collaboration. Review Manager 5 (RevMan 5). Version 5.3. Copenhagen: Nordic Cochrane Centre, The Cochrane Collaboration, 2014.

\section{Roussakou 2017}

Roussakow SV. Clinical and economic evaluation of modulated electrohyperthermia concurrent to dose-dense temozolomide $21 / 28$ days regimen in the treatment of recurrent glioblastoma: a retrospective analysis of a two-centre German cohort trial with systematic comparison and effect-to-treatment analysis. BMJ Open 2017;7(11):e017387.

\section{Salanti 2012}

Salanti G. Indirect and mixed-treatment comparison, network, or multiple-treatments meta-analysis: many names, many benefits, many concerns for the next generation evidence synthesis tool. Research Synthesis Methods 2012;3:80-97.

\section{Saran 2016}

Saran F, Chinot OL, Henriksson R, Mason W, Wick W, Cloughesy $T$, et al. Bevacizumab, temozolomide, and radiotherapy for newly diagnosed glioblastoma: comprehensive safety results during and after first-line therapy CNO CN-01414428. Journal of Neuro-oncology 2016;18(7):991-1001.

\section{Schunemann 2009}

Schünemann HJ. GRADE: from grading the evidence to developing recommendations. A description of the system and a proposal regarding the transferability of the results of clinical research to clinical practice [GRADE: Von der Evidenz zur Empfehlung. Beschreibung des Systems und Lösungsbeitrag zur Übertragbarkeit von Studienergebnissen]. Zeitschrift für Evidenz, Fortbildung und Qualität im Gesundheitswesen. PUBMED 2009;103:391-400.

\section{Shemilt 2018}

Shemilt I, Aluko P, Graybill E, Craig D, Henderson C, Drummond M, et al. Chapter 20: Economics evidence. Draft version (13 September 2018). Cochrane Handbook for Systematic Reviews of Interventions. London: Cochrane 2018:1-21.

\section{Sijben 2008}

Sijben AE, McIntyre JB, Roldán GB, Easaw JC, Yan E, Forsyth PA, et al. Toxicity from chemoradiotherapy in older patients with glioblastoma multiforme. Journal of Neuro-oncology 2008;89(1):97-103.

\section{STATA [Computer program]}

www.stata.com. STATA software version 15. www.stata.com, 2017.

\section{Taphoorn 2015}

Taphoorn MJ, Henriksson R, Bottomley A, Cloughesy T, Wick W, Mason WP, et al. Health-related quality of life in a randomized Phase III study of bevacizumab, temozolomide, and radiotherapy in newly diagnosed glioblastoma. Journal of Clinical Oncology 2015;33:2166-75.

\section{Taphoorn 2018}

Taphoorn MJB, Dirven L, Kanner AA, Lavy-Shahaf G, Weinberg U, Taillibert $S$, et al. Influence of treatment with tumor-treating fields on health-related quality of life of patients with newly diagnosed glioblastoma a secondary analysis of a randomized clinical trial. JAMA 2018;4(4):495-504.

\section{Thumma 2012}

Thumma SR, Fairbanks RK, Lamoreaux WT, Mackay AR, Demakas JJ, Cooke BS, et al. Effect of pretreatment clinical factors on overall survival in glioblastoma multiforme: a Surveillance Epidemiology and End Results (SEER) population analysis. World Journal of Surgical Oncology 2012;3(10):75.

\section{Vuorinen 2003}

Vuorinen V, Hinkka S, Färkkilä M, Jääskeläinen J. Debulking or biopsy of malignant glioma in elderly people - a randomised study. Acta Neurochirurgica 2003;145(1):5-10.

\section{Waschke 2018}

Waschke A, Arefian H, Walter J, Hartmann M, Maschmann J, Kalff R. Cost-effectiveness of the long-term use of temozolomide for treating newly diagnosed glioblastoma in Germany. Journal of Neuro-oncology 2018;138(2):359-67.

\section{Wen 2010}

Wen PY, Macdonald DR, Reardon DA, Cloughesy TF, Sorensen AG, Galanis E, et al. Updated response assessment criteria for high-grade gliomas: response assessment in neuro-oncology working group. Journal of Clinical Oncology 2010;28(11):1963-72.

\section{White 2015}

White IR. Network meta-analysis. Stata Journal 2015;15:4.

\section{Whiting 2016}

Whiting P, Savović J, Higgins JP, Caldwell DM, Reeves BC, Shea B, et al. ROBIS: a new tool to assess risk of bias in systematic reviews was developed. Journal of Clinical Epidemiology 2016;69:225-34. 


\section{Wijnen 2016}

Wijnen BF, van Mastrigt GA, Redekop WK, Majoie HJ, De Kinderen RJA, Evers SM. How to prepare a systematic review of economic evaluations for informing evidencebased healthcare decisions: data extraction, risk of bias, and transferability (part 3/3). Expert Review of Pharmacoeconomics \& Outcomes Research 2016;16(6):723-32.

\section{Woodcock 2018}

Woodcock F, Doble B. Mapping the EORTC-QLQ-C30 to the EQ-5D-3L: an assessment of existing and newly developed algorithms. Medical Decision Making 2018;38(8):954-67.

\section{Yepes-Nuñez 2019}

Yepes-Nuñez JJ, Li S, Guyatt G, Jack SM, Brozek JL, Beyene J, et al. Development of the summary of findings table for network meta-analysis. Journal of Clinical Epidemiology 2019;115:1-13. [DOI: 10.1016/j.jclinepi.2019.04.018]

\section{Yin 2014}

Yin AA, Cai S, Dong Y, Zhang LH, Liu BL, Cheng JX, et al. A meta-analysis of temozolomide versus radiotherapy in elderly glioblastoma patients. Journal of Neuro-oncology 2014;116(2):315-24.

\section{Zhang 2012}

Zhang J, Stevens MF, Bradshaw TD. Temozolomide: mechanisms of action, repair and resistance. Current Molecular Pharmacology 2012;5(1):102-14.

\section{References to other published versions of this review Lawrie 2019}

Lawrie TA, Hanna CR, Rogozińska E, Kernohan A, Vale L, Bulbeck $\mathrm{H}$, et al. Treatment of newly diagnosed glioblastoma in the elderly. Cochrane Database of Systematic Reviews 2019, Issue 2. [DOI: 10.1002/14651858.CD013261]

* Indicates the major publication for the study

\section{CHARACTERISTICS OF STUDIES}

Characteristics of included studies [ordered by study ID]

\section{ARTE 2018}

Methods Design: phase II multi-centre, open-label RCT; randomisation in ratio $2: 1$ (Arm A: Arm B) Country: Switzerland

Accrual dates: March 2013 to August 2015

Trial reg: NCT01443676

Funding: Roche Pharma (Basel, Switzerland)

\section{Participants}

No. enrolled: 75

No. analysed: 75

Inclusion criteria: age 65 years or older, newly diagnosed supratentorial glioblastoma, eligible for first infusion of bevacizumab between 28 and 49 days after surgery for glioblastoma, Karnofsky performance score (KPS) of 60 or more, stable or decreasing corticosteroid dose within 5 days before enrolment, availability of paraffin-embedded tissue for central pathology review and determination of O6methylguanine DNA methyltransferase (MGMT) promoter methylation status, and adequate haematological, renal and liver function. An amendment (November 2013) requested the absence of MGMT promoter methylation when it became clear that MGMT promoter methylation predicted larger benefit from TMZ alone than from RT alone in patients with GBM aged 65+.

Age: approx. median 70 years (range 65 - 79, 65 - 87 arm A and arm B)

Gender: $36 \%$ female, $64 \%$ male

Used diagnostic criteria: WHO classification (2007)

Molecular type of GBM: MGMT methylated 21\%, MGMT unmethylated 73\%, missing (5\%) (data for all participants). Note the amendment to alter inclusion criteria based on MGMT promoter methylation status in the first year of trial recruitment.

Performance status: KPS of 60 or more. 
ARTE 2018 (Continued)

Interventions

Arm A: RT was administered to the gross tumour volume plus a $2 \mathrm{~cm}$ margin over 3 weeks, in $15 \mathrm{frac}-$ tions of $2.66 \mathrm{~Gy}$, to a total $40.0 \mathrm{~Gy}$. Bevacizumab was administered intravenously at $10 \mathrm{mg} / \mathrm{kg}$ bodyweight every 2 weeks.

Arm B: RT was administered to the gross tumour volume plus a $2 \mathrm{~cm}$ margin over 3 weeks, in $15 \mathrm{frac}-$ tions of $2.66 \mathrm{~Gy}$, to a total $40.0 \mathrm{~Gy}$.

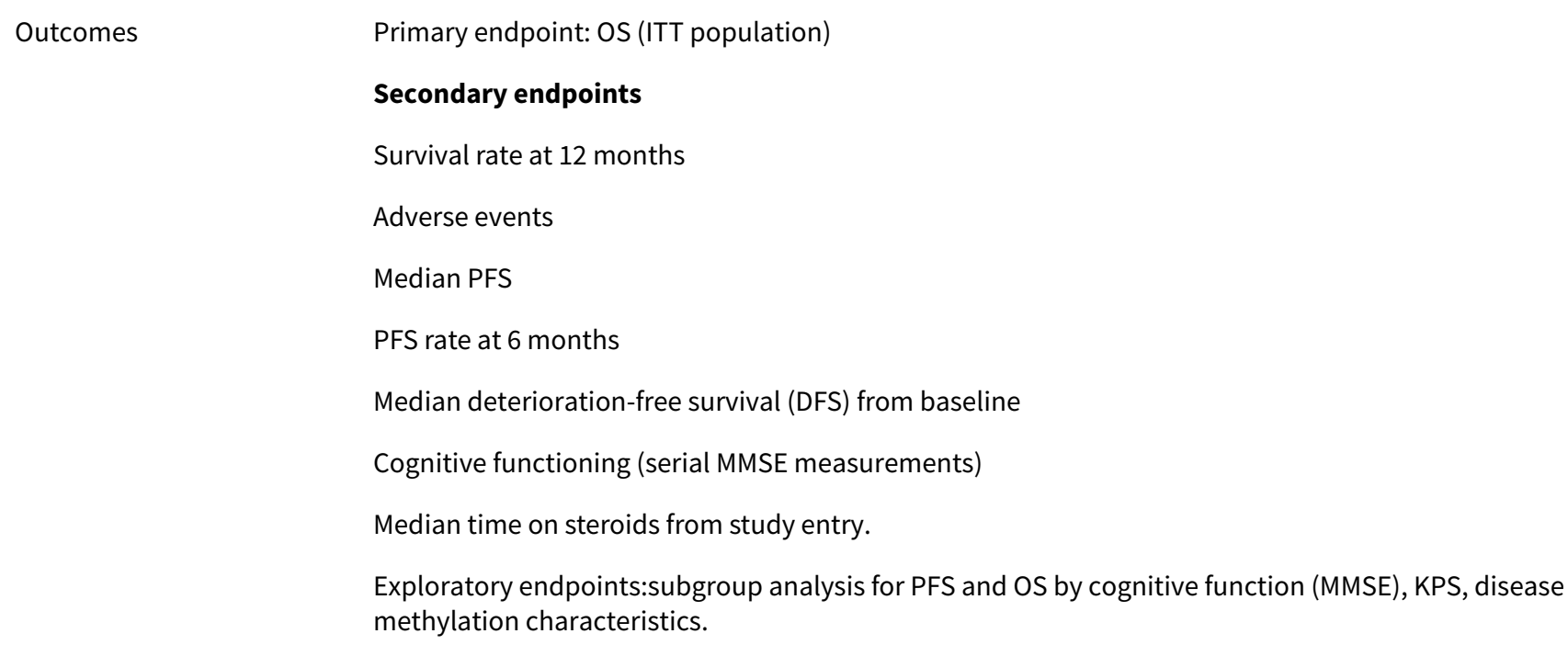
vacizumab with hypofractionated RT prolongs OS in elderly glioblastoma patients.

\section{Risk of bias}

\begin{tabular}{|c|c|c|}
\hline Bias & Authors' judgement & Support for judgement \\
\hline $\begin{array}{l}\text { Random sequence genera- } \\
\text { tion (selection bias) }\end{array}$ & Low risk & $\begin{array}{l}\text { Patients were allocated to treatment arms using a web-based randomisation } \\
\text { system without stratification in a } 2: 1 \text { distribution }\end{array}$ \\
\hline $\begin{array}{l}\text { Allocation concealment } \\
\text { (selection bias) }\end{array}$ & Unclear risk & Not described in the study reports \\
\hline $\begin{array}{l}\text { Blinding of participants } \\
\text { and personnel (perfor- } \\
\text { mance bias) } \\
\text { All outcomes }\end{array}$ & High risk & Open-label \\
\hline $\begin{array}{l}\text { Blinding of outcome as- } \\
\text { sessment (detection bias) } \\
\text { All outcomes }\end{array}$ & Unclear risk & Not described in the study reports \\
\hline $\begin{array}{l}\text { Incomplete outcome data } \\
\text { (attrition bias) } \\
\text { All outcomes }\end{array}$ & Low risk & No patient was lost to follow-up for OS \\
\hline $\begin{array}{l}\text { Selective reporting (re- } \\
\text { porting bias) }\end{array}$ & Low risk & All predefined outcomes were reported. \\
\hline Other bias & Low risk & None noted \\
\hline
\end{tabular}




$\begin{array}{ll}\text { Methods } & \text { Design: phase III RCT } \\ \text { Country: multi-country } \\ \text { Accrual dates: June } 2009 \text { through March 29, } 2011 \\ \text { Trail reg: NCT00943826 } \\ \text { Funding: F. Hoffmann-La Roche }\end{array}$

Participants

No. enrolled: $921(70+, \mathrm{N}=73)$

No. analysed: $921(70+, \mathrm{N}=73)$

Inclusion/exclusion criteria: 18 years of age or older with newly diagnosed, histologically confirmed, supratentorial glioblastoma.

Addiional Inclusion criteria: WHO performance status of 2 or lower; the use of stable or decreasing glucocorticoid doses within the 5 days before randomisation; adequate healing of craniotomy or cranial-biopsy site; adequate hematological, hepatic, and renal function; and acceptable blood coagulation levels.

Investigators submitted available tumour tissue blocks for pathological central review and analysis of status with respect to 0-6-methylguanine-DNA MGMT.

Treatment had to be initiated between 29 and 48 days after the most recent surgery.

Exclusion criteria: evidence of recent symptomatic intracranial haemorrhage on MRI, prior chemotherapy or immunotherapy for glioblastoma or low-grade astrocytoma, prior radiotherapy (RT) to the brain, a history of intracranial abscess within 6 months before randomisation, or a serious nonhealing wound.

Age: approx. 57 years (all participants, in subgroup not given)

Gender: $37 \%$ female $63 \%$ male

Molecular type of GBM: MGMT methylated 26\%, MGMT unmethylated 50\%, missing (24\%) (all participants)

Performance status: WHO performance status of 2 or less $0(50 \%), 1$ or $2(50 \%)$

Interventions

Arm 1: patients received concomitant RT ( 60 Gy as 2-Gy fractions 5 days/week) + oral temozolomide (75 $\mathrm{mg}$ per $\mathrm{m} 2$ of body-surface area per day for max. 49 days), in combination with intravenous bevacizumab (10 mg per kg of body weight) every 2 weeks. The last concomitant doses of TMZ and bevacizumab were administered on the day of the last dose of RT.

Arm 2: patients received concomitant RT (60 Gy as 2-Gy fractions 5 days/week) + oral temozolomide (75 mg per $\mathrm{m} 2$ of body-surface area per day for max. 49 days), in combination with intravenous placebo every 2 weeks. The last concomitant doses of TMZ and placebo were administered on the day of the last dose of RT.

The concomitant-therapy phase in both arms was followed by a 28-day treatment break. In the maintenance phase, patients received TMZ ( $150 \mathrm{mg}$ per $\mathrm{m} 2$ per day on days 1 to 5 during the first cycle and $200 \mathrm{mg}$ per $\mathrm{m} 2$ per day during subsequent cycles if unacceptable toxic effects did not develop) + IV bevacizumab (10 mg per kg) or placebo every 2 weeks, for six 4-week cycles. In the monotherapy phase, IV bevacizumab ( $15 \mathrm{mg}$ per kilogram) or placebo was continued every 3 weeks until the disease progressed or unacceptable toxic effects developed.

Outcomes

Co-primary endpoint: investigator assessed PFS and OS at 1 and 2 years from date of randomisation. Survival estimates determined using Kaplan-Meier methods.

Secondary endpoints: PFS assessed by independent review

Safety

HRQoL (QLQ-C30 and BN20) 
AVAglio 2014 (Continued)

Notes
All the data were collected by the sponsor and were analysed by an author employed by the sponsor, who vouched for the accuracy of the data. They summarised that their interpretation of the results is that this trial showed that the combination of bevacizumab with standard RT plus TMZ for the treatment of newly diagnosed glioblastoma did not improve OS but resulted in a 4.4-month improvement in median PFS, with quality of life and functional status maintained; however, there was an increase in adverse events associated with bevacizumab therapy. The authors did not comment on the applicability of the evidence to elderly patients specifically.

\section{Risk of bias}

\begin{tabular}{lll}
\hline Bias & Authors' judgement & Support for judgement \\
\hline $\begin{array}{l}\text { Random sequence genera- } \\
\text { tion (selection bias) }\end{array}$ & Low risk & $\begin{array}{l}\text { Performed centrally with the use of an interactive voice-response system, with } \\
\text { stratification according to study region and recursive partitioning analysis } \\
\text { class }\end{array}$ \\
\hline $\begin{array}{l}\text { Allocation concealment } \\
\text { (selection bias) }\end{array}$ & Unclear risk & Not described in the study reports \\
\hline $\begin{array}{l}\text { Blinding of participants } \\
\text { and personnel (perfor- } \\
\text { mance bias) }\end{array}$ & Low risk & $\begin{array}{l}\text { The study sponsor, study investigators, and patients were unaware of the } \\
\text { study-group assignments. }\end{array}$ \\
\hline $\begin{array}{l}\text { Blinding of outcome as- } \\
\text { sessment (detection bias) }\end{array}$ & Low risk & $\begin{array}{l}\text { In addition to investigator-assessed progression, radiologists at an indepen- } \\
\text { dent review facility analysed all MRI scans. The independent reviewers were } \\
\text { unaware of the study-group assignments, with read-only access to previous re- } \\
\text { views until the final imaging data set was reviewed; at completion of the study, } \\
\text { a review of the entire scan series verified the time of progression on MRI. In a } \\
\text { final independent review, the determination of progression was calculated } \\
\text { with the use of a prespecified algorithm that combined the assessment of the } \\
\text { scans by the independent reviewer with the investigator's neurologic evalua- } \\
\text { tion and assessment of glucocorticoid use. }\end{array}$
\end{tabular}

Incomplete outcome data Low risk ITT analysis

(attrition bias)

All outcomes

Selective reporting (re- Low risk $\quad$ Pre-specified outcomes are reported
porting bias)

Other bias Unclear risk Unblinding of the assignments was allowed at any time for safety reasons

\section{GLARIUS 2016}

\begin{tabular}{ll}
\hline Methods & Design: phase II RCT Randomisation 2:1 \\
Country: Germany \\
Accrual dates: 2009 to 2011 \\
Trial reg: NCT00967331 \\
Funding: Roche \\
\hline
\end{tabular}

Participants

No enrolled: 566 
Inclusion criteria: chemotherapy- and radiotherapy-naive with newly diagnosed GBM; age older than 18 years, unmethylated MGMT (ratio < 0.6)12; adequate healing of craniotomy; KPS of $70 \%$ or greater; stable or decreasing corticosteroids within 5 days before random assignment; and adequate hematological, hepatic, renal, and coagulation function.

Exclusion: stereotactic biopsy only; overt recent haemorrhage on brain magnetic resonance imaging (MRI); significant vascular disease; history of recurrent thromboembolism; evidence of bleeding diathesis or coagulopathy; gastrointestinal fistula or perforation; history of intra-abdominal or intracranial abscess within 6 months; serious non-healing wound, ulcer, or bone fracture; and Gilbert-Meulengrachts disease.

Age: included patients aged over 18 years. Median age was 56 years; 34 were aged 65+.

Gender: 114 (67.1\%) male. 56 (32.9\%) female.

Molecular type of GBM:unmethylated MGMT GBM only. Patients were classified as nmMGMT if the ratio of MGMT to the b-actin reference gene (ACTB) was less than 0.6 .

Performance status: KPS of 70\% or greater. KPS 90-100 (134 (78.8\%)), KPS 70-80 (34 (20\%)), NR (2 $(1.2 \%))$

Interventions

Arm 1: 60 Gy RT + TMZ concomitant and adjuvant. Daily TMZ $(75 \mathrm{mg} / \mathrm{m} 2)$ during RT followed by six courses of TMZ. This arm included an optional predefined cross-over at recurrence: patients could receive second-line BEV+IRI provided by the sponsor.

Arm 2: 60 Gy RT + BEV + IRI. BEV (bevacizumab) $(10 \mathrm{mg} / \mathrm{kg}$ every 2 weeks) during RT followed by maintenance BEV (10 mg/kg every 2 weeks) plus IRI (irinotecan) $(125 \mathrm{mg} / \mathrm{m} 2$ every 2 weeks).

\section{Outcomes}

Primary endpoint: PFS at 6 months (modified ITT population). Estimated using binary proportions, a contingency table and Fisher's exact test for significance.

Secondary endpoints:PFS in months (with HR), 1 year PFS rate, Median OS (with HR) calculated with a proportional Cox regression model 1 and 2 year OS rates, Change in HRQoL parameters over time, Change in KPS over time, change in MMSE over time, safety.

Notes Thirty-four patients were $65+$ years old and these findings were reported in a related conference abstract (Kebir 2016).

The authors concluded quote: "BEV/IRI resulted in a superior PFS-6 rate and median PFS compared with TMZ. However, BEV+IRI did not improve OS, potentially because of the high crossover rate. BEV + IRI did not alter QOL compared with TMZ. BEV/IRI prolonged progression-free survival but OS was similar in both treatment arms. In the Cox model, age emerged as an independent prognostic factor in BEV/IRI treated patients only (Hazard Ratio, 2.72, $p<0.001$ )."

\section{Risk of bias}

\begin{tabular}{lll}
\hline Bias & Authors' judgement & Support for judgement \\
\hline $\begin{array}{l}\text { Random sequence genera- } \\
\text { tion (selection bias) }\end{array}$ & Low risk & $\begin{array}{l}\text { Patients were allocated to treatment arms using a web-based randomisation } \\
\text { system without stratification in a 2:1 distribution }\end{array}$ \\
\hline $\begin{array}{l}\text { Allocation concealment } \\
\text { (selection bias) }\end{array}$ & Low risk & Randomisation performed using a central web-based randomisation system \\
\hline $\begin{array}{l}\text { Blinding of participants } \\
\text { and personnel (perfor- } \\
\text { mance bias) } \\
\text { All outcomes }\end{array}$ & High risk & Open-label \\
\hline
\end{tabular}


GLARIUS 2016 (Continued)

Blinding of outcome as-
sessment (detection bias)

All outcomes

Incomplete outcome data Low risk No patient was lost to follow-up for OS
(attrition bias)
All outcomes

\begin{tabular}{lll}
\hline $\begin{array}{l}\text { Selective reporting (re- } \\
\text { porting bias) }\end{array}$ & Low risk & All predefined outcomes are reported \\
\hline Other bias & High risk & $\begin{array}{l}\text { All patients in this study had MGMT unmethylated GBM, which is associated } \\
\text { with shorter survival time that MGMT-methylated tumours. Therefore, this may } \\
\text { represent bias in the context of this review. }\end{array}$ \\
\hline
\end{tabular}

Green 1983

Design: 4-arm RCT
Country: USA
Accrual dates: January 1976 to April 1978
Trial reg: not given
Funding: National Cancer Institute, National Institute for Health, Department of Health and Human Ser
vices

No. randomised: 609 (overall) $(65+, \mathrm{N}=$ not specified)
No. analysed: 527 (overall) $(65+, \mathrm{N}=107)$
Inclusion criteria: histologically-demonstrated supratentorial malignant glio
years, and absence of major medical illness which could preclude treatment
Exclusion criteria: any antineoplastic therapy prior randomisation, other th
al doses of corticosteroids within certain prescribed limits).
Age: approx. 56 years overall
Gender: $35 \%$ female, $65 \%$ male
Molecular type of GBM: not reported (older study)
Performance status: median Karnofsky performance status at baseline 70

Interventions

Arm 1: carmustine administered IV at a dose of $80 \mathrm{mg} / \mathrm{m} 2 /$ day on 3 successive days every 8 weeks. Dosage was decreased to $60 \mathrm{mg} / \mathrm{m} 2 /$ day for the same indications of toxicity used for BCNU

Arm 2: high dose (400 mg/m2/day) oral methyl-prednisolone in three divided doses for 7 consecutive days without taper. After a 3-week interval, the treatment was repeated and continued in this 1 week on and 3 weeks off cycle.

Arm 3: procarbazine given orally at a total dose of $150 \mathrm{mg} / \mathrm{m} 2 /$ day in three or four divided doses for 28 consecutive days every 8 weeks

Arm 4: BCNU plus high-dose methyl-prednisolone (as in mono arms)

All participants received a total dose pf 6000 rads in 30-35 fractions of 172-200 rads, 5 days/week over 6 to 7 weeks, delivered to the whole brain by parallel opposed ports with megavoltage equipment. 
Green 1983 (Continued)

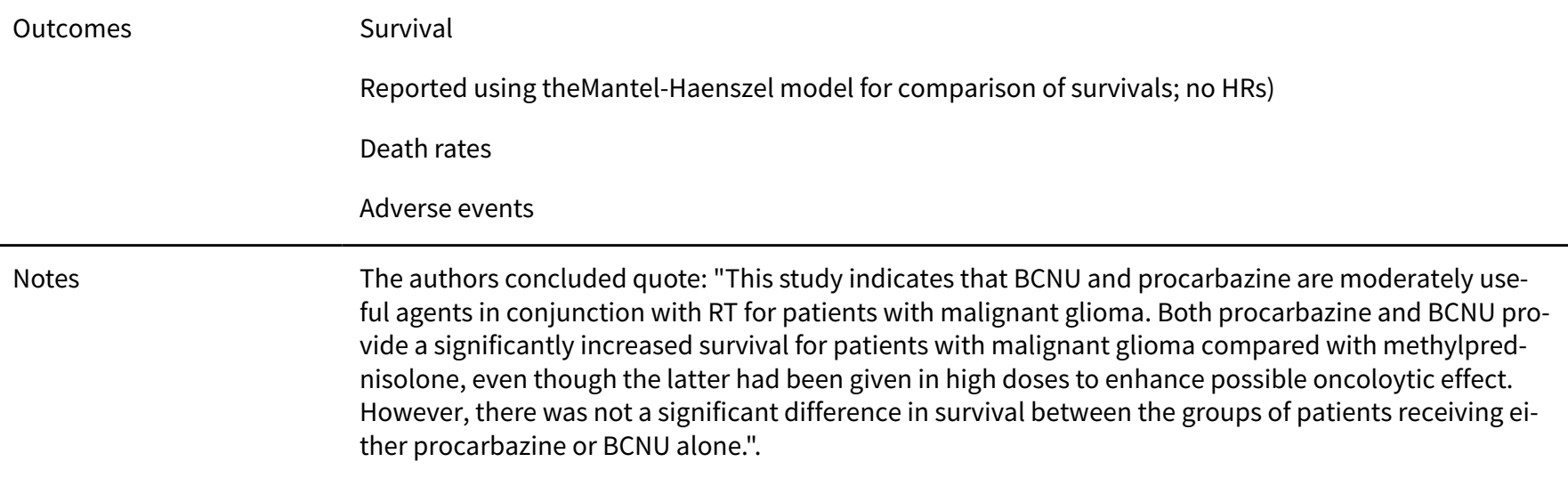

\section{Risk of bias}

\begin{tabular}{|c|c|c|}
\hline Bias & Authors' judgement & Support for judgement \\
\hline $\begin{array}{l}\text { Random sequence genera- } \\
\text { tion (selection bias) }\end{array}$ & Low risk & $\begin{array}{l}\text { Quote: "Patients were randomised to one of the four treatment groups by } \\
\text { means of a telephone call to the BTSG Operations Office." }\end{array}$ \\
\hline $\begin{array}{l}\text { Allocation concealment } \\
\text { (selection bias) }\end{array}$ & Low risk & $\begin{array}{l}\text { Quote:"Patients were randomised to one of the four treatment groups by } \\
\text { means of a telephone call to the BTSG Operations Office." }\end{array}$ \\
\hline $\begin{array}{l}\text { Blinding of participants } \\
\text { and personnel (perfor- } \\
\text { mance bias) } \\
\text { All outcomes }\end{array}$ & High risk & $\begin{array}{l}\text { No specific details given in the primary journal publication but likely to be un- } \\
\text { blinded as some treatments IV and some oral treatments. }\end{array}$ \\
\hline $\begin{array}{l}\text { Blinding of outcome as- } \\
\text { sessment (detection bias) } \\
\text { All outcomes }\end{array}$ & High risk & $\begin{array}{l}\text { Primary endpoint based on survival so that will have a low risk of bias but it } \\
\text { will not be blinded. High risk for adverse events. }\end{array}$ \\
\hline $\begin{array}{l}\text { Incomplete outcome data } \\
\text { (attrition bias) } \\
\text { All outcomes }\end{array}$ & Low risk & $\begin{array}{l}\text { Primary outcomes as specified in the methods were reported for the total ran- } \\
\text { domised population (Other analysis done on the "valid study group" which ex- } \\
\text { cluded } 82 \text { patients would be high risk). }\end{array}$ \\
\hline $\begin{array}{l}\text { Selective reporting (re- } \\
\text { porting bias) }\end{array}$ & Low risk & All predefined outcomes reported \\
\hline Other bias & Unclear risk & $\begin{array}{l}\text { Taken from the text in the paper: "The data in table } 2 \text { suggest heterogeneity } \\
\text { with respect to dose of RT received. However, this could be produced by varia- } \\
\text { tions in the number of patients surviving long enough to receive a full course, } \\
\text { and in fact, the heterogeneity in mean RT dose disappears if calculations are } \\
\text { limited to those patients surviving over } 2 \text { months. The group randomised to } \\
\text { procarbazine received fewer course of chemotherapy than the other groups, } \\
\text { but the heterogeneity (in mean number of courses) among the four treatment } \\
\text { groups was not statistically significant." }\end{array}$ \\
\hline
\end{tabular}

Keime-Guibert 2007

Design: phase III RCT (a triangular sequential design for two-sided alternatives)
Country: France
Accrual dates: Feb 2001 to Jan 2005


Keime-Guibert 2007 (Continued)

\author{
Trial reg: NCT00430911
}

Funding: Research grant Programme Hospitalier de Recherche Clinique.

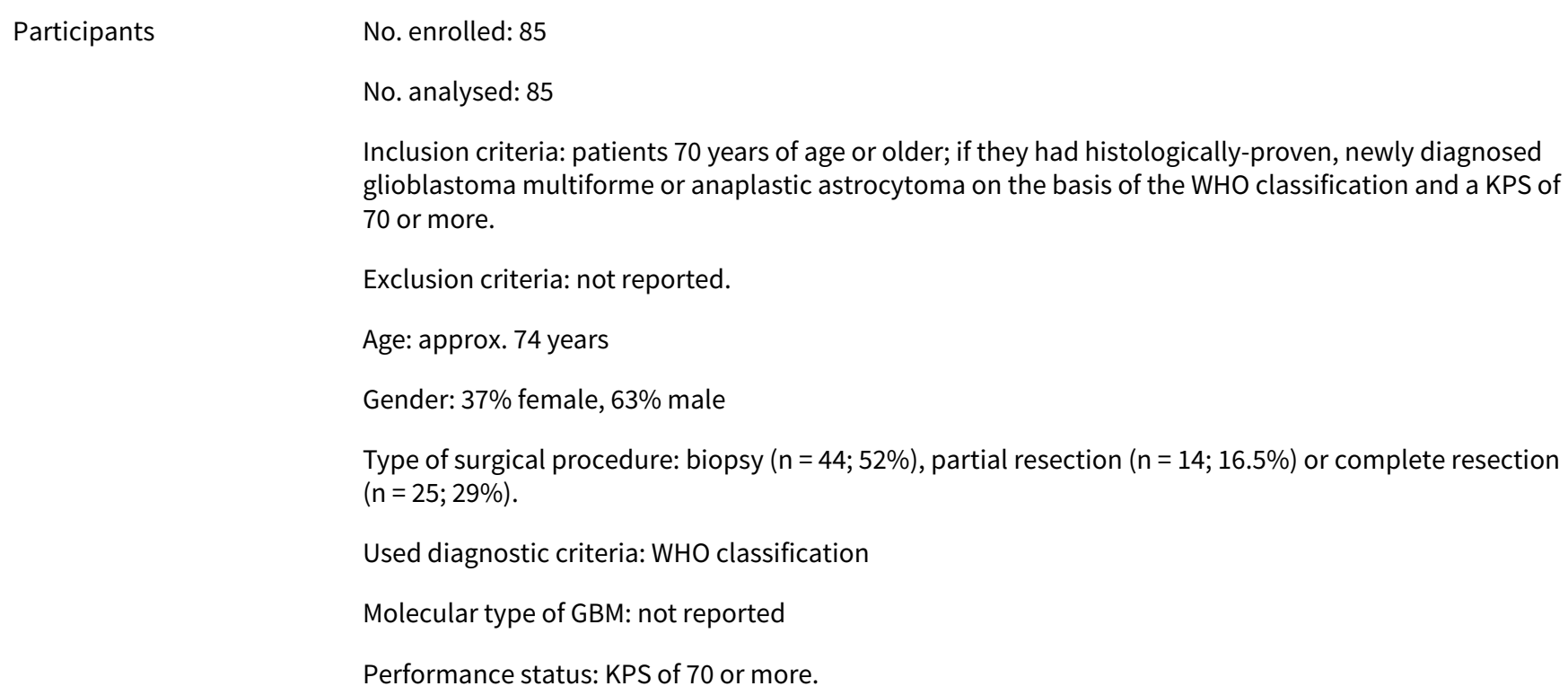

Arm 1: supportive care plus RT (delivered by means of linear accelerators with a nominal energy of 6 $\mathrm{mV}$ or more, consisted of fractionated focal irradiation, at a dose of $1.8 \mathrm{~Gy}$ per fraction, given once daily 5 days per week, for a total dose of $50 \mathrm{~Gy}$. The dose was defined according to the guidelines of the International Commission on Radiation Units and Measurements.

Arm 2: supportive care only; supportive care consisted of treatment with corticosteroids and anticonvulsant agents, physical and psychological support, and management by a palliative care team.

Outcomes Primary endpoint: survival as per ITT population. Median survival for both arms reported with a HR for death using a log-rank test.

Secondary endpoints: PFS; change in performance status (KPS) over time; safety and tolerance of treatment but not clear which tool used to grade toxicity; HRQoL reported using EORTC QLQ-C30 and BN20.

Few patients were alive after the first four follow-up intervals (day 135) therefore HRQoL evaluated at days 1,30,60, 90 and 135 only. HRQoL reported as the change in mean HRQoL scores over time. Global assessment of deterioration over time also reported; cognitive functioning change over time reported using MMSE, Neuro-psychiatric Inventory (NPI) and the Mattis Dementia Rating Scale (MDRS). who have a good performance status at the start of treatment. As compared with supportive care, RT in such patients does not cause further deterioration in the Karnofsky performance status, health-related quality of life, or cognitive functions, but the survival benefit is modest." The trial was discontinued at the first interim analysis, which showed that with a preset boundary of efficacy, RT and supportive care were superior to supportive care alone.

\title{
Risk of bias
}

\begin{tabular}{lll}
\hline Bias & Authors' judgement & Support for judgement \\
\hline $\begin{array}{l}\text { Random sequence genera- } \\
\text { tion (selection bias) }\end{array}$ & Low risk & $\begin{array}{l}\text { Randomisation was performed at the data centre of the Delegation for Clini- } \\
\text { cal Research of the Assistance Publique - Hôpitaux de Paris, and patients were } \\
\text { stratified according to the treatment centre }\end{array}$ \\
\hline
\end{tabular}


Keime-Guibert 2007 (Continued)

$\begin{array}{ll}\begin{array}{l}\text { Allocation concealment Low risk } \\ \text { (selection bias) }\end{array} & \begin{array}{l}\text { Randomisation was performed at the data centre of the Delegation for Clini- } \\ \text { cal Research of the Assistance Publique - Hôpitaux de Paris, and patients were } \\ \text { stratified according to the treatment centre }\end{array}\end{array}$

Blinding of participants $\quad$ High risk $\quad$ None (open-label)
and personnel (perfor-
mance bias)

$\begin{array}{ll}\text { Blinding of outcome as- } & \text { High risk }\end{array}$

All outcomes

\begin{tabular}{ll}
$\begin{array}{l}\text { Incomplete outcome data } \\
\text { (attrition bias) }\end{array}$ & Low risk \\
All outcomes & $\begin{array}{l}\text { Comparisons between the two groups were made on an ITT basis; but low re- } \\
\text { sponse rate on quality of life questionnaires. Therefore, HRQoL was at high risk } \\
\text { for attrition. }\end{array}$ \\
\hline
\end{tabular}

\begin{tabular}{|c|c|c|}
\hline $\begin{array}{l}\text { Selective reporting (re- } \\
\text { porting bias) }\end{array}$ & Low risk & All relevant outcomes were reported \\
\hline Other bias & Unclear risk & $\begin{array}{l}\text { Six patients received } 90 \% \text { or less of the planned radiation dose because of tu- } \\
\text { mour progression (in five patients) and sudden death related to a pulmonary } \\
\text { embolus (in one patient). } \\
\text { One patient who was assigned to the RT group did not receive radiation be- } \\
\text { cause another tumour (duodenal cancer) developed before the start of RT; this } \\
\text { patient received supportive care only }\end{array}$ \\
\hline
\end{tabular}

Malmstrom 2012

Design: phase III RCT
Country: multi-country
Accrual dates: 2 February 2000, and 18 June 2009
Trial reg: NCBTSG (the Nordic)
Funding: Lion's Cancer Research Foundation, University of Umeå (Sweden); Cancer Fonden Sweden,
and an unrestricted grant from Merck. Schering-Plough provided financial support for the study-group
meetings. MDxHealth did the MGMT promoter methylation testing free of charge. In France, Merck pro-
vided temozolomide free of charge.

Participants

\begin{abstract}
No. enrolled: 342, 291 randomised
No. analysed: 291 altogether (123 in 70+ subgroup)

Inclusion criteria: patients with newly diagnosed, histologically confirmed glioblastoma (WHO grade IV astrocytoma) and aged 60 years or older were eligible. To resemble the characteristics of patients seen in clinics, patients with WHO performance scores $0-2$ (even if neurological deficits gave them a performance score of 3) could be included. Patients were required to have adequate haematological levels (neutrophil count $1.5 \times 10^{9} / \mathrm{L}$ or higher, platelets $100 \times 10^{9} / \mathrm{L}$ or higher, and haemoglobin $100 \mathrm{~g} / \mathrm{L}$ or higher), renal (creatinine concentrations in serum less than 1.5 times the upper limit of normal), and liver (bilirubin concentrations in serum less than 1.5 times the upper limit of normal and aspartate amino transferase and alanine aminotransferase no more than three times the upper limit of normal) functions, and were expected by the doctor to tolerate all treatment options.
\end{abstract}

Exclusion criteria: other primary cancers, except radically-treated squamous-cell or basal cell carcinoma of the skin or other curatively treated malignancy without relapse at least 2 years after diagnosis, 
Malmstrom 2012 (Continued)

WHO performance score 3 to 4 (except a score of 3 owing to neurological deficits), any disorder that was likely to interfere with the study treatment, previous therapy for any brain tumour, except surgery or medical treatment within 3 years for other malignant diseases, and previous RT to the head that would prevent further irradiation.

Age: approx. median age for patients in three treatment groups was 70 years (70 years (range 60 to 88 ) in the TMZ, 70 years (60 to 83 ) in the hypofractionated RT, and 70 years (60 to 80) in the standard RT group); the median age for the additional 51 patients randomised only to two treatment groups was 3 years older ( 73 years, range 60 to 83 ).

Gender: $40.7 \%$ female, $59.3 \%$ male

Type of surgical procedure: biopsy $26.7 \%$, resection (partial or complete) $73.3 \%$

Used diagnostic criteria: WHO 2007 criteria

Molecular type of GBM: MGMT methylated 45\%, MGMT unmethylated 55\%, (data for 203 participants)

Performance status (PS): WHO 0-2. (NB. In the results section, there were patients with WHO PS 3 included. The inclusion criteria allowed inclusion of patients with WHO PS 3 if their neurological status specifically gave them a PS of 3).

Interventions

Arm 1: temozolomide ( $200 \mathrm{mg} / \mathrm{m}^{2}$ on days $1-5$ of every 28 days for up to six cycles),

Arm 2: hypofractionated RT (34 Gy administered in 3.4 Gy fractions over 2 weeks)

Arm 3: standard RT (60 Gy administered in 2 Gy fractions over 6 weeks)
Primary endpoint: OS from date of randomisation estimated by the Kaplan-Meier method.

Secondary endpoints: HRQoL (change in mean scores from baseline values for each treatment group at 6 weeks and 3 months); safety

Notes

After 15 October 2004, patients younger than 65 years who were deemed fit to receive combined treatment were excluded, owing to positive results of the European Organisation for Research and Treatment of Cancer (EORTC) trial on concomitant and adjuvant temozolomide and RT for glioblastoma. The age cut-off of 65 years was based on subgroup analyses in that trial, which showed an increase in median survival for patients younger than 65 years who received combined treatment, whereas no such benefit was seen for older patients.

The authors of this trial concluded that quote: "Our findings suggest that temozolomide chemotherapy or hypofractionated RT over 2 weeks might be valid alternative strategies, and that MGMT promoter methylation status might be a useful biomarker to help make treatment decisions."

\section{Risk of bias}

\begin{tabular}{lll}
\hline Bias & Authors' judgement & Support for judgement \\
\hline $\begin{array}{l}\text { Random sequence genera- } \\
\text { tion (selection bias) }\end{array}$ & Low risk & Computer-generated randomisation schedule \\
\hline $\begin{array}{l}\text { Allocation concealment } \\
\text { (selection bias) }\end{array}$ & Unclear risk & $\begin{array}{l}\text { The randomisation lists were generated by computer and were only available } \\
\text { to the Oncology Centre staff. Each time a new patient was to be randomised, } \\
\text { the participating institution sent a randomisation form to the Oncology Centre } \\
\text { by fax, which was returned by fax to the investigator with the relevant treat- } \\
\text { ment information. }\end{array}$ \\
\hline
\end{tabular}

Blinding of participants High risk Patients and study staff were aware of treatment assignment. and personnel (performance bias)

All outcomes 
Malmstrom 2012 (Continued)

Blinding of outcome as- High risk Patients and study staff were aware of treatment assignment. sessment (detection bias) All outcomes

\begin{tabular}{lll}
$\begin{array}{l}\text { Incomplete outcome data } \\
\text { (attrition bias) } \\
\text { All outcomes }\end{array}$ & Unclear risk & $\begin{array}{l}\text { Randomised 342, analysed 291 (85\%); dropouts were balanced between TMZ } \\
\text { and hypofractionated RT; no dropouts in standard RT arm }\end{array}$ \\
\hline $\begin{array}{l}\text { Selective reporting (re- } \\
\text { porting bias) }\end{array}$ & Low risk & All predefined clinical outcomes are reported \\
\hline Other bias & Unclear risk & $\begin{array}{l}\text { Quote: "At the time the study started, common practice included refraining } \\
\text { from standard RT and offering a hypofractionated short course of RT or with- } \\
\text { holding antitumour therapy for patients older than } 60 \text { years who had a poor } \\
\text { outlook. For these reasons, some centres were permitted to randomise pa- } \\
\text { tients to only two of the treatment groups (TMZ or hypofractionated RT) if this } \\
\text { represented their standard of care." }\end{array}$
\end{tabular}

Design: phase III RCT
Country: multi-country
Accrual dates: November 2007 to September 2013
Trial reg: NCT00482677
Funding: supported by grants (015469 and 021039) from the Canadian Cancer Society Research Insti-
tute, by an unrestricted grant from Schering-Plough (now Merck), and by the EORTC Cancer Research
Fund from Belgium.

\section{Participants}

No. enrolled: 562

No. analysed: 562

Inclusion criteria: 65 years of age or older who had newly diagnosed glioblastoma (WHO grade IV astrocytoma), which was histologically confirmed after surgery or biopsy performed less than 28 days before randomisation. Patients were deemed by their physicians not to be suitable to receive conventional RT ( $60 \mathrm{~Gy}$ in 30 fractions over a period of 6 weeks) in combination with TMZ. Eligible patients had an Eastern Cooperative Oncology Group (ECOG) performance status of 0,1 , or 2

Age: approx. median age was 73 years (range, 65 to 90), with $29.5 \%$ of the patients older than 75 years of age

Gender: 39\% female, $61 \%$ male

Type of surgical procedure: $68.3 \%$ of the participants underwent partial or complete surgical resection

Used diagnostic criteria: WHO classification

Molecular type of GBM: MGMT methylated 46.6\%, MGMT unmethylated 53.4\% (data for 354 participants)

Performance status: ECOG 0-2

Interventions

Arm 1: radiation was planned with the use of three-dimensional planning systems for a total dose of $40.05 \mathrm{~Gy}$, administered in 15 daily fractions over a period of 3 weeks 
Arm 2: concomitant temozolomide was administered with RT at a dose of $75 \mathrm{mg}$ per $\mathrm{m} 2$ of body-surface area per day for 21 consecutive days from day 1 until the final day of RT. Adjuvant temozolomide was administered at a dose of 150 to $200 \mathrm{mg}$ perm 2 per day for 5 consecutive days of a 28-day cycle for up to 12 cycles or until disease progression.

Use of antiemetic and infection prophylaxis was at the discretion of the investigator.

\begin{tabular}{ll}
\hline Outcomes & Primary endpoint: OS from date of randomisation \\
& $\begin{array}{l}\text { Secondary endpoints: OS rate at 12, } 18 \text { and } 24 \text { months according to treatment group and MGMT status; } \\
\text { PFS; safety } \\
\text { HRQoL(using QLQ-C30 and QLQ-B20) reported as time to deterioration }\end{array}$ \\
\hline Notes & $\begin{array}{l}\text { Authors concluded that quote; "In elderly patients with glioblastoma, the addition of temozolomide to } \\
\text { short-course radiotherapy resulted in longer survival than short-course radiotherapy alone." }\end{array}$ \\
\hline
\end{tabular}

\section{Risk of bias}

\begin{tabular}{lll}
\hline Bias & Authors' judgement & Support for judgement \\
\hline $\begin{array}{l}\text { Random sequence genera- } \\
\text { tion (selection bias) }\end{array}$ & Low risk & $\begin{array}{l}\text { Treatment assignment was performed centrally with the randomisation al- } \\
\text { gorithm dynamically minimising the chance of an imbalance between trial } \\
\text { groups }\end{array}$ \\
\hline $\begin{array}{l}\text { Allocation concealment } \\
\text { (selection bias) }\end{array}$ & Unclear risk & Treatment assignment was performed centrally \\
\hline $\begin{array}{l}\text { Blinding of participants } \\
\text { and personnel (perfor- } \\
\text { mance bias) } \\
\text { All outcomes }\end{array}$ & High risk & None (open-label) \\
\hline
\end{tabular}

\begin{tabular}{lll}
\hline Blinding of outcome as- & High risk & None (open-label) \\
sessment (detection bias) & \\
All outcomes &
\end{tabular}

\begin{tabular}{ll}
\hline $\begin{array}{l}\text { Incomplete outcome data } \\
\text { (attrition bias) }\end{array}$ & Low risk \\
All outcomes & tion (all randomly assigned patients) for all efficacy end points and the as- \\
& treated population (all patients who received at least one dose of trial treat- \\
& ment) for safety and drug-exposure analyses. However, attrition was a major \\
problem for quality of life data that impacted the quality of these findings.
\end{tabular}

\begin{tabular}{lll}
\hline $\begin{array}{l}\text { Selective reporting (re- } \\
\text { porting bias) }\end{array}$ & Low risk & All predefined outcomes are reported \\
\hline Other bias & Low risk & None noted \\
\hline
\end{tabular}

Roa 2004

Design: phase III RCT
Country: Canada
Accrual dates: between 1996 and 2001
Trial reg: N/A


Roa 2004 (Continued)

Funding: Alberta Cancer

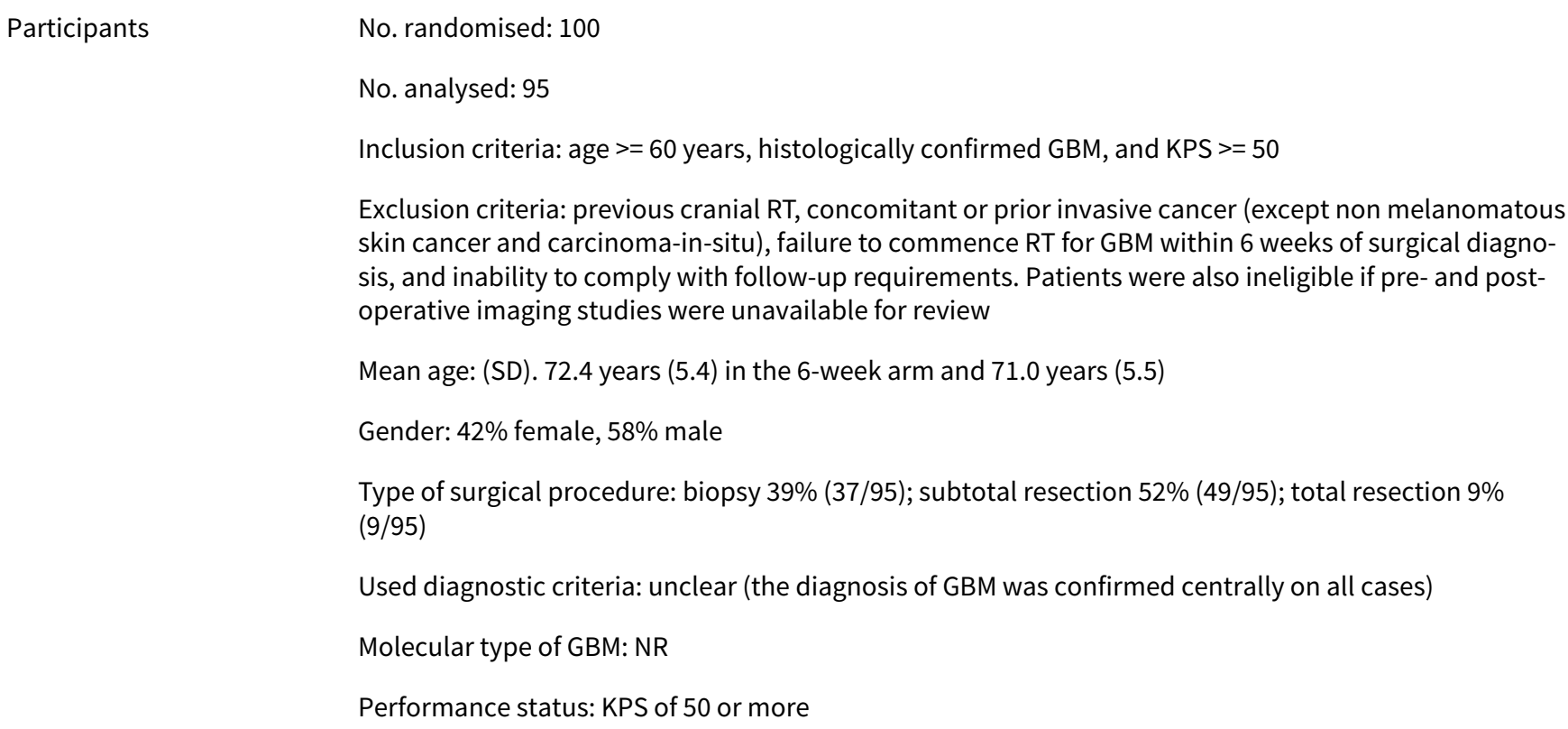

Participants

No. randomised: 100

No. analysed: 95

Inclusion criteria: age $>=60$ years, histologically confirmed GBM, and KPS $>=50$

Exclusion criteria: previous cranial RT, concomitant or prior invasive cancer (except non melanomatous skin cancer and carcinoma-in-situ), failure to commence RT for GBM within 6 weeks of surgical diagnosis, and inability to comply with follow-up requirements. Patients were also ineligible if pre- and postoperative imaging studies were unavailable for review

Mean age: (SD). 72.4 years (5.4) in the 6-week arm and 71.0 years (5.5)

Gender: $42 \%$ female, $58 \%$ male

Type of surgical procedure: biopsy 39\% (37/95); subtotal resection 52\% (49/95); total resection 9\% $(9 / 95)$

Used diagnostic criteria: unclear (the diagnosis of GBM was confirmed centrally on all cases)

Molecular type of GBM: NR

Performance status: KPS of 50 or more

Arm 2: 60Gy in 30 fractions over 6 weeks; patients receiving standard RT were treated in two phases.

RT started within 6 weeks of surgery; the absorbed dose was to be within $10 \%$ of the prescribed dose.

Chemotherapy was not prescribed before or during RT but could be given at the time of disease recurrence

Outcomes

Primary endpoint: OS from date of randomisation. Survival curves generated using Kaplan-Meier method and relative risk calculated using a proportional hazards model.

Secondary endpoints: OS from date of diagnosis; proportion of patients alive at 6 months; HRQoL (KPS and $\mathrm{FACT}-\mathrm{Br} \mathrm{V} 3)$; corticosteroid requirement

Notes

Authors also evaluated post-treatment corticosteroid requirements and found that fewer patients in the short-course arm required an increase in their post-treatment daily dose of corticosteroids ( $23 \%$ versus $49 \%)$.

Authors concluded that quote; "There is no difference in survival between patients receiving standard RT or short-course RT. In view of the similar KPS scores, decreased increment in corticosteroid requirement, and reduced treatment time, the abbreviated course of RT seems to be a reasonable treatment option for older patients with GBM."

\section{Risk of bias}

\begin{tabular}{lll}
\hline Bias & Authors' judgement & Support for judgement \\
\hline $\begin{array}{l}\text { Random sequence genera- } \\
\text { tion (selection bias) }\end{array}$ & Low risk & $\begin{array}{l}\text { An independent statistician at the coordinating centre (Cross Cancer Institute) } \\
\text { produced computer-generated randomisation lists; Patients were stratified by } \\
\text { extent of resection (biopsy versus any degree of resection, as defined by the } \\
\text { operative report) and KPS (<70 v }>=70) .\end{array}$ \\
\hline $\begin{array}{l}\text { Allocation concealment } \\
\text { (selection bias) }\end{array}$ & Low risk & $\begin{array}{l}\text { An independent statistician at the co-ordinating centre (Cross Cancer Insti- } \\
\text { tute) produced computer-generated randomisation lists; Strata-specific, se- } \\
\text { quentially-numbered, sealed opaque envelopes containing the treatment as- } \\
\text { signment were supplied by the statistician to the research nurse at the coordi- }\end{array}$ \\
\hline
\end{tabular}


Roa 2004 (Continued)

nating centre; once patient eligibility had been determined and consent was obtained, participating centres contacted the co-ordinating nurse by fax to request randomisation. The next envelope in the appropriate strata was opened to determine treatment assignment.

\begin{tabular}{lll}
$\begin{array}{l}\text { Blinding of participants } \\
\text { and personnel (perfor- } \\
\text { mance bias) }\end{array}$ & Unclear risk & No details given \\
All outcomes & \\
\hline $\begin{array}{l}\text { Blinding of outcome as- } \\
\text { sessment (detection bias) } \\
\text { All outcomes }\end{array}$ & Unclear risk & No details given \\
\end{tabular}

\begin{tabular}{lll}
\hline $\begin{array}{l}\text { Incomplete outcome data } \\
\text { (attrition bias) } \\
\text { All outcomes }\end{array}$ & Low risk & $\begin{array}{l}\text { Out of } 100 \text { randomised (51 standard RTand 49 shorter course RT) - overall } \\
\text { dropout 5\% (2 withdrawals and 2 deaths standard RT versus 1 withdrawal in } \\
\text { short RT); } 12 \text { versus 5 participants did not complete the treatment }\end{array}$ \\
\hline $\begin{array}{l}\text { Selective reporting (re- } \\
\text { porting bias) }\end{array}$ & Low risk & All predefined outcomes are reported \\
\hline Other bias & Low risk & None noted \\
\hline
\end{tabular}

\section{Roa 2015}

Design: phase III RCT non-inferiority
Country: multi-country
Accrual dates: 2010 and 2013 (from Kepka 2014)
Trial reg: NCT01450449
Funding: supported by the International Atomic Energy Agency (IAEA) under the IAEA Coordinated Re-
search Activities.

\section{Participants}

No. enrolled: $98(65+, N=61)$

No. analysed: $96(65+, N=59)$

Inclusion criteria: frail patients were defined as 50 years old with a KPS of $50 \%$ to $70 \%$; elderly and frail patients were defined as 65 years old with a KPS of $50 \%$ to $70 \%$; and elderly patients were defined as 65 years old with a KPS of $80 \%$ to $100 \%$.

Inclusion criteria: histopathologically-confirmed newly diagnosed GBM (WHO grade 4); initial surgery/ biopsy at diagnosis performed 6 weeks before random assignment; age 50 years at time of entry; KPS $50 \%$; no previous chemotherapy or RT exposure

Exclusion criteria: patients fulfilling either of the following criteria were not eligible for the study: history of other malignancy or history of a serious infection or underlying medical condition

Age: approx. No average; 50 to 65 years 37 (37.8\%), > 6561 (62.2\%)

Gender: $53 \%$ female, $47 \%$ male

Type of surgical procedure: stereotactic biopsy (13.3\%), partial resection (65.3\%), total macroscopic resection $(21.4 \%)$

Used diagnostic criteria: WHO classification

Molecular type of GBM: NR 
Roa 2015 (Continued)

Performance status: KPS of $50 \%$ or more

\begin{tabular}{ll} 
Interventions & Arm 1: short-course RT (25 Gy in five fractions delivered in 1 week) \\
& Arm 2: standard RT (40 Gy in 15 fractions delivered in 3 weeks) \\
\hline Outcomes & OS from date of randomisation calculated using Kaplan-Meier estimates to obtain median survival time \\
& Secondary outcomes: PFS; HRQoL (assessed using QLQ-C30 and QLQ-BN20); Adverse events \\
\hline Notes & $\begin{array}{l}\text { We extracted data on the elderly subgroup from the substudy reported by Guedes de Castro 2017. Au- } \\
\text { thors concluded that quote: "short-course RT regimen of } 25 \text { Gy in } 5 \text { fractions is an acceptable treatment } \\
\text { option for patients aged } 65 \text { years, mainly those with a poor performance status or contraindication to } \\
\text { chemotherapy". Authors planned to report detailed HRQOL data in a separate paper. }\end{array}$
\end{tabular}

\section{Risk of bias}

\begin{tabular}{|c|c|c|}
\hline Bias & Authors' judgement & Support for judgement \\
\hline $\begin{array}{l}\text { Random sequence genera- } \\
\text { tion (selection bias) }\end{array}$ & Low risk & $\begin{array}{l}\text { Random assignment was performed using Excel with the RAND option func- } \\
\text { tion (Microsoft, Redmond, WA). }\end{array}$ \\
\hline $\begin{array}{l}\text { Allocation concealment } \\
\text { (selection bias) }\end{array}$ & Unclear risk & Not given \\
\hline $\begin{array}{l}\text { Blinding of participants } \\
\text { and personnel (perfor- } \\
\text { mance bias) } \\
\text { All outcomes }\end{array}$ & High risk & None (open-label) \\
\hline $\begin{array}{l}\text { Blinding of outcome as- } \\
\text { sessment (detection bias) } \\
\text { All outcomes }\end{array}$ & High risk & None (oen-label) \\
\hline $\begin{array}{l}\text { Incomplete outcome data } \\
\text { (attrition bias) } \\
\text { All outcomes }\end{array}$ & Low risk & Randomised 98 elderly and/or frail, analysed 96 \\
\hline $\begin{array}{l}\text { Selective reporting (re- } \\
\text { porting bias) }\end{array}$ & Low risk & $\begin{array}{l}\text { All predefined outcomes were reported (HRs were calculated from Kaplan } \\
\text { Meier plots) }\end{array}$ \\
\hline Other bias & Low risk & None noted \\
\hline
\end{tabular}

\section{Stupp 2017a}

\begin{tabular}{ll}
\hline Methods & Design: phase III RCT \\
Country: multi-country \\
Accrual dates: July 2009 and December 2014 \\
Trial reg: NCT00916409 \\
Funding: Novocure Ltd. \\
\hline
\end{tabular}



every 28 days for 6 cycles)

Inclusion criteria: aged 18 years or older, had a KPS of 70 or higher (a score of $\geq 70$ ensures independence in activities of daily living), and had newly diagnosed and histologically confirmed supratentorial glioblastoma (WHO grade IV astrocytoma).

Exclusion criteria:pPatients with evidence of progressive disease following radiochemotherapy, infratentorial tumour location, and severe co-morbidities were excluded

Mean age not given for over $65+$, only for the group as a whole (median 56 years, range 19 to 83 in arm 1 and median 57 years, range 19 to 80 in arm 2)

Gender: for the total sample was $68 \%$ male and $32 \%$ female

Used diagnostic criteria: WHO classification

Molecular type of GBM: MGMT methylated 37\%, MGMT unmethylated 53\%, invalid sample (9\%) (data for 571 participants)

Performance status: KPS of 70 or higher

Interventions

Arm 1: tumour treating fields therapy plus maintenance temozolomide after standard chemoradiotherapy (up to 60Gy); delivered through 4 transducer arrays with 9 insulated electrodes each placed on the shaved scalp and connected to a portable device set to generate $200-\mathrm{kHz}$ electric fields within the brain; All treatment was delivered on an outpatient basis and at home.

Arm 2: maintenance temozolomide alone ( 150 to $200 \mathrm{mg} / \mathrm{m} 2 /$ day for 5 days every 28 days for 6 cycles). If tumour progression occurred, second-line therapy was offered per local practice.

Outcomes

Primary endpoint: PFS in ITT population

Secondary endpoint: OS

Exploratory endpoints:

Percentage of patients alive and progression-free at 6 months

Annualised survival rates

HRQoL (QLQ-30 and QLQ-BN20) reported in a separate article (Taphoorn 2018). Mean change in HRQoL from baseline, deterioration free survival (DFS) and time to deterioration (TTD).

MMSE

KPS

Adverse events and tolerability

Notes Prior use of implanted carmustine wafers was allowed and randomisation was after patients had completed chemoradiation. Authors concluded for entire population that quote: "In the final analysis of this randomised clinical trial of patients with glioblastoma who had received standard radiochemotherapy, the addition of tumour treating fields to maintenance TMZ chemotherapy versus maintenance temozolomide alone, resulted in statistically significant improvement in progression-free survival and overall survival."

\section{Risk of bias}

\begin{tabular}{lll}
\hline Bias & Authors' judgement & Support for judgement \\
\hline $\begin{array}{ll}\text { Random sequence genera- } \\
\text { tion (selection bias) }\end{array}$ & Low risk & $\begin{array}{l}\text { Patients were randomised at a ratio of 2:1; performed using a central web- } \\
\text { based randomisation system and was stratified by extent of resection (biop- } \\
\text { sy, partial resection, gross total resection) and by the methylation status of the }\end{array}$ \\
\hline
\end{tabular}




\begin{tabular}{lll}
\hline $\begin{array}{l}\text { Allocation concealment } \\
\text { (selection bias) }\end{array}$ & Low risk & Randomisation performed using a central web-based randomisation system \\
\hline $\begin{array}{l}\text { Blinding of participants } \\
\text { and personnel (perfor- } \\
\text { mance bias) }\end{array}$ & High risk & Open-label \\
All outcomes & \\
\hline
\end{tabular}

$\begin{array}{lll}\begin{array}{l}\text { Blinding of outcome as- } \\ \text { sessment (detection bias) }\end{array} & \text { Low risk } & \text { All MRIs were reviewed by } 2 \text { blinded central independent radiologists (BioClin- } \\ \text { All outcomes } & \text { ica Inc) and were evaluated for tumour response and progression (Macdon- } \\ \text { ald criteria); For cases in which the } 2 \text { reviewers were not in agreement, a third } \\ \text { blinded radiologist adjudicated between them. }\end{array}$

Incomplete outcome data Low risk (attrition bias)

All outcomes

\begin{tabular}{|c|c|c|}
\hline $\begin{array}{l}\text { Selective reporting (re- } \\
\text { porting bias) }\end{array}$ & Low risk & All pre-specified outcomes are reported \\
\hline Other bias & High risk & $\begin{array}{l}\text { In the context of the review, this trial may represent a high risk of bias due to } \\
\text { the timing of randomisation, because patients that die during CRT or have se- } \\
\text { vere early toxicities would have dropped out by the time of randomisation. } \\
\text { Novocure Ltd had a role in the design and conduct of the study, collection, } \\
\text { management, and analysis of the data. After the release of the interim results, } \\
26 \text { patients in the TMZ only arm with favourable prognostic factors and who } \\
\text { had received more cycles of maintenance TMZ crossed over to receive TTF. } \\
\text { These patients were analysed in the group to which they had been randomised } \\
\text { (ITT analysis). The effect of this might have led to an underestimation the im- } \\
\text { pact of the experimental intervention. }\end{array}$ \\
\hline
\end{tabular}

For the main population: ITT for primary outcome, PP for secondary (OS); Overall 53 lost to follow-up ( $7.6 \%)$; $39 / 466$ versus $14 / 229$ (8.4\% versus $6.1 \%$ ) - 9 versus 1 disease progression

Weller 2017

\begin{tabular}{|c|c|}
\hline \multirow[t]{5}{*}{ Methods } & Design: Phase III RCT \\
\hline & Country: multi-country \\
\hline & Accrual dates:12 April 2012, and 15 December 2014 \\
\hline & Trial Reg: NCT01480479 \\
\hline & Funding: Celldex Therapeutics, Inc \\
\hline \multirow[t]{2}{*}{ Participants } & $\begin{array}{l}\text { Inclusion criteria: } 18 \text { years or older with confirmed GBM histology and EGFRvIll expression analysis } \\
\text { by real time (RT) PCR. Patients must have undergone maximal surgical resection and have completed } \\
\text { standard RT (up to } 60 \text { Gy) with concomitant TMZ ( } 75 \mathrm{mg} / \mathrm{m} 2 \text { per day). To be eligible, at least } 90 \% \text { of the } \\
\text { planned RT dose had to be delivered. Patients had to have tumour tissue specimens (paraffin-embed- } \\
\text { ded) from surgical resection available for central pathology review, MGMT status determination, and } \\
\text { analysis of ECFRvIll status. }\end{array}$ \\
\hline & $\begin{array}{l}\text { Exclusion criteria: disease progression during chemoradiation, any additional tumour-specific treat- } \\
\text { ment for GBM, inability to taper corticosteroids to } 2 \mathrm{mg} \text { of dexamethasone or lower (or equivalent) per } \\
\text { day for at least } 3 \text { days before randomisation, ECOG PS of } 3 \text { or higher in the week before randomisation, } \\
\text { diffuse leptomeningeal disease, gliomatosis cerebri, infratentorial disease, active infection, metastatic } \\
\text { disease, and immunosuppressive disease. }\end{array}$ \\
\hline
\end{tabular}


Weller 2017 (Continued)

No. enrolled: $745(65+, N=174)$

No. analysed: $745(65+, N=174)$

Molecular type of GBM: MGMT methylated 34\%, MGMT unmethylated 59\%, missing (7\%) (data for all participants)

Arm 1: rindopepimut plus maintenance TMZ
Arm 2: control plus maintenance TMZ only
All participants received standard chemoradiotherapy before randomisation and had to have received
at least $90 \%$ of the planned RT dose to be eligible for trial inclusion.

Primary endpoint: OS from date of randomisation in patients with newly diagnosed, EGFRvIII positive
GBM and minimal residual disease (MRD) (modified ITTanalysis). OS analysis included HR and sum-
marised using the Kaplan-Meier method.
Secondary endpoints: OS in all patients (ITT), OS in patients with significant residual disease (SRD),
PFS, proportion of patients achieving an objective tumour response (using RANO criteria). Included re-
quirement for corticosteroids.
HRQoL (MDASI-BT, QLQ-C30 and QLQ-BN20), Humoral responses to EGFR vIII, Post-treatment EGFRvIII
expression status. Survival rates at 1,2 and 3 years. Adverse events

Notes Standard RT dose was stated as "up to 60Gy" and standard TMZ dose was $75 \mathrm{mg} / \mathrm{m} 2 \mathrm{per}$ day

\section{Risk of bias}

\begin{tabular}{|c|c|c|}
\hline Bias & Authors' judgement & Support for judgement \\
\hline $\begin{array}{l}\text { Random sequence genera- } \\
\text { tion (selection bias) }\end{array}$ & Low risk & $\begin{array}{l}\text { Patients quote: "were randomly assigned ( } 1: 1) \text { to the treatment groups with a } \\
\text { prespecified randomisations sequence with a block size of four." }\end{array}$ \\
\hline $\begin{array}{l}\text { Allocation concealment } \\
\text { (selection bias) }\end{array}$ & Low risk & $\begin{array}{l}\text { Quote: "Patients, investigators, and the trial funder were masked to treatment } \\
\text { allocation". }\end{array}$ \\
\hline $\begin{array}{l}\text { Blinding of participants } \\
\text { and personnel (perfor- } \\
\text { mance bias) } \\
\text { All outcomes }\end{array}$ & Low risk & $\begin{array}{l}\text { Study treatments were prepared in the pharmacy and given to study staff in } \\
\text { blinded pre-loaded syringes. }\end{array}$ \\
\hline $\begin{array}{l}\text { Blinding of outcome as- } \\
\text { sessment (detection bias) } \\
\text { All outcomes }\end{array}$ & Low risk & $\begin{array}{l}\text { Quote:"The retrospective imaging review committee assessment, masked to } \\
\text { treatment assignment and investigator assessments, was used for the primary } \\
\text { analyses of progression-free survival and objective tumour response. }\end{array}$ \\
\hline $\begin{array}{l}\text { Incomplete outcome data } \\
\text { (attrition bias) } \\
\text { All outcomes }\end{array}$ & Low risk & Low attrition for primary outcome \\
\hline $\begin{array}{l}\text { Selective reporting (re- } \\
\text { porting bias) }\end{array}$ & Unclear risk & HRQoL not yet reported. Will possibly come with a future publication. \\
\hline Other bias & Low risk & None noted. \\
\hline
\end{tabular}

Methods Design: phase III RCT | non-inferiority trial with a 25\% margin


Wick 2012 (Continued)

\section{Country: Germany}

Accrual dates: 15 May 2005 to 2 November 2010 (last randomisation on 2 Nov 2009)

Trial reg: NCT01502241

Funding: Merck, Sharp \& Dohme

\section{Participants}

No. enrolled: 412

No. analysed: 373

Inclusion criteria: de novo histologically confirmed AA or GB and $>65$ years of age, KPS score $>60$, no prior systemic chemotherapy or RT to the brain, and adequate bone marrow reserve, liver, and renal function.

Exclusion criteria: failure to confirm AA or GB would have resulted in exclusion from the ITT population.

Age: approx. 71.5 years

Gender: $53 \%$ female, $47 \%$ male

Type of surgical procedure: resection: complete $28 \%$ partial $30 \%$ biopsy $39 \%$

Used diagnostic criteria: inclusion into the trial was based on local diagnosis. Histological diagnoses were confirmed centrally according to the WHO classifications 2000 and 2007; there was no change in the diagnostic criteria for AA or GB between the two versions of the WHO classification

Molecular type of GBM: MGMT methylated 20\%, MGMT unmethylated 36\%, inconclusive/missing (44\%) (data for all analysed participants)

Performance status: unclear

Interventions

Outcomes

Notes
Arm 1: standard RT (60 Gy in 30 x 2 Gy fractions)

Arm 2: temozolomide (TMZ)a one week on/one week off schedule

The primary endpoint was OS, measured in days from surgery to death. Secondary efficacy end points included event-free survival (EFS), best response, HRQOL (QLQ-C30 and QLQ-BN20 and safety.

Author conclusions: NOA-08 broadens the spectrum of primary treatment of elderly patients with malignant gliomas by demonstrating the non-inferiority of primary treatment of elderly patients with malignant gliomas with TMZ alone. It implements MGMT promoter methylation as a relevant biomarker to decide, when patients may be under-treated with primary RT alone.

\section{Risk of bias}

\begin{tabular}{lll}
\hline Bias & Authors' judgement & Support for judgement \\
\hline $\begin{array}{l}\text { Random sequence genera- } \\
\text { tion (selection bias) }\end{array}$ & Low risk & $\begin{array}{l}\text { Participant allocation was done according to an electronically-generated } \\
\text { randomisation list in blocks of variable length without stratification. The se- } \\
\text { quence was generated prior to study start at the independent Contract Re- } \\
\text { search Organization (CRO), Alcedis (Gießen, Germany). }\end{array}$ \\
\hline $\begin{array}{l}\text { Allocation concealment } \\
\text { (selection bias) }\end{array}$ & Low risk & $\begin{array}{l}\text { Enrolment was done at the study site by an investigator. Assignment was ini- } \\
\text { tiated by FAX transmission from the study site to the CRO for single patients } \\
\text { fulfilling the eligibility criteria. A responsible project manager at the CRO per- } \\
\text { formed the randomisation process and reported the assignment to the trial } \\
\text { group via FAX transmission to the study site. }\end{array}$ \\
\hline
\end{tabular}


Wick 2012 (Continued)
Blinding of participants
High risk
Blinding of investigators or participants was impossible. and personnel (performance bias)

All outcomes

\begin{tabular}{|c|c|c|}
\hline $\begin{array}{l}\text { Blinding of outcome as- } \\
\text { sessment (detection bias) } \\
\text { All outcomes }\end{array}$ & High risk & $\begin{array}{l}\text { Similarly the data had to be analysed with knowledge of the group assign- } \\
\text { ment. Biases were prevented by strict adherence to an analysis plan. }\end{array}$ \\
\hline
\end{tabular}

\begin{tabular}{lll}
\hline $\begin{array}{l}\text { Incomplete outcome data } \\
\text { (attrition bias) } \\
\text { All outcomes }\end{array}$ & High risk & $\begin{array}{l}\text { Overall dropout rate less than 20\% with moderate imbalance between TMZ } \\
\text { and RT with higher dropout in the RT group (5\% versus 14\%) }\end{array}$ \\
\hline $\begin{array}{l}\text { Selective reporting (re- } \\
\text { porting bias) }\end{array}$ & Low risk & Pre-specified outcomes were reported. \\
\hline Other bias & Unclear risk & None noted. \\
\hline
\end{tabular}

BCNU: carmustine; BEV: bevacizumab; DFS: deterioration-free survival; GBM: glioblastoma; HR: hazard ratio; HRQoL: health-related quality of life; IRI: irinotecan; nITT: intention-to-treat; IV: intravenous; kg: kilogram; KPS: Karnofsky performance score; MGMT: methylguanine-DNA-methyltransferase; MMSE: Mini Mental State Exam; MRI: magnetic resonance imaging; OS: overall survival; PFS: progression-free survival; RCT: randomised controlled trial; RT: radiotherapy; SD: standard deviation; TMZ: temozolomide; TTF: tumour treating fields; WHO: World Health Organization.

\section{Characteristics of excluded studies [ordered by study ID]}

\begin{tabular}{ll}
\hline Study & Reason for exclusion \\
\hline Ali 2018 & Ineligible population - no data for the elderly subgroup. This is a recent report of an older trial \\
& (RTOG 9006) with negative findings, for which recruitment occurred from 1990 to 1994. Hyperfrac- \\
tionated RT (72 Gy in 60 twice-daily fractions) was compared with standard RT (60 Gy in 30 daily \\
fractions) for GBM treatment and the authors reported that there was no indication of, or trend to- \\
wards, benefit with hyperfractionated RT for GBM. Although the study included $235 / 694$ people 60 \\
years of age and older, findings for the older subgroup were not reported separately.
\end{tabular}
RTOG 0525 trial (NCT00304031) comparing conventional adjuvant temozolomide (TMZ) with doseintensive TMZ in patients with newly diagnosed glioblastoma on quality of life outcomes. The trial recruited patients age 21 to 84 years. The proportion of patients age 65 or more is unknown and analysis was stratified only by age threshold of 50 years. and radiotherapy in comparison to radiotherapy alone in patients with newly diagnosed glioblastoma multiforme. The trial recruited patients age 18 and more with unknown proportion of elderly patients ( 65 years or more). The age (>50 years) is evaluated as a predictor for time to progression and overall survival - HR 1.75 (P value 0.067 ) and 1.86 (P value 0.058 ), respectively.

\section{Balana 2016}

Ineligible population - no data for the elderly subgroup. This is a report of a phase 2 GENOM 009 trial of bevacizumab (BEV) and TMZ in comparison to TMZ alone as neoadjuvant treatment in patients with unresected glioblastoma. The trial recruited patients age 18 to maximum 75 years. The number of participants available for analysis for progression-free survival, overall survival and toxicity was 93 (45 TMZ and $48 \mathrm{TMZ}+\mathrm{BEV}$ ) with unknown proportion of participants age over 65 or 70 . 


\section{Study Reason for exclusion}

with glioblastoma multiforme. The recruitment occurred between 1986 and 1996. The inclusion age was 18 to maximum of 70 years, thus there was no relevant subgroup of patients in this trial.

Batchelor 2013

Beije 2015

Ineligible population - recurrent glioblastoma. This is a report of a phase 3, placebo-controlled, REGAL trial (NCT00777153) in patients with recurrent glioblastoma.

Ineligible population - recurrent glioblastoma. This is a report of a side study of BELOB trial (NTR1929) in patients with recurrent glioblastoma.

The side study assessed the kinetics of the circulating endothelial calls and their prognostic value.
Ineligible study design. This is a report of a side study of EORTC Brain Tumor Group Study 26951 in participants with anaplastic oligodendroglial tumours or anaplastic oligoastrocytoma. The side study assessed the correlation between MGMT methylation status and outcome and therapy given in EORTC cohort.

Bhandari 2013 Ineligible study population. This is a conference abstract of a study which full text was published in 2017 (Bhandari 2017). The study did not include an elderly subgroup.

Bhandari 2017 Ineligible study population - no data for the elderly subgroup. This is a report of a comparative study of adjuvant TMZ six cycles versus extended 12 cycles in newly diagnosed glioblastoma multiforme. The study recruited 40 postoperative participants between 2012 and 2013 (age range 18 to 65 years). The report does not present any relevant age-related data analysis.

Bleehen 1981

Ineligible study population - no data for the elderly subgroup. This is a report of a randomised trial of misonidazole and radiotherapy (4 weeks with $43.52 \mathrm{GY}$ and 56.56 over 5.5 weeks) for grades 3 and 4 cerebral astrocytoma. The accrual stopped at the end of 1978 , and a total of 55 participants age 18 to 75 years was recruited across three arms. The proportion of those age 65 (or 70 ) or over is unclear. The report does not present any relevant age-related data analysis.

Bleehen 1991

Ineligible study population - no data for the elderly subgroup. This is a report of a randomised trial of two radiotherapy doses in the treatment of grades 3 and 4 astrocytoma. The study randomised 474 patients between 1983 and 1988 (age range $18-73$ years). There were a total of 140 participants age 60-73. The proportion of participants age 65 (or 70 ) or over is unknown. The report does not present any relevant age-related data analysis.

Blumenthal 2015

Ineligible study population - no data for the elderly subgroup. This is a report of a phase 3 randomised trial of radiation therapy (RT) and 06-benzylguanine + BCNU compared with RT and BCNU alone in newly diagnosed glioblastoma and gliosarcoma (SWOG S0001). The study was terminated in 2015, at the time of the interim analysis, per recommendation of the Data and Safety Monitoring Committee. Up to that point, 183 participants were registered. The proportion of participants age 65 or over is unknown (stratification only by below/above 50 years). The report does not present any relevant age-related data analysis.

\begin{tabular}{ll}
\hline Blumenthal 2018 & Not a suitable study design. Not a RCT, an exploratory analysis of RTOG 0525 and RTOG 0825 data. \\
\hline Bogdahn 2011 & $\begin{array}{l}\text { Wrong population - recurrent glioblastoma. This is a report of a phase } 2 \text { randomised trial of target- } \\
\text { ed therapy for high-grade (recurrent /refractory) glioblastoma multiforme or anaplasticastrocy- } \\
\text { toma with TGF-beta2 inhibitor trabedersen. }\end{array}$
\end{tabular}

Boiardi 1992 Wrong population - recurrent glioblastoma. This is a report of a randomised trial of '8-drugs-inone-day' combination in treatment of recurrent glioblastoma multiforme.

\section{Boisen 2018}

Not a suitable study design. This is a report with a secondary analysis of plasma YKL-40 as a biomarker for BEV efficacy using data from AVAglio trial (Chinot et al. 2014) 


\begin{tabular}{ll}
\hline Study & Reason for exclusion \\
\hline Bower 1997 & $\begin{array}{l}\text { Wrong population - recurrent glioblastoma. This is a report of a phase } 2 \text { randomised trial of TMZ in } \\
\text { recurrent or progressive for high-grade glioblastoma multiforme. }\end{array}$ \\
\hline Boxerman 2013 & $\begin{array}{l}\text { Not a suitable study design. This is a report of a secondary analysis using RTOG 0625 and ACRIN } \\
6677 \text { studies to investigate whether early post-treatment progression on FLAIR or post-contrast MRI } \\
\text { predict overall survival. }\end{array}$
\end{tabular}

Brandes 2016

Wrong population - recurrent glioblastoma. This is a report of a phase 2 randomised, non-comparative study of fotemustine or BEV for patients with recurrent glioblastoma (AVAREG).

Brisman 1976

Wrong population - no data for the elderly subgroup. This is a report of a study evaluating adjuvant nitrosourea chemotherapy with carmustine (BCNU), lomustine (CCNU), or semustine (methyl CC$\mathrm{NU}$ ) in addition to surgery and radiotherapy. The study included 62 participants between 1970 and 1972. Overall, there were less than 20 participants age 65 years or more (18 patients).

Wrong population - recurrent glioblastoma. This is a report of a phase 2 randomised trial comparing cediranib plus gefitinib with cediranib plus placebo in subjects with recurrent/progressive glioblastoma.

Buckner 2001

Wrong population - no data for the elderly subgroup. This is a report of a phase 3 study of RT plus carmustine with or without recombinant interferon-alpha in the treatment of patients with newly diagnosed high-grade glioblastoma. The study enrolled 383 participants between 1990 and 1994 of which $41 \%$ (146) are over 60 years of age. The report does not present any relevant age-related data analysis.

Wrong population - no data for the elderly subgroup. This is a report of a phase 3 trial of carmustine and cisplatin compared with carmustine alone and standard RT or accelerated RT in patients with glioblastoma multiforme (NCCT 93-72-52 and SWOG 9503). The study included 451 participants between 1994 and 1999 of which 34\% (137) are over 60 years of age. The report does not present any relevant age-related data analysis.

Wrong population no data for the elderly subgroup. This is a report of a phase 2 randomised trial of an intracerebral injection of $\mathrm{CpG}$ oligonucleotide for newly diagnosed glioblastoma. The study recruited 81 participants. The median age is around 60 years (range 42-78), and the proportion of those age 65 (or 70) or over is unknown. The report does not present any relevant age-related data analysis. study of two doses of neon ion irradiation therapy for glioblastoma. The study recruited 15 participants of unknown age. fast neutrons with megavoltage X-rays in the treatment of glioblastoma.

\section{Chamberlain 2005}

Not a suitable study design. This is a correspondence to the editor of a journal regarding quote: "Abbreviated course of radiation therapy in older patients with glioblastoma multiforme" (Roa 2004).

Chang 1983

Wrong population - no data for the elderly subgroup. This is a report of a randomised trial of postoperative RT and combined postoperative RT with chemotherapy in the management of malignant gliomas. The study enrolled 626 participants between 1974 and 1976. The proportion of trial participants age 65 (or 70 ) or over is unknown ( $27 \%$ were 60 years or over). The report does not present any relevant age-related data analysis.

Chauffer 2014

Wrong population - no data for the elderly subgroup. This is a report of a phase 2 randomised trial of irinotecan and BEV as neo-adjuvant to TMZ-based chemoradiation compared with TMZchemoradiation for unresectable glioblastoma (TEMAVIR trial, ANOCEF group). The study included 


\section{Study Reason for exclusion}

120 participants (age 18-70) between 2009 and 2011. The proportion of those age 65 (or 70) or over is unknown. The report does not present any relevant age-related data analysis.

Chinnaiyan 2018

Wrong population - no data for the elderly subgroup. This is a report of a phase 2 randomised study of everolimus in combination with chemoradiation (EVE+RT+TMZ) in newly diagnosed glioblastoma (NRG Oncology RTOG 0913). The study randomised 171 participants (age 18 or over) between 2012 and 2013. The proportion of those age 70 or over is around $16 \%(28 / 171)$. In the study, the EVE $+\mathrm{RT}+\mathrm{TMZ}$ combination was significantly more toxic than RT+TMZ on its own with no results reported for the elderly subgroup.

Chong 2018 Wrong study design - an audit of treatments for the elderly with glioblastoma in a clinical setting in the UK.

Cianfriglia 1980

Wrong population - no data for the elderly subgroup. This is a report of randomised trial of CCNU-chemotherapy in hemispheric supratentorial glioblastoma. The study recruited 103 participants (age 12 to 80 ) of which 24 were 60-69 years old and three 70-79 years old.

Clarke 2009

Wrong population - no data for the elderly subgroup. This is a report of a phase 2 randomised trial comparing chemotherapy followed by either dose-dense or metronomic TMZ in patients with newly diagnosed glioblastoma. The study involved 85 participants (age 18-70) between 2005 and 2007. The median age in the trial is 56.3 years (range 21-71), and the proportion of those age 65 (or 70 ) or over is unknown.

Not a suitable study design. This is a approval summary from the Food and Drug Administration organisation in the US for TMZ combined with RT for the treatment of newly diagnosed glioblastoma multiforme. The report summarises the findings of Stupp et al. trial (N Engl J Med 2005; 352:987-96) where the age cap was at 70 years, and the analysis was stratified by $<50$ or $>=50$.

Combs 2008

Wrong population - no data for the elderly subgroup. This is a report of a randomised trial evaluating toxicity and outcomes in patients with primary glioblastoma treated with postoperative radiochemotherapy comparing two TMZ regimens. The study involved 160 participants between 1999 and 2007. The median age in the study is 60 years and the proportion of those age 65 (or 70) or over is unknown. The report does not contain any relevant age-related data analysis.

Corn 1994

Not a suitable study design. This is a report of an exploratory analysis of white matter changes in participants of a trial living more than 18 months. The trial is a phase $1 / 2$ dose-seeking study that evaluated twice-daily RT for supratentorial high grade malignant gliomas.

Curran 1992

Wrong population - no data for the elderly subgroup. This is a report of a randomised trial comparing an accelerated hyperfractionated RT (1.6 Gy twice daily fractions) and bis-chlorethyl nitrosourea for malignant glioma. The trial recruited 304 participants (age 18-70) between 1987 and 1989. The proportion of participants age 65 (or 70) or over is unknown. The report does not contain any relevant age-related data analysis. management of glioblastoma in the elderly patients.

Wrong population - no data for the elderly subgroup. This is a report of a randomised trial comparing BCNU with RT, streptozotocin with RT, BCNU with hyperfractionated RT, and BCNU following misonidazole with RT in the postoperative treatment of malignant glioma (BTCG study 77-02). The trial recruited 557 participants (age 15 or over) between 1978 and 1980. The median age in the trial was 58 years (range 15 to 82 years), and the proportion of those age 65 or over is $24.4 \%$. The trial report presents the overall survival data by age for all trial participants without accounting for treatment allocation. 


\section{Study Reason for exclusion}

Dinapoli 1993

Wrong population - no data for the elderly subgroup. This is a report of a phase 3 randomised trial comparing PCNU and carmustine combined with RT in high-grade glioma. The trial recruited 346 participants (age 18 or over) between 1985 and 1989. The median age in the trial was 59 (age range 21 to 84 years), and the proportion of those age 65 (or 70) or over is unknown. The trial reports the overall survival by age group for all trial participants without accounting for treatment allocation.

Du 2018

Wrong population - no data for the elderly subgroup. This is a report of a randomised trial of timorazolamide combined with three-dimensional conformal RT on residual disease after surgery of glioblastoma. The trial recruited 58 participants between 2013 and 2015. The average age in the study was around 45 years (age range 28-78), and the proportion of those 65 (or 70 ) or over is unknown. The report does not contain any relevant age-related data analysis.

Duncan 1986

Wrong population - no data for the elderly subgroup. This is a report of a randomised trial of mixedschedule (neutron/photon) irradiation in the treatment of supratentorial astrocytoma (grade 3 \& 4). The study involved 61 participants between 1979 and 1982. The study population was stratified by age group "16-39", "40-59", and "60 and over" with 25 participants in the final group. The report does not contain any relevant age-related data analysis.

Elinzano 2018 Wrong population - no data for the elderly subgroup. This is a report of a randomised phase 2 trial comparing poliglumex and RT with combined TMZ and RT for glioblastoma without MGMT methylation. The study randomised 63 participants between 2011 and 2014. Participants' age ranged from 21 to 82 years and the proportion of those age 65 (or 70) or over is unknown. The report does not contain any relevant age-related data analysis.

Eljamel 2008 Wrong population - no data for the elderly subgroup. This is a report of a randomised phase 3 trial comparing ALA and Photofrin ${ }^{\circledast}$ fluorescence-guided resection with repetitive photo-dynamic therapy in patients with glioblastoma. The study recruited 27 participants (dates not given) whose mean age was 59.8 years; the proportion of those age 65 (or 70) or over is unknown. The report does not contain any relevant age-related data analysis.

\section{Elliott 1997}

Wrong population - no data for the elderly subgroup. This is a report of a randomised trail comparing RT combined with dibromodulcitol with RT and BCNU in high grade ( 3 and 4 ) astrocytoma. The study included 238 participants between 1980 and 1985 with 52\% (118/229) being 60 years of age or more. No relevant age-related subgroup analysis - one of stratification factors is age $<55$ or $>=$ 55 years.

\begin{tabular}{ll}
\hline Espana 1978 & $\begin{array}{l}\text { Not a suitable study design. This is a report of a one-arm phase } 2 \text { trial evaluating dianhydrogalacti- } \\
\text { ol in malignant glioma. }\end{array}$ \\
\hline Eyre 1983 & $\begin{array}{l}\text { Wrong population - no data for the elderly subgroup. This is a report of a randomised trial compar- } \\
\text { ing RT and CCNU with RT, CCNU and procarbazine in patients with glioblastoma following surgery. } \\
\text { The study recruited } 117 \text { participants between } 1974 \text { and } 1975 . \text { The median age is around } 50 \text { years of } \\
\text { age, and the proportion of those age } 65 \text { (or 70) or over is unknown. The report does not contain any } \\
\text { relevant age-related data analysis. }\end{array}$ \\
\hline
\end{tabular}

Wrong population - no data for the elderly subgroup. This is a report of a randomised trial comparing intratumoral recombinant gamma-interferon as adjuvant to open cytoreduction and external irradiation of $60 \mathrm{~Gy}$ in adults with high-grade cerebral glioma. The study recruited 32 participants (years unknown). The age ranged from 18 to 71 years, and the proportion of those age 65 (or 70 ) or over is unknown. The report does not contain any relevant age-related data analysis. ating safety and efficacy of individualised dendritic cell-based cancer immune therapy for glioblastoma. The study recruited 105 participants (years unknown). The age ranged from 18 to 70 years, 


\begin{tabular}{ll}
\hline Study & Reason for exclusion \\
\hline & $\begin{array}{l}\text { and the proportion of those age } 65 \text { and over is unknown. The report does not contain any relevant } \\
\text { age-related data analysis. }\end{array}$
\end{tabular}

Field 2015

Wrong population - recurrent glioblastoma. This is a report of a randomised phase 2 trial of carboplatin and bevacizumabin recurrent glioblastoma.

Field 2017

Wrong population - recurrent glioblastoma. This is a secondary analysis of health-related quality of life outcomes from a randomised phase 2 trial of carboplatin and bevacizumabin recurrent glioblastoma (Field 2015).

Fischer 1985

Wrong population - no data for the elderly subgroup. This is a report of a randomised trial of RT with or without Levamisole in glioblastoma. The study randomised 25 participants (years unknown) of which only 10 were over 65 years of age.

Fulton 1984

Wrong population - no data for the elderly subgroup. This is a report of a randomised trial comparing misonidazole combined with hyperfractionation in malignant glioma. The randomisation to three arms (RT, fractionated RT and fractionated RT with misonidazole) took place between 1981 and 1982. Subsequently RT arm was dropped and a high dose fractionated RT added. Overall, 128 people with glioblastoma were evaluated (age range 18 to 70 ) of which 47 were over 60 years of age. The report does not contain any relevant age-related data analysis.

Gaber 2013

Wrong population - no data for the elderly subgroup. This is a report of a randomised trial comparing toxicity and efficacy of continuous daily radiosensitiser doses of TMZ concomitant with RT in glioblastoma. The study recruited 60 participants between 2009 and 2012. The mean age is around 48 years, and the proportion of those age 65 (or 70) or over is unknown (> 50 years 26 participants). The report does not contain any relevant age-related data analysis.

Gilbert 2013

Wrong population - no data for the elderly subgroup. This is a report of a randomised phase 3 trial of dose dense TMZ for newly diagnosed glioblastoma. The study randomised 833 participants between 2006 and 2008. The inclusion age is between 18 and 70 years (no mean or median given), and the proportion of those age 65 (or 70 ) or over is unknown (>= 50 years 610 participants). The report does not contain any relevant age-related data analysis.

Glinski 1993

Wrong population - no data for the elderly subgroup. This is a preliminary report of a randomised trial of a postoperative hypofractionated RT compared with conventionally fractionated RT in malignant gliomas. The study recruited 108 participants ( 44 with histologically-proven glioblastoma and 64 with anaplastic astrocytoma) between 1984 and 1989. The median age is around 45 years, and the proportion of those age 65 (or 70) or over is unknown. The report does not contain any relevant age-related data analysis.

Wrong population - no data for the elderly subgroup. This is a report of a randomised phase 3 trial comparing three cycles of infusional carmustine and cisplatin followed by RT with RT and concurrent carmustine in newly diagnosed supratentorial glioblastoma (ECOG trial 2394). The study randomised 219 participants between 1996 and 1999. The median age is 55 years, and the proportion of those age 65 (or 70 ) or over is unknown. The report does not contain any relevant age-related data analysis.

Halperin 1993

Not a suitable study design. This is a report with the findings of an analysis of RT data from the CNS Cancer Consortium's randomised trial (AZQ versus BCNU) in primary malignant brain tumours. The aim of this analysis was to evaluate the influence of boost field size.

Halperin 1996

Wrong population - no data for the elderly subgroup. This is a report of a randomised phase 3 trial (two-stage randomisation) of external beam RT, mitomycin C, carmustine, and 6-mercaptopurine for anaplastic glioma of the brain. During the first randomisation, 327 participants were allocated to respective treatments and 164 at the second one (years not given). The mean age of participants at the time of first randomisation is 53 years, and the proportion of those age 65 (or 70) or over is unknown. The report does not contain any relevant age-related data analysis (stratification $<45$ years versus $>=45$ years). 


\section{Study Reason for exclusion}

Harada 1996

Wrong population - insufficient details regarding population's age. This is a conference abstract of a randomised trial of two therapies (RT and MCNU and RT with MCNU with Interferon-beta) for a malignant glioma. The study recruited unspecified number of participants of unknown age.

Hatlevoll 1985

Wrong population - no data for the elderly subgroup. This is a report of a randomised trial of combined modality treatment of high grade ( 3 and 4 ) in operated astrocytoma. The study recruited 280 participants (years unknown) age between 20 and 69 years, thus there is no relevant subgroup of patients in this trial.

Henriksson 2006

Wrong population - no data for the elderly subgroup. This is a report of a randomised phase 3 trial comparing three cycles of infusional carmustine and cisplatin followed by RT with RT and concurrent carmustine in newly diagnosed supratentorial glioblastoma (ECOG trial 2394). The study randomised 219 participants between 1996 and 1999. The median age is 55 years, and the proportion of those age 65 (or 70 ) or over is unknown. The report does not contain any relevant age-related data analysis.

Hiesiger $1995 \quad$ Wrong population - no data for the elderly subgroup. This is a report of a randomised trial of intra-arterial cisplatin compared with intravenous PCNU for primary brain tumours (Brain Tumor Cooperative Group trial 8420A).The study randomised 311 participants of a median age 45 . The the proportion of those age 65 (or 70) or over is unknown. The report does not contain any relevant age-related data analysis.

Hildebrand 1994

Wrong population - no data for the elderly subgroup. This is a report of a randomised trial of adjuvant chemotherapy (dibromodulcitol and $\mathrm{BCNU}$ ) given postoperatively in patients with newly diagnosed malignant gliomas. The study run between 1989 and 1991, and 269 participants were randomised to RT or RT with chemotherapy. The median age in the study is 54 years with range between 19 and 79. The proportion of those age 65 (or 70) or over is unknown. The report does not contain any relevant age-related data analysis.

Hitchon 1999

Wrong population - no data for the elderly subgroup. This is a report of a long-term follow-up of patients randomised trial to treatment with and without brachytherapy. The study randomised 26 participants 15 years of age or older (mean age around 56 years). The proportion of those age 65 (or 70) or over is unknown. The report does not contain any relevant age-related data analysis.

Hofland 2014

Wrong population - no data for the elderly subgroup. This is a report of a randomised phase 2 trial of a neoadjuvant BEV and irinotecan compared with BEV and TMZ followed by concomitant chemoradiotherapy in patients with newly diagnosed glioblastoma. Overall, 65 participants were randomised between 2008 and 2010. The median age is around 60 years (age range 30-77 years) with unknown proportion of participants age 65 (or 70) or over. The report does not contain any relevant age-related data analysis.

Imbesi 2006

Wrong population - no data for the elderly subgroup. This is a report of a randomised phase 3 trial comparing intravenous and intraarterial ACNU in patients with a newly diagnosed glioblastoma.Overall, 43 participants were included in the study. The mean age is around 56 years (age range 32 - 69 years) and there was no relevant subgroup of patients in this trial.

Iwadate 1993 Wrong population - no data for the elderly subgroup. This is a report of a randomised trial of intra-arterial mannitol infusion prior to ACNU and cisplatin for malignant brain tumours. The study randomised 98 participants (years unknown) age between 6 and 69 years, thus there was no relevant subgroup of patients in this trial.

Jeremic 1999

Wrong study design. This is a report of a phase 2 trial (single arm) of short course RT in elderly and frail patients with glioblastoma. The study involved 47 elderly and frail participants between 1987 and 1993. The age range of included participants was 60 to 76 with a median of 69 years.

Karacetin 2011

Wrong population - no data for the elderly subgroup. This is a report of a randomised trial comparing concomitant TMZ and RT with RT alone in newly diagnosed glioblastoma. The study included 40 participants between 2004 and 2006. The median age is 51 years (age range 19-73) with un- 


\begin{tabular}{|c|c|}
\hline Study & Reason for exclusion \\
\hline & $\begin{array}{l}\text { known proportion of participants age } 65 \text { (or } 70 \text { ) or over. The report does not contain any relevant } \\
\text { age-related data analysis. }\end{array}$ \\
\hline Kim 2011 & $\begin{array}{l}\text { Wrong population - no data for the elderly subgroup. This is a report of phase } 3 \text { randomised trial of } \\
\text { RT followed by adjuvant TMZ with or without neoadjuvant ACNU-CDDP chemotherapy in newly di- } \\
\text { agnosed glioblastoma. The study included } 82 \text { participants ( } 48.8 \% \text { of the target sample) between } \\
2005 \text { and 2007; six participants were subsequently excluded due to ineligibility leaving data from } \\
76 \text { participants available for the analysis. The mean age is around } 51 \text { years in both arms with an un- } \\
\text { known proportion of participants age } 65 \text { years (or } 70 \text { ) or over. The trial was prematurely terminated } \\
\text { due to unacceptable toxicity. }\end{array}$ \\
\hline
\end{tabular}

Wrong population - no data for the elderly subgroup. This is a report of a randomised trial comparing single versus multiple drug therapy in the combined treatment of malignant gliomas. The study included 173 participants between 1983 and 1989. The age of majority of the participants is between 51 and 77 years, and the proportion of participants age 65 years (or 70) or over is unknown. The report does not contain any relevant age-related data analysis.

Koc 2008 Wrong study design. This is a report of a prospective evaluation of fluorescein sodium-guided surgery in glioblastoma.

Kocher 2008

Wrong population - no data for the elderly subgroup. This is a report of a randomised trial of postoperative radiotherapy and simultaneous TMZ without adjuvant chemotherapy for glioblastoma.

The study included 65 participants between 2002 and 2004. The median age is 58 and 59 years in $\mathrm{RT}$ and RT+TMZ arms, respectively with range 34 and 69 years; there is no relevant subgroup of patients in this trial. tra-arterial versus intravenous infusion of ACNU in newly diagnosed glioblastoma.

The study included 84 participants between 1987 and 1995. The mean age is 54 and 59 years in intra-arterial and intravenous arms, respectively with range from 16 to 78 years. The proportion of participants age 65 years (or 70 ) or over in unknown. The report does not contain any relevant agerelated data analysis. autologous cytokine-induced killer cell immunotherapy in newly diagnosed glioblastoma.

The study included 180 participants between 2008 and 2012. The mean age is 55 and 54 years in CIK immunotherapy and control arms, respectively with range from 19 to 68 years. The proportion of participants age 65 years (or 70 ) or over in unknown. The report does not contain any relevant agerelated data analysis.

Lamers 2008

Ineligible population and design - no data for the elderly subgroup. This is a report of cost-effectiveness of concomitant and adjuvant TMZ for newly diagnosed glioblastoma in comparison to radiotherapy. The report does not contain any relevant age-related data.

Ineligible population - no data for the elderly subgroup. This is a report of phase 2 randomised trial of TMZ with radiochemotherapy for newly diagnosed glioblastoma. The study included 21 participants between 1999 and 2001. The median age of participants is 44 years with an unknown proportion of participants age 65 years (or 70) or over.The report does not contain any relevant age-related data. 2 , randomised trial of radiotherapy (RT) and TMZ for newly diagnosed glioblastoma. The study included 106 participants; the median age of participants is 55 years in RT and 59 years in TMZ arm. The proportion of participants age 65 yeas (or 70 ) or over in unknown and the report does not contain any relevant age-related data. 


\section{Study \\ Reason for exclusion}

Lenartz 2000

Ineligible population - no data for the elderly subgroup. This is a report of a randomised trial to evaluate the effect of adjuvant treatment of glioma with ML-1 standardised mistletoe extract. The study included 38 participants between 1994 and 1995. The mean age of participants is 57 years with an unknown proportion of participants age 65 years (or 70 ) or over. The report does not contain any relevant age-related data.

Levin 1979

Ineligible population - no data for the elderly subgroup. This is a report of phase 3 randomised trial of BCNU, hydroxyurea, and(RT versus BCNU combined with RT for primary malignant gliomas. The study included 99 participants of unspecified age, and the report does not contain any relevant age-related data.

Ineligible population - no data for the elderly subgroup. This is a report of phase 3 randomised trial of chemotherapy (post radiotherapy) an Alpha-Difluoromethylornithine-Procarbazine, N-(2Chloroethyl)-N'-cyclohexyl-N-nitrosurea, Vincristine (DFMO-PCV) in comparison to PCV for glioblastoma. The study included 272 participants between 1998 and 1999. The median age of participants is 53 years in DEMO-PCV and 50 years in PCV arm with an unknown proportion of participants age 65 (or 70 ) or over. The report does not contain any relevant age-related data.

Levin 2006 Ineligible population - no data for the elderly subgroup. This is a report of a randomised, double-blind, placebo-controlled trial of marismastat after surgery and radiotherapy for glioblastoma. The study included 162 participants between 1996 and 19999. The median age of participants is around 57 years with an unknown proportion of participants age 65 years (or 70 ) or over. The report does not contain any relevant age-related data. diotherapy (RT) compared to RT with the long-acting opioid antagonist naltrexone (NTX) for malignant glioma. The study included 21 participants between 1990 and 1992. The median age of participants is 52 years in RT and 49 years in RT+NTX arm; the proportion of participants age 65 (or 70) or over is less than 20 .

\begin{tabular}{ll}
\hline Lorimer 2016 & Not an RCT, a study examining prognostic factors. \\
\hline Ludgate 1988 & $\begin{array}{l}\text { Ineligible population - no data for the elderly subgroup. This is a report of a randomised trial of su- } \\
\text { perf ractionated radiotherapy (RT) for malignant gliomas. The study included } 76 \text { participants of un- } \\
\text { specified age between } 1981 \text { and } 1983 . \text { The proportion of participants age } 65 \text { years (or } 70 \text { ) or over in } \\
\text { unknown. The report does not contain any relevant age-related data. }\end{array}$
\end{tabular}

Mallick 2018 Wrong population - a small study with no elderly subgroup. open-label, trial of early postsurgical TMZ with concomitant RT for newly diagnosed glioblastoma. The study included 99 participants between 2008 and 2012. The mean age of all participants is 50.2 (SD 11.8) years. The proportion of participants age 65 (or 70) or over is unknown, and the report does not contain any relevant age-related data.

Marshall 2006

Ineligible population - no data for the elderly subgroup. This is a secondary analysis of a randomised trial of cisplatin with concurrent radiotherapy in glioblastoma on hearing loss. The study included 451 participants, of which 230 randomised to arms C (standard RT with carmustine and cisplatin), and D (accelerated RT with carmustine and cisplatin). The mean age of participants at baseline is 55.8 years, and the proportion of participants age 65 (or 70 ) or over is unknown. The report does not contain any relevant age-related data.

McCarthy 2017 This is a commentary on the results of the Stupp 2005 trial.

Montemor 2008

Ineligible population - no data for the elderly subgroup. This is a report of a randomised trial of chemoradiotherapy with weekly paclitaxel (GR1) in comparison to RT alone (GR2) for anaplastic astrocytoma (AA) and glioblastoma (GB). The study included 61 participants between 1998 and 2002 . The median age of participants range from 35.29 years in GR1/AA group to 54.33 years in GR2/GB; 


\begin{tabular}{ll}
\hline Study & Reason for exclusion \\
\hline the proportion of participants age 65 (or 70) or over is unknown. The report does not contain any \\
relevant age-related data.
\end{tabular}

Napolitano $1999 \quad$ Not a suitable study design. This is a report of phase 2 clinical, sequential, study of radiotherapy and a combination of BCNU and tamoxifen.

Nelson 1988

Ineligible population - no data for the elderly subgroup. This trial with four treatment arms (60 Gy to the whole brain; 60 Gy plus 10-Gy boost; 60 Gy plus carmustine (BCNU); and 60 Gy plus semustine plus dacarbazine) included Grade 3 and 4 gliomas and stratified findings by under or over 50 years. Eight patients were over 70 years.

Payne 1982

Ineligible population - no data for the elderly subgroup. This is a report of a randomised trial of chemotherapy with hypofractionated or standard radiotherapy for malignant astrocytoma. The study included 157 participants between 1977 and 1980. The median age of participants at baseline is 56 years, and the proportion of participants age 70 and over less than 20 participants $(n=$ 13). diotherapy alone in comparison to radiotherapy with CCNU. The study included 139 participants, of which none was over 65 years of age. options of radiotherapy ( $35 \mathrm{~Gy}$ in 10 fractions vs 60 Gy in 30 fractions) for glioblastoma in elderly. The study included 69 participants between 1990 and 1996. The median age of participants is 58 and 59 years in $60 \mathrm{~Gy}$ and $35 \mathrm{~Gy}$ arms, respectively. The proportion of participants age 65 (or 70 ) or over is unknown. The report does not contain any relevant age-related data.

\section{Pinzi 2017}

Prados 2001
This is an editorial on postoperative chemoradiotherapy in elderly patients with glioblastoma.

Ineligible population - no data for the elderly subgroup. This is a report of phase 3 randomised trial of accelerated hypofractionation with or without difluromethylornithine (DFMO) in comparison with standard radiotherapy with or without DFMO in newly diagnosed glioblastoma. The study included 231 participants, and their median age is 57 years. The proportion of participants age 65 (or 70) or over in unknown. The report does not contain any relevant age-related data.

Reagan 1976
Ineligible population - no data for the elderly subgroup. This is a report of a randomised trial of three treatment schedules: radiotherapy (RT) alone, CCNU, and combination of both. The study included 63 participants between 1970 and 1972. The mean age of participants is 52.3, 53 and 58 years in RT, CCNU and the combined arms, respectively. The proportion of participants age 65 (or 70) or over is unknown. The report does not contain any relevant age-related data. 


\section{Study \\ Reason for exclusion}

Reyes-Botero 2018

Ineligible study design - a non-randomised phase II trial $(n=66)$ that treated patients aged $70+$, and with a KPS of under 70 with TMZ $130-150 \mathrm{mg} / \mathrm{m} 2$ per day for 5 days every 4 weeks concomitantly with bevacizumab $10 \mathrm{mg} / \mathrm{kg}$ every two weeks.

Shapiro 1976

Ineligible population - no data for the elderly subgroup. This is a report of a randomised trial of carmustine (group A) and vincristine (group B). The study included 33 participants; the median age of participants is 60 years in group A and 58 in group B. The proportion of participants age 65 (or 70 ) or over is unknown. The report does not contain any relevant age-related data.

Shapiro 1989

Ineligible population - no data for the elderly subgroup. This is a report of a randomised trial of three chemotherapy (BCNU alone, alternating course BCNU and procarbazine and BCNU with hydroxyurea alternating procarbazine and VM-26) and two radiotherapy regimens for malignant glioma. The study included 571 participants between 1980 and 1981. The median age of participants is 56 years (range 15 - 84), and the proportion of participants age 65 and or over is $21 \%$, but the report does not contain any relevant age-related data.

Shapiro 1992

Ineligible population - no data for the elderly subgroup. This is a report of a randomised trial of intra-arterial versus intravenous BCNU, with or without 5-fluorouracil (intravenous) for newly diagnosed glioma. The study included 505 participants, and the median age is 56 years. The proportion of participants age 65 (or 70 ) or over is $21.4 \%$, but the report does not contain any relevant age-related data.

Sharma 2003 Ineligible population - no data for the elderly subgroup. This is a report of a randomised trial of two different radiotherapy regimens. The study included 50 participants age less than 60 years of age between 1996 and 1998.

Simpson 1976

Ineligible population - no data for the elderly subgroup. This is a report of a randomised trial of two different radiotherapy regiments. The study included 134 participants of unspecified age between 1965 and 1968. The report does not contain any relevant age-related data. trial of brachytherapy boost with or without hyperthermia for glioblastoma. The study included 112 participants between 1990 and 1995. The median age of participants is 54 years (range 21-78). The proportion of participants age 65 (or 70) or over is unknown, and the report does not contain any relevant age-related data.

Socha $2016 \quad$ Ineligible population - recurrent glioblastoma.

Soffietti $2017 \quad$ Not an RCT, a single-arm study.

Solero 1979

Ineligible population - no data for the elderly subgroup. This is a report of a randomised trial of radiotherapy alone, in combination with BCNU or CCNU. The study included 105 participants of unspecified age between 1972 and 1976.

Solomon 2013

Ineligible population - no data for the elderly subgroup. This is a report of a randomised trial of radiotherapy (RT) with nimotuzumab or placebo for high-grade glioma (anaplastic astrocytoma and glioblastoma). The study included 70 participants between 2005 and 2010 . The mean age of participants is 45.5 and 47.2 years in arm without and with nimotuzumab, respectively. The proportion of participants age 65 (or 70) or over in unknown and the report does not contain any relevant age-related data.

\begin{tabular}{|c|c|}
\hline Solth 2018 & Ineligible study design - a clinical audit of treatment of GBM in the elderly in a UK setting. \\
\hline Souhami 2004 & $\begin{array}{l}\text { Ineligible population - no data for the elderly subgroup. This is a report of a randomised trial of } \\
\text { stereotactic radiosurgery (SRS) with standard radiotherapy (RT) and carmustine versus RT with car- } \\
\text { mustine for glioblastoma (report of RTOG } 93-05 \text { protocol). The study included } 203 \text { participants be- } \\
\text { tween } 1994 \text { and 2000. The mean age of participants is } 55.5 \text { and } 56.4 \text { years in RT alone and RT+SRS, }\end{array}$ \\
\hline
\end{tabular}




\section{Study Reason for exclusion}

respectively. The proportion of participants age 65 (or 70 ) or over in $26.5 \%$, but the report does not contain any relevant age-related data.

Stadler 1984

Ineligible population - no data for the elderly subgroup. This is a report of 6-month follow-up data from a randomised trial of misonidazole and radiotherapy for high-grade astrocytoma (The Vienna study). There were 45 participants available for the analysis by 1983 (study start in 1977). The mean age of participants is 52 years in misonidazole with RT arm and 56 years in arm with RT alone. The proportion of participants age 65 (or 70 ) or over and the report does not contain any relevant agerelated data. Stragliotto 2013 Not relevant study objective. This is a report of a randomised trial of add-on therapy of valganci-
clovir in cytomegalovirus-positive glioblastoma.

Stummer 2006

Not relevant study objective. This is a report of a randomised trial of fluorescence-guided surgery with 5-aminolevulinic acid for resection of malignant glioma.

\section{Stummer 2011}

Stummer 2017
This is a secondary report from the randomised 5-aminolevulinic acid study (Stummer 2006).

Not relevant study objective. This is a report of a randomised trial comparing three different doses of 5-aminolevulinic acid for resection of malignant glioma.
Stupp 2002

Ineligible population - no data for the elderly subgroup. This is a report of a randomised trial of ra-
diotherapy (RT) alone vs RT with temozolomide (TMZ) both followed by adjuvant TMZ. The study
included 573 participants between 2000 and 2002 . The median age of the participants is 56 years,
and the proportion of participants age 65 (or 70) or over in unknown.

Not a suitable study design. This is a report of a study investigating the safety, tolerability, and survival of radiotherapy with temozolomide (TMZ) followed by adjuvant TMZ for newly diagnosed glioblastoma.

Stupp $2009 \quad$ Ineligible population. This is a report with a five-year follow-up data of the Stupp 2005 trial.

Stupp $2014 \quad$ Ineligible population - no data for the elderly subgroup. This is a report of phase 3 randomised trial of cilengitide with the standard of care for newly diagnosed glioblastoma with methylated MGMT (CENTRIC EORTC 26071-22072). The study included 545 participants between 2008 and 2011.The median age of the participants is 58 years in both arms with an unknown proportion of participants age 65 (or 70) or over. The report does not contain any relevant age-related data.

Stupp 2015

Ineligible population - no data for the elderly subgroup. This is a report of an interim analysis of the randomised trial of Tumor-Treating Fields with temozolomide (TMZ) in comparison to TMZ alone for glioblastoma. The study included 315 participants between 2009 and 2014. The mean age of the participants in the sample is 55.8 years (median 57) in both arms with an unknown proportion of participants age 65 (or 70) or over. The report does not contain any relevant age-related data.

Szczepanek 2013

Ineligible population - no data for the elderly subgroup. This is a report of a randomised trial of radiotherapy (RT) alone in comparison to RT with temozolomide (TMZ) both followed by adjuvant TMZ. The study included 58 participants between 2003 and 2005. The mean age of the participants is 55 years, and the proportion of participants age 65 (or 70) or over is unknown.

Takakura 1986 Ineligible population - no data for the elderly subgroup. This is a report of a randomised trial of radiotherapy (RT) alone in comparison to RT with ACNU for malignant gliomas. The study included 105 participants between 1980 and 1981. Neither the median age of the participants nor the proportion of participants age 65 (or 70 ) or over is given.

Taphoorn 2005 Ineligible population. This is a secondary analysis of Stupp 2005 trial focusing on the quality of life data. 


\section{Study Reason for exclusion}

Urtasun 1982

Ineligible population - no data for the elderly subgroup. This is a report of a randomised trial of radiotherapy and misonidazole for high-grade glioma. The study included 59 participants. The mean age of participants was 55, 56 and 59 years in RT alone, RT with metronidazole and RT with misonidazole respectively. The proportion of participants age 65 (or 70) or over is unknown, and the report does not contain any relevant age-related data.

Ushio 1985 Ineligible population - no data for an elderly subgroup. 13/105 patients were over 60 in this Japanese trial.

Vellayappan 2017 This is an editorial on combined-modality hypofractionated radiotherapy for elderly with glioblastoma.

\section{Wakabayashi 2018}

Wang 2008

Weller 2003 Inelgible population - no elderly subgroup.

No PDF available.

Ineligible population - no data for the elderly subgroup. This is a report of a randomised trial of radiotherapy with ACNU and VM26 in comparison to RT with ACNU and Ara-C for glioma (glioblastoma or anaplastic gliomas). The study included 375 participants between 1994 and 2000. The median age of the participants is 50 and 51 years in ACNU + VM26 and ACNU+Ara-C arm. The proportion of participants age 65 (or 70) or over is unknown, and the report does not contain any relevant age-related data.

Werner-Wasik 1996

Ineligible population - no data for the elderly subgroup. This is a report of phase $1 / 2$ randomised trial of two regimens of radiotherapy (hypofractionated versus accelerated hypofractionated), both with carmustine for malignant gliomas. The study included 747 participants between 1983 and 1989. The mean age of the participants is 52.3 years in the study, and the proportion of participants age 65 (or 70) or over is unknown. The report does not contain any relevant age-related data.

Westphal 2003

Ineligible population - no data for the elderly subgroup. This is a report of phase 3 randomised trial of chemotherapy with BCNU wafer for primary malignant glioma. The study included 240 participants between 1997 and 1999. The mean age of the participants is 52.6 in the wafer arm and 53.6 years in the placebo arm. The proportion of participants age 65 (or 70) or over is unknown, and the report does not contain any relevant age-related data.

\section{Westphal 2006} Ineligible population. This is a secondary analysis of long-term follow-up data of a Westphal 2003 trial.

Westphal 2013

Not relevant study objective. This is a report of phase 3 randomised trial of locally applied adenovirus-mediated gene therapy with a prodrug converting enzyme (herpes-simplex-virus thymidine kinase; sitimagene ceradenovec) followed by intravenous ganciclovir in patients with newly diagnosed resectable glioblastoma (ASPECT).

Westphal 2015

Ineligible population - no data for the elderly subgroup. This is a report of phase 3, open-label randomised trial of nimotuzumab for newly diagnosed glioblastoma. The study included 149 participants between 2007 and 2010. The mean age of participants in the experimental arm is 52.9 and 55.9 years in the control arm. The proportion of participants age 65 (or 70 ) or over in unknown. The report does not contain any relevant age-related data.

Wick 2009

Ineligible population - no data for the elderly subgroup. This is a report of phase 3 randomised trial of sequential radiochemotherapy with procarbazine, lomustine, and vincristine or temozolomide for anaplastic glioma. The study included 318 (analysed data from 274) participants between 1999 and 2005. The median age of the participants is 44 in RT arm and 42 years in PCV or TMZ arm. The proportion of participants age 65 (or 70 ) or over is unknown, and the report does not contain any relevant age-related data. 


\begin{tabular}{ll}
\hline Study & Reason for exclusion \\
\hline Wick 2016 & $\begin{array}{l}\text { Ineligible population - no data for the elderly subgroup. This is a report of phase } 2 \text { randomised tri- } \\
\text { al of radiotherapy (RT) and temsirolimus (TEM) in comparison to radiochemotherapy with temo- } \\
\text { zolomide for newly diagnosed glioblastoma without MGMT (EORTC 26082). The study included 257 } \\
\text { participants between } 2009 \text { and 2012. The median age of the participants is 55 and 58 years in TEM } \\
\text { and standard of care arm, respectively. The proportion of participants age } 65 \text { (or } 70 \text { ) or over is un- } \\
\text { known, and the report does not contain any relevant age-related data. }\end{array}$ \\
\hline Yang 2018 & $\begin{array}{l}\text { Ineligible population - no data for the elderly subgroup. This is a report of a randomised trial of ra- } \\
\text { diotherapy (RT) with concomitant and adjuvant temozolomide (TMZ) versus RT with concomitant } \\
\text { and adjuvant local delivery of ACNU rendezvousing with oral TMZ. The study included only partici- } \\
\text { pants age } 18 \text { to } 65 \text { years. }\end{array}$ \\
\hline Zhu 2017 & $\begin{array}{l}\text { Ineligible population. This is a secondary analysis of Stupp 2015 trial focusing on the quality of life } \\
\text { data. }\end{array}$ \\
\hline
\end{tabular}

ACNU: nimustine; BCNU: carmustine; BEV: bevacizumab; CCNU: lomustine; CDDP: cisplatin; CIK: cytokine-induced killer cells;GBM: glioblastoma; HR: hazard ratio; KPS: Karnofsky performance score; MGMT: methylguanine-DNA-methyltransferase; MRI: magnetic resonance imaging; PCV: procarbazine and vincristine; RT: radiotherapy; SRD: stereotactic radiosurgery; TEM: temsirolimusTMZ: temozolomide; RTOG:Radiation Therapy Oncology Group.

Characteristics of ongoing studies [ordered by study ID]

\section{NCT01602588}

Trial name or title

A randomised trial investigating the additional benefit of Hydroxychloroquine (HCQ) to short course radiotherapy (SCRT) in patients aged 70 years and older with high grade gliomas (HGG) ClinicalTrials.gov Identifier: NCT01602588

Methods Phase II, parallel two-arm, open-label RCT with randomisation in 1:2 ratio

Participants

Target sample: 57

Actual enrolment: 54

Inclusion: aged 70+. ECOG PS 0 or 1.

Interventions

Reference arm: short course RT alone. Dose is 30 Gy in 6 fractions given on alternate days over 2 weeks.

Experimental arm: short course RT plus hydroxychloroquine $200 \mathrm{mg}$ orally twice daily from 14 days after surgery until progression.

Outcomes

Analysis will be by ITT, whereby patients will be examined according to the assigned treatment.

Primary outcome: survival time at 1 year.

\section{Secondary outcomes}

Toxicity/adverse events during and up to 30 days after treatment.

One-year cause-specific survival and 6-month progression-free survival.

$\mathrm{HRQ}$ oL - difference between HRQoL at 8 weeks post treatment compared to baseline will be assessed. HRQoL questionnaires used are QLQ-C30 and BN20.

Corticosteroid dependence.

Starting date Opened to recruitment on 21 $\quad$ St May 2012.


NCT01602588 (Continued)

Study completion date: November 2017.

$\begin{array}{ll}\text { Contact information } & \text { Professor Susan Short, St James's University Hospital, Leeds } \\ & \text { UCL (sponsor) } \\ \text { CRUK (funder) }\end{array}$

\section{NUTMEG 2018}

Trial name or title

A randomised phase II study of NivolUmab and TeMozolomide versus temozolomide alone in newly diagnosed Elderly patients with Glioblastoma (NUTMEG) to analyse overall survival.

Study registration ID: ACTRN12617000267358

\begin{tabular}{ll}
\hline Methods & Phase Il parallel two-arm, multi-centre, open-label RCT with randomisation in 2:1 ratio \\
\hline Participants & Target sample size: 102 \\
& $\begin{array}{l}\text { Adults } 65 \text { years or above, with newly diagnosed histologically confirmed GBM (WHO grade IV } \\
\text { glioma including gliosarcoma) following surgery. }\end{array}$ \\
\hline
\end{tabular}

Interventions

\section{Intervention}

Patients will receive radiotherapy (40 Gy/15 fractions, weekdays over 21 days) concomitantly with temozolomide (TMZ) tablets $75 \mathrm{mg} / \mathrm{m} 2$ daily for 21 days.

After a 4-week break the experimental group will receive nivolumab intravenous infusions ( $240 \mathrm{mg}$ days 1 and 15 every 28 days for cycles 1-4; then $480 \mathrm{mg}$ day 1 every 28 days for cycles 5-6) with concomitant adjuvant TMZ tablets days 1-5, every 28 days) for 6 cycles. TMZ will be dosed at $150 \mathrm{mg} /$ $\mathrm{m} 2$ for the first cycle. If well tolerated TMZ is then given at $200 \mathrm{mg} / \mathrm{m} 2$ for cycles $2-6$.

\section{Comparator}

Patients will receive RT (40 Gy/15 fractions) concomitantly with temozolomide (TMZ) 75 mg/m2.

Patients assigned to the control group will receive the standard treatment of adjuvant TMZ (150 $\mathrm{mg} / \mathrm{m} 2$ to $200 \mathrm{mg} / \mathrm{m} 2$ days $1-5$ every 28 days) for 6 cycles.

\section{Outcomes}

Overall survival, progression-free survival, adverse events, QoL, neurological functioning

Patients are assessed at baseline then every 8 weeks until study treatment finishes/disease progression.

\begin{tabular}{ll}
\hline Starting date & 02/03/2018 \\
\hline Contact information & NUTMEG Trial Co-ordinator \\
& nutmeg@ctc.usyd.edu.au
\end{tabular}

\section{Notes}

The study aims to evaluate whether the combination of adjuvant nivolumab with TMZ improves overall survival outcomes for this patient population.

GBM: glioblastoma; MGMT: methylguanine-DNA-methyltransferase; HRQoL: health-related quality of life; RCT: randomised controlled trial; RT: radiotherapy; TMZ: temozolomide;WHO: World Health Organization 
DATA AND ANALYSES

Comparison 1. Radiotherapy (50 Gy) versus supportive care

\begin{tabular}{|c|c|c|c|c|}
\hline $\begin{array}{l}\text { Outcome or subgroup } \\
\text { title }\end{array}$ & $\begin{array}{l}\text { No. of } \\
\text { studies }\end{array}$ & $\begin{array}{l}\text { No. of } \\
\text { partici- } \\
\text { pants }\end{array}$ & Statistical method & Effect size \\
\hline $1 \mathrm{HRQOL}$ & 1 & & Mean Difference (IV, Random, 95\% CI) & Subtotals only \\
\hline 1.1 At 30 days & 1 & 59 & Mean Difference (IV, Random, 95\% CI) & $-4.20[-6.33,-2.07]$ \\
\hline 1.2 At 60 days & 1 & 45 & Mean Difference (IV, Random, 95\% CI) & $-4.70[-7.33,-2.07]$ \\
\hline 1.3 At 90 days & 1 & 39 & Mean Difference (IV, Random, 95\% CI) & $-7.60[-11.03,-4.17]$ \\
\hline 1.4 At 135 days & 1 & 26 & Mean Difference (IV, Random, 95\% CI) & $10.70[6.01,15.39]$ \\
\hline 2 Cognition & 1 & & Mean Difference (IV, Random, 95\% CI) & Subtotals only \\
\hline 2.1 At 30 days & 1 & 59 & Mean Difference (IV, Random, 95\% CI) & $-0.40[-3.24,2.44]$ \\
\hline 2.2 At 60 days & 1 & 45 & Mean Difference (IV, Random, 95\% CI) & $-5.60[-9.20,0.00]$ \\
\hline 2.3 at 90 days & 1 & 39 & Mean Difference (IV, Random, 95\% CI) & $-21.0[-25.18,-16.82]$ \\
\hline 2.4 at 135 days & 1 & 26 & Mean Difference (IV, Random, 95\% CI) & $-13.0[-18.84,-7.16]$ \\
\hline 3 Fatigue & 1 & & Mean Difference (IV, Random, 95\% CI) & Subtotals only \\
\hline 3.1 At 30 days & 1 & 59 & Mean Difference (IV, Random, 95\% CI) & $2.10[-0.49,4.69]$ \\
\hline 3.2 At 60 days & 1 & 45 & Mean Difference (IV, Random, 95\% CI) & $8.60[4.77,12.43]$ \\
\hline 3.3 At 90 days & 1 & 39 & Mean Difference (IV, Random, 95\% CI) & $11.70[8.24,15.16]$ \\
\hline 3.4 At 135 days & 1 & 26 & Mean Difference (IV, Random, 95\% CI) & $0.5[-6.68,7.68]$ \\
\hline $\begin{array}{l}4 \text { Progression-free sur- } \\
\text { vival }\end{array}$ & 1 & 81 & Hazard Ratio (Random, 95\% Cl) & $0.28[0.17,0.46]$ \\
\hline
\end{tabular}

Analysis 1.1. Comparison 1 Radiotherapy ( $50 \mathrm{~Gy}$ ) versus supportive care, Outcome $1 \mathrm{HRQOL}$.

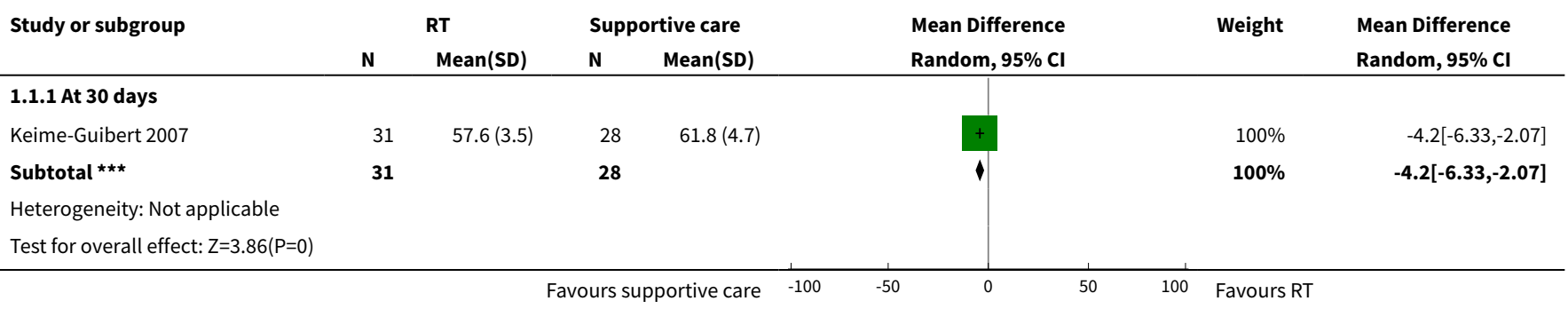




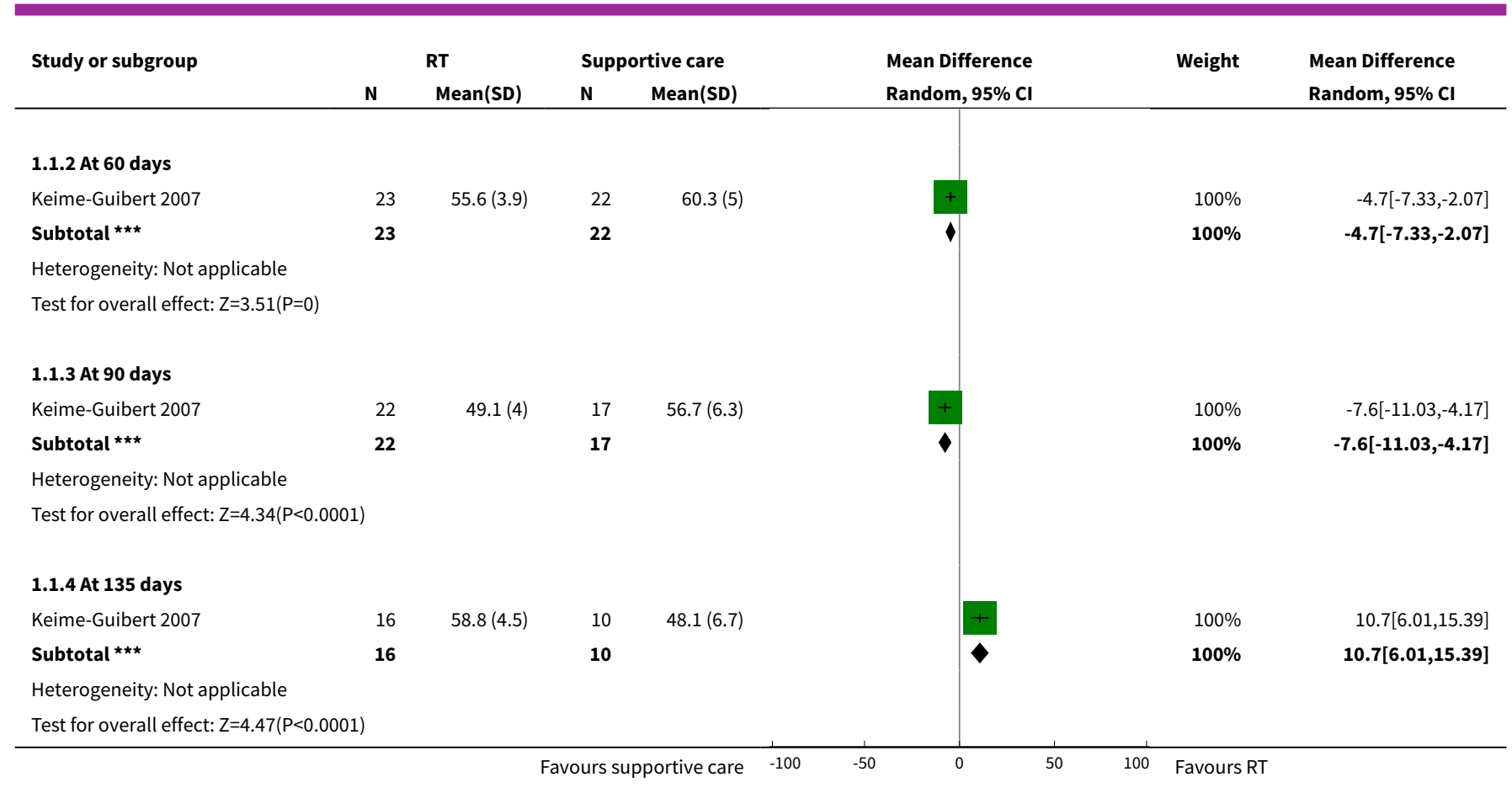

Analysis 1.2. Comparison 1 Radiotherapy ( $50 \mathrm{~Gy}$ ) versus supportive care, Outcome 2 Cognition.

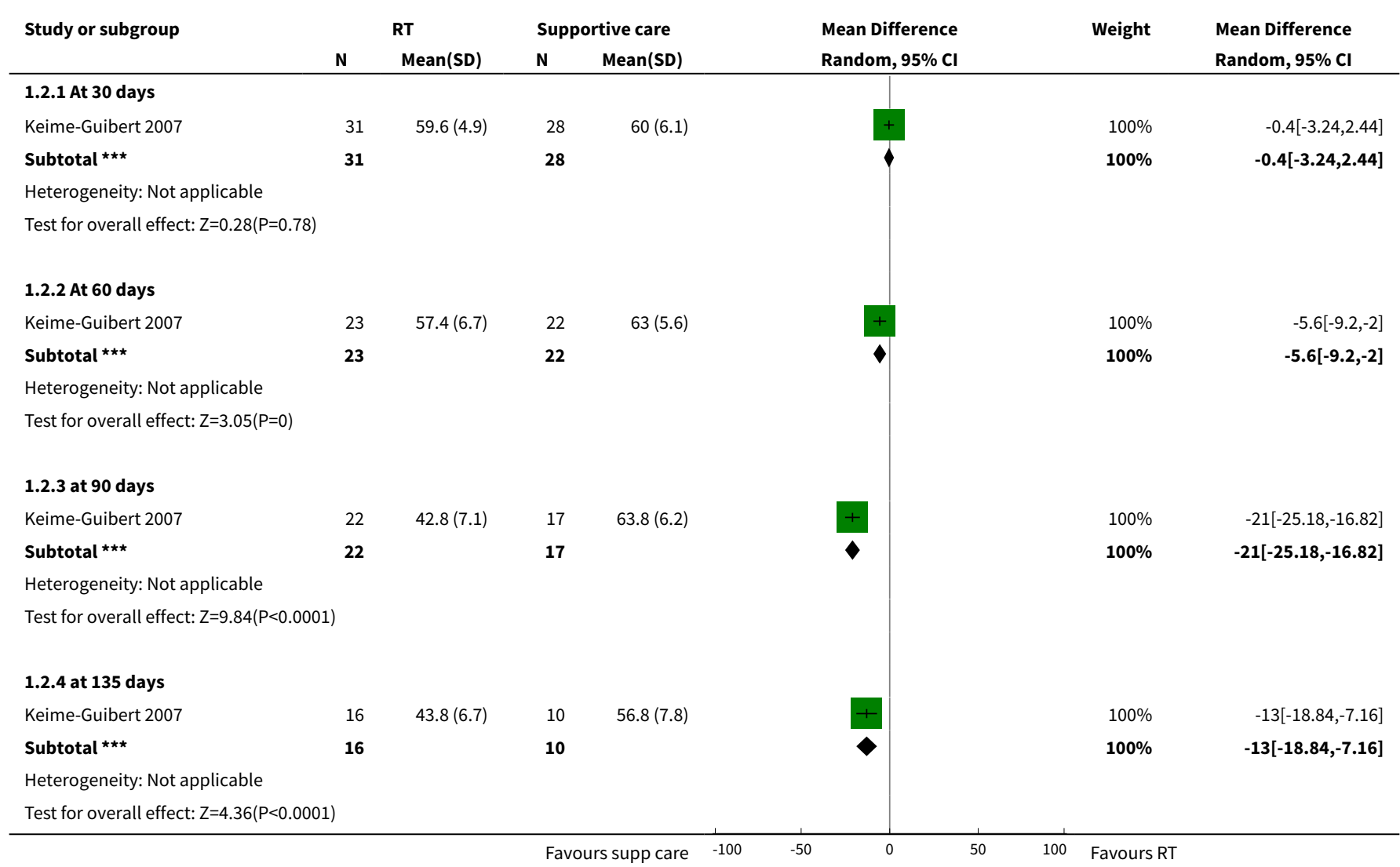


Analysis 1.3. Comparison 1 Radiotherapy (50 Gy) versus supportive care, Outcome 3 Fatigue.

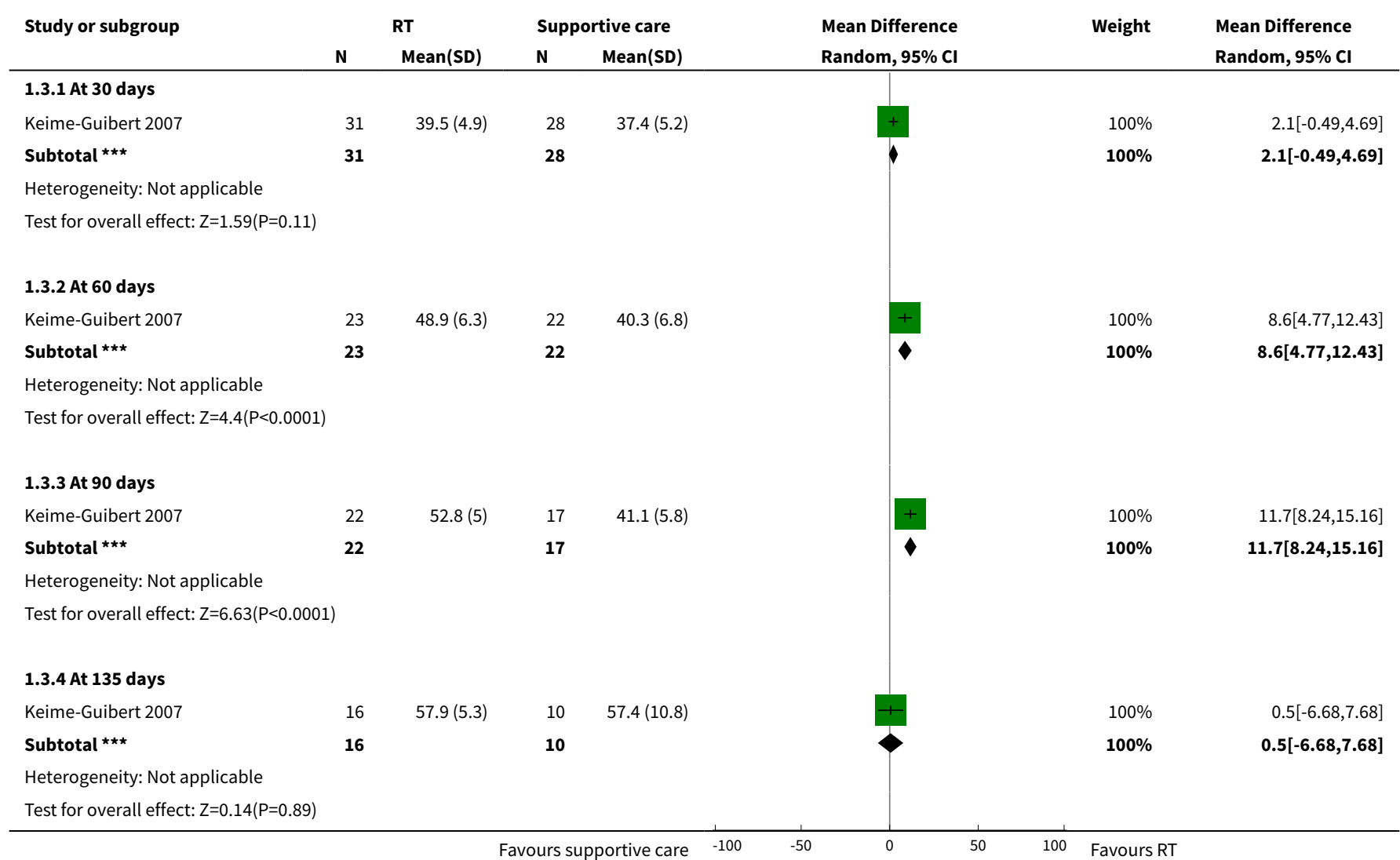

\section{Analysis 1.4. Comparison 1 Radiotherapy (50 Gy) versus supportive care, Outcome 4 Progression-free survival.}

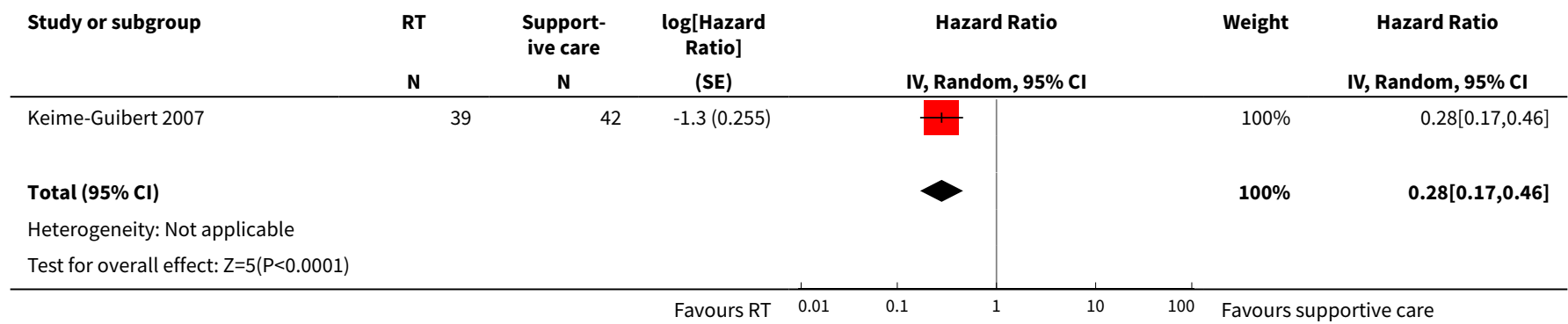

\section{Comparison 2. Short-course radiotherapy versus standard radiotherapy}

\begin{tabular}{lllll}
\hline Outcome or subgroup title & $\begin{array}{l}\text { No. of } \\
\text { studies }\end{array}$ & $\begin{array}{l}\text { No. of } \\
\text { partici- } \\
\text { pants }\end{array}$ & Statistical method & Effect size \\
\hline 1 HRQOL at 4 weeks & 2 & & $\begin{array}{l}\text { Mean Difference (IV, Random, 95\% } \\
\text { CI) }\end{array}$ & Subtotals only \\
\hline
\end{tabular}




\begin{tabular}{|c|c|c|c|c|}
\hline Outcome or subgroup title & $\begin{array}{l}\text { No. of } \\
\text { studies }\end{array}$ & $\begin{array}{l}\text { No. of } \\
\text { partici- } \\
\text { pants }\end{array}$ & Statistical method & Effect size \\
\hline 1.1 RT (40 Gy) vs RT (60 Gy) & 1 & 85 & $\begin{array}{l}\text { Mean Difference (IV, Random, 95\% } \\
\mathrm{Cl})\end{array}$ & $0.0[0.0,0.0]$ \\
\hline $1.2 \mathrm{RT}(25 \mathrm{~Gy})$ vs RT (40 Gy) & 1 & 40 & $\begin{array}{l}\text { Mean Difference (IV, Random, 95\% } \\
\mathrm{CI})\end{array}$ & $3.40[-8.33,15.13]$ \\
\hline $2 \mathrm{HRQOL}$ at 8 weeks & 2 & & $\begin{array}{l}\text { Mean Difference (IV, Random, 95\% } \\
\mathrm{CI})\end{array}$ & Subtotals only \\
\hline 2.1 RT (40 Gy) vs RT (60 Gy) & 1 & 72 & $\begin{array}{l}\text { Mean Difference (IV, Random, 95\% } \\
\mathrm{CI})\end{array}$ & $0.0[0.0,0.0]$ \\
\hline 2.2 RT (25 Gy) vs RT (40 Gy) & 1 & 24 & $\begin{array}{l}\text { Mean Difference (IV, Random, 95\% } \\
\mathrm{CI})\end{array}$ & $0.0[-13.58,13.58]$ \\
\hline 3 Treatment toxicity G3+ & 1 & & Risk Ratio (M-H, Random, 95\% Cl) & Subtotals only \\
\hline 3.1 RT (40 Gy) vs RT (60 Gy) & 1 & 61 & Risk Ratio (M-H, Random, 95\% Cl) & $0.0[0.0,0.0]$ \\
\hline
\end{tabular}

Analysis 2.1. Comparison 2 Short-course radiotherapy versus standard radiotherapy, Outcome 1 HRQOL at 4 weeks.

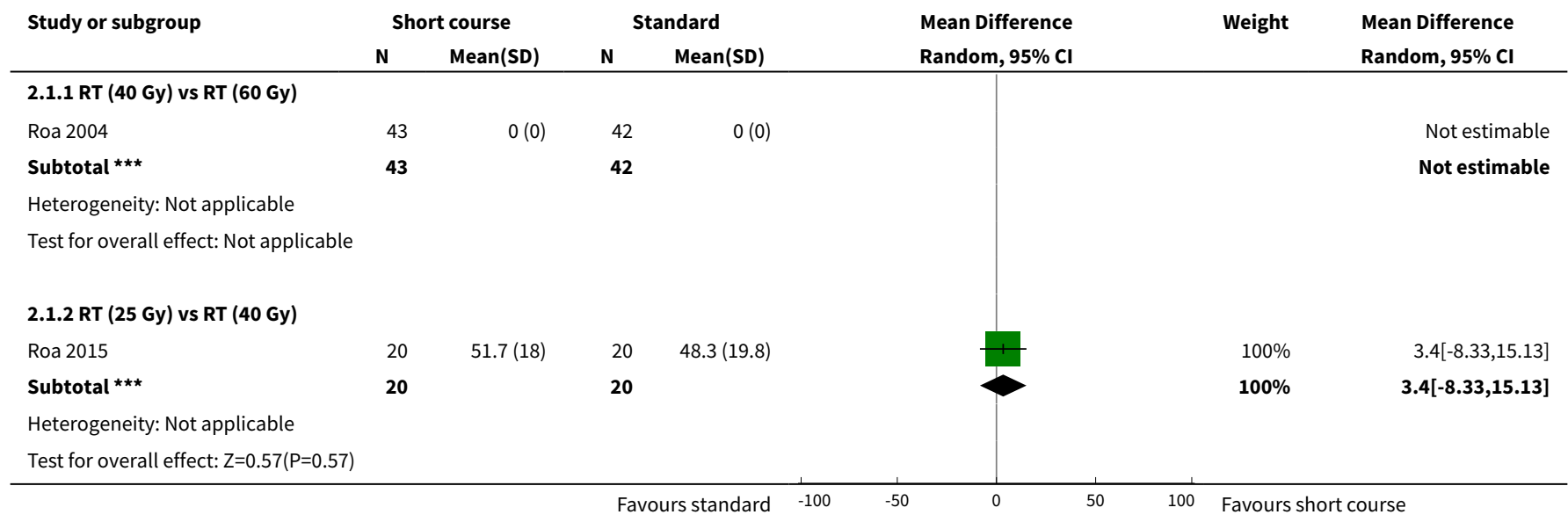

Analysis 2.2. Comparison 2 Short-course radiotherapy versus standard radiotherapy, Outcome 2 HRQOL at 8 weeks.

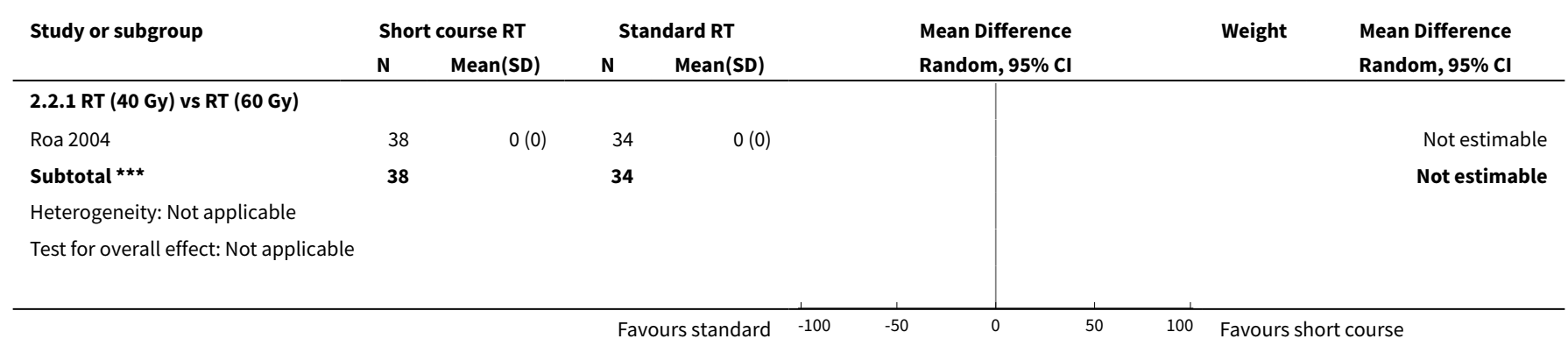




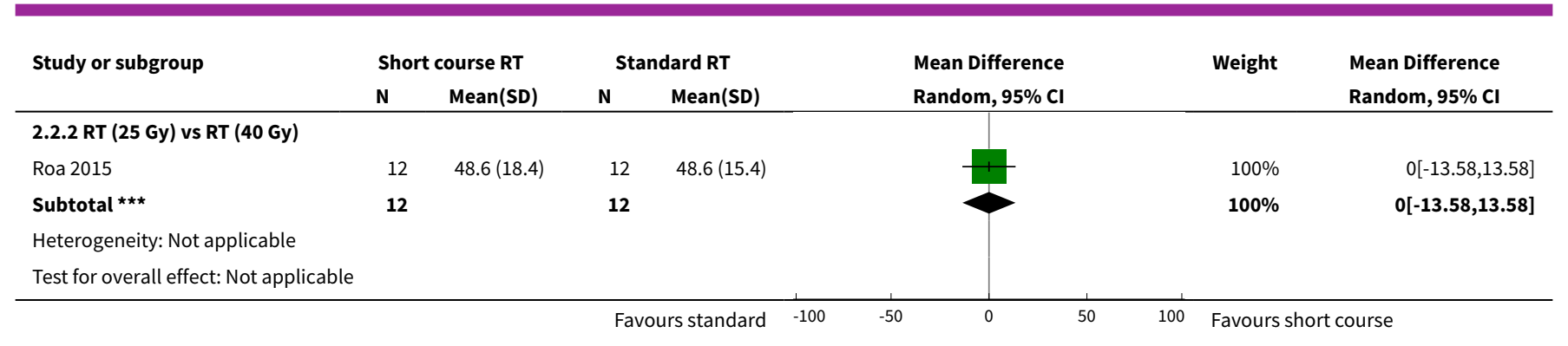

Analysis 2.3. Comparison 2 Short-course radiotherapy versus standard radiotherapy, Outcome 3 Treatment toxicity G3+.

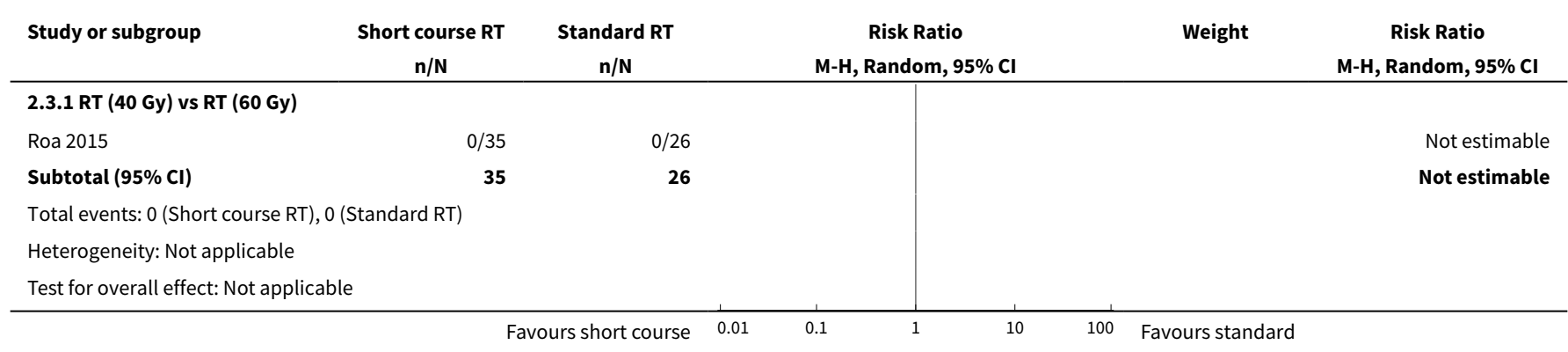

\section{Comparison 3. Chemotherapy versus radiotherapy}

\begin{tabular}{|c|c|c|c|c|}
\hline Outcome or subgroup title & $\begin{array}{l}\text { No. of } \\
\text { studies }\end{array}$ & $\begin{array}{l}\text { No. of } \\
\text { partici- } \\
\text { pants }\end{array}$ & Statistical method & Effect size \\
\hline 1 Progression-free survival & 1 & & Hazard Ratio (Random, 95\% Cl) & Subtotals only \\
\hline 1.1 TMZ vs RT (60 Gy) & 1 & 373 & Hazard Ratio (Random, 95\% Cl) & $1.15[0.92,1.44]$ \\
\hline 2 Thromboembolic event G3+ & 1 & & Risk Ratio (M-H, Random, 95\% Cl) & Subtotals only \\
\hline 2.1 TMZ vs RT (60 Gy) & 1 & 373 & Risk Ratio (M-H, Random, 95\% Cl) & $2.74[1.26,5.94]$ \\
\hline 3 Neutropenia G3+ & 1 & & Risk Ratio (M-H, Random, 95\% Cl) & Subtotals only \\
\hline 3.1 TMZ vs RT (60 Gy) & 1 & 373 & Risk Ratio (M-H, Random, 95\% Cl) & $7.30[1.70,31.31]$ \\
\hline 4 Lymphopenia G3+ & 1 & & Risk Ratio (M-H, Random, 95\% Cl) & Subtotals only \\
\hline 4.1 TMZ vs RT (60 Gy) & 1 & 373 & Risk Ratio (M-H, Random, 95\% Cl) & $41.99[5.85,301.31]$ \\
\hline 5 Thrombocytopenia G3+ & 1 & & Risk Ratio (M-H, Random, 95\% Cl) & Subtotals only \\
\hline 5.1 TMZ vs RT (60 Gy) & 1 & 373 & Risk Ratio (M-H, Random, 95\% Cl) & $3.19[1.07,9.53]$ \\
\hline 6 Infection G3+ & 1 & & Risk Ratio (M-H, Random, 95\% Cl) & Subtotals only \\
\hline 6.1 TMZ vs RT (60 Gy) & 1 & 373 & Risk Ratio (M-H, Random, 95\% Cl) & $1.39[0.86,2.26]$ \\
\hline
\end{tabular}




\begin{tabular}{|c|c|c|c|c|}
\hline Outcome or subgroup title & $\begin{array}{l}\text { No. of } \\
\text { studies }\end{array}$ & $\begin{array}{l}\text { No. of } \\
\text { partici- } \\
\text { pants }\end{array}$ & Statistical method & Effect size \\
\hline 7 Fatigue/asthenia G3+ & 1 & & Risk Ratio (M-H, Random, 95\% Cl) & Subtotals only \\
\hline 7.1 TMZ vs RT (60 Gy) & 1 & 373 & Risk Ratio (M-H, Random, 95\% Cl) & $1.10[0.63,1.91]$ \\
\hline 8 Nausea/vomiting G3+ & 1 & & Risk Ratio (M-H, Random, 95\% Cl) & Subtotals only \\
\hline 8.1 TMZ vs RT (60 Gy) & 1 & 373 & Risk Ratio (M-H, Random, 95\% Cl) & $5.48[0.67,45.05]$ \\
\hline 9 Weight loss G3+ & 1 & & Risk Ratio (M-H, Random, 95\% Cl) & Subtotals only \\
\hline 9.1 TMZ vs RT (60 Gy) & 1 & 373 & Risk Ratio (M-H, Random, 95\% Cl) & $4.57[0.22,94.47]$ \\
\hline 10 Neurological symptoms G3+ & 1 & & Risk Ratio (M-H, Random, 95\% Cl) & Subtotals only \\
\hline 10.1 TMZ vs RT (60 Gy) & 1 & 373 & Risk Ratio (M-H, Random, 95\% Cl) & $1.31[0.82,2.10]$ \\
\hline 11 Seizures G3+ & 1 & & Risk Ratio (M-H, Random, 95\% Cl) & Subtotals only \\
\hline 11.1 TMZ vs RT (60 Gy) & 1 & 373 & Risk Ratio (M-H, Random, 95\% Cl) & $1.19[0.60,2.39]$ \\
\hline 12 Elevated liver enzymes G3+ & 1 & & Risk Ratio (M-H, Random, 95\% Cl) & Subtotals only \\
\hline 12.1 TMZ vs RT (60 Gy) & 1 & 373 & Risk Ratio (M-H, Random, 95\% Cl) & $1.71[0.97,3.03]$ \\
\hline 13 Cutaneous adverse event G3+ & 1 & & Risk Ratio (M-H, Random, 95\% Cl) & Subtotals only \\
\hline 13.1 TMZ vs RT (60 Gy) & 1 & 373 & Risk Ratio (M-H, Random, 95\% Cl) & $0.91[0.06,14.49]$ \\
\hline
\end{tabular}

Analysis 3.1. Comparison 3 Chemotherapy versus radiotherapy, Outcome 1 Progression-free survival.

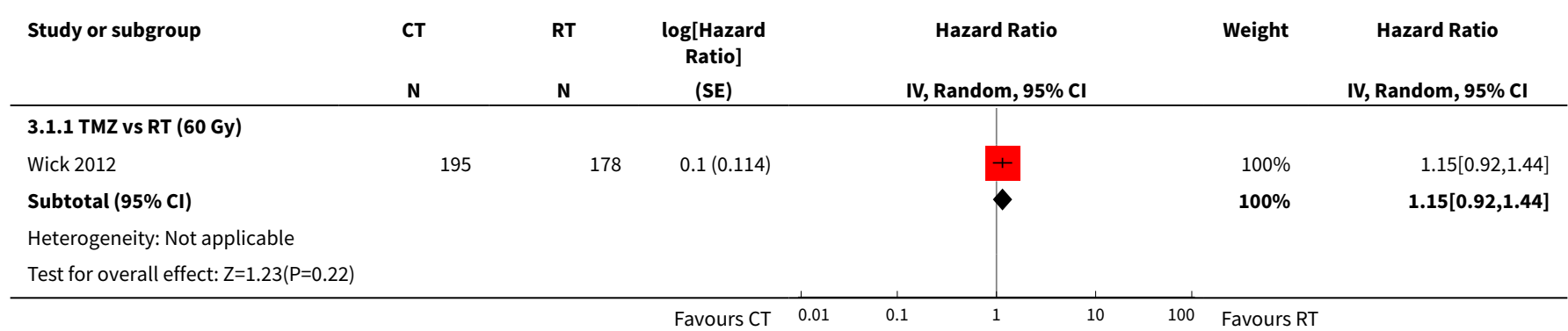

\section{Analysis 3.2. Comparison 3 Chemotherapy versus radiotherapy, Outcome 2 Thromboembolic event G3+.}

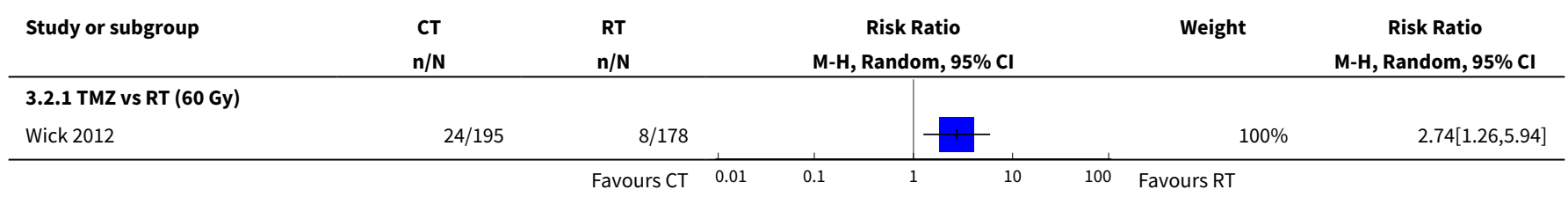




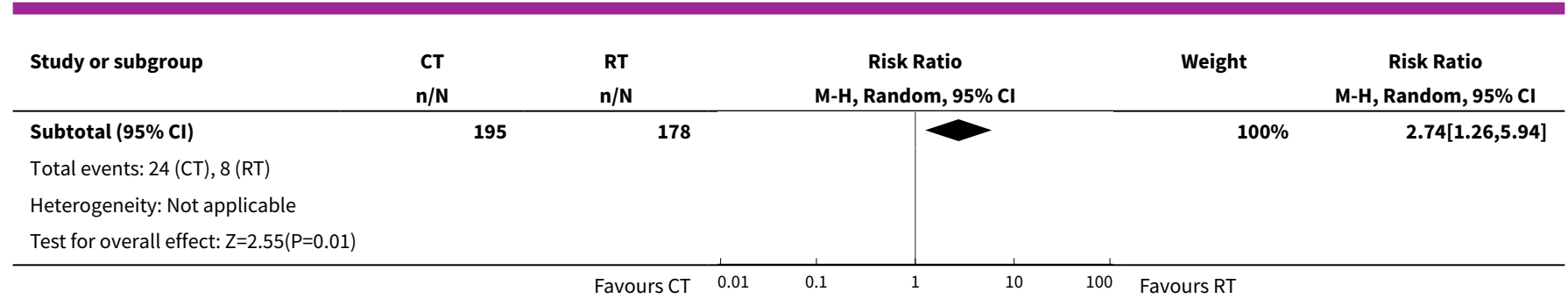

Analysis 3.3. Comparison 3 Chemotherapy versus radiotherapy, Outcome 3 Neutropenia G3+.

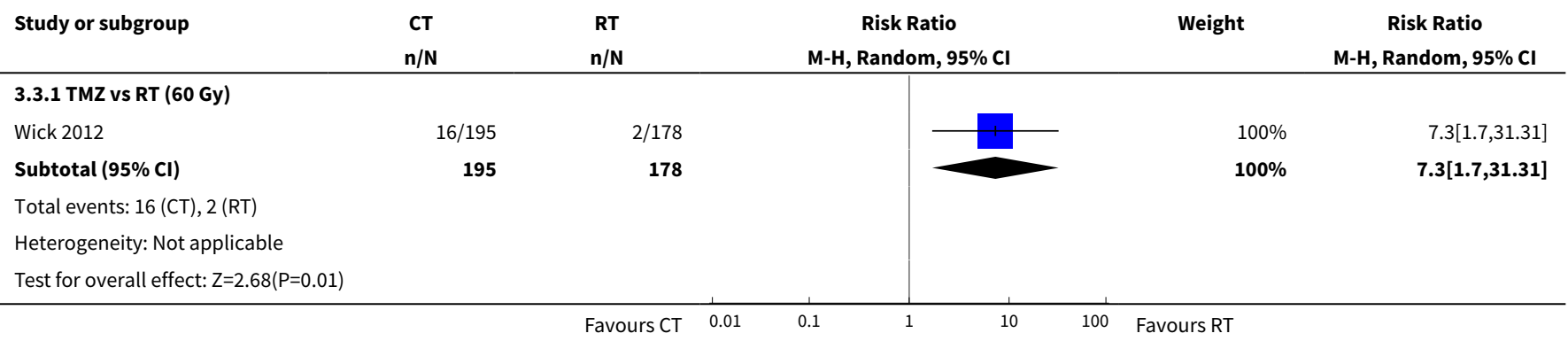

Analysis 3.4. Comparison 3 Chemotherapy versus radiotherapy, Outcome 4 Lymphopenia G3+.

\begin{tabular}{|c|c|c|c|c|c|}
\hline Study or subgroup & $\begin{array}{l}\text { CT } \\
n / N\end{array}$ & $\begin{array}{l}\text { RT } \\
n / N\end{array}$ & $\begin{array}{c}\text { Risk Ratio } \\
\text { M-H, Random, 95\% Cl }\end{array}$ & Weight & $\begin{array}{c}\text { Risk Ratio } \\
\text { M-H, Random, 95\% Cl }\end{array}$ \\
\hline \multicolumn{6}{|l|}{ 3.4.1 TMZ vs RT ( 60 Gy) } \\
\hline Subtotal $(95 \% \mathrm{Cl})$ & 195 & 178 & & $100 \%$ & $41.99[5.85,301.31]$ \\
\hline \multicolumn{6}{|l|}{ Total events: 46 (CT), 1 (RT) } \\
\hline \multicolumn{6}{|l|}{ Heterogeneity: Not applicable } \\
\hline \multicolumn{6}{|l|}{ Test for overall effect: $Z=3.72(P=0)$} \\
\hline & & Favours CT & 0.1 & ours RT & \\
\hline
\end{tabular}

Analysis 3.5. Comparison 3 Chemotherapy versus radiotherapy, Outcome 5 Thrombocytopenia G3+.

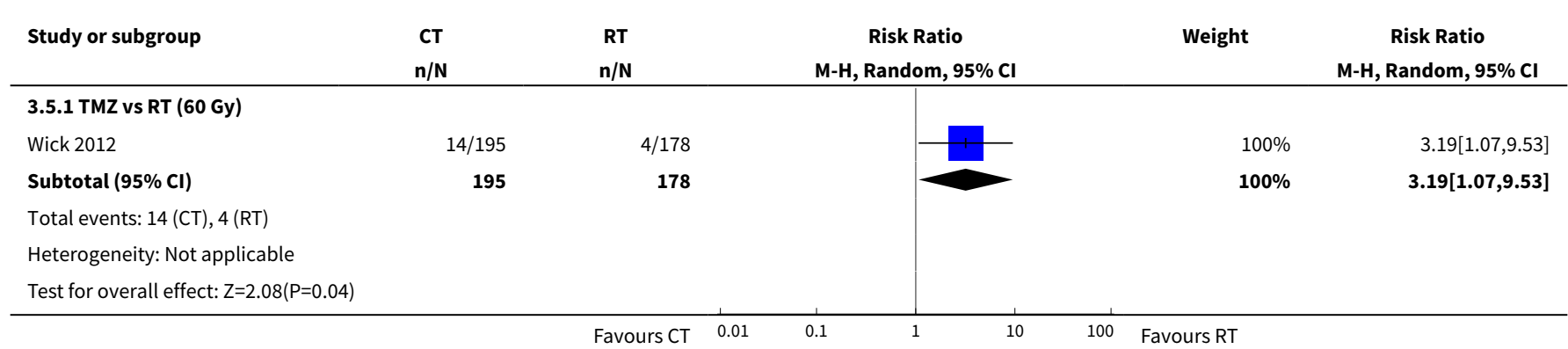


Analysis 3.6. Comparison 3 Chemotherapy versus radiotherapy, Outcome 6 Infection G3+.

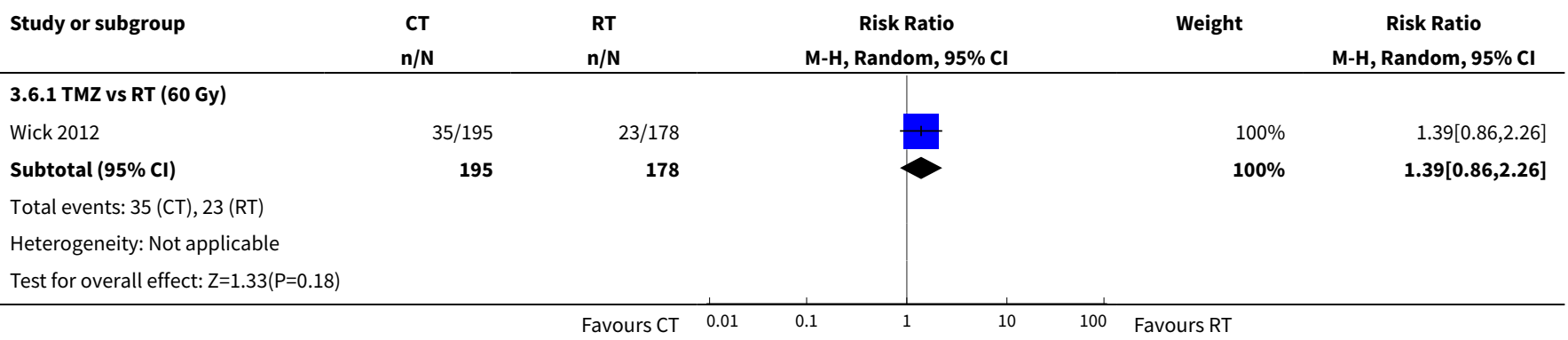

Analysis 3.7. Comparison 3 Chemotherapy versus radiotherapy, Outcome 7 Fatigue/asthenia G3+.

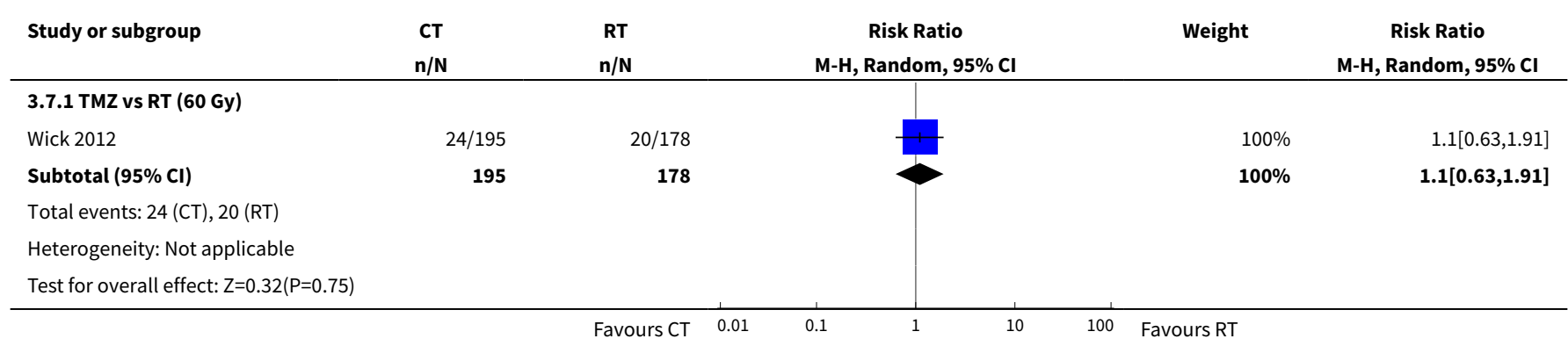

Analysis 3.8. Comparison 3 Chemotherapy versus radiotherapy, Outcome $8 \mathrm{Nausea/vomiting} \mathrm{G3+.}$

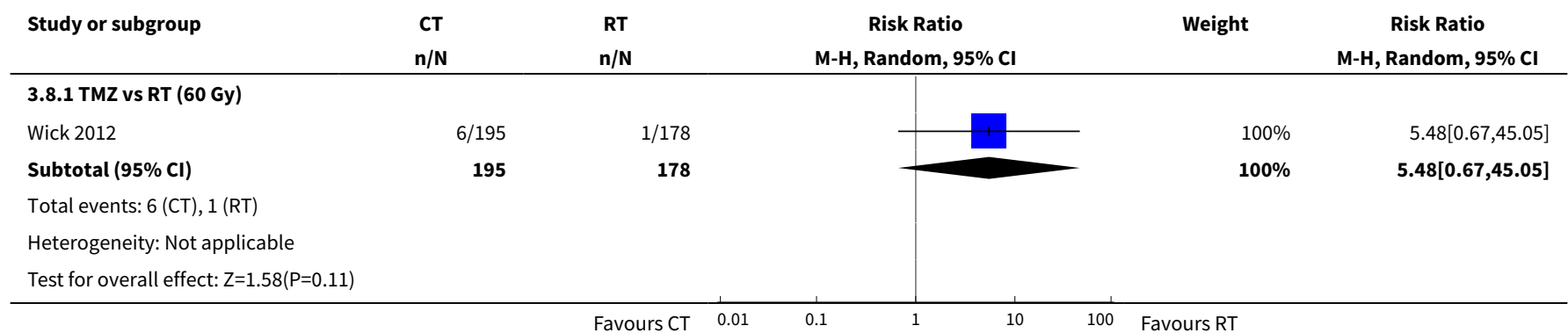

Analysis 3.9. Comparison 3 Chemotherapy versus radiotherapy, Outcome 9 Weight loss G3+.

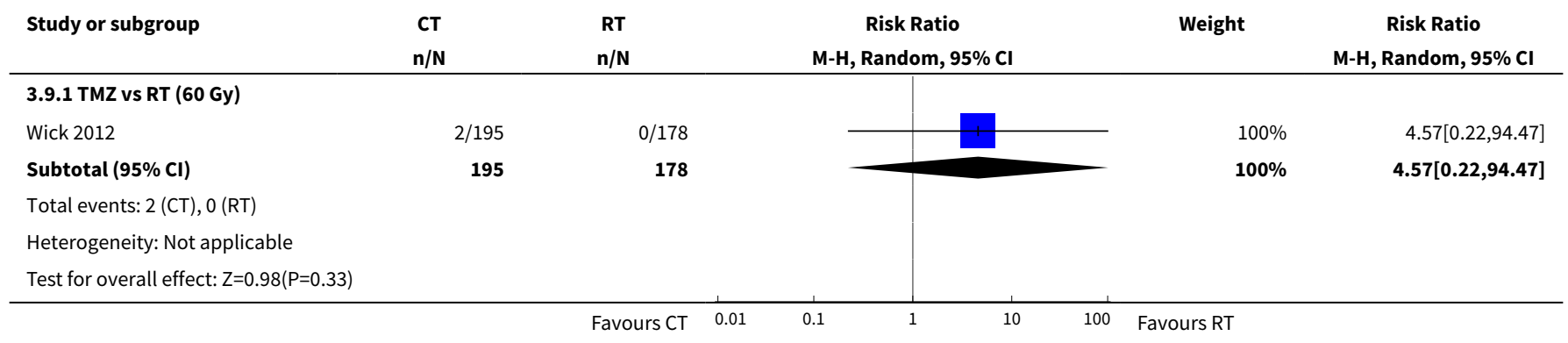


Analysis 3.10. Comparison 3 Chemotherapy versus radiotherapy, Outcome 10 Neurological symptoms G3+.

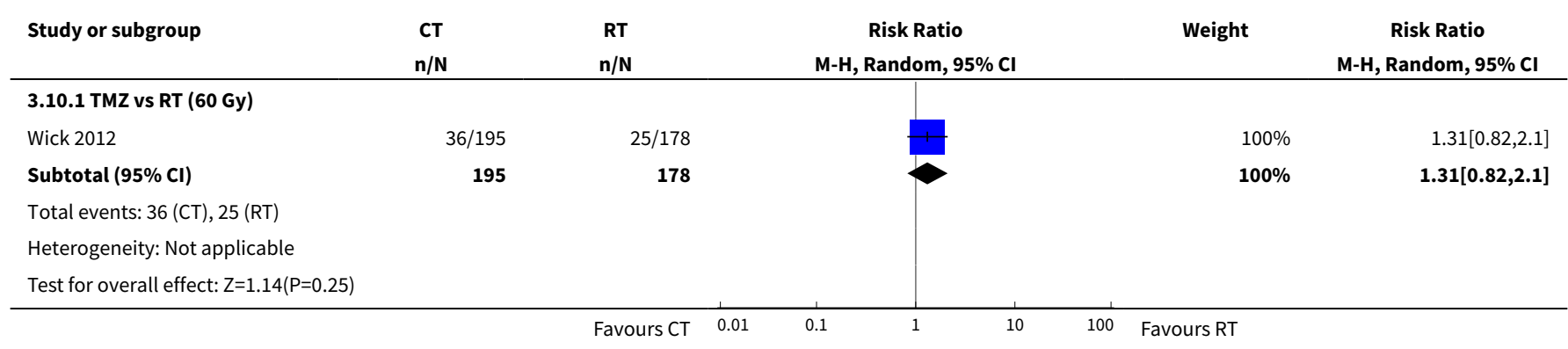

\section{Analysis 3.11. Comparison 3 Chemotherapy versus radiotherapy, Outcome 11 Seizures G3+.}

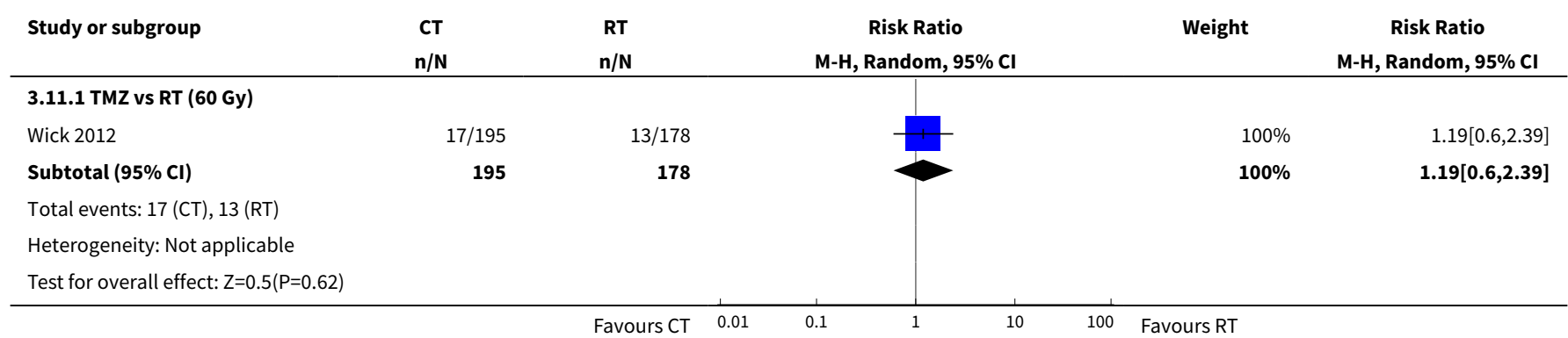

Analysis 3.12. Comparison 3 Chemotherapy versus radiotherapy, Outcome 12 Elevated liver enzymes G3+.

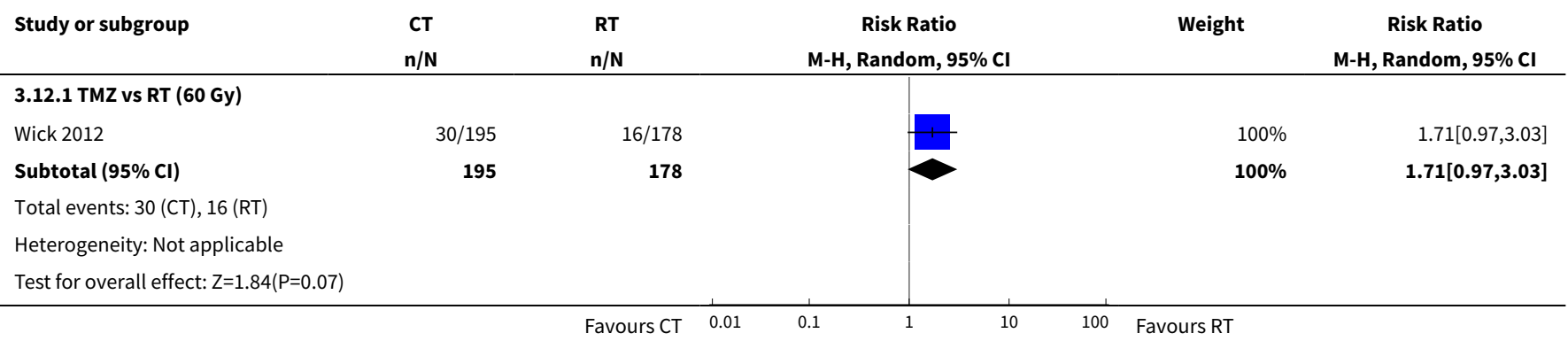

Analysis 3.13. Comparison 3 Chemotherapy versus radiotherapy, Outcome 13 Cutaneous adverse event G3+.

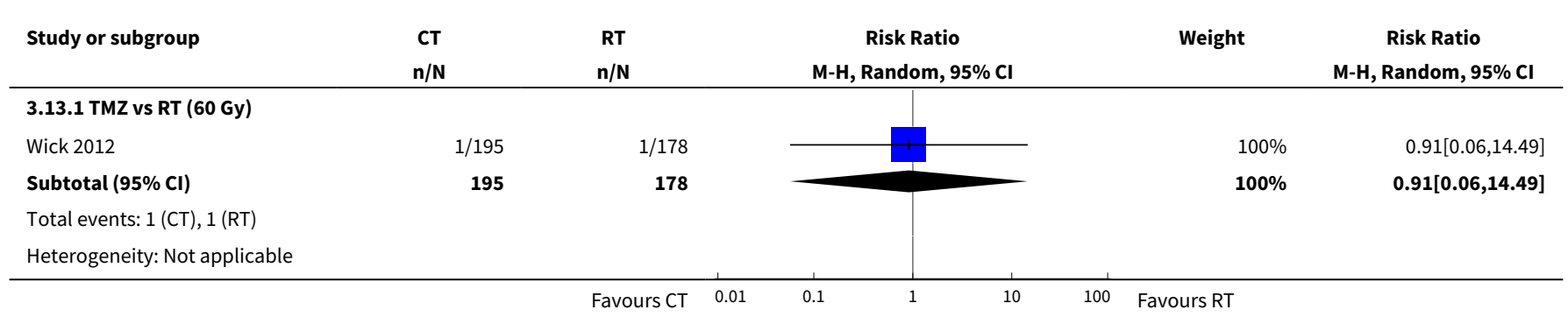




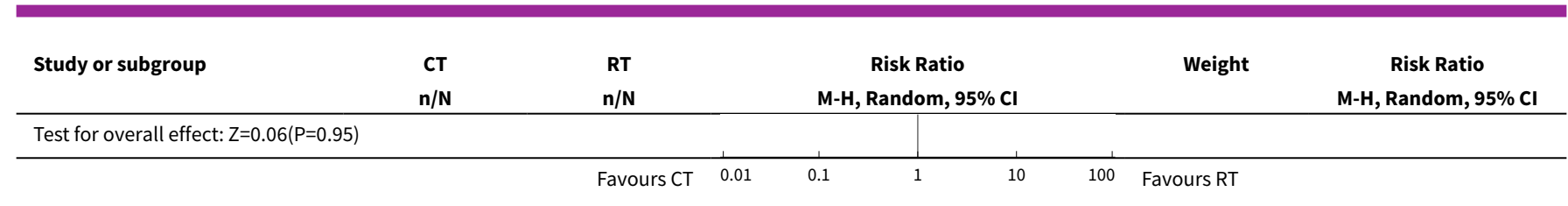

\section{Comparison 4. Chemoradiotherapy versus radiotherapy}

\begin{tabular}{|c|c|c|c|c|}
\hline Outcome or subgroup title & $\begin{array}{l}\text { No. of } \\
\text { studies }\end{array}$ & $\begin{array}{l}\text { No. of } \\
\text { partici- } \\
\text { pants }\end{array}$ & Statistical method & Effect size \\
\hline 1 Progression-free survival & 1 & & $\begin{array}{l}\text { Hazard Ratio (Random, 95\% } \\
\mathrm{Cl} \text { ) }\end{array}$ & Subtotals only \\
\hline 1.1 TMZ+RT (40 Gy) vs RT (40 Gy) & 1 & 562 & $\begin{array}{l}\text { Hazard Ratio (Random, 95\% } \\
\mathrm{Cl} \text { ) }\end{array}$ & $0.50[0.41,0.61]$ \\
\hline 2 Neutropenia G3+ & 1 & & $\begin{array}{l}\text { Risk Ratio (M-H, Random, 95\% } \\
\text { Cl) }\end{array}$ & Subtotals only \\
\hline 2.1 TMZ + RT (40 Gy) vs RT (40 Gy) & 1 & 515 & $\begin{array}{l}\text { Risk Ratio (M-H, Random, 95\% } \\
\mathrm{Cl} \text { ) }\end{array}$ & $10.30[2.45,43.34]$ \\
\hline 3 Thrombocytopenia G3+ & 1 & & $\begin{array}{l}\text { Risk Ratio (M-H, Random, 95\% } \\
\mathrm{Cl} \text { ) }\end{array}$ & Subtotals only \\
\hline 3.1 TMZ + RT (40 Gy) vs RT (40 Gy) & 1 & 527 & $\begin{array}{l}\text { Risk Ratio (M-H, Random, 95\% } \\
\text { Cl) }\end{array}$ & $28.56[3.92,207.86]$ \\
\hline 4 Lymphopenia G3+ & 1 & & $\begin{array}{l}\text { Risk Ratio (M-H, Random, 95\% } \\
\mathrm{Cl} \text { ) }\end{array}$ & Subtotals only \\
\hline 4.1 TMZ + RT (40 Gy) vs RT (40 Gy) & 1 & 521 & $\begin{array}{l}\text { Risk Ratio (M-H, Random, 95\% } \\
\mathrm{Cl} \text { ) }\end{array}$ & $2.65[1.75,4.01]$ \\
\hline 5 Leucopenia G3+ & 1 & & $\begin{array}{l}\text { Risk Ratio (M-H, Random, 95\% } \\
\text { Cl) }\end{array}$ & Subtotals only \\
\hline 5.1 TMZ + RT (40 Gy) vs RT (40 Gy) & 1 & 528 & $\begin{array}{l}\text { Risk Ratio (M-H, Random, 95\% } \\
\mathrm{Cl} \text { ) }\end{array}$ & $18.16[2.45,134.64]$ \\
\hline 6 Anaemia G3+ & 1 & & $\begin{array}{l}\text { Risk Ratio (M-H, Random, 95\% } \\
\mathrm{Cl} \text { ) }\end{array}$ & Subtotals only \\
\hline 6.1 TMZ + RT (40 Gy) vs RT (40 Gy) & 1 & 528 & $\begin{array}{l}\text { Risk Ratio (M-H, Random, 95\% } \\
\text { Cl) }\end{array}$ & $6.69[0.35,128.88]$ \\
\hline 7 Treatment toxicity G3+ & 1 & & $\begin{array}{l}\text { Risk Ratio (M-H, Random, 95\% } \\
\mathrm{Cl} \text { ) }\end{array}$ & Subtotals only \\
\hline 7.1 TMZ + RT (40 Gy) vs RT (40 Gy) & 1 & 528 & $\begin{array}{l}\text { Risk Ratio (M-H, Random, 95\% } \\
\mathrm{Cl} \text { ) }\end{array}$ & $1.04[0.68,1.59]$ \\
\hline
\end{tabular}


Analysis 4.1. Comparison 4 Chemoradiotherapy versus radiotherapy, Outcome 1 Progression-free survival.

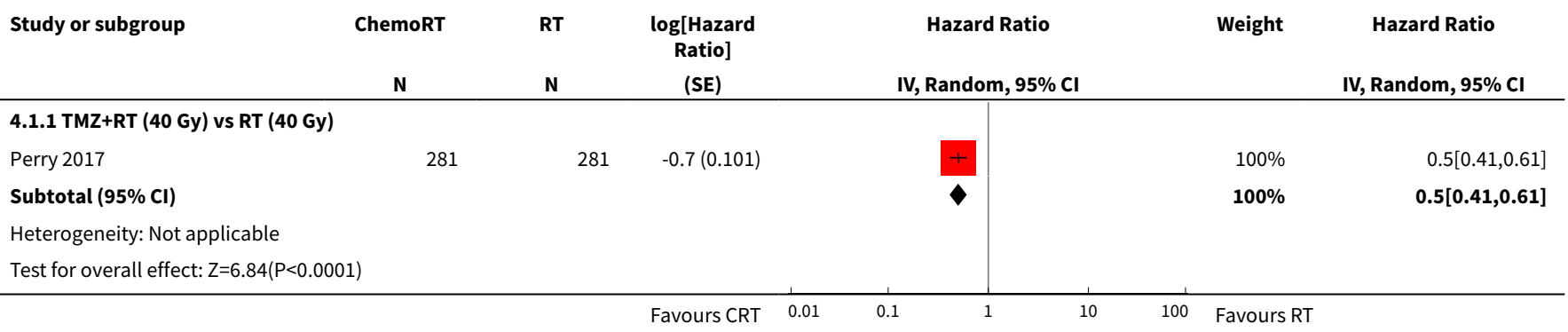

Analysis 4.2. Comparison 4 Chemoradiotherapy versus radiotherapy, Outcome 2 Neutropenia G3+.

\begin{tabular}{|c|c|c|c|c|c|}
\hline Study or subgroup & $\begin{array}{c}\text { ChemoRT } \\
\mathrm{n} / \mathrm{N}\end{array}$ & $\begin{array}{l}\mathbf{R T} \\
\mathrm{n} / \mathrm{N}\end{array}$ & $\begin{array}{c}\text { Risk Ratio } \\
\text { M-H, Random, } 95 \% \text { Cl }\end{array}$ & Weight & $\begin{array}{c}\text { Risk Ratio } \\
\text { M-H, Random, } 95 \% \text { CI }\end{array}$ \\
\hline \multicolumn{6}{|c|}{ 4.2.1 TMZ + RT (40 Gy) vs RT (40 Gy) } \\
\hline Perry 2017 & $22 / 266$ & $2 / 249$ & & $100 \%$ & $10.3[2.45,43.34]$ \\
\hline Subtotal $(95 \% \mathrm{CI})$ & 266 & 249 & & $100 \%$ & $10.3[2.45,43.34]$ \\
\hline \multicolumn{6}{|c|}{ Total events: 22 (ChemoRT), 2 (RT) } \\
\hline \multicolumn{6}{|c|}{ Heterogeneity: Not applicable } \\
\hline
\end{tabular}

Analysis 4.3. Comparison 4 Chemoradiotherapy versus radiotherapy, Outcome 3 Thrombocytopenia G3+.

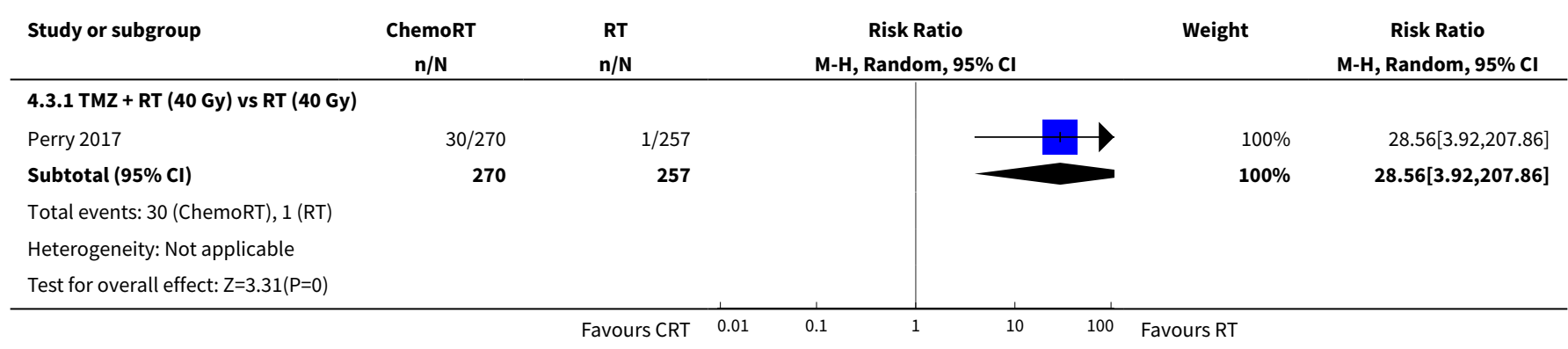

Analysis 4.4. Comparison 4 Chemoradiotherapy versus radiotherapy, Outcome 4 Lymphopenia G3+.

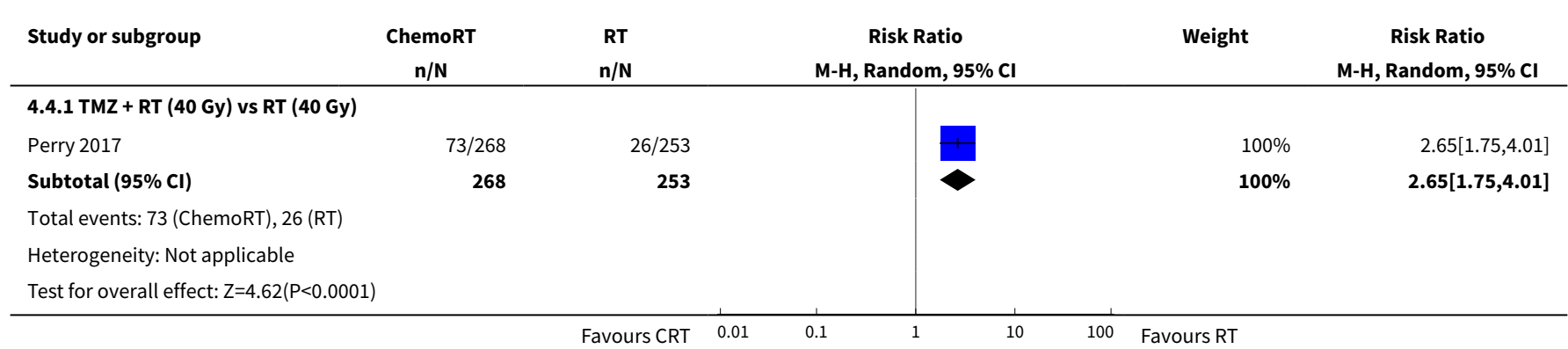


Analysis 4.5. Comparison 4 Chemoradiotherapy versus radiotherapy, Outcome 5 Leucopenia G3+.

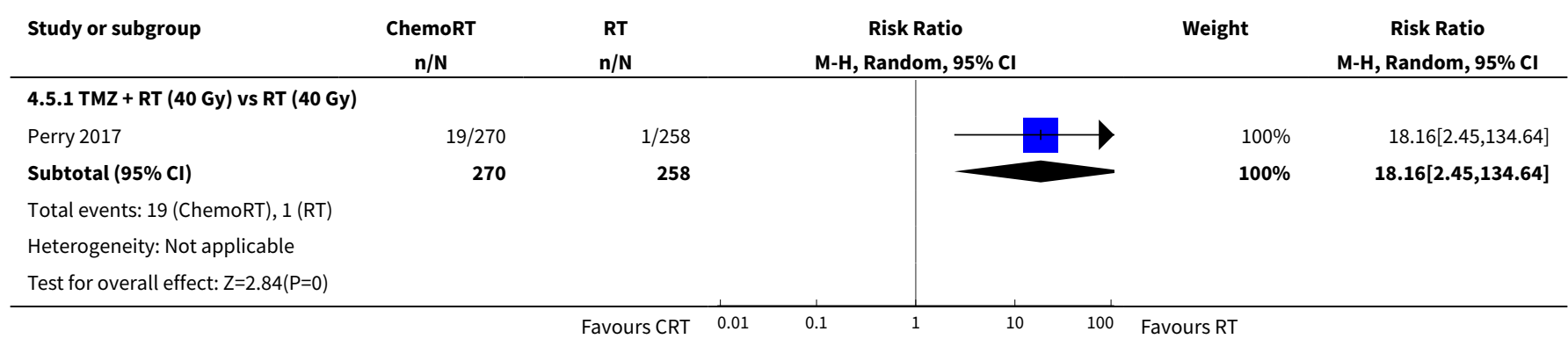

Analysis 4.6. Comparison 4 Chemoradiotherapy versus radiotherapy, Outcome 6 Anaemia G3+.

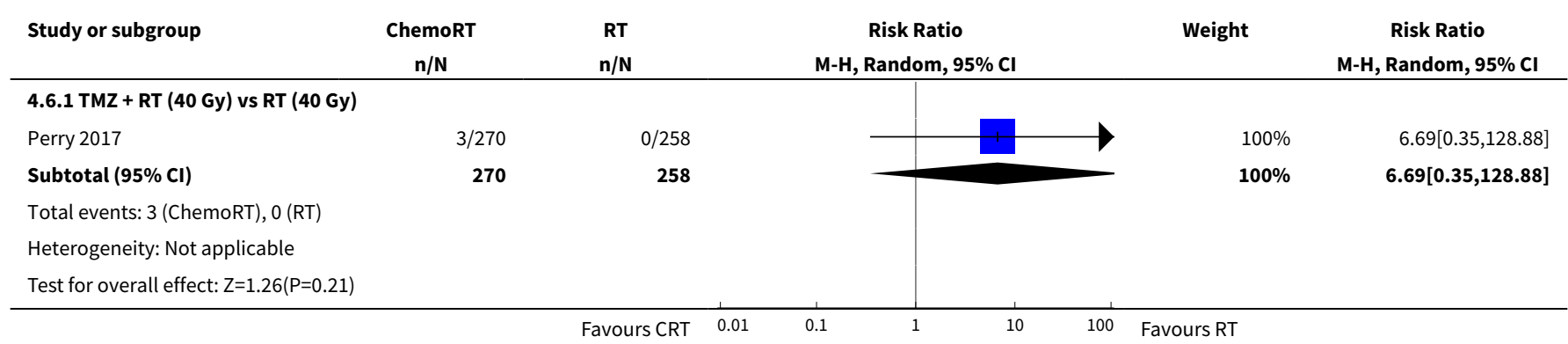

\section{Analysis 4.7. Comparison 4 Chemoradiotherapy versus radiotherapy, Outcome 7 Treatment toxicity G3+.}

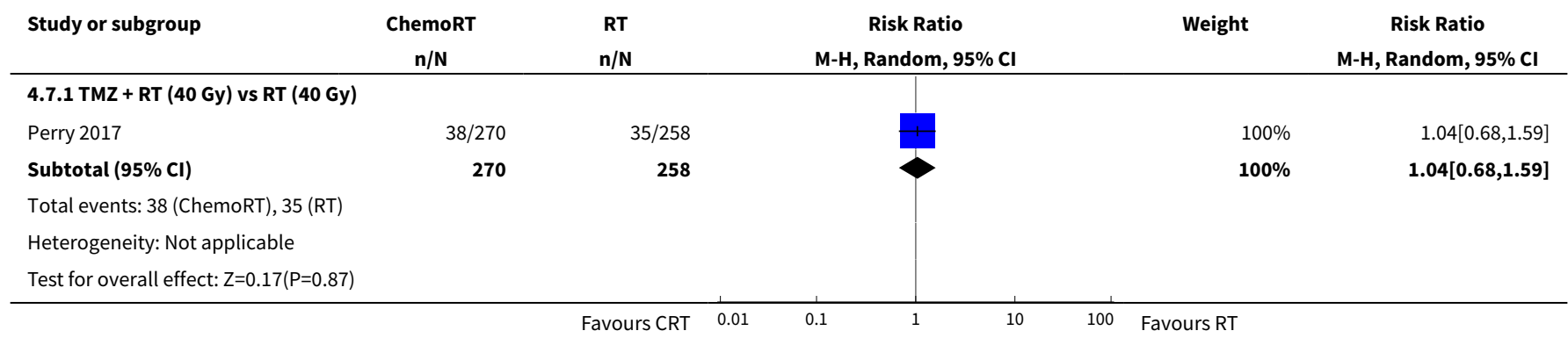

\section{Comparison 5. Other + chemoradiotherapy versus chemoradiotherapy}

\begin{tabular}{lllll}
\hline Outcome or subgroup title & $\begin{array}{l}\text { No. of } \\
\text { studies }\end{array}$ & $\begin{array}{l}\text { No. of } \\
\text { partici- } \\
\text { pants }\end{array}$ & Statistical method & Effect size \\
\hline 1 Progression-free survival & 1 & & Hazard Ratio (Random, 95\% Cl) & Subtotals only \\
\hline $\begin{array}{l}1.1 \mathrm{BEV}+\mathrm{chemoRT}(60 \mathrm{~Gy}) \text { vs } \\
\text { chemoRT }\end{array}$ & 1 & 73 & Hazard Ratio (Random, $95 \% \mathrm{Cl})$ & $0.78[0.46,1.32]$ \\
\hline
\end{tabular}




\begin{tabular}{lllll}
\hline Outcome or subgroup title & $\begin{array}{l}\text { No. of } \\
\text { studies }\end{array}$ & $\begin{array}{l}\text { No. of } \\
\text { partici- } \\
\text { pants }\end{array}$ & Statistical method & Effect size \\
\hline 2 Thromboembolic events G3+ & 1 & & Risk Ratio (M-H, Random, 95\% Cl) & Subtotals only \\
\hline $\begin{array}{l}2.1 \mathrm{BEV}+\text { chemoRT }(60 \mathrm{~Gy}) \text { vs } \\
\text { chemoRT }\end{array}$ & 1 & 73 & Risk Ratio (M-H, Random, 95\% Cl) & $16.63[1.00,275.42]$ \\
\hline
\end{tabular}

\section{Analysis 5.1. Comparison 5 Other + chemoradiotherapy versus} chemoradiotherapy, Outcome 1 Progression-free survival.

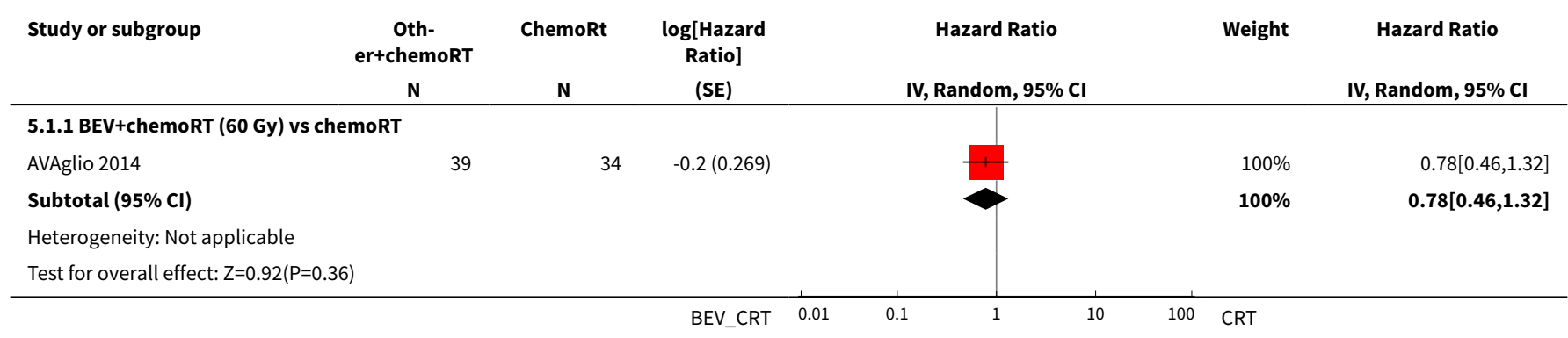

\section{Analysis 5.2. Comparison 5 Other + chemoradiotherapy versus} chemoradiotherapy, Outcome 2 Thromboembolic events G3+.

\begin{tabular}{|c|c|c|c|c|c|}
\hline Study or subgroup & $\begin{array}{c}\text { Oth- } \\
\text { er+chemoRT } \\
n / N \\
\end{array}$ & $\begin{array}{c}\text { ChemoRt } \\
\text { n/N }\end{array}$ & $\begin{array}{c}\text { Risk Ratio } \\
\text { M-H, Random, } 95 \% \mathrm{Cl} \\
\end{array}$ & Weight & $\begin{array}{c}\text { Risk Ratio } \\
\text { M-H, Random, } 95 \% \mathrm{Cl} \\
\end{array}$ \\
\hline \multicolumn{3}{|c|}{ 5.2.1 BEV+chemoRT (60 Gy) vs chemoRT } & & & \\
\hline AVAglio 2014 & $9 / 39$ & $0 / 34$ & & $100 \%$ & $16.63[1,275.42]$ \\
\hline Subtotal $(95 \% \mathrm{Cl})$ & 39 & 34 & & $100 \%$ & $16.63[1,275.42]$ \\
\hline \multicolumn{6}{|c|}{ Total events: 9 (Other+chemoRT), 0 (ChemoRt) } \\
\hline Test for overall effect & & & & & \\
\hline
\end{tabular}

\section{Comparison 6. Other + radiotherapy ( $40 \mathrm{~Gy}$ ) versus radiotherapy (40 Gy)}

\begin{tabular}{lllll}
\hline Outcome or subgroup title & $\begin{array}{l}\text { No. of } \\
\text { studies }\end{array}$ & $\begin{array}{l}\text { No. of } \\
\text { partici- } \\
\text { pants }\end{array}$ & Statistical method & Effect size \\
\hline 1 Progression-free survival & 1 & & Hazard Ratio (Random, 95\% Cl) & Subtotals only \\
\hline 1.1 BEV+RT vs RT & 1 & 75 & Hazard Ratio (Random, 95\% Cl) & $0.46[0.27,0.78]$ \\
\hline 2 Thromboembolic events G3+ & 1 & 75 & Risk Ratio (M-H, Random, 95\% Cl) & $2.0[0.46,8.73]$ \\
\hline 3 Haematological events G3+ & 1 & 75 & Risk Ratio (M-H, Random, 95\% Cl) & $2.55[0.13,51.17]$ \\
\hline \hline
\end{tabular}




\begin{tabular}{llllll}
\hline Outcome or subgroup title & $\begin{array}{l}\text { No. of } \\
\text { studies }\end{array}$ & $\begin{array}{l}\text { No. of } \\
\text { partici- } \\
\text { pants }\end{array}$ & Statistical method & Effect size \\
\hline 4 Infections G3+ & 1 & 75 & Risk Ratio (M-H, Random, 95\% Cl) & $1.17[0.33,4.13]$ \\
\hline 5 Fatigue G3+ & 1 & 75 & Risk Ratio (M-H, Random, 95\% Cl) & $0.75[0.13,4.20]$ \\
\hline 6 Seizures G3+ & 1 & 75 & Risk Ratio (M-H, Random, 95\% Cl) & $4.59[0.26,82.01]$ \\
\hline 7 Headaches G3+ & 1 & 75 & Risk Ratio (M-H, Random, 95\% Cl) & $0.17[0.01,4.03]$ \\
\hline 8 Neuropsychiatric events G3+ & 1 & 75 & Risk Ratio (M-H, Random, 95\% Cl) & $2.0[0.24,16.97]$ \\
\hline 9 Neurological events G3+ & 1 & 75 & Risk Ratio (M-H, Random, 95\% Cl) & $0.9[0.34,2.40]$ \\
\hline 10 Hypertension G3+ & 1 & 75 & Risk Ratio (M-H, Random, 95\% Cl) & $1.0[0.20,5.09]$ \\
\hline 11 Cutaneous adverse events G3+ & 1 & 75 & Risk Ratio (M-H, Random, 95\% Cl) & $0.0[0.0,0.0]$
\end{tabular}

Analysis 6.1. Comparison 6 Other + radiotherapy ( $40 \mathrm{~Gy}$ ) versus radiotherapy (40 Gy), Outcome 1 Progression-free survival.

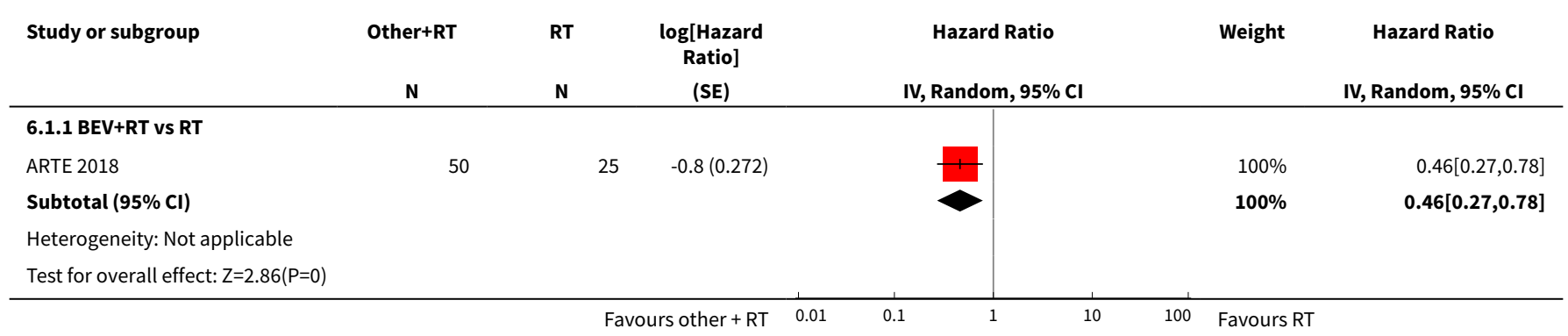

Analysis 6.2. Comparison 6 Other + radiotherapy ( $40 \mathrm{~Gy}$ ) versus radiotherapy ( $40 \mathrm{~Gy}$ ), Outcome 2 Thromboembolic events $\mathrm{G} 3+$.

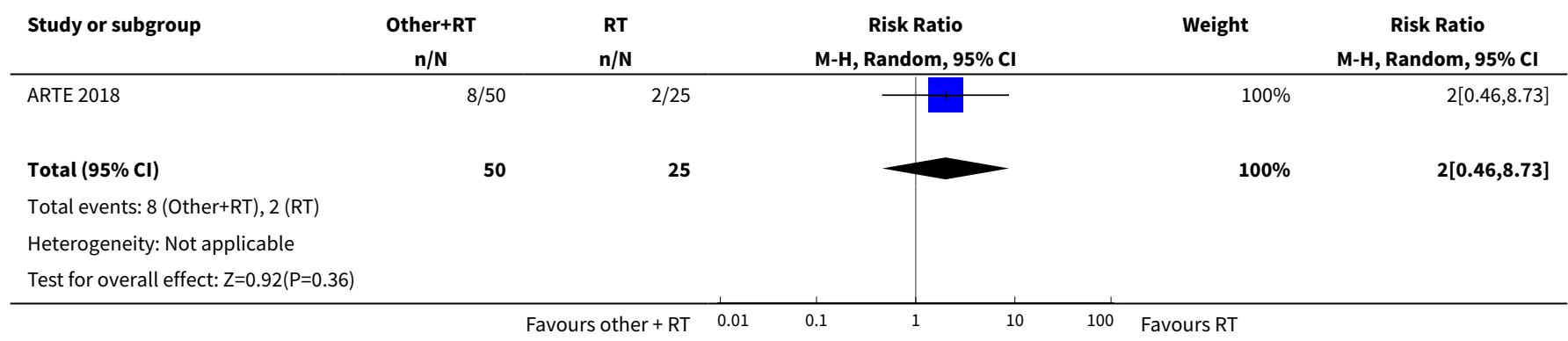


Analysis 6.3. Comparison 6 Other + radiotherapy (40 Gy) versus radiotherapy (40 Gy), Outcome 3 Haematological events G3+.

\begin{tabular}{|c|c|c|c|c|c|}
\hline Study or subgroup & $\begin{array}{c}\text { Other+RT } \\
\mathrm{n} / \mathrm{N}\end{array}$ & $\begin{array}{l}\text { RT } \\
\mathrm{n} / \mathrm{N}\end{array}$ & $\begin{array}{c}\text { Risk Ratio } \\
\text { M-H, Random, } 95 \% \mathrm{CI}\end{array}$ & Weight & $\begin{array}{c}\text { Risk Ratio } \\
\text { M-H, Random, } 95 \% \mathrm{Cl}\end{array}$ \\
\hline ARTE 2018 & $2 / 50$ & $0 / 25$ & 1 & $100 \%$ & $2.55[0.13,51.17]$ \\
\hline Total $(95 \% \mathrm{Cl})$ & 50 & 25 & & $100 \%$ & $2.55[0.13,51.17]$ \\
\hline \multicolumn{6}{|c|}{ Total events: 2 (Other+RT), 0 (RT) } \\
\hline \multicolumn{6}{|c|}{ Heterogeneity: Not applicable } \\
\hline Test for overall effec & & & & & \\
\hline
\end{tabular}

Analysis 6.4. Comparison 6 Other + radiotherapy (40 Gy) versus radiotherapy (40 Gy), Outcome 4 Infections G3+.

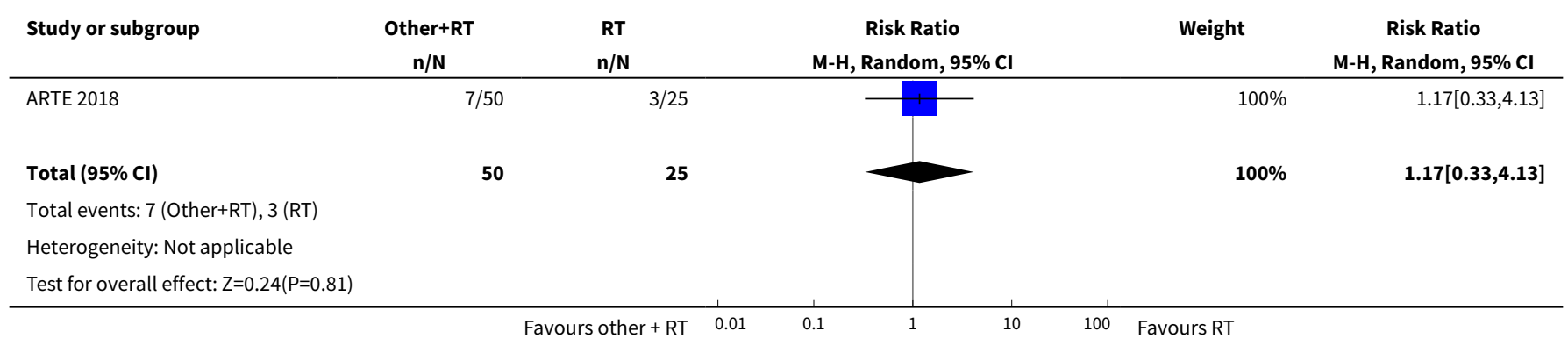

Analysis 6.5. Comparison 6 Other + radiotherapy ( $40 \mathrm{~Gy}$ ) versus radiotherapy (40 Gy), Outcome 5 Fatigue G3+.

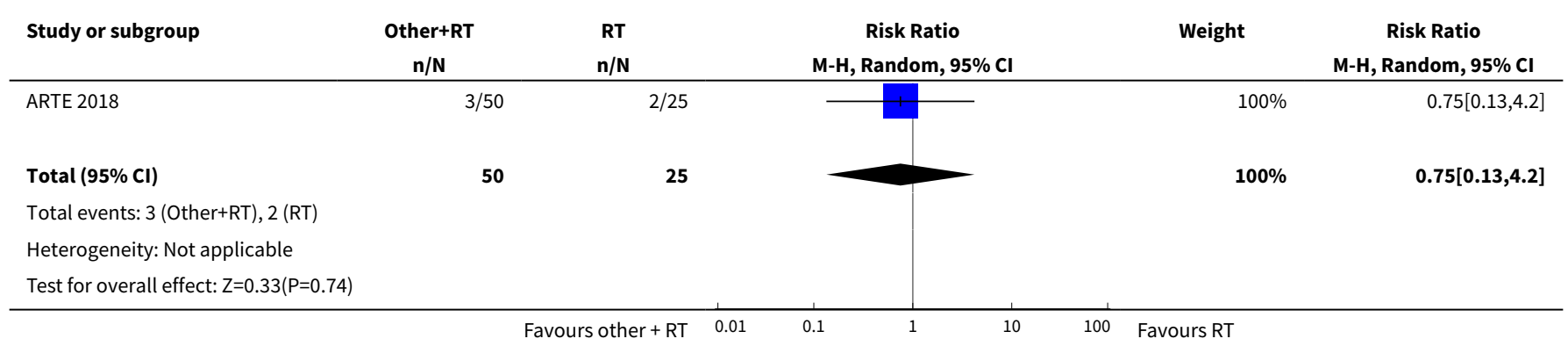

Analysis 6.6. Comparison 6 Other + radiotherapy (40 Gy) versus radiotherapy (40 Gy), Outcome 6 Seizures G3+.

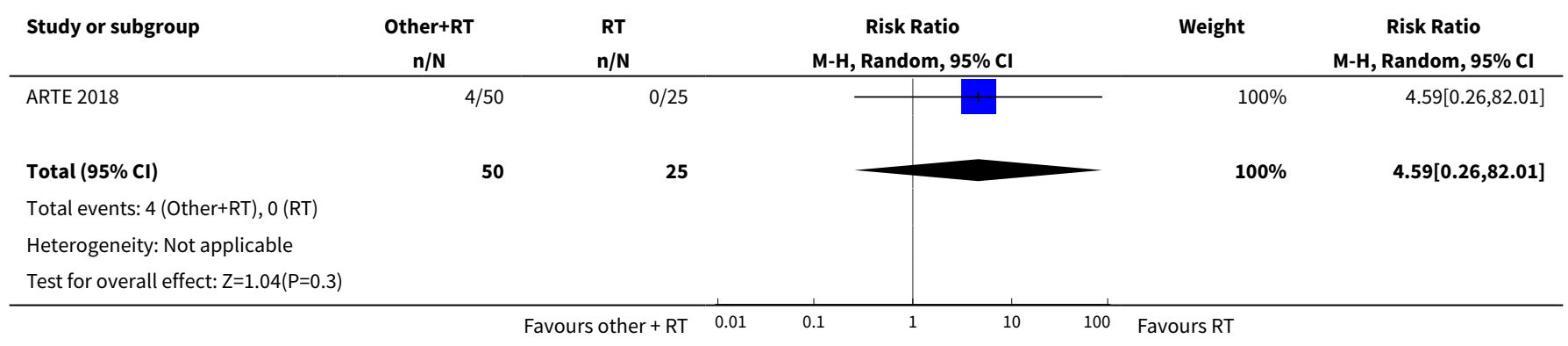


Analysis 6.7. Comparison 6 Other + radiotherapy ( $40 \mathrm{~Gy}$ ) versus radiotherapy ( $40 \mathrm{~Gy}$ ), Outcome 7 Headaches $\mathrm{G3}+$.

\begin{tabular}{|c|c|c|c|c|c|}
\hline Study or subgroup & $\begin{array}{c}\text { Other+RT } \\
n / N\end{array}$ & $\begin{array}{l}\mathrm{RT} \\
\mathrm{n} / \mathrm{N}\end{array}$ & $\begin{array}{c}\text { Risk Ratio } \\
\text { M-H, Random, } 95 \% \mathrm{Cl}\end{array}$ & Weight & $\begin{array}{c}\text { Risk Ratio } \\
\text { M-H, Random, } 95 \% \mathrm{Cl}\end{array}$ \\
\hline ARTE 2018 & $0 / 50$ & $1 / 25$ & {$\left[\begin{array}{l}-2 \\
\end{array}\right.$} & $100 \%$ & $0.17[0.01,4.03]$ \\
\hline Total $(95 \% \mathrm{Cl})$ & 50 & 25 & & $100 \%$ & $0.17[0.01,4.03]$ \\
\hline \multicolumn{6}{|c|}{ Total events: 0 (Other+RT), 1 (RT) } \\
\hline \multicolumn{6}{|c|}{ Heterogeneity: Not applicable } \\
\hline Test for overall effect & & & & & \\
\hline
\end{tabular}

Analysis 6.8. Comparison 6 Other + radiotherapy ( $40 \mathrm{~Gy})$ versus radiotherapy (40 Gy), Outcome 8 Neuropsychiatric events G3+.

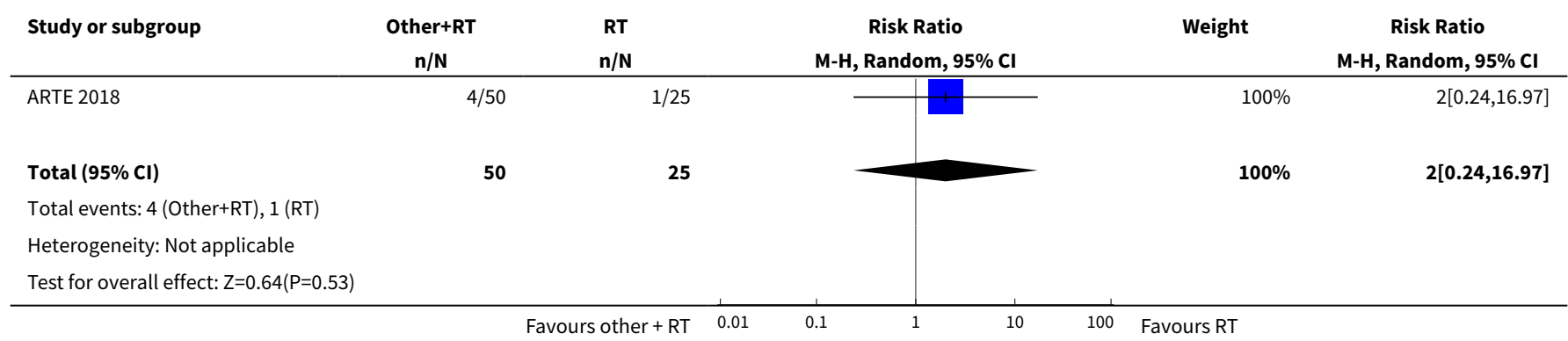

Analysis 6.9. Comparison 6 Other + radiotherapy ( $40 \mathrm{~Gy}$ ) versus radiotherapy (40 Gy), Outcome 9 Neurological events G3+.

\begin{tabular}{|c|c|c|c|c|c|}
\hline Study or subgroup & $\begin{array}{c}\text { Other+RT } \\
\text { n/N } \\
\end{array}$ & $\begin{array}{l}\text { RT } \\
\mathrm{n} / \mathrm{N} \\
\end{array}$ & $\begin{array}{c}\text { Risk Ratio } \\
\text { M-H, Random, } 95 \% \text { Cl }\end{array}$ & Weight & $\begin{array}{c}\text { Risk Ratio } \\
\text { M-H, Random, 95\% Cl }\end{array}$ \\
\hline ARTE 2018 & $9 / 50$ & $5 / 25$ & $\longrightarrow$ & $100 \%$ & $0.9[0.34,2.4]$ \\
\hline Total $(95 \% \mathrm{Cl})$ & 50 & 25 & & $100 \%$ & $0.9[0.34,2.4]$ \\
\hline \multicolumn{6}{|c|}{ Total events: 9 (Other+RT), 5 (RT) } \\
\hline \multicolumn{6}{|c|}{ Heterogeneity: $\mathrm{Tau}^{2}=0 ; \mathrm{Chi}^{2}=0, \mathrm{df}=0(\mathrm{P}<0.0001) ; \mathrm{I}^{2}=100 \%$} \\
\hline
\end{tabular}

Analysis 6.10. Comparison 6 Other + radiotherapy (40 Gy) versus radiotherapy (40 Gy), Outcome 10 Hypertension G3+.

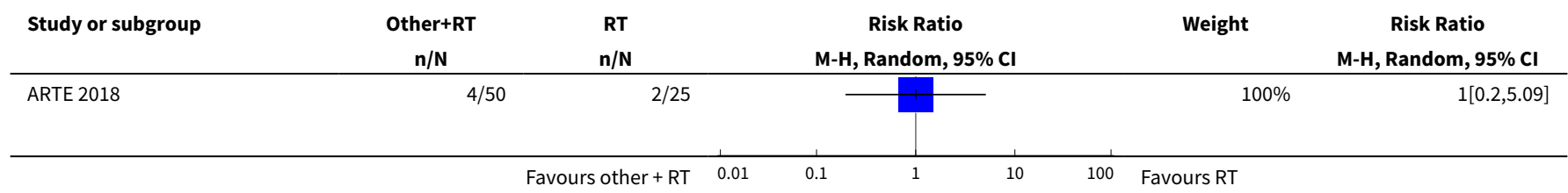




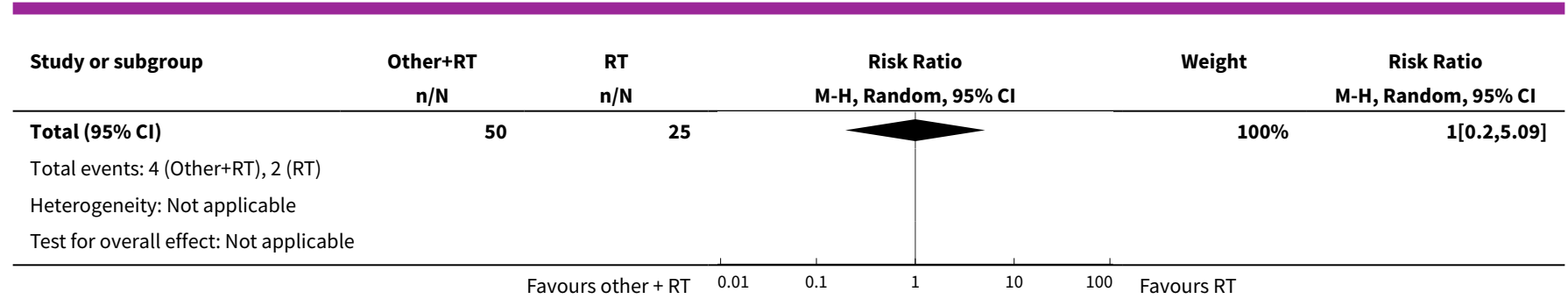

Analysis 6.11. Comparison 6 Other + radiotherapy (40 Gy) versus radiotherapy (40 Gy), Outcome 11 Cutaneous adverse events G3+.

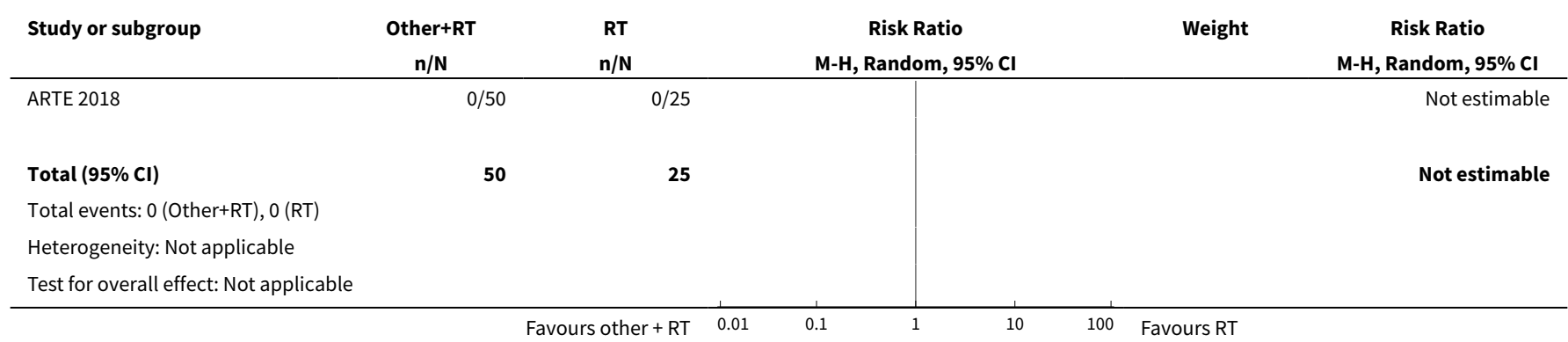

Analysis 6.12. Comparison 6 Other + radiotherapy ( $40 \mathrm{~Gy})$ versus radiotherapy ( $40 \mathrm{~Gy}$ ), Outcome 12 Gastrointestinal events G3+.

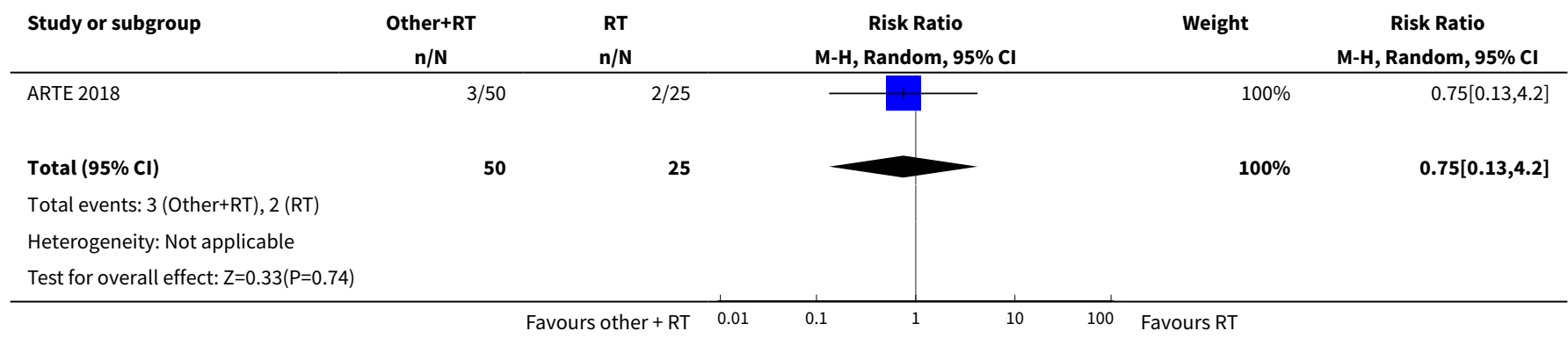

\section{ADDITIONAL TABLES}

Table 1. Table of radiotherapy regimens used in included studies and biologically effective doses

\begin{tabular}{llc}
\hline Dose fractionation & EQD2 (Gy) & BED (Gy) \\
\hline $60 \mathrm{~Gy} / 30$ fractions & 60 & 75 \\
\hline $50 \mathrm{~Gy} / 28$ fractions & 49 & 61 \\
\hline $40 \mathrm{~Gy} / 15$ fractions & 42 & 53 \\
\hline $34 \mathrm{~Gy} / 10$ fractions & 39 & 48 \\
\hline
\end{tabular}


Table 1. Table of radiotherapy regimens used in included studies and biologically effective doses (Continued)

EQD2 and BED calculated for an alpha/beta of 8

$\mathrm{EQD2}$ = equivalent dose; $\mathrm{BED}$ = biologically effective dose Gy $=$ Gray 


\begin{tabular}{|c|c|c|c|c|c|c|c|c|c|}
\hline \multirow[t]{2}{*}{ Study ID } & \multirow{2}{*}{$\begin{array}{l}\text { Elderly } \\
\text { definition } \\
\text { (years) }\end{array}$} & \multirow{2}{*}{$\begin{array}{l}\text { No. } \\
\text { analysed }\end{array}$} & \multirow{2}{*}{$\begin{array}{l}\text { Male } \\
\text { gender } \\
(\%)\end{array}$} & \multirow{2}{*}{$\begin{array}{l}\text { Performance } \\
\text { status }\end{array}$} & \multirow{2}{*}{$\begin{array}{l}\text { MGMT methylated/ } \\
\text { unmethylated/ } \\
\text { unknown (\%) }\end{array}$} & \multicolumn{4}{|l|}{ Treatment option } \\
\hline & & & & & & 1 & 2 & 3 & 4 \\
\hline ARTE 2018 & $\geq 65$ & 75 & 64 & $K P S \geq 60$ & $21 \% / 73 \% / 5 \%{ }^{*}$ & $\mathrm{RT}_{40}$ & $\mathrm{RT}_{40}+\mathrm{BEV}$ & - & - \\
\hline AVAglio 2014 & $\geq 70$ & 73 & 63 & WHO 0-2 & $26 \% / 59 \% / 24 \%$ & $\begin{array}{l}\mathrm{RT}_{60}+\mathrm{TMZ}+ \\
\text { maintenance }\end{array}$ & $\begin{array}{l}\mathrm{RT}_{60}+\mathrm{TMZ}+ \\
\text { maintenance } \\
+\mathrm{BEV}\end{array}$ & - & - \\
\hline GLARIUS 2016 & $\geq 65$ & 34 & $67 c$ & $\mathrm{KPS} \geq 70$ & $100 \%$ unmethylated & $\mathrm{RT}_{60}+\mathrm{TMZ}$ & $\mathrm{RT}_{60}+\mathrm{BEV}+\mid \mathrm{RI}$ & - & - \\
\hline Green 1983 & $\geq 65$ & 107 & 65 & $\mathrm{KPS} \geq 70$ & - & $\mathrm{RT}_{60}+$ carmustine & $\mathrm{RT}_{60}+$ steroid & $\begin{array}{l}\mathrm{RT}_{60}+\mathrm{p}- \\
\text { rocar- } \\
\text { bazine }\end{array}$ & $\begin{array}{l}\mathrm{RT}_{60}+\mathrm{BC}- \\
\mathrm{NU}+\text { steroid }\end{array}$ \\
\hline Keime-Guibert 2007 & $\geq 70$ & 85 & 63 & $\mathrm{KPS} \geq 70$ & - & $\mathrm{RT}_{50}$ & $\begin{array}{l}\text { Supportive } \\
\text { care }\end{array}$ & - & - \\
\hline Malmstrom 2012 & $\geq 70^{a}$ & 123 & 59 & WHO 0-2 & $45 \% / 55 \% / \mathrm{NR}^{e}$ & $\mathrm{RT}_{60}$ & $\mathrm{RT}_{30-34}$ & TMZ & - \\
\hline Perry 2017 & $\geq 65$ & 562 & 61 & ECOG 0-2 & $47 \% / 53 \% / \mathrm{NR}^{f}$ & $\mathrm{RT}_{40}$ & $\begin{array}{l}\mathrm{RT}_{40}+\mathrm{TMZ}+ \\
\text { maintenance } \\
\mathrm{TMZ}\end{array}$ & - & - \\
\hline Roa 2004 & $\geq 60 b$ & 95 & 47 & $\mathrm{KPS} \geq 50$ & - & $\mathrm{RT}_{60}$ & $\mathrm{RT}_{40}$ & & \\
\hline Roa 2015 & $\geq 65^{c}$ & 61 & 58 & $\mathrm{KPS} \geq 50$ & - & $\mathrm{RT}_{40}$ & $\mathrm{RT}_{25}$ & - & - \\
\hline Stupp 2017a & $\geq 65$ & 134 & 68 & $\mathrm{KPS} \geq 70$ & $37 \% / 53 \% / 9 \%$ & $\begin{array}{l}\mathrm{RT}_{60}+\mathrm{TMZ}+ \\
\text { maintenance } \\
\mathrm{TMZ}\end{array}$ & $\begin{array}{l}\mathrm{RT}_{60}+\mathrm{TMZ}+ \\
\text { maintenance } \\
\mathrm{TMZ}+\mathrm{TTF}\end{array}$ & - & - \\
\hline Weller 2017 & $\geq 65$ & 96 & $63^{d}$ & ECOG 0-2 & $34 \% / 59 \% / 7 \%$ & $\mathrm{RT}_{60^{+}}+\mathrm{TMZ}$ & $\begin{array}{l}\mathrm{RT}_{60}+\mathrm{TMZ}+ \\
\text { maintenance } \\
\mathrm{TMZ}+\mathrm{RIN}\end{array}$ & - & - \\
\hline Wick 2012 & $\geq 65$ & 373 & 47 & $K P S \geq 60$ & $20 \% / 36 \% / 44 \%$ & $\mathrm{RT}_{60}$ & TMZ & - & - \\
\hline
\end{tabular}


BEV: bevacizumab; ECOG: Eastern Cooperative Oncology Group; Gy: Grays; IRI: irinotecan; KPS: Karnofsky performance score; RIN: rindopepimut; RT: radiotherapy; TTF: tumour treating fields; TMZ: temozolomide; WHO: World Health Organization

$a$ The whole sample $(n=291)$ comprised participants $\geq 60$ years. The median age was 70 years for all study groups, ranging between 60 and 88 years.

bMedian age was approximately 72 with a standard deviation of 5 years

c Data for the $\geq 65$ year age group were reported in the Guedes de Castro 2017 substudy report.

$d$ Gender data specific to the elderly subgroup were not reported separately

For approximately $70 \%$ of participants with MGMT data available

${ }^{f}$ For approximately $63 \%$ of total participants with MGMT data available 
Table 3. Performance scores

\begin{tabular}{|c|c|c|c|}
\hline Karnofsky Status & $\begin{array}{l}\text { Karnofsky } \\
\text { Grade }\end{array}$ & ECOG Grade & ECOG Status \\
\hline Normal, no complaints & 100 & 0 & $\begin{array}{l}\text { Fully active, able to carry on all pre-disease performance } \\
\text { without restriction }\end{array}$ \\
\hline $\begin{array}{l}\text { Able to carry on normal activities. Minor } \\
\text { signs or symptoms of disease }\end{array}$ & 90 & 1 & $\begin{array}{l}\text { Restricted in physically strenuous activity but ambulato- } \\
\text { ry and able to carry out work of a light or sedentary na- } \\
\text { ture, e.g. light house work, office work }\end{array}$ \\
\hline Normal activity with effort & 80 & 1 & $\begin{array}{l}\text { Restricted in physically strenuous activity but ambulato- } \\
\text { ry and able to carry out work of a light or sedentary na- } \\
\text { ture, e.g. light house work, office work }\end{array}$ \\
\hline $\begin{array}{l}\text { Care for self. Unable to carry on normal } \\
\text { activity or to do active work }\end{array}$ & 70 & 2 & $\begin{array}{l}\text { Ambulatory and capable of all self-care but unable to } \\
\text { carry out any work activities. Up and about more than } \\
50 \% \text { of waking hours }\end{array}$ \\
\hline $\begin{array}{l}\text { Requires occasional assistance, but able } \\
\text { to care for most of his needs }\end{array}$ & 60 & 2 & $\begin{array}{l}\text { Ambulatory and capable of all self-care but unable to } \\
\text { carry out any work activities. Up and about more than } \\
50 \% \text { of waking hours }\end{array}$ \\
\hline $\begin{array}{l}\text { Requires considerable assistance and } \\
\text { frequent medical care }\end{array}$ & 50 & 3 & $\begin{array}{l}\text { Capable of only limited self-care, confined to bed or } \\
\text { chair more than } 50 \% \text { of waking hours }\end{array}$ \\
\hline $\begin{array}{l}\text { Disabled. Requires special care and as- } \\
\text { sistance }\end{array}$ & 40 & 3 & $\begin{array}{l}\text { Capable of only limited self-care, confined to bed or } \\
\text { chair more than } 50 \% \text { of waking hours }\end{array}$ \\
\hline $\begin{array}{l}\text { Severly disabled. Hospitalisation indi- } \\
\text { cated though death non imminent }\end{array}$ & 30 & 4 & $\begin{array}{l}\text { Completely disabled. Cannot carry on any self-care. To- } \\
\text { tally confined to bed or chair }\end{array}$ \\
\hline $\begin{array}{l}\text { Very sick. Hospitalisation necessary. Ac- } \\
\text { tive supportive treatment necessary }\end{array}$ & 20 & 4 & $\begin{array}{l}\text { Completely disabled. Cannot carry on any self-care. To- } \\
\text { tally confined to bed or chair }\end{array}$ \\
\hline Moribund & 10 & 4 & $\begin{array}{l}\text { Completely disabled. Cannot carry on any self-care. To- } \\
\text { tally confined to bed or chair }\end{array}$ \\
\hline Dead & 0 & 5 & Dead \\
\hline
\end{tabular}

As published in Am J Clin. Oncol: Oken 1982 


\begin{tabular}{|c|c|c|c|c|c|c|c|c|c|}
\hline & Trial & OS & QoL & PFS & $\begin{array}{l}\text { Severe ad- } \\
\text { verse events }\end{array}$ & $\begin{array}{l}\text { Cognitive } \\
\text { impair- } \\
\text { ments }\end{array}$ & $\begin{array}{l}\text { Function- } \\
\text { al impair- } \\
\text { ment }\end{array}$ & Fatigue & 등ㅇㅇ \\
\hline 1 & Green 1983 & $\begin{array}{l}\text { For } 65+\text { age subgroup, } \\
\text { number of deaths } \\
\text { (overall, no time point } \\
\text { specified) and death } \\
\text { rate (number of deaths } \\
\text { per } 10 \text { patient-months) } \\
\text { reported. }\end{array}$ & Not for $65+$ subgroup. & $\begin{array}{l}\text { Not for } \\
65+\text { sub- } \\
\text { group. }\end{array}$ & $\begin{array}{l}\text { Not for } 65+ \\
\text { subgroup. }\end{array}$ & $\begin{array}{l}\text { Not for } \\
65+\text { sub- } \\
\text { group. }\end{array}$ & $\begin{array}{l}\text { Not for } \\
65+\text { sub- } \\
\text { group. }\end{array}$ & $\begin{array}{l}\text { Not for } \\
65+\text { sub- } \\
\text { group. }\end{array}$ & 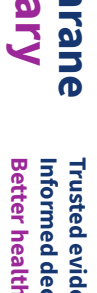 \\
\hline 2 & $\begin{array}{l}\text { Roa } 2004 \text { (Elderly pa- } \\
\text { tients only in this trial, } \\
\text { defined as age } 60 \text { years } \\
\text { or over; mean age was } \\
72 \text { years with SD } 5 \text { years) }\end{array}$ & $\begin{array}{l}\text { Median OS reported } \\
\text { (ITT analysis), includ- } \\
\text { ing HR and a KM curve. } \\
\text { Percentage of patients } \\
\text { alive at } 6 \text { months also } \\
\text { reported (Table } 1 \text { and } \\
\text { Figure } 1 \text { of main manu- } \\
\text { script). }\end{array}$ & $\begin{array}{l}\text { Low rates of FACT-Br version } \\
3 \text { completion ( } 45 \% \text { overall) } \\
\text { by patients precluded mean- } \\
\text { ingful analysis. Protocol spec- } \\
\text { ified FACT-Br completion at } \\
\text { baseline, } 3 \text { weeks after start- } \\
\text { ing RT, at the end of RT, and at } \\
\text { 3-month intervals thereafter. } \\
\text { Table } 2 \text { of main manuscript. }\end{array}$ & Not done. & Not reported. & $\begin{array}{l}\text { Not re- } \\
\text { ported. }\end{array}$ & $\begin{array}{l}\text { Difference } \\
\text { in aver- } \\
\text { aged KPS } \\
\text { scores and } \\
\text { change } \\
\text { in KPS } \\
\text { over time } \\
\text { between } \\
\text { the two } \\
\text { groups } \\
\text { (0-6 } \\
\text { months } \\
\text { from start } \\
\text { of RT). } \\
\text { KPS at } \\
\text { baseline, } \\
3 \text { weeks, } \\
6 \text { weeks, } \\
\text { first and } \\
\text { second } \\
\text { follow up. } \\
\text { Table 1, } \\
\text { Table } 2 \\
\text { and Fig- } \\
\text { ure } 2 \text { of } \\
\text { main man- } \\
\text { uscript. }\end{array}$ & $\begin{array}{l}\text { Not re- } \\
\text { ported. }\end{array}$ & 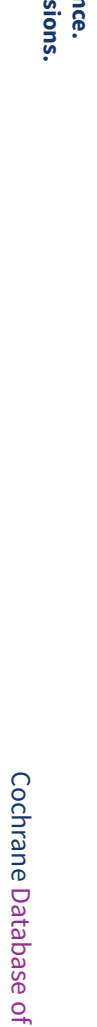 \\
\hline 3 & $\begin{array}{l}\text { Keime-Guibert } 2007 \\
\text { (Elderly patients only - } \\
\text { aged } 70 \text { years or over). }\end{array}$ & $\begin{array}{l}\text { Median OS reported } \\
\text { (ITT analysis), includ- } \\
\text { ing HR and KM curve. }\end{array}$ & $\begin{array}{l}\text { QLQ-C30 and QLQ-BN20 and } \\
\text { completion rate. Changes in } \\
\text { mean score at baseline, day } \\
30 \text {, day } 60 \text {, day } 90 \text { and day } \\
135 .\end{array}$ & $\begin{array}{l}\text { Median } \\
\text { PFS. }\end{array}$ & $\begin{array}{l}\text { Tolerance of } \\
\text { treatment re- } \\
\text { ported but } \\
\text { not clear }\end{array}$ & $\begin{array}{l}\text { QLQ-C30 } \\
\text { includes } \\
\text { cogni- } \\
\text { tive. MDRS } \\
\text { score at }\end{array}$ & $\begin{array}{l}\text { KPS de- } \\
\text { cline over } \\
\text { time. }\end{array}$ & $\begin{array}{l}\text { QLQ-C30 } \\
\text { includes } \\
\text { fatigue. }\end{array}$ & 竞 \\
\hline
\end{tabular}




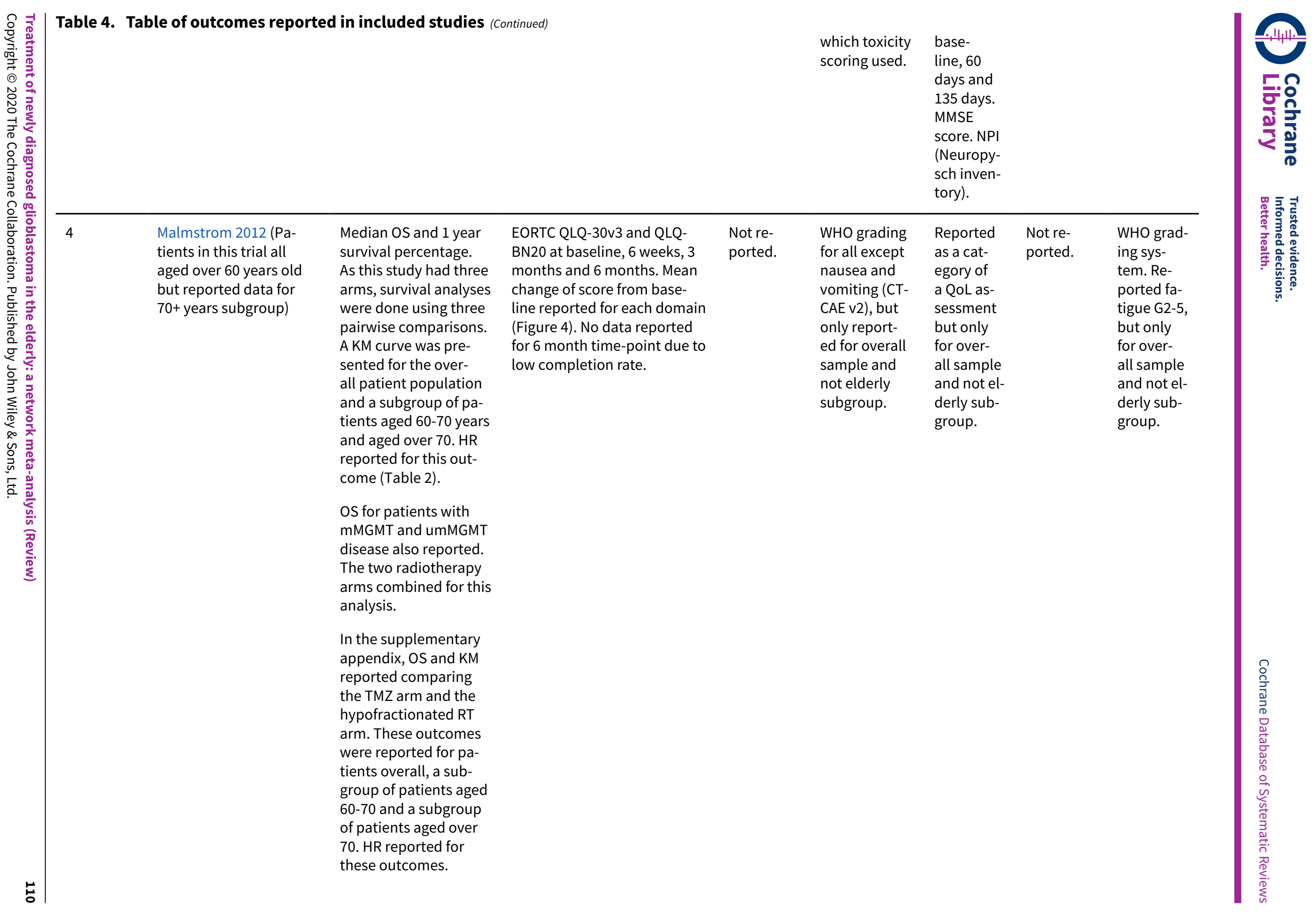




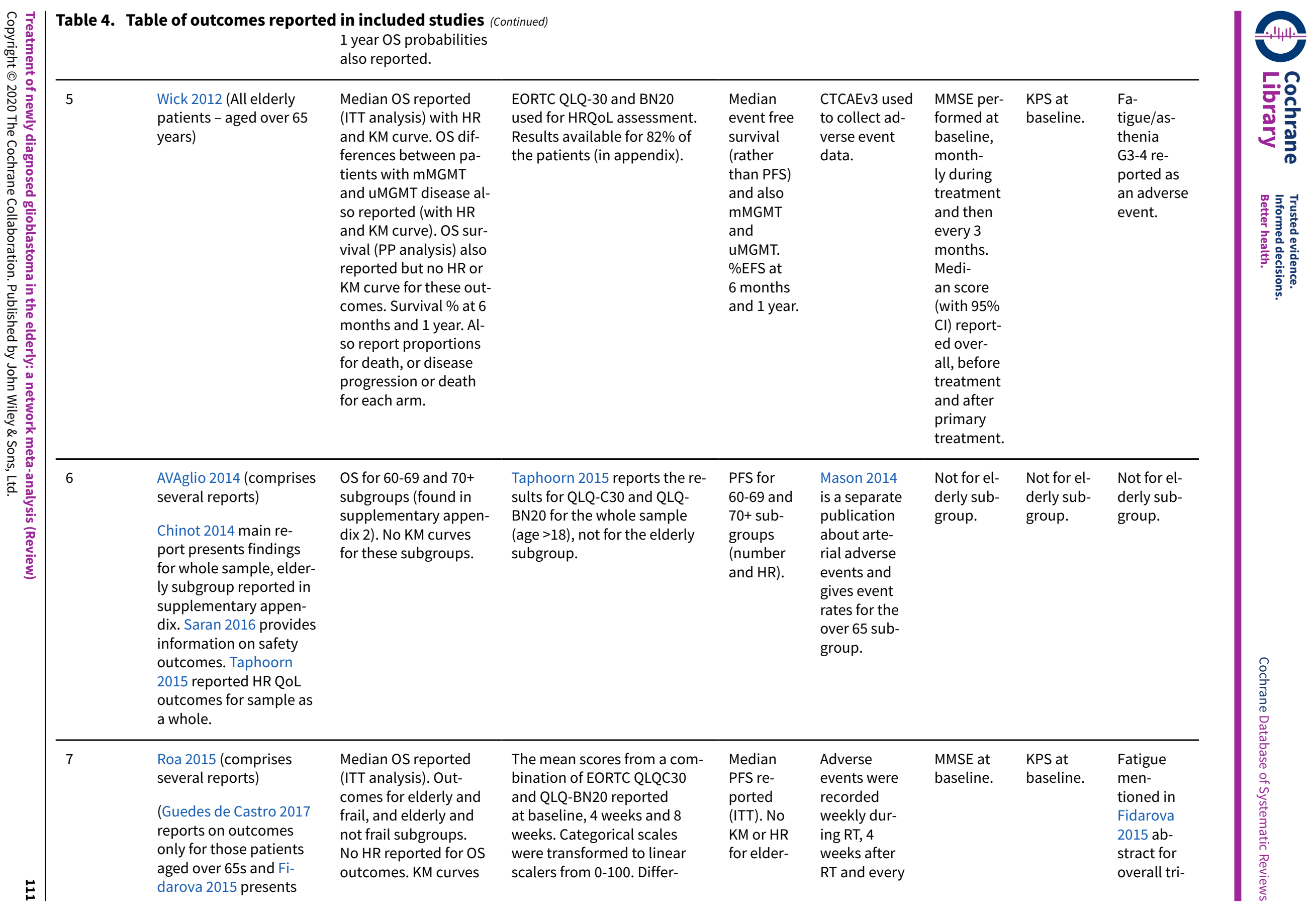




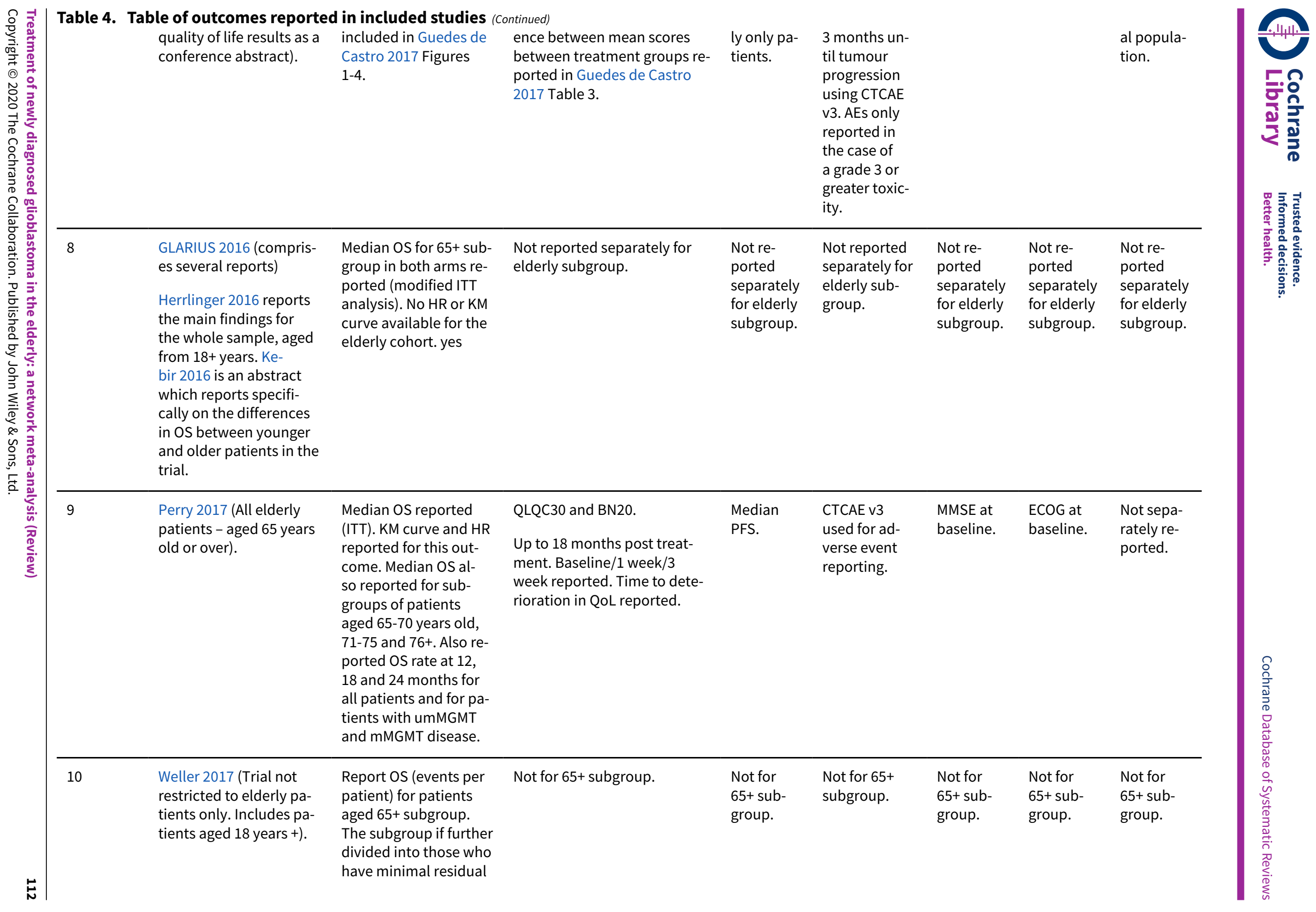




\begin{tabular}{|c|c|c|c|c|c|c|c|c|}
\hline & & $\begin{array}{l}\text { disease (MRD) and sig- } \\
\text { nificant residual dis- } \\
\text { ease (SRD). There is a } \\
\text { HR given for patients } \\
\text { aged } 65+\text { in the MRD } \\
\text { subgroup and in the } \\
\text { SRD subgroup sepa- } \\
\text { rately. There is no HR } \\
\text { reported for the } 65+ \\
\text { group overall. No KM } \\
\text { curves for the elderly } \\
\text { subgroup. }\end{array}$ & & & & & & \\
\hline 11 & $\begin{array}{l}\text { Stupp 2017a } \\
\text { (Trial not restricted to el- } \\
\text { derly patients only. In- } \\
\text { cludes patients aged } 18 \\
\text { years +). Taphoorn } 2018 \\
\text { is separate publication } \\
\text { which reports on HRQoL } \\
\text { outcomes. }\end{array}$ & $\begin{array}{l}\text { Median OS for } 65+ \\
\text { subgroup. HR and KM } \\
\text { curve reported for this } \\
\text { outcome in the } 65+ \\
\text { subgroup. The propor- } \\
\text { tion of patients in each } \\
\text { arm of the trial who } \\
\text { were alive at the end } \\
\text { of the study also re- } \\
\text { ported. }\end{array}$ & $\begin{array}{l}\text { HR QoL was measured using } \\
\text { EORTC QLQ-C30 and BN20 } \\
\text { questionnaires at baseline } \\
\text { and every } 3 \text { months for up to } \\
12 \text { months. Mean QoL scores } \\
\text { and mean change from base- } \\
\text { line reported. Outcomes not } \\
\text { reported separately for elder- } \\
\text { ly subgroup. }\end{array}$ & $\begin{array}{l}\text { Not re- } \\
\text { ported } \\
\text { separately } \\
\text { for elderly } \\
\text { subgroup. }\end{array}$ & $\begin{array}{l}\text { Not reported } \\
\text { separately for } \\
\text { elderly sub- } \\
\text { group. }\end{array}$ & $\begin{array}{l}\text { Not re- } \\
\text { ported } \\
\text { separately } \\
\text { for elderly } \\
\text { subgroup. }\end{array}$ & $\begin{array}{l}\text { Not re- } \\
\text { ported } \\
\text { separately } \\
\text { for elderly } \\
\text { subgroup. }\end{array}$ & $\begin{array}{l}\text { Not re- } \\
\text { ported } \\
\text { separately } \\
\text { for elderly } \\
\text { subgroup. }\end{array}$ \\
\hline 12 & $\begin{array}{l}\text { ARTE } 2018 \text { (All elderly } \\
\text { patients in the trial - } \\
\text { aged } 65 \text { years or over) }\end{array}$ & $\begin{array}{l}\text { Median OS (ITT and } \\
\text { PP) and } 1 \text { year survival } \\
\text { rate. Also reported OS } \\
\text { depending on molecu- } \\
\text { lar panel subtype. No } \\
\text { HR reported for medi- } \\
\text { an OS differences. KM } \\
\text { curves are shown. }\end{array}$ & $\begin{array}{l}\text { Reported median deteriora- } \\
\text { tion free survival from base- } \\
\text { line. Individual functional and } \\
\text { symptom scores from EORTC } \\
\text { QLQ-C30/BN20 before tumour } \\
\text { progression analysed in a } \\
\text { generalised linear model that } \\
\text { controlled for time treatment } \\
\text { interactions. }\end{array}$ & $\begin{array}{l}\text { Medi- } \\
\text { an PFS. } \\
\text { ITT and } \\
\text { PP. And } \\
\% \text { PFS at } 6 \\
\text { months. } \\
\text { Also had } \\
\text { indepen- } \\
\text { dent cen- } \\
\text { tral review } \\
\text { for some } \\
\text { patients. } \\
\text { (66 with } \\
\text { MRI avail- } \\
\text { able). Al- } \\
\text { so looked } \\
\text { at PFS per } \\
\text { molecular } \\
\text { panel sub- } \\
\text { type. }\end{array}$ & $\begin{array}{l}\text { Yes, reported } \\
\text { in supplemen- } \\
\text { tary material. } \\
\text { G3-5 fatigue, } \\
\text { seizures, } \\
\text { headaches, } \\
\text { other neuro, } \\
\text { neuropysch, } \\
\text { haematolog- } \\
\text { ical, arterial } \\
\text { hypertension, } \\
\text { thromboem- } \\
\text { bolic, all in- } \\
\text { fections, cuta- } \\
\text { neous, Gl. }\end{array}$ & $\begin{array}{l}\text { MMSE at } \\
\text { baseline } \\
\text { and ser- } \\
\text { ial mea- } \\
\text { surements } \\
\text { (0,7,19 } \\
\text { weeks). }\end{array}$ & $\begin{array}{l}\text { KPS at } \\
\text { baseline. }\end{array}$ & $\begin{array}{l}\text { Fatigue re- } \\
\text { ported as } \\
\text { a catego- } \\
\text { ry of QoL } \\
\text { and as an } \\
\text { adverse } \\
\text { events. }\end{array}$ \\
\hline
\end{tabular}




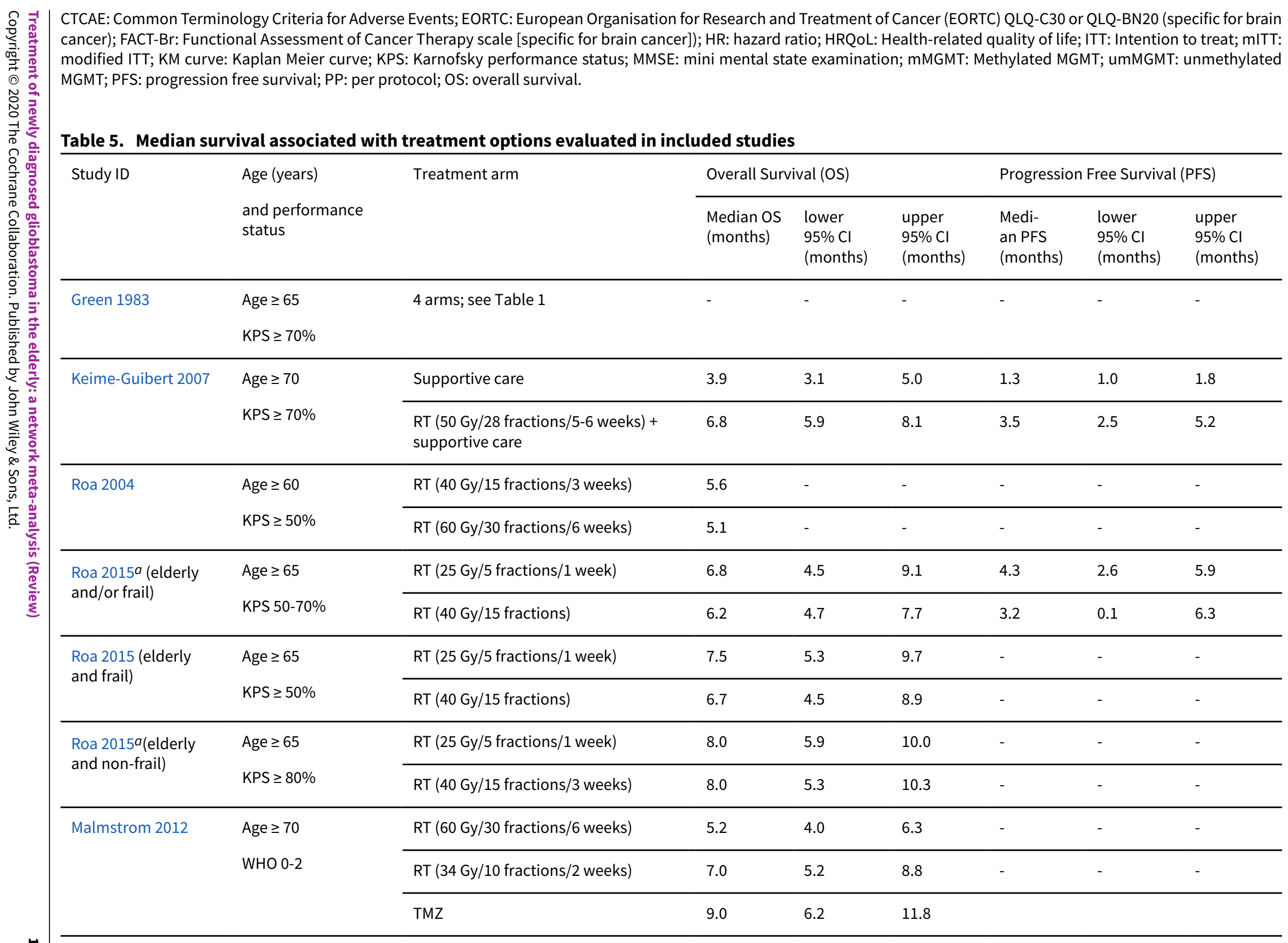




\begin{tabular}{|c|c|c|c|c|c|c|c|c|}
\hline \multirow{2}{*}{$\begin{array}{l}\text { Malmstrom } 2012 \text { (un- } \\
\text { methylated) }\end{array}$} & Age $\geq 70$ & RT (any schedule) & 7.0 & 5.8 & 8.3 & - & - & - \\
\hline & WHO 0-2 & TMZ & 6.8 & 5.9 & 7.7 & - & - & - \\
\hline \multirow{2}{*}{$\begin{array}{l}\text { Malmstrom } 2012 \\
\text { (methylated) }\end{array}$} & Age $\geq 70$ & RT (any schedule) & 8.2 & 6.6 & 9.9 & - & - & - \\
\hline & WHO 0-2 & TMZ & 9.7 & 8.0 & 11.4 & - & - & - \\
\hline \multirow[t]{2}{*}{ Wick $2012^{b}$} & Age $\geq 65$ & RT (60Gy/30 fractions/6 weeks) & 9.6 & 8.2 & 10.8 & 4.7 & 4.2 & 5.2 \\
\hline & $\mathrm{KPS} \geq 60 \%$ & TMZ & 8.6 & 7.3 & 10.2 & 3.3 & 3.2 & 4.1 \\
\hline \multirow{2}{*}{$\begin{array}{l}\text { Wick } 2012 \\
\text { (unmethylated) }\end{array}$} & Age $\geq 65$ & RT (60Gy/30 fractions/6 weeks) & 10.4 & 8.0 & 11.6 & 4.6 & 3.7 & 6.3 \\
\hline & $\mathrm{KPS} \geq 60 \%$ & TMZ & 7.0 & 5.7 & 8.7 & 3.3 & 3.0 & 3.5 \\
\hline \multirow{2}{*}{$\begin{array}{l}\text { Wick } 2012 \\
\text { (methylated) }\end{array}$} & \multirow{2}{*}{$\begin{array}{l}\text { Age } \geq 65 \\
\text { KPS } \geq 60 \%\end{array}$} & RT (60Gy/30 fractions/6 weeks) & 9.6 & 6.4 & $\begin{array}{l}\text { not } \\
\text { reached }\end{array}$ & 4.6 & 4.2 & 5.0 \\
\hline & & TMZ & $\begin{array}{l}\text { not } \\
\text { reached }\end{array}$ & 10.1 & $\begin{array}{l}\text { not } \\
\text { reached }\end{array}$ & 8.4 & 5.5 & 11.7 \\
\hline \multirow[t]{2}{*}{ Perry 2017} & Age $\geq 65$ & RT (40 Gy/15 fractions/3 weeks) & 7.6 & 7.0 & 8.4 & 3.9 & 3.5 & 4.3 \\
\hline & ECOG 0-2 & $\begin{array}{l}\mathrm{RT} \text { ( } 40 \mathrm{~Gy} / 15 \text { fractions } / 3 \text { weeks) + TMZ } \\
\text { + maintenance TMZ }\end{array}$ & 9.3 & 8.3 & 10.3 & 5.3 & 4.6 & 6.2 \\
\hline \multirow{2}{*}{$\begin{array}{l}\text { Perry } 2017 c \\
\text { (unmethylated) }\end{array}$} & Age $\geq 65$ & RT (40 Gy/15 fractions/3 weeks) & 7.9 & - & - & - & - & - \\
\hline & ECOG 0-2 & $\begin{array}{l}\text { RT ( } 40 \text { Gy/15 fractions/ } 3 \text { weeks) + TMZ } \\
\text { + maintenance TMZ }\end{array}$ & 10 & - & - & - & - & - \\
\hline \multirow{2}{*}{$\begin{array}{l}\text { Perry } 2017 c \\
\text { (methylated) }\end{array}$} & \multirow{2}{*}{$\begin{array}{l}\text { Age } \geq 65 \\
\text { ECOG } 0-2\end{array}$} & RT (40 Gy/15 fractions/3 weeks) & 7.7 & - & - & - & - & - \\
\hline & & $\begin{array}{l}\text { RT ( } 40 \text { Gy/ } 15 \text { fractions } / 3 \text { weeks) + TMZ } \\
\text { + maintenance TMZ }\end{array}$ & 13.5 & - & - & - & - & - \\
\hline \multirow[t]{2}{*}{ AVAglio 2014} & \multirow{2}{*}{$\begin{array}{l}\text { Age } \geq 70 \\
\text { WHO 0-2 }\end{array}$} & $\begin{array}{l}\mathrm{RT} \text { ( } 60 \mathrm{~Gy} / 30 \text { fractions) + TMZ + main- } \\
\text { tenance TMZ }\end{array}$ & - & - & - & - & - & - \\
\hline & & $\begin{array}{l}\mathrm{RT}(60 \mathrm{~Gy} / 30 \text { fractions })+\mathrm{TMZ}+\mathrm{BEV}+ \\
\text { maintenance }\end{array}$ & - & - & - & - & - & - \\
\hline
\end{tabular}


Table 5. Median survival associated with treatment options evaluated in included studies (Continued)

\begin{tabular}{|c|c|c|c|c|c|c|c|c|}
\hline \multirow[t]{2}{*}{ Stupp 2017ad } & $\begin{array}{l}\text { Age } \geq 65 \\
\text { KPS } \geq 70 \%\end{array}$ & $\begin{array}{l}\mathrm{RT}( \pm 60 \mathrm{~Gy} / 30 \text { fractions } / 6 \text { weeks })+ \\
\mathrm{TMZ}+\text { maintenance TMZ }\end{array}$ & 13.7 & 7.6 & 24.8 & - & - & - \\
\hline & $\begin{array}{l}\text { Age } \geq 65 \\
\text { KPS } \geq 70 \%\end{array}$ & $\begin{array}{l}\text { RT }( \pm 60 \text { Gy/30 fractions } / 6 \text { weeks })+ \\
\text { TMZ + maintenance TMZ + TTFields }\end{array}$ & 17.4 & 9.0 & 31.5 & - & - & - \\
\hline \multirow[t]{2}{*}{ ARTE 2018} & Age $\geq 65$ & RT (40 Gy/15 fractions/3 weeks) & 12.2 & 9.2 & 15.2 & 4.8 & 3.0 & 6.6 \\
\hline & $K P S \geq 60 \%$ & RT (40 Gy/15 fractions/3 weeks) + BEV & 12.1 & 10.2 & 14.0 & 7.6 & 6.2 & 9.0 \\
\hline \multirow{2}{*}{$\begin{array}{l}\text { GLARIUS } 2016 \text { e } \\
\text { (unmethylated) }\end{array}$} & $\begin{array}{l}\text { Age } \geq 65 \\
\text { KPS }>70 \%\end{array}$ & $\begin{array}{l}\mathrm{RT}(60 \mathrm{~Gy} / 30 \text { fractions } / 6 \text { weeks) + TMZ } \\
\text { + maintenance }\end{array}$ & 17.5 & - & - & - & - & - \\
\hline & & $\begin{array}{l}\text { RT ( } 60 \text { Gy/30 fractions } / 6 \text { weeks) + BEV } \\
+ \text { IRI + maintenance }\end{array}$ & 13.4 & - & - & - & - & - \\
\hline \multirow[t]{2}{*}{ Weller 2017} & Age $\geq 65$ & $\begin{array}{l}\mathrm{RT}(60 \mathrm{~Gy} / 30 \text { fractions } / 6 \text { weeks })+\mathrm{TMZ} \\
\text { + maintenance }\end{array}$ & - & - & - & - & - & - \\
\hline & & $\begin{array}{l}\mathrm{RT}(60 \mathrm{~Gy} / 30 \text { fractions } / 6 \text { weeks) + TMZ } \\
+ \text { maintenance + RIN }\end{array}$ & - & - & - & - & - & - \\
\hline
\end{tabular}

BEV: bevacizumab; ECOG: Eastern Cooperative Oncology Group; Gy: Grays; IRI: irinotecan; KPS: Karnofsky performance score; OS: overall survival; PFS: progression free survival; RIN: rindopepimut; RT: radiotherapy; TTF: tumour treating fields; TMZ: temozolomide; WHO: World Health Organization

aData from the Guedes de Castro et al 2017 substudy report on patients $\geq 65$ years only

bThis study reported event free survival (EFS), not PFS. Findings by MGMT methylation status were reported by authors in the later (2017) publication.

cFrom Perry 2012 abstract

dMGMT promotor methylation status was not reported separately for the elderly subgroup. Median survival data were reported as time from randomisation not diagnosis. Randomisation in this trial occurred after concomitant chemoradiotherapy.

eFrom substudy data reported in a conference proceeding abstract by Kebir et al, 2016. 
Table 6. CHEC list ${ }^{\star}$ for included economic studies

\begin{tabular}{|c|c|}
\hline CHEC ITEM & Ghosh et al (2018) \\
\hline Is the study population clearly described? & $\mathbf{Y}$ \\
\hline Are competing alternatives clearly described? & $\mathbf{Y}$ \\
\hline Is a well-defined research question posed in answerable form? & $\mathbf{Y}$ \\
\hline Is the economic study design appropriate to the stated objective? & $\mathbf{Y}$ \\
\hline $\begin{array}{l}\text { Is the chosen time horizon appropriate to include relevant costs and } \\
\text { consequences? }\end{array}$ & $\mathbf{N}$ \\
\hline Is the actual perspective chosen appropriate? & $\mathbf{N}$ \\
\hline Are all important and relevant costs for each alternative identified & $\mathbf{N}$ \\
\hline Are all costs measured appropriately in physical units? & $\mathbf{Y}$ \\
\hline Are costs valued appropriately? & $\mathbf{N}$ \\
\hline Are all important and relevant outcomes for each alternative identified? & $\mathbf{N}$ \\
\hline Are all outcomes measured appropriately? & $\mathbf{N}$ \\
\hline Are outcomes valued appropriately? & $\mathbf{N}$ \\
\hline Is an incremental analysis of costs and outcomes of alternatives performed? & $\mathbf{Y}$ \\
\hline Are all future costs and outcomes discounted appropriately? & $\mathbf{N}$ \\
\hline $\begin{array}{l}\text { Are all important variables, whose values are uncertain, appropriately subjected to sensitivity } \\
\text { analysis? }\end{array}$ & $\mathbf{N}$ \\
\hline Do the conclusions follow from the data reported? & $\mathbf{N}$ \\
\hline $\begin{array}{l}\text { Does the study discuss the generalizability of the results to other settings and patient/client } \\
\text { groups? }\end{array}$ & $\mathbf{N}$ \\
\hline $\begin{array}{l}\text { Does the article indicate that there is no potential conflict of interest of study researcher(s) and } \\
\text { funder(s)? }\end{array}$ & $\mathbf{Y}$ \\
\hline Are ethical and distributional issues discussed appropriately? & $\mathbf{N}$ \\
\hline
\end{tabular}

*Evers 2005

Table 7. CHEERS checklist* of included studies

\section{CHEERS Quality Checklist}

\section{Section of paper Component}


Table 7. CHEERS checklist* of included studies (Continued)

Ghosh et al (2018)

Title and abstract Identify the study as an economic evaluation or use more specific terms such as "cost-ef- 114 fectiveness analysis", and describe the interventions compared.

Provide a structured summary of objectives, perspective, setting, methods (including 114 study design and inputs), results (including base case and uncertainty analyses), and conclusions.

\section{Methods}

Supplementary material

Not reported

Not reported

Describe the perspective of the study and relate this to the costs being evaluated.

$114-115$

Describe the interventions or strategies being compared and state why they were chosen.

Partially, stated

State the time horizon(s) over which costs and consequences are being evaluated and say why appropriate.

Report the choice of discount rate(s) used for costs and outcomes and say why appropri- Not reported ate.

Describe what outcomes were used as the measure(s) of benefit in the evaluation and their relevance for the type of analysis performed.

Describe fully the design features of the single effectiveness study and why the single study was a sufficient source of clinical effectiveness data.

Describe approaches used to estimate resource use associated with the alternative inNot reported terventions. Describe primary or secondary research methods for valuing each resource item in terms of its unit cost. Describe any adjustments made to approximate to opportunity costs.

Report the dates of the estimated resource quantities and unit costs. Describe methods for adjusting estimated unit costs to the year of reported costs if necessary. Describe methods for converting costs into a common currency base and the exchange rate.

Describe and give reasons for the specific type of decision-analytical model used. Provid- N/A ing a figure to show model structure is strongly recommended.

Describe all structural or other assumptions underpinning the decision-analytical model. N/A

Describe all analytical methods supporting the evaluation. This could include methods for dealing with skewed, missing, or censored data; extrapolation methods; methods for pooling data; approaches to validate or make adjustments (such as half cycle corrections) to a model; and methods for handling population heterogeneity and uncertainty.

\section{Results}

Report the values, ranges, references, and, if used, probability distributions for all parameters. Report reasons or sources for distributions used to represent uncertainty where

Not reported appropriate. Providing a table to show the input values is strongly recommended.

For each intervention, report mean values for the main categories of estimated costs and outcomes of interest, as well as mean differences between the comparator groups. If applicable, report incremental cost-effectiveness ratios.

Partial, uncertainty discussed. 
Table 7. CHEERS checklist* of included studies (Continued)

Describe the effects of sampling uncertainty for the estimated incremental cost and incre- $\quad 116$ mental effectiveness parameters, together with the impact of methodological assumptions (such as discount rate, study perspective).

If applicable, report differences in costs, outcomes, or cost-effectiveness that can be explained by variations between subgroups of patients with different baseline characteristics or other observed variability in effects that are not reducible by more

information.

Discussion Summarise key study findings and describe how they support the conclusions reached. Discuss limitations and the generalisability of the findings and how the findings fit with current knowledge.

\section{Other}

Describe how the study was funded and the role of the funder in the identification, design, conduct, and reporting of the analysis. Describe other non-monetary sources of support.

Describe any potential for conflict of interest of study contributors in accordance with journal policy. In the absence of a journal policy, we recommend authors comply with International Committee of

Medical Journal Editors recommendations.

*Evers 2005

Table 8. Table of estimate effects and certainty ratings for overall survival

\begin{tabular}{|c|c|c|c|c|c|c|}
\hline \multirow[t]{2}{*}{ Comparison } & \multicolumn{2}{|c|}{ Direct Evidence } & \multicolumn{2}{|l|}{ Indirect Evidence } & \multicolumn{2}{|l|}{ Network Evidence } \\
\hline & HR $(95 \% \mathrm{CI})$ & Certainty & $\operatorname{HR}(95 \% \mathrm{CI})$ & Certainty & $\operatorname{HR}(95 \% \mathrm{CI})$ & Certainty \\
\hline RT60* vs Supp Care & $\begin{array}{l}0.47(0.29 \text { to } \\
0.76)\end{array}$ & $\begin{array}{l}\text { Moder- } \\
\text { ate }^{1}\end{array}$ & Not estimable 2 & - & 0.47 (0.29 to 0.76$)$ & Moderate \\
\hline RT40 vs Supp Care & - & - & $0.44(0.25$ to 0.77$)$ & Low $^{3}$ & 0.44 (0.25 to 0.77$)$ & Low \\
\hline CRT vs Supp Care & - & - & - & - & 0.30 (0.17 to 0.53$)$ & $\begin{array}{l}\text { Not grad- } \\
\text { ed4 }\end{array}$ \\
\hline TMZ vs Supp Care & - & - & $0.42(0.25$ to 0.71$)$ & Low $^{3}$ & 0.42 (0.25 to 0.71$)$ & Low \\
\hline BEV_CRT vs Supp Care & - & - & - & - & 0.25 (0.11 to 0.54$)$ & $\begin{array}{l}\text { Not grad- } \\
\text { ed } 4\end{array}$ \\
\hline BEV_RT vs Supp Care & - & - & - & - & $0.48(0.23$ to 1.00$)$ & $\begin{array}{l}\text { Not grad- } \\
\text { ed } 4\end{array}$ \\
\hline CRT vs RT40 & $\begin{array}{l}0.67 \text { ( } 0.56 \text { to } \\
0.80)\end{array}$ & High & - & - & 0.67 (0.56 to 0.80$)$ & High \\
\hline BEV_CRT vs RT40 & - & - & 0.56 (0.31 to 0.99$)$ & $\begin{array}{l}\text { Moder- } \\
\text { ate }^{5}\end{array}$ & 0.56 (0.31 to 0.99$)$ & Moderate \\
\hline
\end{tabular}


Table 8. Table of estimate effects and certainty ratings for overall survival (Continued)

\begin{tabular}{|c|c|c|c|c|c|c|}
\hline TMZ vs RT40** & $\begin{array}{l}0.72 \text { ( } 0.50 \text { to } \\
1.05)\end{array}$ & Low $^{6}$ & - & - & $0.95(0.71$ to 1.26$)$ & Low \\
\hline BEV_RT vs RT40 & $\begin{array}{l}1.08(0.65 \text { to } \\
1.78)\end{array}$ & Low6 & Not estimable 2 & - & 1.08 (0.66 to 1.78$)$ & Low \\
\hline RT40 vs RT60 & $\begin{array}{l}0.74 \text { (0.55 to } \\
1.01)\end{array}$ & Low $^{6}$ & Not estimable 2 & - & $0.94(0.72$ to 1.23$)$ & Low \\
\hline BEV_RT vs RT60 & - & - & 1.01 (0.58 to 1.79$)$ & Very low ${ }^{7}$ & 1.01 (0.58 to 1.79$)$ & Very low \\
\hline BEV_CRT vs RT60 & - & - & - & - & 0.52 (0.28 to 0.98$)$ & $\begin{array}{l}\text { Not grad } \\
\text { ed }^{4}\end{array}$ \\
\hline CRT vs RT60 & - & - & 0.63 (0.46 to 0.87$)$ & Low $^{8}$ & 0.63 (0.46 to 0.87$)$ & Low \\
\hline TMZ vs RT60 & $\begin{array}{l}0.86(0.68 \text { to } \\
1.09)\end{array}$ & Very low 9 & - & - & $0.89(0.71$ to 1.11$)$ & Very low \\
\hline
\end{tabular}

\begin{tabular}{lllllll}
\hline BEV_RT vs CRT & - & - & $1.61(0.95$ to 2.74$)$ & Low10 & 1.61 (0.95 to 2.74) & Low \\
\hline BEV_CRT vs CRT & $\begin{array}{l}0.83(0.48 \text { to } \\
1.43)\end{array}$ & Low6 & Not estimable & - & 0.83 (0.48 to 1.44) \\
\hline TMZ vs CRT & - & - & $1.42(1.01$ to 1.98$)$ & Low10 & 1.42 (1.01 to 1.98) & Low \\
\hline
\end{tabular}

\begin{tabular}{|c|c|c|c|c|c|c|}
\hline BEV_RT vs TMZ & - & - & 1.14 (0.64 to 2.02 ) & $\begin{array}{l}\text { Very } \\
\text { low } 10,11\end{array}$ & 1.14 (0.64 to 2.02$)$ & Very low \\
\hline BEV_CRT vs TMZ & - & - & - & - & 0.59 (0.31 to 1.12$)$ & $\begin{array}{l}\text { Not grad } \\
\text { ed } 4\end{array}$ \\
\hline BEV_CRT vs BEV_RT & - & - & - & - & 0.52 (0.24 to 1.10$)$ & $\begin{array}{l}\text { Not grad- } \\
\mathrm{ed}^{4}\end{array}$ \\
\hline
\end{tabular}

\footnotetext{
1 Evidence derived from a single small study

2 Could not be estimated because the intervention was not connected via a loop in the evidence network

3 Contributing direct evidence was of moderate or low certainty

4 There was no direct evidence for this comparison, which did not connect via a common comparator, therefore the certainty of evidence was not graded.

5 Contributing direct evidence was of high or moderate certainty

6 Downgraded for study design limitations and imprecision

7 Contributing direct evidence was of low certainty; network estimate imprecise
} 
Table 8. Table of estimate effects and certainty ratings for overall survival (Continued)

8 Contributing direct evidence was of high or low certainty

9 Downgraded for imprecision, study design limitations and inconsistency

10 Contributing direct evidence was of high or low certainty

11Downgraded for imprecision

${ }^{\star}$ RT50 (Keime-Guibert 2007) coded as RT60.

**RT34 (Malmstrom 2012) coded as RT40.

Abbreviations: BEV_CRT = bevacizumab plus chemoradiotherapy; $\mathrm{Cl}=$ confidence interval; ; $\mathrm{CRT}=$ chemoradiotherapy; $\mathrm{RT} 40=$ radiotherapy (40Gy in 15 fractions); RT60 = radiotherapy (60Gy in 30 fractions); Supp Care = supportive care; TMZ = temozolomide; TTF_AC $=$ tumour treating fields with adjuvant chemotherapy (after concomitant chemotherapy)

Table 9. Overview of SUCRA rankings

\begin{tabular}{|c|c|c|c|c|c|}
\hline Treatment option & $\begin{array}{l}\text { Main NMA mod- } \\
\text { el }\end{array}$ & $\begin{array}{l}\text { Sensitivity analysis } \\
\text { A }\end{array}$ & $\begin{array}{l}\text { Sensitivity analysis } \\
\text { B }\end{array}$ & $\begin{array}{l}\text { Sensitivity analy- } \\
\text { sis C }\end{array}$ & $\begin{array}{l}\text { Sensitivity analy- } \\
\text { sis D }\end{array}$ \\
\hline BEV_CRT & 1.4 & 1.4 & 1.4 & - & - \\
\hline CRT & 1.8 & 1.8 & 1.9 & $1.1^{*}$ & $1.1^{\star}$ \\
\hline TMZ & 3.8 & 3.8 & 3.7 & 2.8 & 2.8 \\
\hline RT40 & 4.3 & 4.3 & 4.2 & 3.3 & 3.3 \\
\hline BEV_RT & 4.7 & 4.7 & 4.8 & 3.8 & 3.8 \\
\hline RT60 & 5.0 & 5.1 & 5.0 & 4.0 & 4.0 \\
\hline Supp_Care & 7.0 & 7.0 & 7.0 & 6.0 & 6.0 \\
\hline
\end{tabular}

\section{${ }^{*}$ CRT40}

BEV_CRT = chemoradiotherapy plus bevacizumab; CRT = chemoradiotherapy; RT40 = radiotherapy (40Gy in 15 fractions); RT60 = radiotherapy (60Gy in 30 fractions); Supp_Care = supportive care; TMZ = temozolomide; TTF_AC = tumour treating fields with adjuvant chemotherapy (after concomitant chemotherapy)

Sensitivity analysis A: Keime-Guibert 2007 study's RT50 arm is coded as RT40; sensitivity analysis B: network without a loop due to exclusion of the Malmstrom 2012 TMZ vs RT40 arm to avoid duplication of data; sensitivity analysis C.1 and C.2: disconnected networks due to nonpooling of CRT40 and CRT60 arms from different studies; sensitivity analysis D: disconnected network due to non-pooling of CRT40 and CRT60 arms from different studies, and Keime-Guibert 2007 study arm RT50 coded as RT40.

Table 10. Data extraction table for economic studies

\begin{tabular}{|c|c|c|c|c|c|}
\hline $\begin{array}{l}\text { Author(s), } \\
\text { Year \& Title }\end{array}$ & $\begin{array}{l}\text { Type of } \\
\text { Evalua- } \\
\text { tions }\end{array}$ & $\begin{array}{l}\text { Sources } \\
\text { of effec- } \\
\text { tiveness } \\
\text { data }\end{array}$ & $\begin{array}{l}\text { Sources of } \\
\text { Cost Data }\end{array}$ & Sources of outcome valuations & $\begin{array}{l}\text { Analyt- } \\
\text { ical ap- } \\
\text { proach }\end{array}$ \\
\hline $\begin{array}{l}\text { Ghosh } 2018 \\
\text { Improved } \\
\text { cost-effective- } \\
\text { ness of short- } \\
\text { course radio- } \\
\text { therapy in el- } \\
\text { derly and/or }\end{array}$ & $\begin{array}{l}\text { Cost- } \\
\text { effec- } \\
\text { tiveness } \\
\text { analysis } \\
\text { Cost-utili- } \\
\text { ty analysis }\end{array}$ & $\begin{array}{l}\text { Effective- } \\
\text { ness data } \\
\text { was tak- } \\
\text { en from } \\
\text { a phase } \\
\text { III ran- } \\
\text { domised } \\
\text { trial. }\end{array}$ & $\begin{array}{l}\text { Direct unit } \\
\text { medical } \\
\text { costs were } \\
\text { collected } \\
\text { from each } \\
\text { country } \\
\text { participat- } \\
\text { ing in the }\end{array}$ & $\begin{array}{l}\text { Outcomes presented were overall survival (OS) and pro- } \\
\text { gression free survival (PFS). The outcomes were also pre- } \\
\text { sented as QALYs. Preference values were taken from Eu- } \\
\text { ropean Organization for Research and Treatment of Can- } \\
\text { cer Quality of Life Questionnaire (EORTC QLQ-C30). The } \\
\text { scores were mapped onto the EQ-5D questionnaire from } \\
\text { which utility values were derived. The values were taken } \\
\text { from three sources; Kontodimopoulos 2009, Kim } 2012 \text { and }\end{array}$ & $\begin{array}{l}\text { Restrict- } \\
\text { ed mean } \\
\text { overall } \\
\text { survival } \\
\text { (RMOS) } \\
\text { Incremen- } \\
\text { tal cost- }\end{array}$ \\
\hline
\end{tabular}


Table 10. Data extraction table for economic studies (Continued)

frail patients

with glioblas-

toma trial (from

2015).
McKenzie 2009. The QALY calculation based on the assumption that the patient on treatment is to live for 4 months. effectiveness ratio (ICER). 


\begin{tabular}{|c|c|c|c|c|c|c|c|c|}
\hline $\begin{array}{l}\text { Compo- } \\
\text { nent }\end{array}$ & Study & Country & $\begin{array}{l}\text { Estimated } \\
\text { costs of } \\
\text { resources } \\
\text { used }\end{array}$ & Source & Currency & $\begin{array}{l}\text { Av } \\
\text { sol } \\
\text { Arr }\end{array}$ & $\begin{array}{l}\text { nber of Re- } \\
\text { d } \\
2\end{array}$ & Source \\
\hline \multirow{5}{*}{$\begin{array}{l}\text { Dexam- } \\
\text { etha- } \\
\text { sone } 4 \mathrm{mg} \\
\text { tablet }\end{array}$} & $\begin{array}{l}\text { Ghosh } \\
2018\end{array}$ & Belarus & 0.27 & Not reported & $\begin{array}{l}\text { US Dollars (conversion not re- } \\
\text { ported) }\end{array}$ & 44 & 16 & Trial Datase \\
\hline & & $\begin{array}{l}\text { Brazil (Porto } \\
\text { Alegre) }\end{array}$ & 0.06 & - Not reported & $\begin{array}{l}\text { US Dollars (conversion not re- } \\
\text { ported) }\end{array}$ & 44 & 60 & Trial Datase \\
\hline & & Georgia & 0.3 & Not reported & $\begin{array}{l}\text { US Dollars (conversion not re- } \\
\text { ported) }\end{array}$ & 18 & 4 & Trial Datase \\
\hline & & India & 0.01 & Not reported & $\begin{array}{l}\text { US Dollars (conversion not re- } \\
\text { ported) }\end{array}$ & 32 & 24 & Trial Datase \\
\hline & & Poland & 1.36 & Not reported & $\begin{array}{l}\text { US Dollars (conversion not re- } \\
\text { ported) }\end{array}$ & 12 & 8 & Trial Datase \\
\hline \multirow[t]{5}{*}{ CT } & $\begin{array}{l}\text { Ghosh } \\
2018\end{array}$ & Belarus & 269 & Not reported & $\begin{array}{l}\text { US Dollars (conversion not re- } \\
\text { ported) }\end{array}$ & 4 & 3 & Trial Datase \\
\hline & & $\begin{array}{l}\text { Brazil (Porto } \\
\text { Alegre) }\end{array}$ & 119 & Not reported & $\begin{array}{l}\text { US Dollars (conversion not re- } \\
\text { ported) }\end{array}$ & 4 & 3 & Trial Datase \\
\hline & & Georgia & 130 & Not reported & $\begin{array}{l}\text { US Dollars (conversion not re- } \\
\text { ported) }\end{array}$ & 1 & 1 & Trial Datase \\
\hline & & India & 25 & Not reported & $\begin{array}{l}\text { US Dollars (conversion not re- } \\
\text { ported) }\end{array}$ & 1 & 1 & Trial Datase \\
\hline & & Poland & 57 & Not reported & $\begin{array}{l}\text { US Dollars (conversion not re- } \\
\text { ported) }\end{array}$ & 4 & 1.5 & Trial Datase \\
\hline \multirow[t]{3}{*}{ MRI } & $\begin{array}{l}\text { Ghosh } \\
2018\end{array}$ & Belarus & 330 & Not reported & $\begin{array}{l}\text { US Dollars (conversion not re- } \\
\text { ported) }\end{array}$ & 5 & - & Trial Datase \\
\hline & & $\begin{array}{l}\text { Brazil (Porto } \\
\text { Alegre) }\end{array}$ & 293 & Not reported & $\begin{array}{l}\text { US Dollars (conversion not re- } \\
\text { ported) }\end{array}$ & 4 & - & Trial Datase \\
\hline & & Georgia & 230 & Not reported & $\begin{array}{l}\text { US Dollars (conversion not re- } \\
\text { ported) }\end{array}$ & 1 & 3 & Trial Datase \\
\hline
\end{tabular}




\begin{tabular}{|c|c|c|c|c|c|c|c|c|}
\hline & & India & 58.3 & Not reported & $\begin{array}{l}\text { US Dollars (conversion not re- } \\
\text { ported) }\end{array}$ & 3 & 1 & Trial Dataset \\
\hline & & Poland & 130 & Not reported & $\begin{array}{l}\text { US Dollars (conversion not re- } \\
\text { ported) }\end{array}$ & 3 & 3 & Trial Dataset \\
\hline \multirow[t]{5}{*}{$\begin{array}{l}\mathrm{RT}(5 \text { frac- } \\
\text { tions) }\end{array}$} & \multirow[t]{5}{*}{$\begin{array}{l}\text { Ghosh } \\
2018\end{array}$} & Belarus & 600 & Not reported & $\begin{array}{l}\text { US Dollars (conversion not re- } \\
\text { ported) }\end{array}$ & - & - & Trial Dataset \\
\hline & & $\begin{array}{l}\text { Brazil (Porto } \\
\text { Alegre) }\end{array}$ & 1046 & Not reported & $\begin{array}{l}\text { US Dollars (conversion not re- } \\
\text { ported) }\end{array}$ & - & - & Trial Dataset \\
\hline & & Georgia & 2900 & Not reported & $\begin{array}{l}\text { US Dollars (conversion not re- } \\
\text { ported) }\end{array}$ & - & - & Trial Dataset \\
\hline & & India & 25 & Not reported & $\begin{array}{l}\text { US Dollars (conversion not re- } \\
\text { ported) }\end{array}$ & - & - & Trial Dataset \\
\hline & & Poland & 3472 & Not reported & $\begin{array}{l}\text { US Dollars (conversion not re- } \\
\text { ported) }\end{array}$ & - & - & Trial Dataset \\
\hline \multirow[t]{5}{*}{$\begin{array}{l}\mathrm{RT} \text { (15 } \\
\text { fractions) }\end{array}$} & \multirow[t]{5}{*}{$\begin{array}{l}\text { Ghosh } \\
2018\end{array}$} & Belarus & 1800 & Not reported & $\begin{array}{l}\text { US Dollars (conversion not re- } \\
\text { ported) }\end{array}$ & - & - & Trial Dataset \\
\hline & & $\begin{array}{l}\text { Brazil (Porto } \\
\text { Alegre) }\end{array}$ & 1985 & Not reported & $\begin{array}{l}\text { US Dollars (conversion not re- } \\
\text { ported) }\end{array}$ & - & - & Trial Dataset \\
\hline & & Georgia & 3800 & Not reported & $\begin{array}{l}\text { US Dollars (conversion not re- } \\
\text { ported) }\end{array}$ & - & - & Trial Dataset \\
\hline & & India & 42 & Not reported & $\begin{array}{l}\text { US Dollars (conversion not re- } \\
\text { ported) }\end{array}$ & - & - & Trial Dataset \\
\hline & & Poland & 3472 & Not reported & $\begin{array}{l}\text { US Dollars (conversion not re- } \\
\text { ported) }\end{array}$ & - & - & Trial Dataset \\
\hline
\end{tabular}




\section{APPEN DICES}

\section{Appendix 1. Search strategies}

\section{CENTRAL search strategy}

\#1 MeSH descriptor: [Glioblastoma] this term only \#2 glioblastoma* or $\mathrm{GBM}^{\star}$ or $\mathrm{GB}^{\star}$ or astrocyt ${ }^{\star}$

\#3 \#1 or \#2

\#4 MeSH descriptor: [Aged] explode all trees

$\# 5$ aged $^{*}$ or old ${ }^{*}$ or ageing ${ }^{\star}$ or geriatric ${ }^{*}$

\#6 elder* or "over 60" or "over 65" or "over 70" or "over 80" or "60 year*" or "65 year" or "70 year*" or "85 year*"

\#7 \#4 or \#5 or \#6

\#8 \#3 and \#7

\#9 MeSH descriptor: [Neurosurgery] this term only

\#10 Any MeSH descriptor with qualifier(s): [Surgery - SU]

$\# 11$. surg* or neurosurg $^{\star}$ or craniotomy ${ }^{\star}$ or resect ${ }^{\star}$ or EOR* or intraoperative $^{\star}$ )

\#12. MeSH descriptor: [Radiotherapy] explode all trees

\#13. radiotherap ${ }^{\star}$ or RT or radiat* or irradiat ${ }^{*}$

\#14 Any MeSH descriptor with qualifier(s): [Radiotherapy - RT]

\#15 MeSH descriptor: [Antineoplastic Agents] explode all trees

\#16 MeSH descriptor: [Antineoplastic Combined Chemotherapy Protocols] this term only

\#17 temozolomide or TMZ or Temodal or Temodar or Temodal or Temcad* or chemotherap* or procarbazine or Lomustine or CCNU or vincristine or PCV or cisplatinum or carboplatinum

\#18 MeSH descriptor: [Chemoradiotherapy] explode all trees

\#19 radiochemo* or chemoradio*

\#20 MeSH descriptor: [Immunotherapy] explode all trees

\#21 immunotherap*

\#22 MeSH descriptor: [Steroids] explode all trees

\#23 dexamethasone or prednisolone or methylprednisolone

$\# 24 \# 9$ or \#10 or \#11 or \#12 or \#13 or \#14 or \#15 or \#16 or \#17 or \#18 or \#19 or \#20 or \#21 or \#22 or \#23

$\# 25 \# 8$ and \#24

\section{MEDLINE search strategy for effectiveness evidence}

1. Glioblastoma/

2. (glioblastoma* or Glioblastoma* or $\mathrm{GB}^{\star}$ or astrocyt $\left.{ }^{\star}\right)$.ti,ab.

3. 1 or 2

4. $\exp$ Aged/

5. $\left(\right.$ aged $^{\star}$ or old ${ }^{\star}$ or ageing ${ }^{\star}$ or geriatric $\left.{ }^{\star}\right) . t i, a b$.

6. (elder ${ }^{\star}$ or "over 60 " or "over 65" or "over 70" or "over 80" or "over 85" or "60 year*" or "65 year" or "70 year*" or "80 year" or "85 year" $\left.{ }^{\star}\right)$.ti,ab.

7.4 or 5 or 6

8. 3 and 7

9. Neurosurgery/

10. surgery.fs.

11. (surg ${ }^{\star}$ or neurosurg ${ }^{\star}$ or craniotomy ${ }^{\star}$ or resect ${ }^{\star}$ or EOR ${ }^{\star}$ or intraoperative* ${ }^{\star}$.mp.

12. exp Radiotherapy/

13. radiotherapy.fs.

14. (radiotherap ${ }^{\star}$ or RT or radiat* or irradiat $\left.^{\star}\right) . t i, a b$.

15. exp Antineoplastic Agents/

16. Antineoplastic Combined Chemotherapy Protocols/

17. (temozolomide or TMZ or Temodal or Temodar or Temodal or Temcad* or chemotherap* or procarbazine or Lomustine or CCNU or vincristine or PCV or cisplatinum or carboplatinum).mp.

18. exp Chemoradiotherapy/

19. (radiochemo* or chemoradio*).mp.

20. exp immunotherapy/

21. immunotherap*.mp.

22. exp steroids/

23. (dexamethasone or prednisolone or methylprednisolone).mp.

24.9 or 10 or 11 or 12 or 13 or 14 or 15 or 16 or 17 or 18 or 19 or 20 or 21 or 22 or 23

25.8 and 24 
26. randomized controlled trial.pt.

27. controlled clinical trial.pt.

28. randomized.ab.

29. placebo.ab.

30. clinical trials as topic.sh.

31. randomly.ab.

32. trial.ti

33. 26 or 27 or 28 or 29 or 30 or 31 or 32

34. (animals not (humans and animals)).sh.

35.33 not 34

36. 25 and 35

key:

$\mathrm{mp}=$ title, original title, abstract, name of substance word, subject heading word

$\mathrm{pt}=$ publication type

$a b=a b s t r a c t$

$\mathrm{fs}=$ floating subheading

sh=Medical Subject Heading

\section{MEDLINE search strategy for economic evidence}

1. Glioblastoma/

2. (glioblastoma* or Glioblastoma* or $\mathrm{GB}^{\star}$ or astrocyt ${ }^{\star}$ ).ti,ab.

3. 1 or 2

4. exp Aged/

5. $\left(\right.$ aged $^{\star}$ or old ${ }^{\star}$ or ageing ${ }^{\star}$ or geriatric $\left.{ }^{\star}\right)$.ti,ab.

6. (elder* or "over 60" or "over 65" or "over 70" or "over 80" or "60 year*" or "65 year" or "70 year" or "85 year*").ti,ab.

7. 4 or 5 or 6

8. 3 and 7

9. Neurosurgery/

10. surgery.fs.

11. (surg $^{\star}$ or neurosurg ${ }^{\star}$ or craniotomy ${ }^{\star}$ or resect ${ }^{\star}$ or EOR ${ }^{\star}$ or intraoperative ${ }^{\star}$ ).mp.

12. exp Radiotherapy/

13. radiotherapy.fs.

14. (radiotherap ${ }^{\star}$ or RT or radiat* ${ }^{\star}$ or irradiat $\left.{ }^{\star}\right) . \mathrm{ti}, \mathrm{ab}$

15. exp Antineoplastic Agents/

16. Antineoplastic Combined Chemotherapy Protocols/

17. (temozolomide or TMZ or Temodal or Temodar or Temodal or Temcad* or chemotherap* or procarbazine or Lomustine or CCNU or vincristine or PCV or cisplatinum or carboplatinum).mp.

18. exp Chemoradiotherapy/

19. (radiochemo* or chemoradio*).mp.

20. exp IMMUNOTHERAPY/

21. immunotherap ${ }^{\star} . \mathrm{mp}$.

22. $\exp$ STEROIDS/

23. (dexamethasone or prednisolone or methylprednisolone).mp.

24.9 or 10 or 11 or 12 or 13 or 14 or 15 or 16 or 17 or 18 or 19 or 20 or 21 or 22 or 23

25. 8 and 24

26. Economics/

27. exp "costs and cost analysis"/

28. Economics, Dental/

29. exp economics, hospital/

30. Economics, Medical/

31. Economics, Nursing/

32. Economics, Pharmaceutical/

33. (economic $\$$ or cost or costs or costly or costing or price or prices or pricing or pharmacoeconomic\$).ti,ab.

34. (expenditure\$ not energy).ti,ab.

35. value for money.ti,ab.

36. budget\$.ti,ab.

37.26 or 27 or 28 or 29 or 30 or 31 or 32 or 33 or 34 or 35 or 36

38. ((energy or oxygen) adj cost).ti,ab.

39. (metabolic adj cost).ti,ab.

40. ((energy or oxygen) adj expenditure).ti,ab. 
41.38 or 39 or 40

42. 37 not 41

43. letter.pt.

44. editorial.pt.

45. historical article.pt.

46.43 or 44 or 45

47.42 not 46

48. 25 and 47

\section{key:}

$\mathrm{mp}=$ title, original title, abstract, name of substance word, subject heading word

$\mathrm{pt}=$ publication type

$a b=a b s t r a c t$

$\mathrm{fs}=$ floating subheading

sh=Medical Subject Heading

\section{Embase search strategy for effectiveness evidence}

1. glioblastoma/

2. (glioblastoma* or $\mathrm{GBM}^{\star}$ or $\mathrm{GB}^{\star}$ or astrocyt $\left.{ }^{\star}\right)$.ti,ab.

3. 1 or 2

4. exp Aged/

5. $\left(\right.$ aged $^{\star}$ or old ${ }^{\star}$ or ageing ${ }^{\star}$ or geriatric $\left.{ }^{\star}\right)$.ti,ab.

6. (elder* or "over 60 " or "over 65" or "over 70" or "over 80 " or "over 85" or "60 year" or "65 year" or "70 year" or "80 year" or "85 year").ti,ab.

7.4 or 5 or 6

8. 3 and 7

9. neurosurgery/

10. surgery.fs.

11. (surg ${ }^{\star}$ or neurosurg ${ }^{\star}$ or craniotomy ${ }^{\star}$ or resect ${ }^{\star}$ or EOR ${ }^{\star}$ or intraoperative ${ }^{\star}$ ).mp.

12. exp radiotherapy/

13. radiotherapy.fs.

\left. 14. (radiotherap* ${\text { or RT or radiat* }{ }^{\star} \text { or irradiat }}^{\star}\right) . \mathrm{ti}, \mathrm{ab}$.

15. exp chemotherapy/

16. exp antineoplastic agent/

17. (temozolomide or TMZ or Temodal or Temodar or Temodal or Temcad* or chemotherap* or procarbazine or Lomustine or CCNU or vincristine or PCV or cisplatinum or carboplatinum).mp.

18. exp chemoradiotherapy/

19. (radiochemo* or chemoradio*).mp.

20. exp immunotherapy/

21. immunotherap*.mp.

22. exp steroid/

23. (dexamethasone or prednisolone or methylprednisolone).mp.

24.9 or 10 or 11 or 12 or 13 or 14 or 15 or 16 or 17 or 18 or 19 or 20 or 21 or 22 or 23

25. 8 and 24

26. crossover procedure/

27. double-blind procedure/

28. randomized controlled trial/

29. single-blind procedure/

30. random*.mp.

31. factorial ${ }^{*} . \mathrm{mp}$.

32. (crossover ${ }^{\star}$ or cross over ${ }^{\star}$ or cross-over $\left.{ }^{\star}\right) . \mathrm{mp}$.

33. placebo*.mp.

34. (double* adj blind $\left.{ }^{\star}\right) \cdot m p$.

35. (singl* adj blind $\left.{ }^{\star}\right)$.mp.

36. assign ${ }^{\star} \cdot \mathrm{mp}$.

37. allocat ${ }^{\star} . \mathrm{mp}$.

38. volunteer ${ }^{\star} . \mathrm{mp}$.

39.26 or 27 or 28 or 29 or 30 or 31 or 32 or 33 or 34 or 35 or 36 or 37 or 38

40.25 and 39

key:

Treatment of newly diagnosed glioblastoma in the elderly: a network meta-analysis (Review) 
$\mathrm{mp}=$ title, original title, abstract, name of substance word, subject heading word $\mathrm{pt}=$ publication type

$a b=a b s t r a c t$

$\mathrm{fs}=$ floating subheading

sh=Medical Subject Heading

\section{Embase search strategy for economic evidence}

1. glioblastoma/

2. (glioblastoma* or $\mathrm{GBM}^{\star}$ or $\mathrm{GB}^{\star}$ or astrocyt ${ }^{\star}$ ).ti,ab.

3. 1 or 2

4. exp Aged/

5. $\left(\right.$ aged $^{\star}$ or old ${ }^{\star}$ or ageing ${ }^{\star}$ or geriatric $\left.{ }^{\star}\right)$.ti,ab.

6. (elder* or "over 60 " or "over 65" or "over 70" or "over 80 " or "over 85" or "60 year*" or "65 year" or "70 year*" or "80 year" or "85 year" $) . t i, a b$.

7.4 or 5 or 6

8.3 and 7

9. neurosurgery/

10. surgery.fs.

11. (surg ${ }^{\star}$ or neurosurg ${ }^{\star}$ or craniotomy ${ }^{\star}$ or resect ${ }^{\star}$ or EOR ${ }^{\star}$ or intraoperative $\left.{ }^{\star}\right)$.mp.

12. exp radiotherapy/

13. radiotherapy.fs.

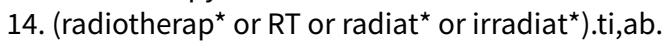

15. exp chemotherapy/

16. exp antineoplastic agent/

17. (temozolomide or TMZ or Temodal or Temodar or Temodal or Temcad* or chemotherap* or procarbazine or Lomustine or CCNU or vincristine or PCV or cisplatinum or carboplatinum).mp.

18. exp chemoradiotherapy/

19. (radiochemo* or chemoradio*).mp.

20. exp immunotherapy/

21. immunotherap ${ }^{\star} . \mathrm{mp}$.

22. exp steroid/

23. (dexamethasone or prednisolone or methylprednisolone).mp.

24.9 or 10 or 11 or 12 or 13 or 14 or 15 or 16 or 17 or 18 or 19 or 20 or 21 or 22 or 23

25. 8 and 24

26. Health Economics/

27. $\exp$ Economic Evaluation/

28. exp Health Care Cost/

29. pharmacoeconomics/

30.26 or 27 or 28 or 29

31. (econom $\$$ or cost or costs or costly or costing or price or prices or pricing or pharmacoeconomic\$).ti,ab.

32. (expenditure\$ not energy).ti,ab.

33. (value adj2 money).ti,ab.

34. budget\$.ti,ab.

35.31 or 32 or 33 or 34

36. 30 or 35

37. letter.pt.

38. editorial.pt.

39. note.pt.

40.37 or 38 or 39

41. 36 not 40

42. (metabolic adj cost).ti,ab.

43. ((energy or oxygen) adj cost).ti,ab.

44. ((energy or oxygen) adj expenditure).ti,ab.

45.42 or 43 or 44

46.41 not 45

47. 25 and 46

48. (exp animal/ or nonhuman/ or exp animal experiment/) not human/

49. 47 not 48

\section{key:}

$\mathrm{mp}=$ title, original title, abstract, name of substance word, subject heading word 
$\mathrm{pt}=$ publication type

$a b=a b s t r a c t$

$\mathrm{fs}=$ floating subheading

sh=Medical Subject Heading

\section{Appendix 2. 'Risk of bias' assessment}

We will assess the risk of bias according to the following criteria.

\section{Random sequence generation}

- Low risk of bias e.g. participants assigned to treatments on basis of a computer-generated random sequence or a table of random numbers

- High risk of bias e.g. participants assigned to treatments on basis of date of birth, clinic identification-number or surname, or no attempt to randomise participants

- Unclear risk of bias e.g. not reported, information not available

\section{Allocation concealment}

- Low risk of bias e.g. where the allocation sequence could not be foretold

- High risk of bias e.g. allocation sequence could be foretold by patients, investigators or treatment providers

- Unclear risk of bias e.g. not reported

\section{Blinding of participants and personnel}

- Low risk of bias if participants and personnel were adequately blinded

- High risk of bias if participants or personnel, or both, were not blinded to the intervention that the participant received

- Unclear risk of bias if this was not reported or unclear

\section{Blinding of outcomes assessors}

- Low risk of bias if outcome assessors were adequately blinded to the intervention that the participant received

- High risk of bias if outcome assessors were not blinded to the intervention that the participant received

- Unclear risk of bias if this was not reported or unclear

\section{Incomplete outcome data}

We will record the proportion of participants whose outcomes were not reported at the end of the study. We will code a satisfactory level of loss to follow-up for each outcome as follows.

- Low risk of bias, if fewer than $20 \%$ of patients were lost to follow-up and reasons for loss to follow-up were similar in both treatment arms

- High risk of bias, if more than $20 \%$ of patients were lost to follow-up or reasons for loss to follow-up differed between treatment arms

- Unclear risk of bias if loss to follow-up was not reported

\section{Selective reporting of outcomes}

- Low risk of bias e.g. review reports all outcomes specified in the protocol

- High risk of bias e.g. it is suspected that outcomes have been selectively reported

- Unclear risk of bias e.g. it is unclear whether outcomes had been selectively reported

\section{Other bias}

- Low risk of bias, i.e. no other source of bias suspected and the trial appears to be methodologically sound

- High risk of bias, if we suspect that the trial was prone to an additional bias

- Unclear risk of bias, if we are uncertain whether an additional bias may have been present

WHAT'S NEW

\begin{tabular}{lll}
\hline Date & Event & Description \\
\hline 27 March 2020 & Amended & Author contact details amended. \\
\hline
\end{tabular}




\section{CONTRIBUTIONS OF AUTHORS}

Theresa Lawrie and Catherine Hanna were involved in all stages of the review and wrote the first draft, with further revisions undertaken by both according to comments from the other authors and peer reviewers. Ewelina Rogozinska assisted with study selection, data extraction, analysis and grading of the evidence. Ashleigh Kernohan and Tomos Robinson prepared the economic evaluation components. All authors approved the final version.

\section{DECLARATIONS OF INTEREST}

Catherine R Hanna: none known

Theresa A Lawrie: none known

Ewelina Rogozińska: none known

Ashleigh Kernohan: none known

Sarah Jefferies: none known

Helen Bulbeck: none known

Usama M Ali: none known

Tomos Robinson: none known

Robin Grant: none known

\section{SOURCES OF SUPPORT}

\section{Internal sources}

- No sources of support supplied

\section{External sources}

- NIHR 16/144 Cochrane Programme Grant Scheme, UK. 